MARCEL HENRIQUE MILITÃO DIB

\title{
Fundamentos do Fresamento: uma aplicação em microfresamento
}




\section{MARCEL HENRIQUE MILITÃO DIB}

Fundamentos do fresamento: uma aplicação em microfresamento

Dissertação apresentada à Escola de Engenharia de São Carlos, da Universidade de São Paulo, como parte dos requisitos para a obtenção do título de Mestre em Engenharia Mecânica.

Área de Concentração: Manufatura

Orientador: Prof. Dr. Renato Goulart Jasinevicius 
AUTORIZO A REPRODUĈ̃O TOTAL OU PARCIAL DESTE TRABALHO, POR QUALQUER MEIO CONVENCIONAL OU ELETRÔNICO, PARA FINS DE ESTUDO E PESQUISA, DESDE QUE CITADA A FONTE.

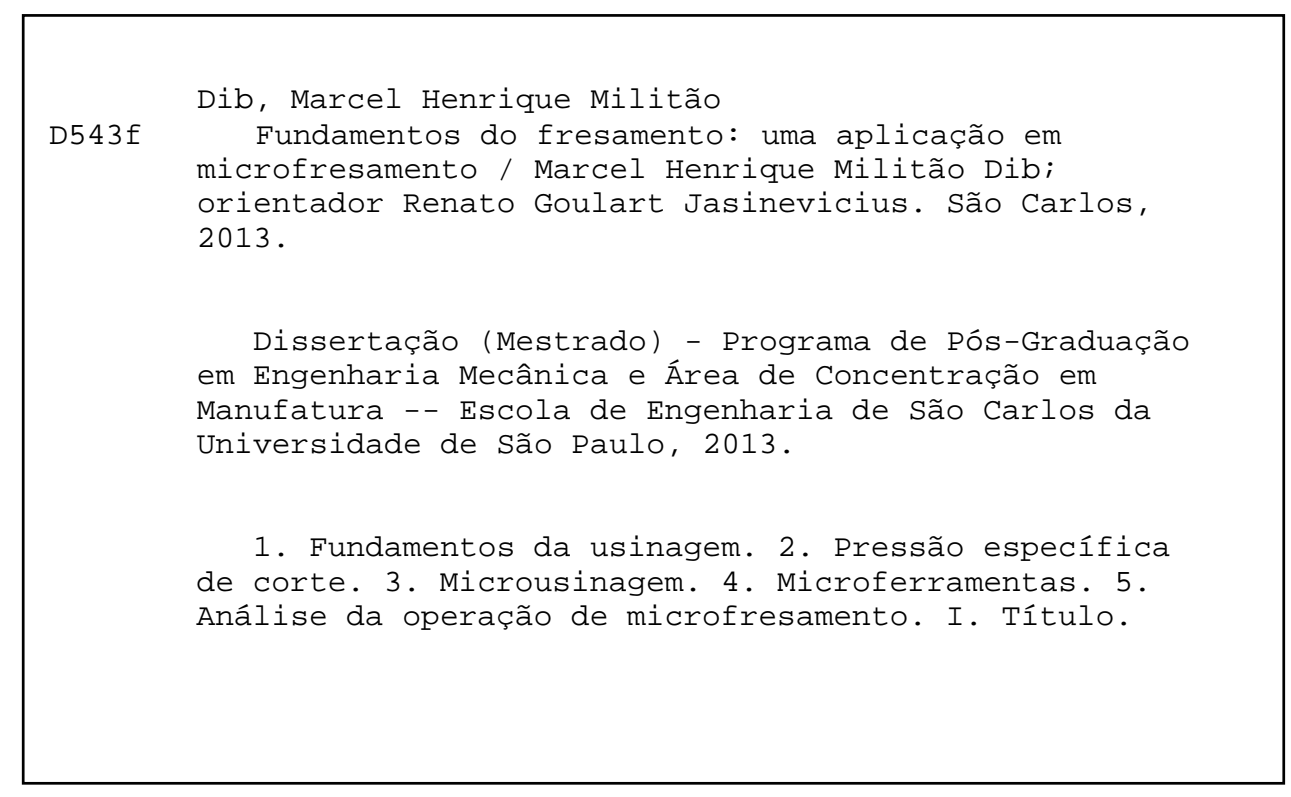


FOLHA DE JULGAMENTO

Candidato: Tecnólogo MARCEL HENRIQUE MILITÃO DIB.

Título da dissertação: "Fundamentos do fresamento: uma aplicação em microfresamento".

Data da defesa: 17/09/2013

Comissão Julgadora:

Resultado:

Prof. Associado Renato Goulart Jasinevicius (orientador)

(Escola de Engenharia de São Carlos/EESC)

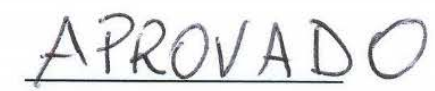

Prof. Associado Jaime Gilberto Duduch

(Escola de Engenharia de São Carlos/EESC)

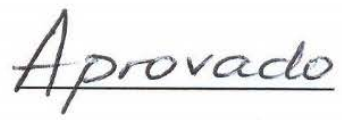

Prof. Dr. Anselmo Eduardo Diniz

APROVADO

(Universidade Estadual de Campinas/UNICAMP)

Coordenador do Programa de Pós-Graduação em Engenheira Mecânica:

Prof. Associado Marcelo Areias Trindade

Presidente da Comissão de Pós-Graduação:

Prof. Titular Denis Vinicius Coury 


\section{DEDICATÓRIA}

À minha avó Verônica Militão Nunes pelo carinho, cuidado e esforço dedicados a mim, à minha mãe Isabel Cristina Militão pela educação que me forneceu, e a toda minha família pelos grandes exemplos de superação. 


\section{AGRADECIMENTOS}

Ao meu orientador Prof. Dr. Renato Goulart Jasinevicius, por acreditar e confiar em mim, apoiar e orientar o desenvolvimento deste trabalho.

A Daniela Teodoro de Souza, pelas inúmeras revisões gramaticais, apoio em momentos difíceis e compreensão ao longo da elaboração deste trabalho.

Ao Me. Aldo Marcel Yoshida Rigatti, pelas aulas particulares de programação, por fornecer programas abertos e auxílio durante a aquisição de sinais.

Ao Prof. Dr. Alessandro Roger Rodrigues, pelos esclarecimentos no que diz respeito a usinagem, planejamento dos experimentos e revisão do trabalho.

Ao Prof. Dr. Anselmo Eduardo Diniz, por revisar, fornecer suas devidas opiniões e ajudar no desenvolvimento dos capítulos deste trabalho.

Ao Prof. Dr. Jaime Gilberto Duduch, por se disponibilizar em revisar a tradução dos resumos de artigos científicos.

Ao técnico Adolfo Ferrarin, pela ajuda e esclarecimentos das máquinas e equipamentos de medição usados, e por fornecer as ferramentas de corte.

Ao Me. Ricardo Arai por diversas vezes controlar, programar e executar o centro de usinagem CNC para realização dos experimentos.

Aos técnicos Mauro, José Carlos, Luís Carlos e Botelho pela ajuda nas fases experimentais e o bom convívio ao longo destes dois anos.

Ao Prof. Dr. Reginaldo Teixeira Coelho pela disponibilização de infraestrutura para realização dos ensaios de microusinagem.

Ao Me. Cleiton Lazaro Fazolo de Assis, pela ajuda no desenvolvimento deste trabalho e pela ajuda na caracterização do material ensaiado.

Aos amigos Fernando, André, Vagner, Adriana, Alessandro e Branco pelo companheirismo no decorrer destes anos.

À CAPES pela concessão da bolsa de estudos e apoio financeiro para publicações de artigos durante o desenvolvimento do mestrado.

À empresa Arotec, representada pelo Sr. Alex Coleti, e a Olympus, representada pela Sra. Patrícia Santos, pela disponibilização do microscópio confocal.

A Deus por até aqui ter me dado saúde e paz, por ter colocado pessoas boas em meu caminho, por me proporcionar grandes oportunidades e por me fortalecer todas as vezes que pensei em desistir. 


\section{EPÍGRAFE}

“O homem é um animal que usa ferramentas... em nenhum lugar você o encontra sem ferramenta; sem ferramenta, ele não é nada; com ferramenta ele é tudo". 


\section{RESUMO}

DIB, M. H. M. (2013). Fundamentos do fresamento: uma aplicação em microfresamento. Dissertação (Mestrado) - Escola de Engenharia de São Carlos, Universidade de São Paulo, São Carlos, 2013.

Nos últimos anos, o estudo do microfresamento tem recebido grande atenção devido a seu uso na fabricação de microcomponentes como células de combustível, microatuadores ou sensores, circuitos integrados, etc. O objetivo deste trabalho é apresentar os fundamentos do fresamento aplicados ao microfresamento. Para isto foi investigado, em escala reduzida, o comportamento de alguns princípios fundamentais da usinagem convencional, tais como espessura de corte instantânea, espessura de corte média, força de corte, pressão específica de corte, potência de corte, entre outros. A importância deste trabalho justifica-se pela necessidade de se entender como estes princípios comportam-se em escalas reduzidas. Inicialmente foi realizada uma investigação da literatura a fim de mostrar a origem de alguns destes princípios fundamentais. Em seguida, uma análise critica destes fundamentos foi apresentada e experimentos foram realizados com o intuito de confrontar o levantamento teórico com os resultados práticos. Para isso foram realizados testes de microfresamento com duas microfresas de metal duro constituídas de dois dentes cada uma com diâmetro de $0,8 \mathrm{~mm}$. O raio da aresta de corte de cada ferramenta foi medido usando um microscópio confocal e os valores variaram de 1,8 $\mu \mathrm{m}$ a 3,3 $\mu \mathrm{m}$. O material usado nos experimentos foi um alumínio liga (RSA 6061) de grãos ultrafinos (valor médio de $1 \mu \mathrm{m}$ ). O fresamento adotado foi o frontal parcial (não engajado) com penetrações de trabalho de 0,2 mm e 0,4 mm. Os avanços por dente usados foram de $5 \mu \mathrm{m}$ e $10 \mu \mathrm{m}$ a uma profundidade de usinagem de $50 \mu \mathrm{m}$. A máquina usada foi um centro de usinagem CNC de três eixos com potência nominal de 18 kw e rotação máxima de 24000 RPM. A máxima velocidade de corte alcançada foi de $50 \mathrm{~m} / \mathrm{min}$. Para coletar o sinal das forças de usinagem um dinamômetro piezoelétrico modelo 9256 C2 (Kistler) foi usado. Os resultados experimentais mostraram que o comportamento da variação da força de corte, o aumento da pressão específica de corte com o decréscimo da espessura de corte, energia de corte, potência de corte e representação da energia e potência de corte com base na força de corte média durante a formação do cavaco, são semelhantes ao comportamento destes parâmetros durante a usinagem convencional. Com base nestes resultados, foi mostrado que os fundamentos do fresamento podem ser aplicados em microfresamento para explicar o comportamento da microusinagem.

Palavras-chave: fundamentos da usinagem, pressão específica de corte, microusinagem, microferramentas, análise da operação de microfresamento. 


\section{ABSTRACT}

DIB, M.H.M. (2013). Fundamentals of End Milling operation: an application to Micro End Milling. Master Science Dissertation - Escola de Engenharia de São Carlos, Universidade de São Paulo, São Carlos, 2013.

Recently, micro end milling is a subject that has received a large contribution due to its feasibility to be applied to the manufacturing of micro components such as fuel cells, micro actuators and sensors, integrated circuits, etc. The objective of this study is to present fundamental principles of machining of end milling operation applied to the micro end milling operation. It will be investigated the behavior at small scale of some known conventional machining parameters such as instantaneous thickness of cut, average thickness of cut, cutting force, specific cutting pressure, cutting power among others. The relevance of this study is justified by the need of understanding how those cutting parameters behave when the machining scale is reduced. Firstly, a review of the literature was carried out in order to show the origin of some fundamental principles of machining of materials. Thereafter, a critical analysis was held on these fundamentals and experimental cutting tests were designed and carried out aiming to comparing the experimental results with the expected trend shown by those parameters in conventional machining scale. The micro end milling tests used two carbide two teeth micro end mills with a diameter of $0,8 \mathrm{~mm}$. The cutting edge of each tool was measured using a confocal optical profiler and the values ranged from $1,8 \mu \mathrm{m}$ up to $3,3 \mu \mathrm{m}$. The workpiece material used in the cutting experiments was an ultra fine grain (average $1 \mu \mathrm{m}$ ) aluminum alloy (RSA 6061). The machining operation was partial (not engaged) end milling with radial depths of cut of $0,2 \mathrm{~mm}$ and $0,4 \mathrm{~mm}$. The feed per tooth used were $5 \mu \mathrm{m}$ and $10 \mu \mathrm{m}$ at constant depth of cut of $50 \mu \mathrm{m}$. The machine tool used was a three axis CNC machining center with $18 \mathrm{kw}$ nominal power and maximum spindle speed of 24000 RPM. At the maximum spindle speed the maximum cutting speed reached was $50 \mathrm{~m} / \mathrm{min}$. A mini piezoelectric dynamometer multicomponent model 9256 C2 (Kistler) was used to gather the cutting forces signals during machining. Therefore, the experimental results showed that the cutting force variation behavior, the increase of specific cutting pressure with the decrease of thickness of cut, cutting energy, cutting power, representing the energy and cutting power representation based on the average cutting force during chip formation are similar to the behavior of these parameters during conventional machining. Based upon that it is shown that the fundamental principles may well be applied to explain the machining behavior at very reduced scales during micro end milling operation.

Keywords: machining fundamentals, specific cutting pressure, micromachining, micro tools, micro end milling operation analysis. 


\section{LISTA DE ILUSTRAÇÕES}

Figura 2.1 - Fresamento tangencial e frontal, concordante e discordante, respectivamente............ 6

Figura 2.2 - a) fresamento em cheio. b) fresamento parcial c) fresamento de face............................ 6

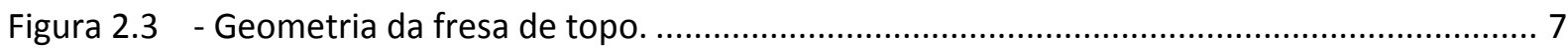

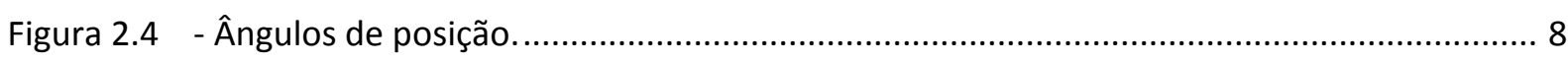

Figura 2.5 - Simulação do percurso efetivo de corte do dente de uma fresa. ..................................... 9

Figura 2.6 - Percurso efetivo do ponto da aresta de uma fresa. Ri: raio da fresa; f: avanço. ............. 9

Figura 2.7 - Movimentos sucessivos de um dente de uma fresa no fresamento em ch eio............. 10

Figura 2.8 - Analogia do tempo de corte em vazio para uma fresa de apenas um dente. ................ 12

Figura 2.9 - Fluxograma do processo de fresamento referente ao tempo de movimento em vazio. 12

Figura 2.10 - Fresamento frontal parcial. a) movimento de corte. b) cavaco indeformado................ 13

Figura 2.11 - Geometria do movimento dinâmico efetivo de corte versus geometria simplificada... 15

Figura 2.12 - Ponto de referência do ângulo de contato segundo a literatura..................................... 15

Figura 2.13 - Ponto de referência do ângulo de contato $\psi$............................................................... 16

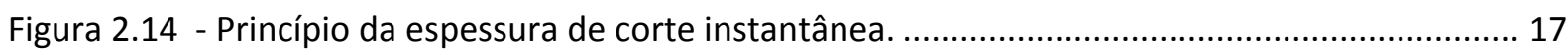

Figura 2.15 - Representação do efeito de aproximação. .............................................................. 18

Figura 2.16 - Cavaco indeformado para um ângulo de posição menor que $90^{\circ}$................................. 19

Figura 2.17 - Comparação entre as áreas dadas pelas equações (2.20) e (2.21) ............................... 21

Figura 2.18 - Fresamento com ângulo de posição à $90^{\circ}$. .............................................................. 23

Figura 2.19 - Fresamento com ângulo de posição menor que $90^{\circ}$. .................................................. 24

Figura 2.20 - Componentes da força de usinagem em fresamento frontal parcial discordante .......... 27

Figura 2.21 - Pressão exercida sobre o dente da fresa pela camada de material a ser removida...... 28

Figura 2.22 - Região de contato na ferramenta de corte. Fu, Fmino, Fpl......................................... 34

Figura 2.23 - Pressão específica de corte versus a espessura de corte............................................... 35

Figura 2.24 - Sobreposição das forças de corte devido ao corte simultâneo. ...................................... 36

Figura 2.25 - Simulação do corte para um movimento correspondente ao ângulo $\psi \mathrm{z}$.......................... 40

Figura 2.26 - Representação da equação diferencial da energia de corte........................................... 42

Figura 2.27 - Apresentação da solução da integral pelo método numérico. ....................................... 43

Figura 2.28 - Comportamento do M versus m, para o ângulo $\psi^{\prime}$ da Figura 2.25 ............................... 44

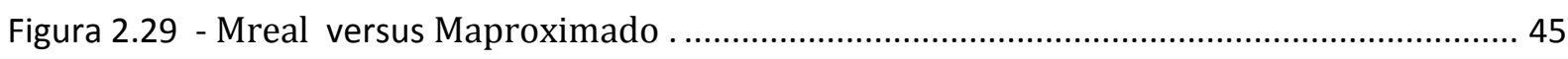

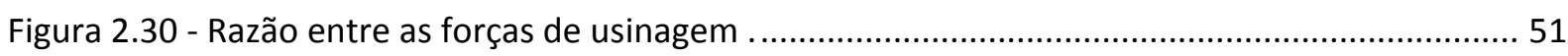

Figura 2.31 - Esquema da mínima espessura de corte. (re: raio da aresta principal)........................... 52

Figura 2.32 - Relação da espessura mínima e o raio da aresta principal. ............................................ 53

Figura 2.33 - Variação do ângulo $\gamma^{\prime}$ e da espessura mínima com o raio de aresta................................. 54

Figura 3.1 - Conjunto para análise das componentes da força de usinagem..................................... 59

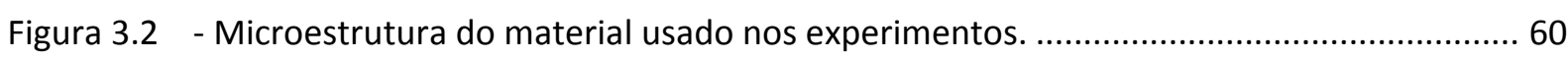

Figura 3.3 - Medidas da ferramenta de corte (escala do desenho 20:1) ......................................... 61

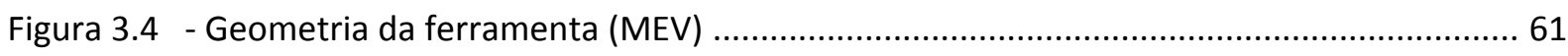

Figura 3.5 - Método de fixação do corpo de prova no dinamômetro.............................................. 62

Figura 3.6 - Sequência da ordem de execução das condições de microfresamento. ......................... 63

Figura 3.7 - Transformada discreta de Fourier do sinal da força no microfresamento. .................... 64

Figura 3.8 - Frequência de aquisição no fresamento não engajado. ............................................. 65

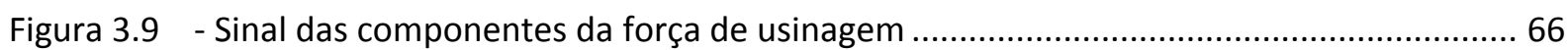




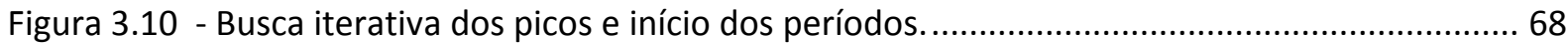

Figura 3.11 - Período médio do sinal, fresamento discordante: força de corte crescente................... 69

Figura 3.12 - Deslocamento da força de corte para origem (eliminando o ruído). ............................. 70

Figura 3.13 - Integração numérica do sinal da força de corte pelo método do trapézio. .................... 71

Figura 4.1 - Regiões de cortes para medição do ae e do ap.......................................................... 73

Figura 4.2 - Ilustração da estratégia de fresamento, exemplo da condição C3 do Ensaio 1.............. 74

Figura 4.3 - Medição das condições de fresamento e das penetrações de trabalho parciais ............ 75

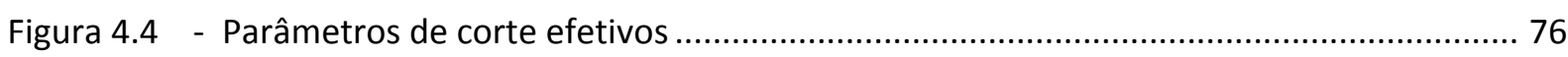

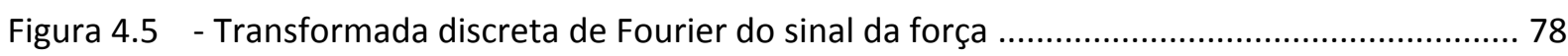

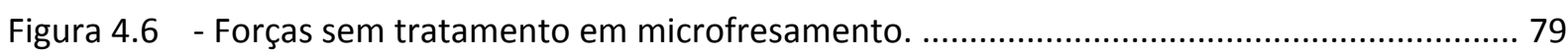

Figura 4.7 - Linha média da Força ativa..................................................................................... 80

Figura 4.8 - Intervalo de confiança da Força ativa, $\mathrm{F}_{\mathrm{T}}$, do microfresamento..................................... 80

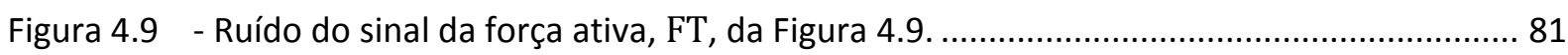

Figura 4.10 - Efeito do ruído: pico do ruído com o vale do sinal da força ativa................................... 82

Figura 4.11 - Efeito do ruído: pico do ruído com o pico do sinal da força ativa .................................. 82

Figura 4.12 - Componentes da força de usinagem em microfresamento frontal parcial ..................... 83

Figura 4.13 - Componentes da força de usinagem em microfresamento........................................... 84

Figura 4.14 - Força de corte em microfresamento frontal parcial. .................................................... 85

Figura 4.15 - Forças de corte médias das condições de fresamento. ............................................... 86

Figura 4.16 - Esquematização da espessura mínima de corte no processo de fresamento................ 88

Figura 4.17 - Superfície principal de corte, ampliação 20 vezes. .......................................................... 89

Figura 4.18 - Superfície principal de corte, ampliação 5 vezes ............................................................ 90

Figura 4.19 - Superfície principal de corte: a) ampliação 20 vezes; b) ampliação 5 vezes.................... 90

Figura 4.20 - Indício da espessura mínima de corte na força ativa e de corte. .................................... 91

Figura 4.21 - hmin e o ângulo efetivo de saída $\gamma \mathrm{i}$ : a) Ensaio 2, C1; b) Ensaio 1, C3.......................... 92

Figura 4.22 - Espessura mínima de corte em função do ae, fz e re.................................................. 93

Figura 4.23 - Efeito das médias correspondente a variável de resposta espessura mínima de corte. 94

Figura 4.24 - Ângulo de cisalhamento determinado pelo cavaco...................................................... 96

Figura 4.25 - Imagem do cavaco (MEV): $\mathrm{f}_{\mathrm{z}}=5 \mu \mathrm{m} /$ dente $\mathrm{a}_{\mathrm{e}}=$ raio da fresa................................... 96

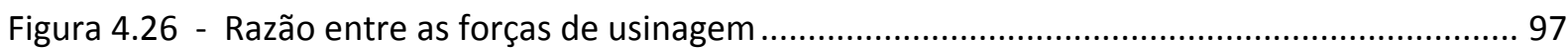

Figura 4.27 - Razão entre as forças de usinagem, determinada na espessura de corte máxima........ 99

Figura 4.28 - Pressão Específica de Corte Instantânea na formação do cavaco ................................. 100

Figura 4.29 - Pressão específica de corte: a) valores médios de $\left.k_{s}, b\right) k_{s 1}$ e m estimados.................... 101

Figura 4.30 - Energia de corte das condições de microfresamento .................................................. 103

Figura 4.31 - Energia específica de corte versus Pressão específica de corte. ..................................... 104

Figura 4.32 - Potência de corte em microfresamento com tempo de movimento em vazio............ 105

Figura 4.33 - Potência de corte das condições de microfresamento................................................. 106

Figura 4.34 - Comparação entre PcQe, PcQ e Pcuc $\Sigma$. .................................................................... 106

Figura 4.35 - Cavaco, condição $C 4$ ( $\mathrm{f}_{\mathrm{z}}=10 \mu \mathrm{m} /$ dente), constituído de lamelas justapostas. ............. 108

Figura 4.36 - Cavaco, condição C3: $\mathrm{f}_{\mathrm{z}}=10 \mu \mathrm{m} /$ dente, $\mathrm{a}_{\mathrm{e}}=0,393 \mathrm{~mm}, \mathrm{a}_{\mathrm{p}}=0,446 \mathrm{~mm}$ e $\psi=90$ …. 108

Figura 4.37 - Investigação da espessura mínima de corte por meio da análise do cavaco no MEV. . 109

Figura 4.38 - Frequência de formação das lamelas........................................................................ 110

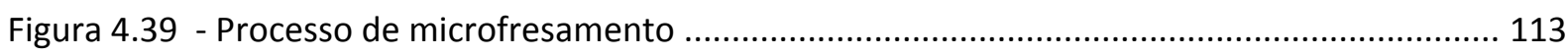

Figura 4.40 - Valores da rugosidade na direção de avanço............................................................. 116

Figura 4.41 - Rt na direção de avanço, em função do ae, fz e re ..................................................... 116 
Figura 4.42 - Ra, Rq na direção de avanço, em função do ae, fz e re 117

Figura 4.43 - Valores da rugosidade na direção perpendicular ao avanço....................................... 119

Figura 4.44 - Rt na direção perpendicular ao avanço, em função do ae, fz e re ............................. 120

Figura 4.45 - Ra, Rq na direção perpendicular ao avanço, em função do ae, fz e re ....................... 120

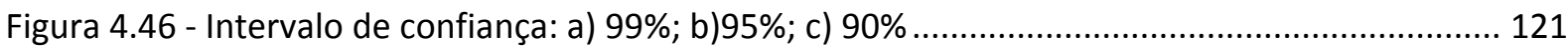

Figura 4.47 - Valores dos parâmetros de rugosidade Sa, Sq e Sz............................................. 124

Figura 4.48 - Intervalo de confiança das médias, com base no desvio padrão combinado .............. 124

Figura 4.49 - Parâmetros de rugosidade tridimensional Ssk e Sku. ............................................. 125

Figura A.1 - Mínimo ae para o corte engajado. .............................................................. 133

Figura A.2 - Área superficial do cavaco indeformado. ........................................................ 134

Figura A.3 - Método para aproximação da área superficial As ................................................. 136 


\section{LISTA DE TABELAS}

Tabela 2. 1 - Mínima penetração de trabalho (aemin) para o corte engajado.................................. 13

Tabela 2. 2 - Comparação dos resultados fornecidos por um software e as equações ...................... 22

Tabela 2. 3 - Tempo de corte e tempo passivo para uma volta da ferramenta................................... 25

Tabela 2. 4 - Formulações da pressão específica de corte................................................................ 30

Tabela 2. 5 - Constante específica de corte ks1 e o coeficiente angular m. (FERRARESI, 1977) ....... 33

Tabela 2. 6 - Simulação da força de corte para cinco dentes na zona de usinagem .......................... 41

Tabela 2. 7 - Formação do cavaco com o decréscimo da espessura de corte (Ducobu et al.,2012).. 55

Tabela 2. 8 - Síntese de equações em fresamento frontal (ângulos das equações em radianos)..... 56

Tabela 3. 1 - Parâmetro de ensaio ( uma réplica ) .......................................................................... 58

Tabela 3. 2 - Composição química do material usado nos experimentos (\%) ..................................... 59

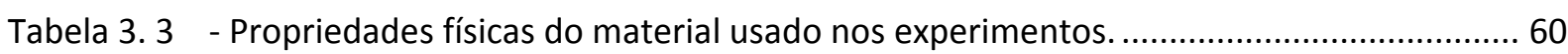

Tabela 3. 4 - Propriedades mecânicas do material usado nos experimentos.................................... 60

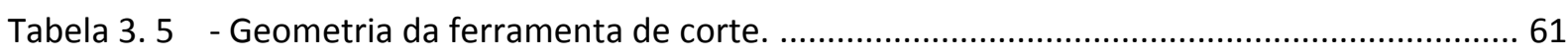

Tabela 4. 1 - Perfilometria óptica das medidas efetivas das condições de fresamento. ..................... 76

Tabela 4. 2 - Amostras da aquisição do sinal na região de usinagem............................................... 77

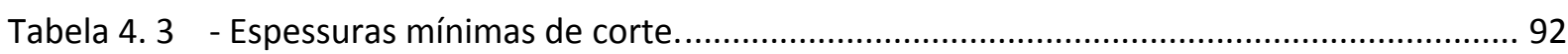

Tabela 4. 4 - Ângulos de saída críticos para alguns materiais (Sedriks e Mulherarn, 1964). ............. 92

Tabela 4. 5 - Quadro ANOVA sobre as respostas da espessura mínima de corte............................... 93

Tabela 4. 6 - Razão entre as forças de usinagem das condições de fresamento ............................... 98

Tabela 4. 7 - ks1 e m (STEMMER, 2007; ÁLISSON et al.,2009; SANDVIK, 2013; DORMER, 2013) .... 102

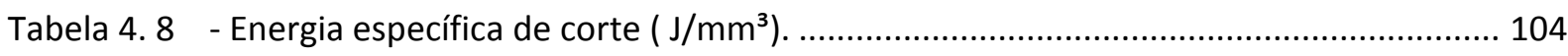

Tabela 4. 9 - Cavacos gerados em microfresamento frontal parcial................................................ 107

Tabela 4. 10 - Apresentação das superfícies geradas no primeiro ensaio (Ensaio 1) . ........................ 111

Tabela 4. 11 - Apresentação das superfícies geradas no segundo ensaio (Ensaio 2). ....................... 112

Tabela 4. 12 - Ray, $\mathrm{Rq}_{\mathrm{y}}$ e Rty do primeiro ensaio (unidades em $\mu \mathrm{m}$ ). ............................................... 114

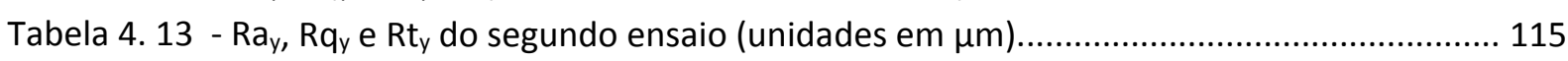

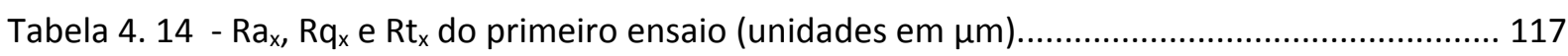

Tabela 4. 15 - Ra $a_{x} R_{x}$ e Rt do segundo ensaio (unidades em $\mu \mathrm{m}$ ) ................................................. 118

Tabela 4. 16 - Apresentação das superfícies e seus parâmetros de medição (Ensaio 1).................... 122

Tabela 4. 17 - Apresentação das superfícies e seus parâmetros de medição (Ensaio 2)................... 123

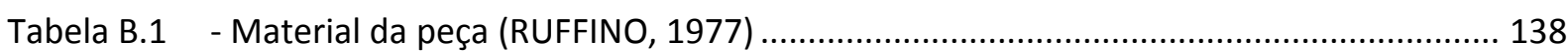

Tabela B.2 - Ferramenta de corte: pastilha de metal duro 7,5×11×17 mm (RUFFINO, 1977)......... 138

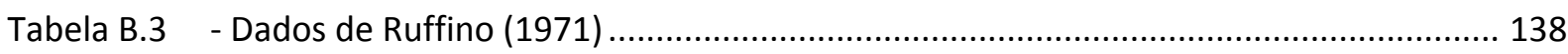




\section{LISTA DE SIGLAS}

$\begin{array}{ll}\text { ABNT } & \text { Associação Brasileira de Normas Técnicas } \\ \text { ANOVA } & \text { Análise de variância } \\ \text { ASM } & \text { Sociedade Americana dos Metais } \\ \text { ASME } & \text { Sociedade Americana de Engenharia Mecânica } \\ \text { AWF } & \text { Associação de Produção Econômica da Alemanha } \\ \text { CAD } & \text { Projeto Auxiliado por Computador } \\ \text { CNC } & \text { Comando Numérico Computadorizado } \\ \text { FFT } & \text { Transformada discreta de Fourier } \\ \text { DIN } & \text { Instituto Alemão de Normalização } \\ \text { PCD } & \text { Diamante Policristalino } \\ \text { MEV } & \text { Microscopia Eletrônica de Varredura } \\ \text { EDS } & \text { Espectroscopia de energia dispersiva }\end{array}$




\section{LISTA DE SÍMBOLOS}

\section{LETRAS ROMANAS MAÍCULAS}

$\mathrm{N}$

A

$\mathrm{S}$

$\overline{\mathrm{S}}$

$\overline{\mathrm{A}_{\mathrm{S}}}$

$\mathrm{A}_{\mathrm{S}}$

$\mathrm{Sz}$

$\mathrm{L}_{\mathrm{c}}$

$\overline{\mathrm{L}_{\mathrm{c}}}$

$\mathrm{L}_{\mathrm{ex}}$

$\mathrm{L}_{\text {in }}$

$\mathrm{L}_{\mathrm{f}}$

$\mathrm{F}_{\mathrm{T}}$

$\mathrm{F}_{\text {ap }}$

$\mathrm{F}_{\mathrm{f}}$

$\mathrm{F}_{\mathrm{n}}$

$\mathrm{F}_{\mathrm{c}}$

$\mathrm{F}_{\mathrm{c}_{\text {máx }}}$

$\mathrm{F}_{\mathrm{c}_{\mathrm{m}}}$

$\mathrm{F}_{\mathrm{p}}$

$\mathrm{F}_{\mathrm{pl}}$

$\mathrm{F}_{\mathrm{u}}$

$\mathrm{F}_{\text {min }}$

$\mathrm{F}_{\mathrm{p}}$

$\mathrm{F}_{\mathrm{aq}}$

$\mathrm{F}_{\text {la }}$

$\mathrm{R}_{\mathrm{c}}$
Amostras

Área da região referente ao desgaste de flanco $\left[\mathrm{mm}^{2}\right]$

Área da seção de corte $\left[\mu \mathrm{m}^{2}\right]$

Área média da seção de corte $\left[\mu \mathrm{m}^{2}\right]$

Área superficial média do cavaco indeformado [m²]

Área superficial do cavaco indeformado [ $\left.\mathrm{mm}^{2}\right]$

Altura máxima da rugosidade no plano tridimensional

Comprimento de corte $[\mu \mathrm{m}]$

Comprimento de corte médio $[\mu \mathrm{m}]$

Comprimento externo do contorno da área superficial $[\mu \mathrm{m}]$

Comprimento interno do contorno da área superficial $[\mu \mathrm{m}]$

Deslocamento na direção de avanço [mm]

Força ativa [N]

Força de apoio [N]

Força de avanço [N]

Força de compressão [N]

Força de corte [N]

Força de corte máxima [N]

Força de corte medida [N]

Força de profundidade [N]

Força de riscamento [N]

Força de usinagem [N]

Força mínima para remover o cavaco [N]

Força passiva ou força de profundidade [N]

Frequência de aquisição [Hz]

Frequência de formação das lamelas [Hz]

Grau de recalque [adimensional] 
Rt Máxima altura da rugosidade nas direções x ou y

Ra Média aritmética nas direções x ou y

Sa Média aritmética no plano tridimensional médio

Rq Média quadrática nas direções x ou y

Z $\quad$ Número de dentes da fresa

$\mathrm{P}_{\mathrm{c}} \quad$ Potência de corte $[\mathrm{w}]$

$\mathrm{P}_{\mathrm{c}}\left(\mathrm{F}_{\mathrm{c}_{\text {médio }}}\right)$ Potência de corte em função da força de corte média [w]

$\mathrm{P}_{\mathrm{c}}(\mathrm{Q}) \quad$ Potência de corte em função da taxa convencional de material removido [w]

$P_{c}\left(Q_{e}\right) \quad$ Potência de corte em função da taxa efetiva de material removido [w]

$\mathrm{P}_{\mathrm{c}}\left(\mathrm{u}_{\mathrm{c}}(\Sigma)\right)$ Potência de corte total em função da integral discreta [w]

C1 Primeira condição de usinagem

C4 Quarta condição de usinagem

$\mathrm{R} \quad$ Raio nominal da fresa [mm]

Sq Rugosidade média quadrática no plano tridimensional

C2 Segunda condição de usinagem

$\mathrm{F}_{\mathrm{x}} \quad$ Sinal da força do dinamômetro na direção horizontal [N]

$\mathrm{F}_{\mathrm{y}} \quad$ Sinal da força do dinamômetro na direção transversal [N]

$\mathrm{F}_{\mathrm{z}} \quad$ Sinal da força do dinamômetro na direção vertical [N]

Ssk Grau de simetria das alturas da superfície em relação ao plano médio (Skewness)

Sku Existência de picos abruptos na distribuição da superfície (Kurtosis)

Q Taxa de material removido $\left[\mathrm{mm}^{3} / \mathrm{min}\right]$

$\mathrm{Q}_{\mathrm{e}} \quad$ Taxa efetiva de material removido $\left[\mathrm{mm}^{3} / \mathrm{min}\right]$

C3 Terceira condição de usinagem

$\mathrm{V}_{\mathrm{f}} \quad$ Velocidade de avanço [ $\left.\mathrm{mm} / \mathrm{min}\right]$

$\mathrm{V}_{\mathrm{c}} \quad$ Velocidade de corte $[\mathrm{m} / \mathrm{min}]$

$\mathrm{V}_{\mathrm{L}} \quad$ Volume do cavaco indeformado $\left[\mathrm{mm}^{3}\right]$

\section{LETRAS ROMANAS MINÚSCULAS}

$\begin{array}{ll}\mathrm{F} & \text { Avanço }[\mathrm{mm}] \\ \mathrm{f}_{\mathrm{z}} & \text { Avanço por dente }[\mu \mathrm{m} / \text { dente] } \\ \mathrm{m} & \text { Coeficiente angular da reta [adimensional] } \\ \mathrm{K} & \text { Constante }\end{array}$




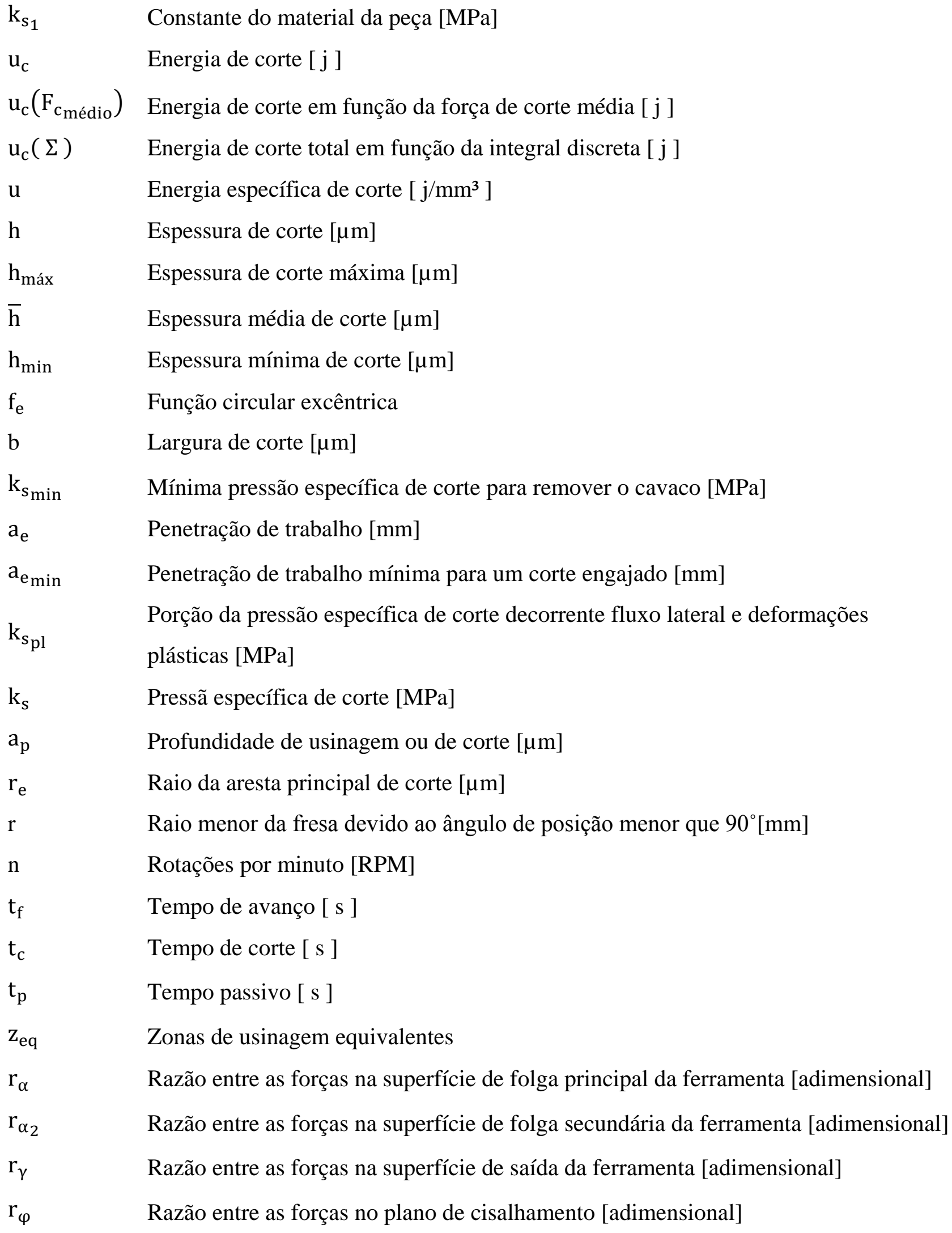




\section{LETRAS GREGAS}

$\theta \quad$ Ângulo de abertura correspondente a espessura mínima de corte [grau]

$\varphi$ Ângulo de cisalhamento [grau]

$\psi \quad$ Ângulo de contato [rad]

$\alpha \quad$ Ângulo de folga principal [grau]

$\alpha_{2}$

Ângulo de folga secundário [grau]

$\lambda \quad$ Ângulo de inclinação [grau]

$\varepsilon \quad$ Ângulo de ponta [grau]

$\chi \quad$ Ângulo de posição [grau]

$\chi_{\mathrm{r}} \quad$ Ângulo de posição no fresamento [grau]

$\gamma \quad$ Ângulo de saída [grau]

$\gamma_{\mathrm{i}} \quad$ Ângulo efetivo de saída [grau]

$\psi_{\mathrm{z}} \quad$ Ângulo entre os dentes da fresa [rad]

$\beta_{1} \quad$ Coeficiente de regressão ou coeficiente angular

$\mathrm{Ei} \quad$ Erro experimental

$\tau_{\mathrm{r}} \quad$ Tensão de cisalhamento na ruptura do material [N/mm²]

$\Delta \psi \quad$ Variação incremental do ângulo de contato [rad] 


\section{SUMÁRIO}

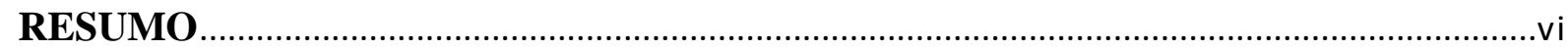

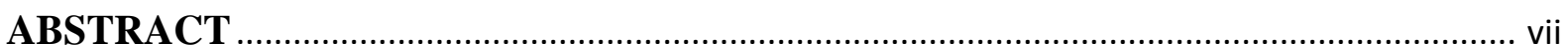

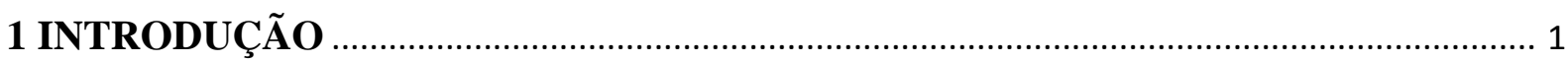

1.1 OBJETIVOS

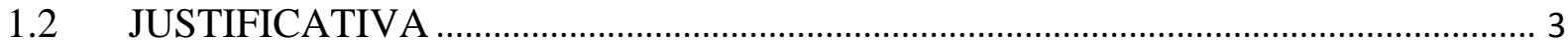

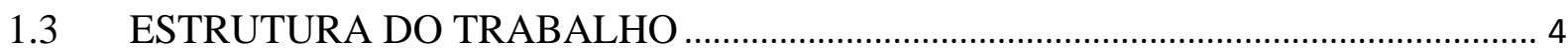

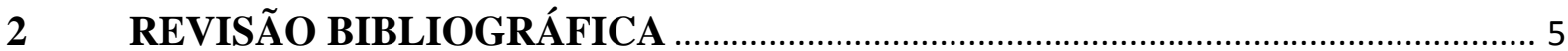

2.1 GEOMETRIA DA FERRAMENTA DE CORTE …...................................................... 7

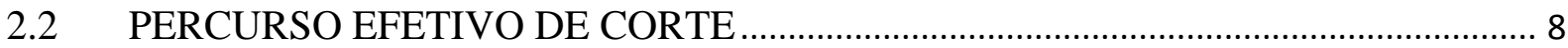

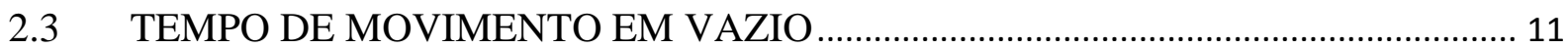

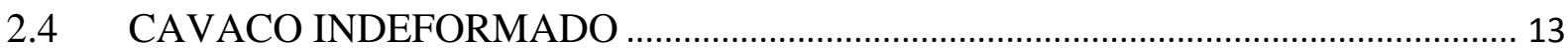

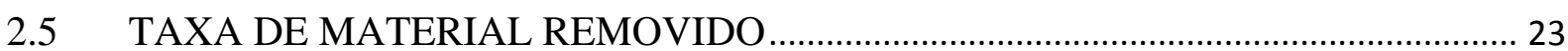

2.6 COMPONENTES DA FORÇA DE USINAGEM …...................................................... 26

2.7 PRESSÃO ESPECÍFICA DE CORTE EM FRESAMENTO ......................................... 28

2.7.1 Estimando as constante ks1 e m do material da peça..................................................30

2.8 FORÇA DE RISCAMENTO E O EFEITO DE ESCALA …............................................ 34

2.9 A FORÇA DE CORTE MÉDIA EM USINAGEM SIMULTÂNEA............................. 36

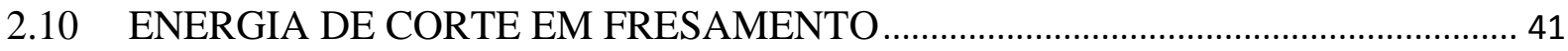

2.10.1 Energia de corte em usinagem simultânea................................................................47

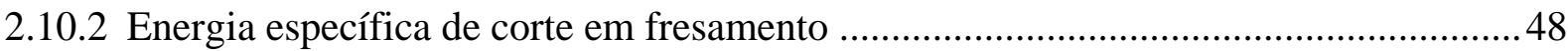

2.10.3 Energia específica de corte em usinagem simultânea..................................................49

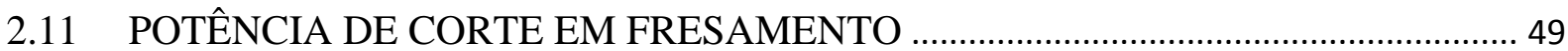

2.11.1 Potência de corte em usinagem simultânea ................................................................50

2.12 RAZÃO ENTRE AS FORSÇAS DE USINAGEM NO FRESAMENTO ..................... 51

2.13 ESPESSURA MÍNIMA DE CORTE …....................................................................... 52

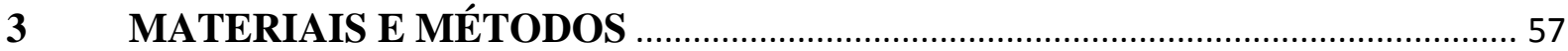

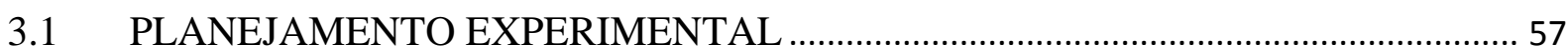

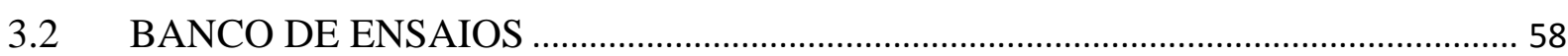

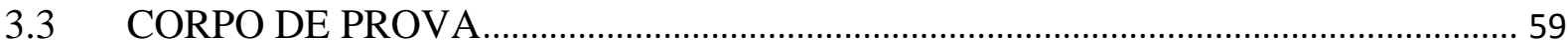

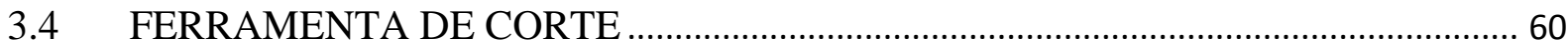

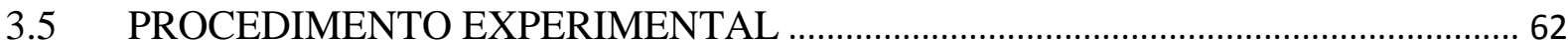




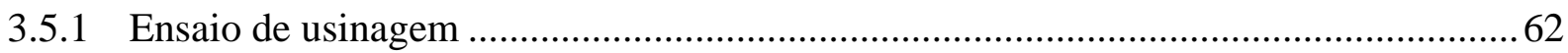

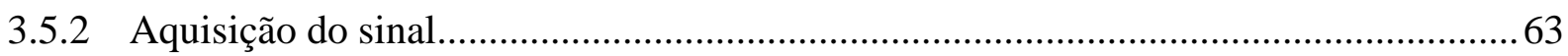

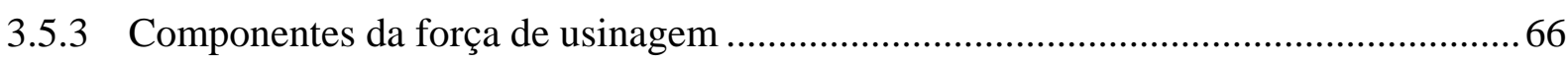

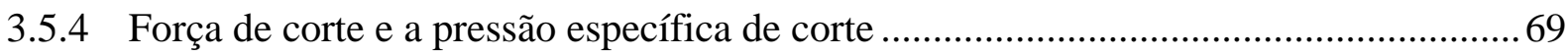

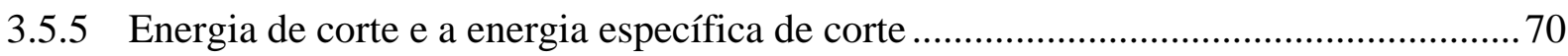

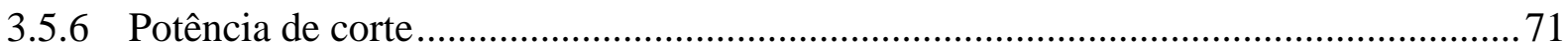

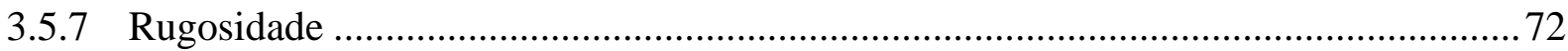

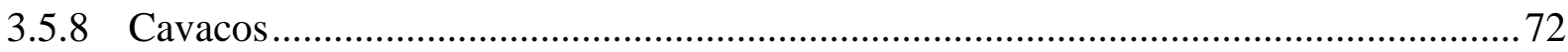

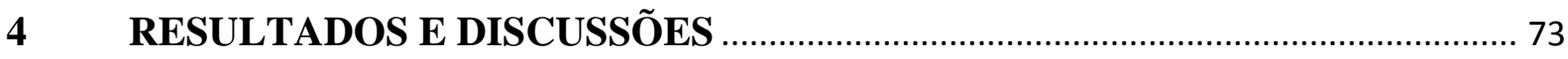

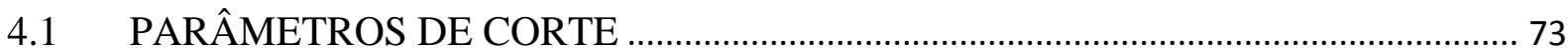

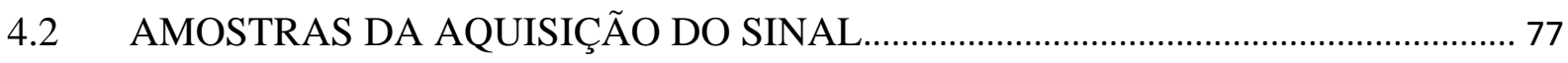

4.3 SINAL MÉDIO DAS COMPONENTES DA FORÇA DE USINAGEM ...................... 78

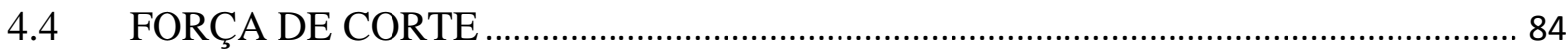

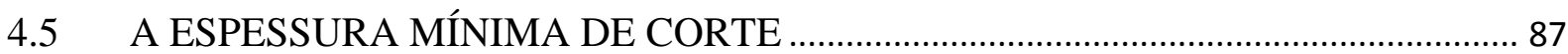

4.6 RAZÃO ENTRE AS FORÇAS DE USINAGEM …....................................................... 94

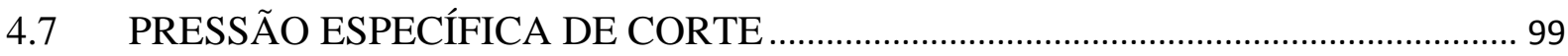

4.8 ENERGIA DE CORTE E A ENERGIA ESPECÍFICA DE CORTE............................. 102

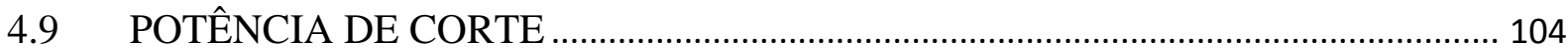

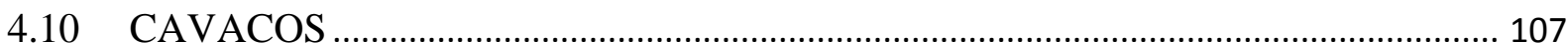

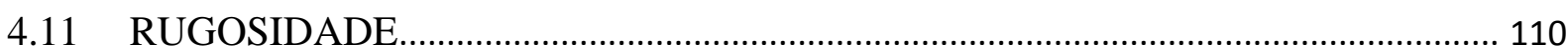

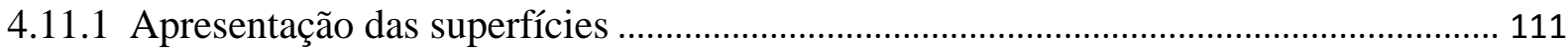

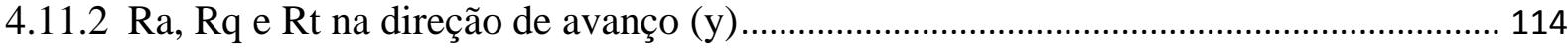

4.11.3 Ra, Rq e Rt na direção perpendicular ao avanço (x)..................................................... 117

4.11.4 Sa, Sq, Sz, Ssk e Sku da superfície ........................................................................... 122

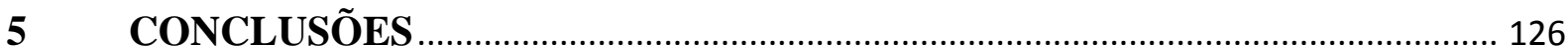

5.1 RECOMENDAÇÕES PARA TRABALHOS FUTUROS …...................................... 128

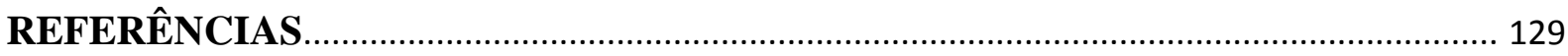

APÊNDICE A - RESOLUÇÃO DA TABELA 2.1 E EQUAÇÕES, (2. 20) e (2. 21)....... 133 APÊNDICE B - EXEMPLO NUMÉRICO: DETERMINANDO ks1 e z ........................ 138 


\section{INTRODUÇÃO}

Estudos sobre microusinagem vêm sendo desenvolvidos desde o final da década de sessenta (TANIGUCHI, 1983). Estas atividades resultaram no que é conhecido como usinagem de ultraprecisão (WEULE; HÜNTRUP; TRITSCHIER, 2001). O principal objetivo deste tipo de usinagem é alcançar uma rugosidade óptica menor que 10 nanômetros, usando uma ferramenta de diamante. O diamante é considerado material ideal para ferramentas de corte em razão da combinação de duas propriedades fundamentais: elevada dureza e excelente condutividade térmica. Além disso, pode ser obtido a um grau de afiação muito reduzido (JASINEVICIUS et al., 2004).

No final da década de oitenta, o processo de usinagem de ultraprecisão foi estendido para a microestrutura da peça com o objetivo de produzir moldes de lentes de Fresnel e componentes para aplicação de microfluidos. Neste novo campo de aplicação, para componentes miniaturizados, muitas das estruturas para micromoldes foram caracterizadas pelo alto grau de recalque, alta complexidade geométrica e moderada qualidade superficial. Justamente, as vantagens do microfresamento são a alta relação de corte (grau de recalque), liberdade de movimentos nas três direções (x, y e z), além de ter compatibilidade com uma ampla variedade de materiais. Neste contexto, o microfresamento com ferramentas de metal duro surge como um método de fabricação promissor para estas aplicações (WEULE; HÜNTRUP; TRITSCHIER, 2001; YUN et al., 2011)

Tal método de fabricação pode ser usado para desenvolver componentes e dispositivos em diversos campos, tais como peças automotivas, engenharia aeroespacial e instrumentos hospitalares, pois requerem micropeças precisas que são menores que as habituais e com maior funcionalidade. Exemplos de tais peças incluem micro células de combustível, micro atuadores ou sensores e circuitos integrados (HONG et al., 2012).

Em geral, este tipo de usinagem em escala reduzida é definida com base nas dimensões da ferramenta de corte, as quais estão entre uma faixa de 1 a $1000 \mu \mathrm{m}$. Entretanto, o aspecto mais relevante que caracteriza este tipo de operação consiste no fato da espessura de corte e do tamanho de grão do material da peça, serem da ordem do raio de aresta da ferramenta de corte (CAMARA et al., 2012)

O tamanho reduzido da fresa tem levantado um problema que ainda não tem sido cuidadosamente considerado nos processos convencionais de fresamento. Reduzindo-se o diâmetro da fresa, o avanço por dente deve ser suficientemente pequeno para evitar deflexões 
ou a quebra da ferramenta, assim sendo, as forças atuantes na ferramenta também diminuem. No entanto, o raio da aresta de corte não diminui com o diâmetro da ferramenta, consequentemente o avanço por dente pode ser da ordem do raio de aresta, e por isso podem ocorrer deformações do material nesta região dando início a um fluxo de material para lateral da ferramenta (YUN et al., 2011).

Nestes aspectos, o raio de aresta torna-se significativo comparado com a espessura de corte da camada de material a ser removida e não pode ser negligenciado em microusinagem, pois quando a espessura de corte é menor que o raio de aresta da ferramenta, um ângulo efetivo de saída negativo faz com que a recuperação elástica do material seja mais crítica. Dependendo do valor da espessura de corte, na região do raio de aresta, não haverá formação de cavaco. Em microusinagem esta espessura crítica é conhecida como a espessura mínima de corte. Por este motivo, explorar a interação da mínima espessura de corte e do raio de aresta da ferramenta é essencial para evitar ou minimizar o fluxo lateral e remover a quantidade de material estabelecida (ARAMCHAROEN; MATIVENGA, 2009).

A mínima espessura de corte afeta o desempenho do processo de usinagem em termos de força de corte, desgaste da ferramenta, acabamento, estabilidade do processo, entre outros. Assim o conhecimento da espessura mínima de corte é importante para seleção das condições adequadas de usinagem (ÖZEL; LIU, 2009).

As componentes da força de usinagem em fresamento variam a todo momento devido à dinâmica do processo, e mudanças contínuas entre o fluxo lateral e o cisalhamento do material ocorrem durante o microfresamento (DHANORKER; ÖZEL; LIU, 2007). Para um boa qualidade de usinagem, a componente na direção da velocidade de corte (força de corte) é um dos fatores mais importantes a serem analisados. Para que a taxa de produção seja mais elevada e a ferramenta de corte suporte tal esforço, o conhecimento desta força em microfresamento deve ser aumentado (HUANG et al., 2010).

Camara et al. (2012), afirmam ainda que o efeito de escala em microfresamento é, certamente, a questão principal deste tipo de usinagem. O efeito de escala é definido como o aumento das tensões de cisalhamento com o decréscimo da espessura de corte ou, em outras palavras, como o aumento da pressão específica de corte com o decréscimo da espessura.

Para estudar o efeito da mínima espessura de corte nas componentes da força de usinagem e o decréscimo da pressão ou energia específica de corte em microfresamento, outros fatores também precisam ser abordados, tais como espessura de corte, taxa de material removido, geometria da ferramenta de corte, razão entre as forças de usinagem , mecanismo de formação do cavaco, dentre outros. Estes princípios, por sua vez, estão bem definidos nos 
processos de usinagem convencionais, e em contrapartida algumas especificidades precisam ser acrescentadas à microusinagem. Em virtude de tal necessidade, este trabalho procura fornecer uma considerável contribuição nestes aspectos abordando o microfresamento.

\subsection{OBJETIVOS}

O presente trabalho tem por objetivo analisar se os fundamentos do processo de fresamento convencional podem ser aplicados diretamente ao microfresamento. Para isso diversos parâmetros foram avaliados como:

- A estrutura do cavaco indeformado;

- A espessura de corte e a espessura de corte média;

- A taxa de material removido;

- A variação das forças de usinagem;

- A razão entre as forças de usinagem;

- A energia de corte;

- A energia específica de corte;

- O efeito de escala na pressão específica de corte;

- A potência de corte.

\subsection{JUSTIFICATIVA}

A indústria de microcomponentes de maneira geral requer, em seu aperfeiçoamento, maior precisão na fabricação e melhores acabamentos em seus produtos. Estes ramos industriais baseiam-se numa mecânica essencialmente de precisão, na qual é necessário eliminar a vibração das microferramentas e as deformações do material da peça (fluxo lateral), variáveis que por sua vez dependem das forças de corte, taxa de material removido, energia específica de corte e outras grandezas envolvidas no processo de microusinagem.

A importância deste trabalho justifica-se pela necessidade de se entender como os princípios fundamentais da usinagem convencional comportam-se em escalas reduzidas. Para isto, é preciso realizar experimentos com microferramentas e dispositivos com alta sensibilidade em máquinas precisas, pois ao correlacionar os princípios da usinagem 
convencional com a microusinagem por meio de resultados experimentais, é possível compreender se a interação ferramenta/material muda com a mudança de escala.

Uma vez esclarecidos os pontos mais problemáticos da usinagem em microescala, tornase possível determinar os parâmetros de corte de modo que não afetem o desempenho da ferramenta, ou provoquem danos que prejudiquem a remoção de material (formação de cavacos) durante a microusinagem, proporcionando melhor acabamento e o controle das tolerâncias dimensionais.

\subsection{ESTRUTURA DO TRABALHO}

Este trabalho está dividido em seis capítulos, referências e dois apêndices, os quais estão descritos brevemente a seguir:

Capítulo 1: contextualização do tema, abordando o processo de microfresamento e suas especificidades.

Capítulo 2: revisão da literatura dos princípios fundamentais da usinagem, tais como o mecanismo de corte dos metais, a taxa de material removido, a força de corte, a pressão específica de corte, o efeito de escala, a energia de corte, a energia específica de corte, a potência de corte, a razão entre as forças de usimagem e a espessura mínima de corte.

Capítulo 3: apresenta uma análise crítica dos fundamentos de usinagem aplicados no processo de fresamento, com o intuito de fornecer um melhor entendimento sobre estes princípios em cortes intermitentes.

Capítulo 4: contempla os procedimentos experimentais, equipamentos e o tipo de ferramentas usados para a realização dos ensaios de microfresamento, a coleta dos dados do sinal das forças de usinagem para as análises e o método de tratamento destas.

Capítulo 5: apresenta os resultados da pesquisa, assim como a análise dos princípios de usinagem aplicados em microfresamento. Há ainda a discussão decorrente destes resultados, juntamente com as explicações propostas pertinentes ao assunto.

Capítulo 6: reune as possíveis conclusões a que se pôde chegar e indica temas que podem ser desenvolvidos com base nos resultados desta pesquisa.

Referências: contém as referências da literatura que serviram de base para o embasamento teórico, conceitos e fundamentação dos resultados obtidos.

Apêndice A: apresenta as resoluções de três equações.

Apêndice B: fornece um exemplo numérico de determinação das constantes ks1 e m. 


\section{REVISÃO BIBLIOGRÁFICA}

Neste capítulo são apresentados os fundamentos do fresamento. O objetivo deste capítulo é analisar de forma crítica e minuciosa estes fundamentos, de modo a favorecer um melhor entendimento sobre estes princípios.

Segundo Ferraresi, Ruffino e Pallerosi (1974), o fresamento é a operação de usinagem com formação de cavaco que se caracteriza por: a ferramenta multicortante, dita fresa, é provida de arestas cortantes dispostas simetricamente ao redor de um eixo; a ferramenta é provida de um movimento de rotação ao redor de seu eixo, permitindo assim que cada uma das arestas cortantes (ditos dentes da fresa) retire a parte de material que lhe compete; o movimento de avanço, que permite o prosseguimento da operação, é geralmente feito pela própria peça em usinagem, que está fixada na mesa da máquina, (raramente o movimento de avanço é feito pela própria ferramenta); o movimento de avanço obriga a peça a passar sob a ferramenta que lhe dá a forma e dimensão desejadas.

A American Society for Metals (ASM) define fresamento como o processo de usinagem no qual o material é removido pelo movimento rotativo da ferramenta multicortante; cada ferramenta remove uma pequena quantidade de metal a cada revolução do eixo árvore. A peça e a ferramenta de corte podem se movimentar em mais de uma direção ao mesmo tempo, assim qualquer superfície pode se usinada. (METALS HANDBOOK, 1989).

Conforme Diniz, Marcondes e Coppini (2001), o fresamento é a operação de usinagem que se caracteriza por: a ferramenta, chamada fresa, que é provida de arestas cortantes dispostas simetricamente em torno de um eixo; o movimento de corte é proporcionado pela rotação da fresa ao redor do seu eixo; o movimento de avanço é geralmente feito pela própria peça em usinagem, que está fixada na mesa da máquina, o qual obriga a peça a passar sob a ferramenta em rotação.

Segundo Stemmer (2005), fresagem é um processo de usinagem no qual a remoção de material da peça se realiza de modo intermitente, pelo movimento rotativo da ferramenta que geralmente é multicortante, assim, é possível gerar superfícies das mais variadas formas.

Portanto, pode-se entender que o fresamento é a remoção de material com espessura de corte instantaneamente variável, em corte interrompido gerado pela combinação entre o avanço da mesa e o movimento rotativo da ferramenta multicortante com geometria definida. 
Segundo Diniz, Marcondes e Coppini (2001), os principais tipos de fresamento são o tangencial (Figura 2. 1 - a e b) e o frontal (Figura 2. 1 - c e d), além do corte ser concordante ou discordante. $\mathrm{O}$ fresamento tangencial realiza grande parte da usinagem na superfície cilíndrica da ferramenta $\left(a_{p}>a_{e}\right)$, e o fresamento frontal age na superfície frontal da ferramenta $\left(a_{e}>a_{p}\right)$, em que $a_{e}$ é a penetração de trabalalho e $a_{p}$ é a profundidade de usinagem. $O$ corte concordante ocorre quando o sentido do movimento de avanço da peça tem o mesmo sentido do movimento de rotação da fresa. Já no corte discordante, o sentido de movimento da peça é ao contrário do movimento de rotação da fresa:

a)

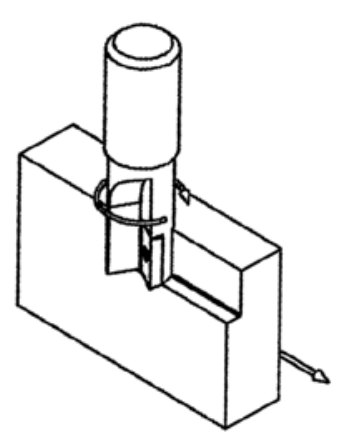

c)

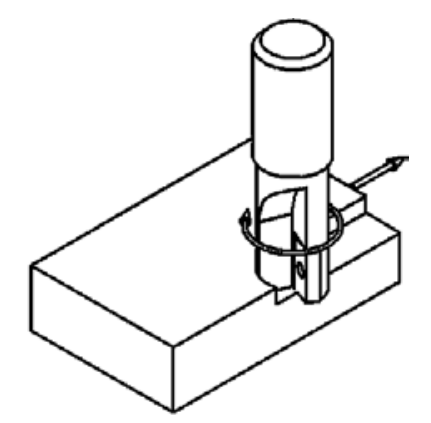

b)

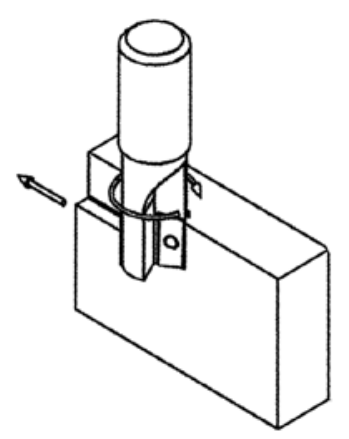

d)

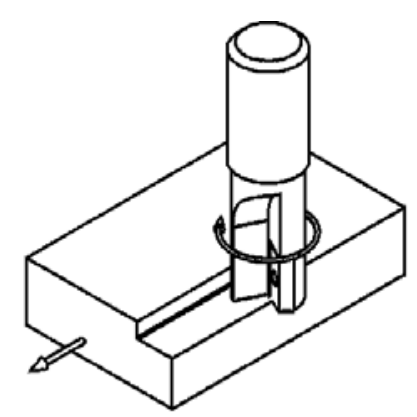

Figura 2. 1 - Fresamento tangencial e frontal, concordante e discordante, respectivamente.

No fresamento frontal distinguem-se ainda outras três formas de fresar: fresamento em cheio, fresamento parcial e fresamento de face (Figura 2.2).

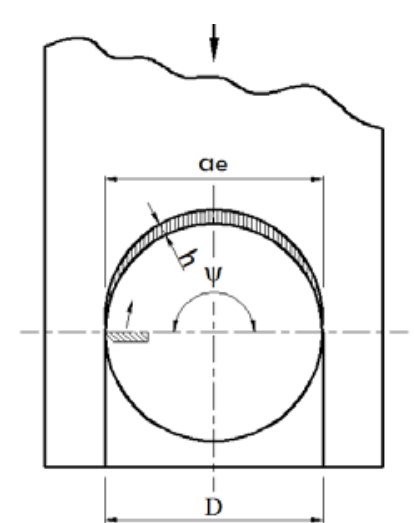

a)

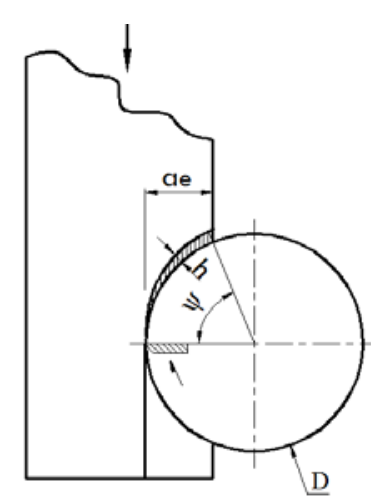

b)

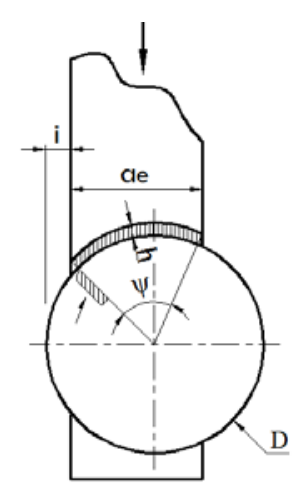

c)

Figura 2.2 - a) fresamento em cheio. b) fresamento parcial c) fresamento de face. 
Conforme a Figura 2.2, é possível observar que a espessura de corte, que se encontra dentro do ângulo de contato $\psi$, é variável. Esta espessura varia conforme o movimento de giro e de avanço da ferramenta. Em corte discordante, a espessura de corte se inicia com um valor mínimo e vai aumentando gradativamente até um valor máximo; por outro lado, quando o corte é concordante, a espessura de corte começa com um valor máximo e vai diminuindo até um valor mínimo. Os cortes discordante e concordante podem ser observados, respectivamente, na Figura 2.2-a: a imagem da ferramenta de corte posicionada nesta figura com o objetivo de realizar um movimento circular da esquerda para a direita, permite notar que o corte é ascendente até o eixo de simetria da fresa. Tal corte é definido como discordante, sendo que logo após este eixo o corte passa a ser concordante, pois a espessura de corte começa a diminuir.

\subsection{GEOMETRIA DA FERRAMENTA DE CORTE}

Toda fresa é composta por dentes cortantes (no caso da Figura 2. 3 são quatro dentes que compõem a fresa). As características principais de cada dente são: ângulo de saída ( $\gamma$ ), ângulo de inclinação $(\lambda)$, raio de ponta $\left(r_{\varepsilon}\right)$, raio da aresta principal $\left(r_{e}\right)$, aresta principal de corte e aresta secundária de corte. Conforme o número de dentes presentes em uma fresa, tem-se o ângulo formado entre eles: $\psi_{\mathrm{z}}$.

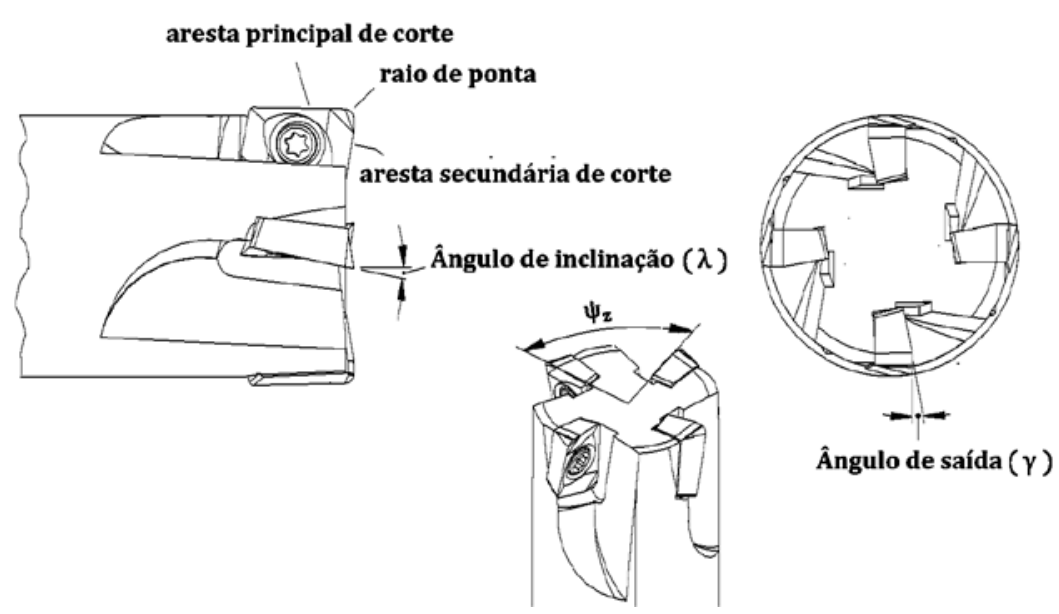

Figura 2. 3 - Geometria da fresa de topo.

Outra característica importante da geometria da ferramenta é o ângulo de posição do dente da fresa $\chi_{r}$ (Figura 2. 4). Este é o ângulo entre a aresta principal de corte da pastilha e a superfície da peça. Espessura de cavacos, forças de corte e vida útil da ferramenta são todas especialmente afetadas pelo ângulo de posição. Os ângulos de posição mais comuns são 90, 
$45^{\circ}$ e $10^{\circ}$ (SANDIVIK, 2012). Quando a fresa possui ângulo de posição menor que $90^{\circ}$, esta é composta por um raio menor $(r)$, um raio maior $(R)$, e a penetração de trabalho $\left(a_{e}\right)$, que é definida pelo ponto extremo posicionado de acordo com a interação da aresta inclinada e profundidade de usinagem $\left(a_{p}\right)$.
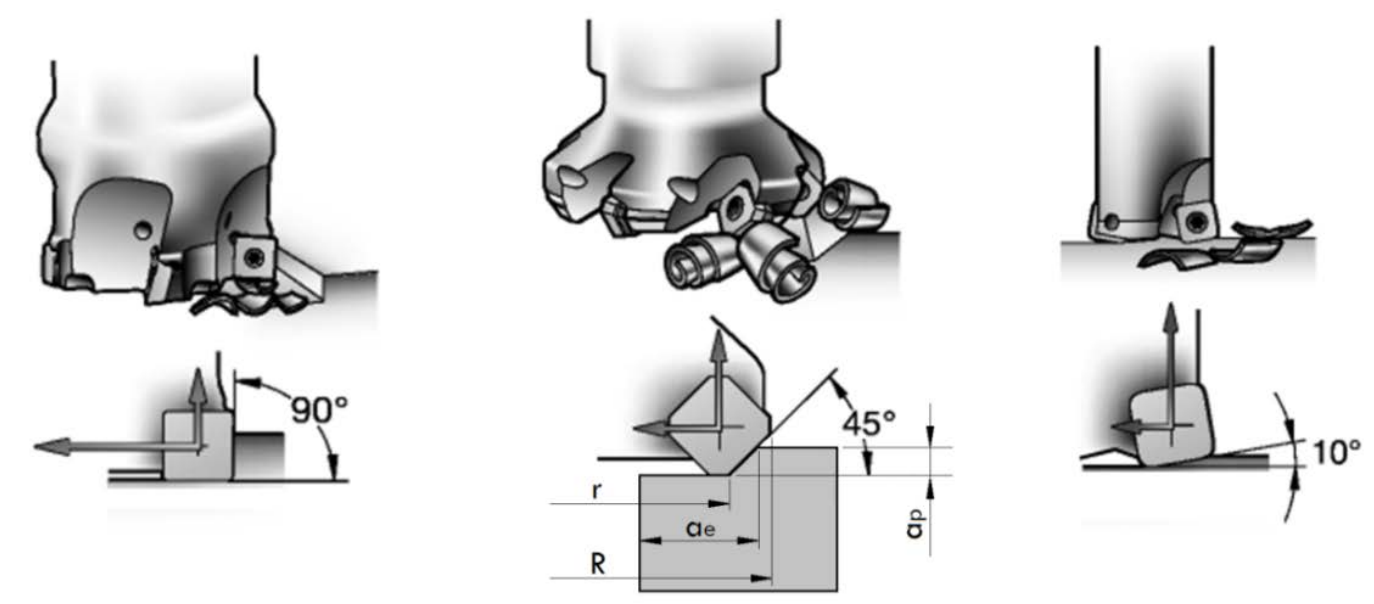

Figura 2. 4 - Ângulos de posição.

Fonte: Modificado de Sandvik (2012).

\subsection{PERCURSO EFETIVO DE CORTE}

O percurso efetivo de corte $\mathrm{L}_{\mathrm{e}}$ é o espaço percorrido pelo ponto de referência da aresta cortante, segundo a direção efetiva de corte (FERRARESI, 1977).

Bao e Tansel (2000) fizeram um estudo sistemático do percurso efetivo de corte no fresamento, e concluíram que o percurso não é totalmente circular.

De modo a verificar o percurso efetivo de corte no processo de fresamento, foi fixada uma caneta no eixo árvore de uma fresadora como mostra a Figura 2. 5-a. A ponta da caneta representa o ponto de referência da aresta cortante. Encostando a ponta da caneta em um papel, combinando o maior avanço da máquina com a menor rotação da mesma, e marcando no papel apenas a primeira volta, é possível observar claramente o efeito de assimetria do semi-círculo superior (arco AB) que representa o corte discordante, com o semicírculo inferior (arco BC) que representa o corte concordante, como mostra a Figura 2. 5-b. 


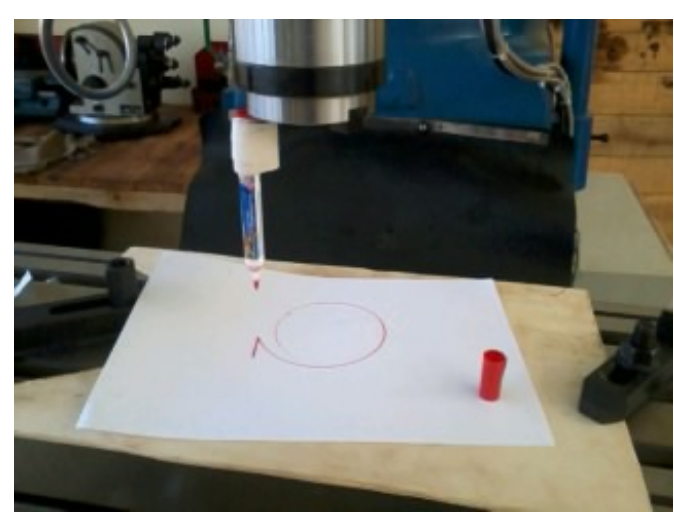

a)

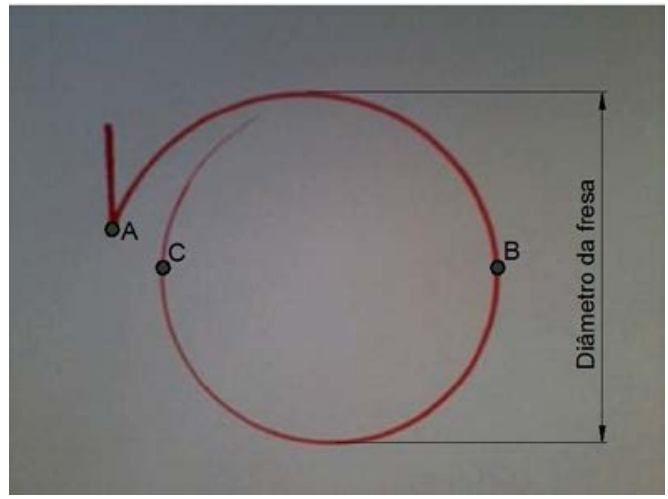

b)

Figura 2. 5 - Simulação do percurso efetivo de corte do ponto da aresta cortante do dente de uma fresa.

Para melhor entender o fenômeno da Figura 2. 5, foi criada uma macro (sub-rotina capaz de executar tarefas pré-programadas) em um software CAD de modo a simular o percurso efetivo de corte da ferramenta (Figura 2.6). A execução desta macro gera ponto a ponto a combinação do movimento de rotação em sentido horário com o movimento de avanço. A resultante desta combinação é a curvatura em linha contínua mais espessa da Figura 2.6. Esta curvatura começa em um ponto inicial A, passando pelo ponto B em meia volta e, completando uma volta, chega ao ponto C. A distância f do ponto A ao ponto C corresponde exatamente ao avanço programado.

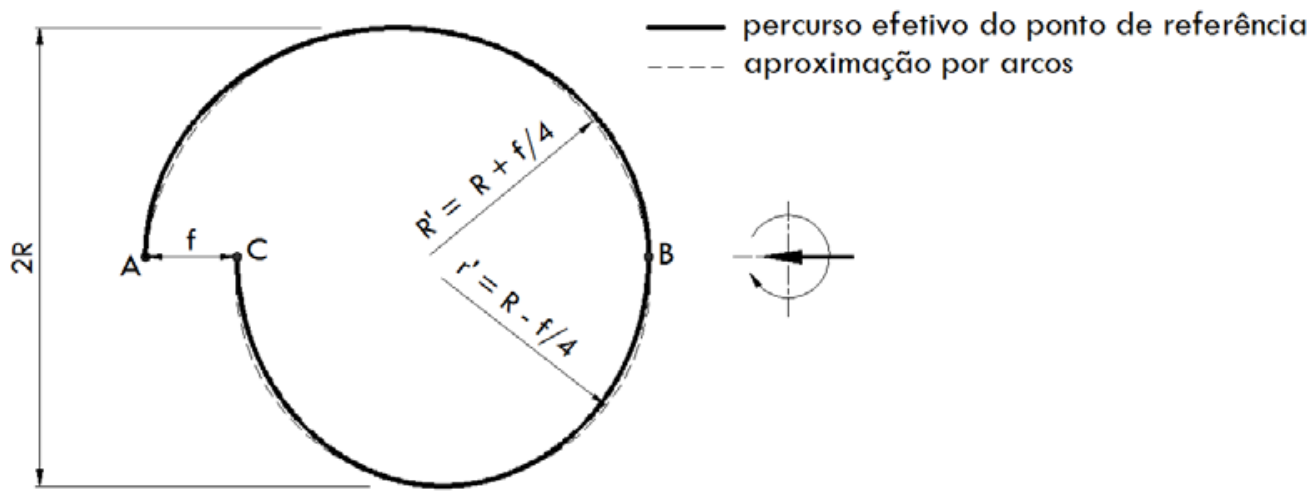

Figura 2.6 - Percurso efetivo do ponto da aresta de uma fresa. Ri: raio da fresa; f: avanço.

O arco mais alongado (arco AB) é a combinação do movimento de rotação da fresa com o de avanço da peça em sentidos opostos (movimento discordante). $\mathrm{O}$ arco menos alongado (arco BC) é também a combinação dos movimentos, porém o movimento de rotação da ferramenta tem o mesmo sentido do avanço da mesa (movimento concordante).

Estudo realizado por Sandvik (2013) destaca que no corte discordante a aresta de corte é forçada dentro do corte, criando um efeito de esfregamento ou de queima devido ao atrito, 
altas temperaturas e, geralmente, contato com a superfície endurecida pelo trabalho causado pela aresta anterior. De tal modo, estes fatores reduzem a vida útil da ferramenta.

Corroborando esta ideia, quando o movimento é discordante, é gerado o arco AB que é mais alongado do que o arco BC gerado pelo movimento concordante. Assim sendo, o percurso efetivo da ferramenta no movimento discordante (arco AB) é maior que o percurso efetivo do movimento concordante (arco BC). Portanto, pode-se concluir que o fato de que o movimento discordante oferece uma distância maior para a ferramenta percorrer, ocasionará um desgaste mais rápido da ferramenta do que no movimento concordante, reduzindo sua vida útil. Porém, como a diferença do raio dos arcos se dá em função do avanço - e este é muito menor que o raio da ferramenta - a relação do comprimento da trajetória do movimento discordante com o movimento concordante, estatisticamente, é desprezível.

Por meio de um software de desenho bidimensional, foi possível simular o percurso efetivo do ponto de referência da aresta de uma fresa como mostra a curvatura em linha contínua mais espessa da Figura 2.6; com este mesmo software foi possível traçar um arco (linha tracejada da Figura 2.6) selecionando três pontos da curvatura em linha contínua mais espessa. Observouse que o raio $\mathrm{R}^{\prime}$ do arco $\mathrm{AB}$ possui um valor correspondente ao raio da fresa mais um quarto do avanço $\left(\mathrm{R}^{\prime}=\mathrm{R}+\mathrm{f} / 4\right)$; e o raio r' do arco $\mathrm{BC}$ possui um valor correspondente ao raio da fresa menos um quarto do avanço $\left(\mathrm{r}^{\prime}=\mathrm{R}-\mathrm{f} / 4\right)$.

Projetando uma frequência de movimentos, é possível notar uma pequena defasagem ( $\delta$ ) entre o início da espessura de corte e o final da mesma. Esta defasagem ocorre devido às diferenças dimensionais dos arcos AB e BC. A Figura 2. 7-b fornece tal efeito para duas voltas do eixo árvore; a Figura 2. 77-a mostra a simulação em uma máquina fresadora por meio de uma caneta fixada no eixo árvore da máquina, em que o eixo árvore está na menor rotação e a mesa no máximo avanço.

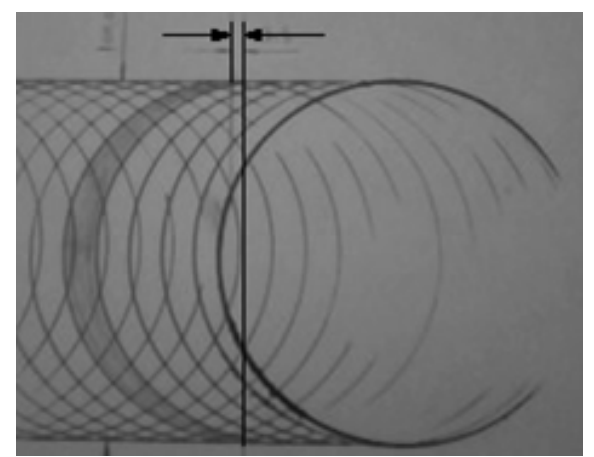

a)

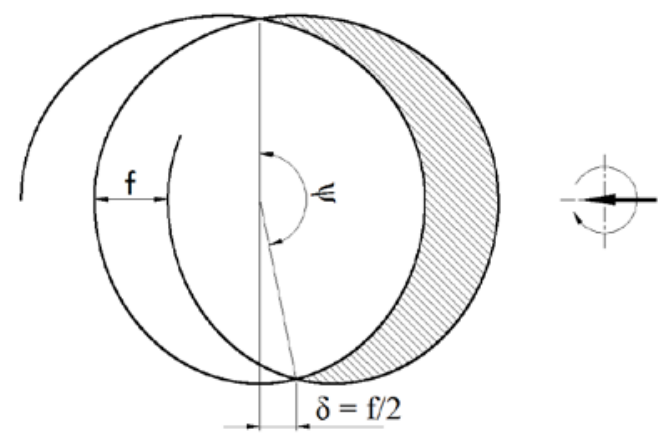

b)

Figura 2. 7 - Movimentos sucessivos de um dente de uma fresa no fresamento em cheio. 
Foi possível observar que todas as diferenças analisadas até aqui (raio do arco AB, raio do arco BC e a defasagem $\delta$ ) existem em função do avanço. Sendo assim, tais variações podem ser desconsideradas, pois no fresamento, na maioria das vezes, o avanço é muito menor que o raio da fresa. Em teoria, o percurso efetivo de corte do ponto de referência da aresta de corte da ferramenta pode ser representado por sucessivos círculos, com diâmetros correspondentes ao da fresa, intercalados conforme o avanço. Este método simplifica os cálculos da espessura de corte no fresamento, que será visto nos tópicos posteriores.

\subsection{TEMPO DE MOVIMENTO EM VAZIO}

Devido ao número de dentes $(Z)$ presentes em uma fresa, e o fresamento adotado (fresamento em cheio, parcial ou de face), pode haver um tempo necessário durante a saída de um dente e a entrada de outro na zona de usinagem (determinada pelo ângulo de contato $\psi$ ).

Quando a saída de um dente e a entrada de outro na zona de usinagem é simultânea, ou quando há mais de um dente nesta zona, ocorre o que é conhecido como corte engajado. Esta técnica auxilia na diminuição de vibrações, melhor acabamento e precisão dimensional, e menores desgastes da ferramenta de corte (METALS HANDBOOK, 1989).

Quando existe um tempo entre a saída de um dente e a entrada de outro na zona de usinagem, ocorre o que é conhecido como movimento em vazio. Se em um processo de fresamento houver movimento em vazio, não há usinagem e, portanto, não ocorre a remoção de material, energia e potência consumida neste tempo.

Para entender melhor o tempo de movimento em vazio no fresamento, é dado um exemplo simples: supõe-se que uma fresa com um único dente realiza um fresamento em cheio, percebe-se que meia volta da ferramenta realizará a usinagem, e a outra metade completará a volta em vazio, conforme mostra a Figura 2.8-a. Durante o tempo que o dente levou para dar meia volta em vazio não houve usinagem, ou seja, neste tempo não se tem forças atuando na ferramenta e nem há remoção de material. De forma a facilitar a compreensão deste efeito, pode ser feita uma analogia com torneamento: o tempo que uma ferramenta leva para tornear uma peça é considerado como tempo ativo; no momento que a ferramenta termina de tornear, esta sai da peça e volta para a posição inicial. Esta trajetória de saída e posicionamento é considerado como tempo passivo, conforme mostra a Figura 2.8-b. Este tempo passivo é equivalente ao tempo de movimento em vazio do fresamento. 
a)

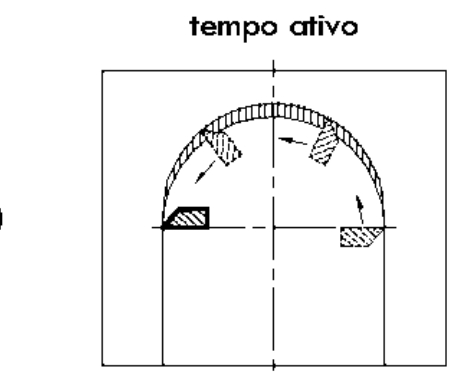

tempo de movimento em vazio

b)
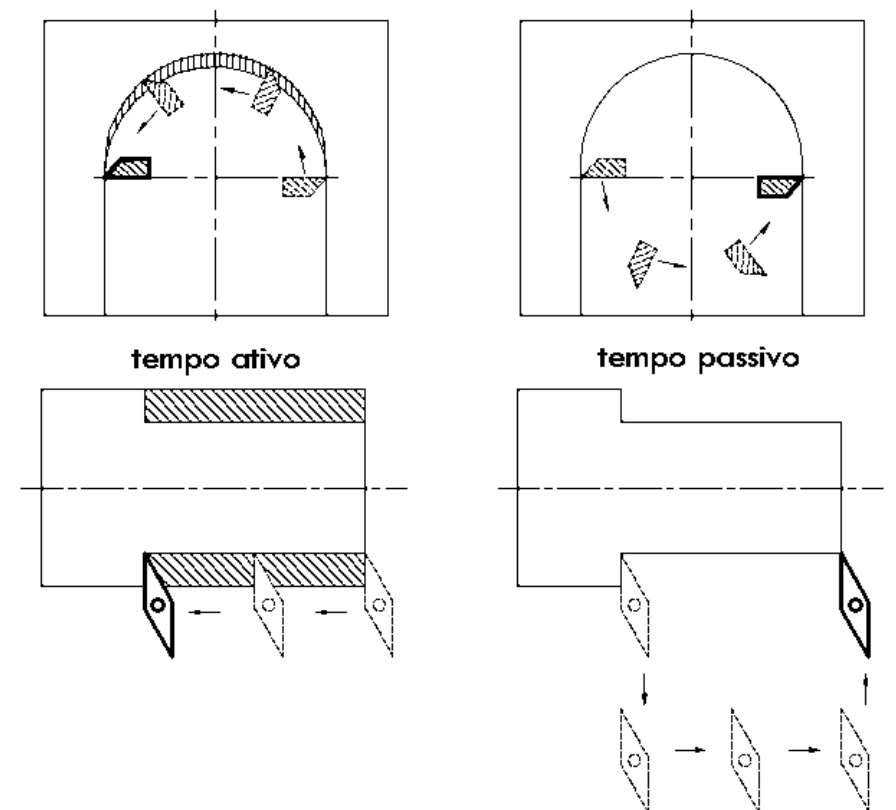

Figura 2.8 - Analogia do tempo de corte em vazio para uma fresa de apenas um dente.

O tempo de movimento em vazio, no fresamento, vai depender do ângulo formado entre os dentes de uma fresa e o ângulo de contato da zona de usinagem. O fluxograma a seguir mostra os possíveis caminhos para ocorrer tal efeito:

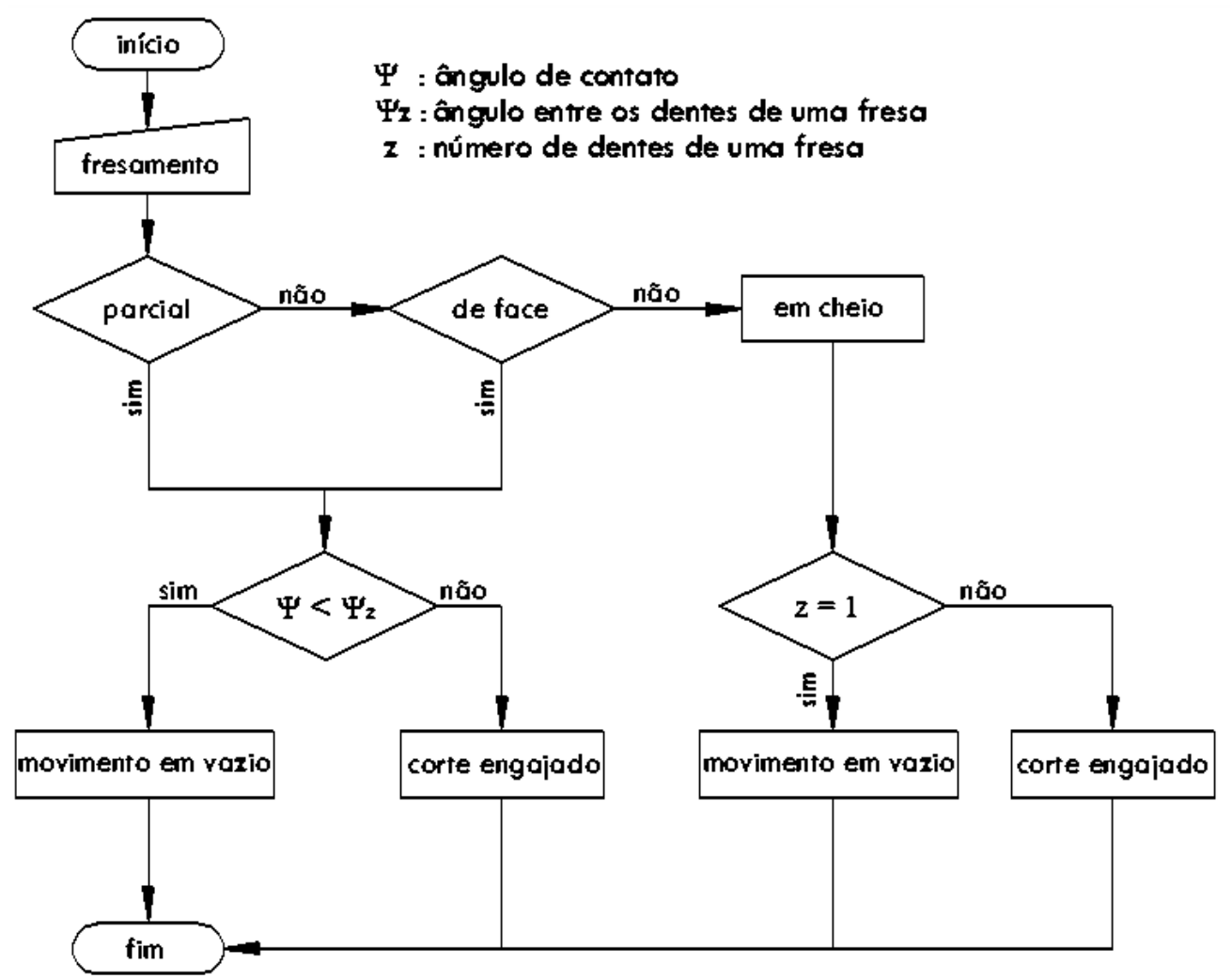

Figura 2.9 - Fluxograma do processo de fresamento referente ao tempo de movimento em vazio. 
A Tabela 2.1 (cuja dedução encontra-se no Apêndice A) fornece, de acordo com os números de dentes $\mathrm{Z}$ de uma fresa e seu raio $\mathrm{R}$, a mínima penetração de trabalho $\left(\mathrm{a}_{\mathrm{e}_{\min }}\right)$ para um corte engajado, ou seja, eliminação do tempo de movimento em vazio.

Tabela 2.1 - Mínima penetração de trabalho $\left(\mathrm{a}_{\mathrm{e}_{\min }}\right)$ para o corte engajado.

\begin{tabular}{ccccccccccccc}
\hline $\mathrm{z}$ & 2 & 3 & 4 & 5 & 6 & 7 & 8 & 9 & 10 & 11 & 12 & $\ldots$ \\
\hline $\mathrm{a}_{\mathrm{e}_{\min }}$ & $2 \mathrm{R}$ & $1,5 \mathrm{R}$ & $\mathrm{R}$ & $0,7 \mathrm{R}$ & $0,5 \mathrm{R}$ & $0,38 \mathrm{R}$ & $0,3 \mathrm{R}$ & $0,24 \mathrm{R}$ & $0,2 \mathrm{R}$ & $0,16 \mathrm{R}$ & $0,14 \mathrm{R}$ & $\ldots$ \\
\hline
\end{tabular}

\subsection{CAVACO INDEFORMADO}

Juntamente com todos os fenômenos do fresamento analisados nos parágrafos anteriores, é importante, também, conhecer a estrutura por onde o dente da fresa passa e realiza a remoção de material. A esta estrutura é dado o nome de cavaco indeformado (Figura 2.10).

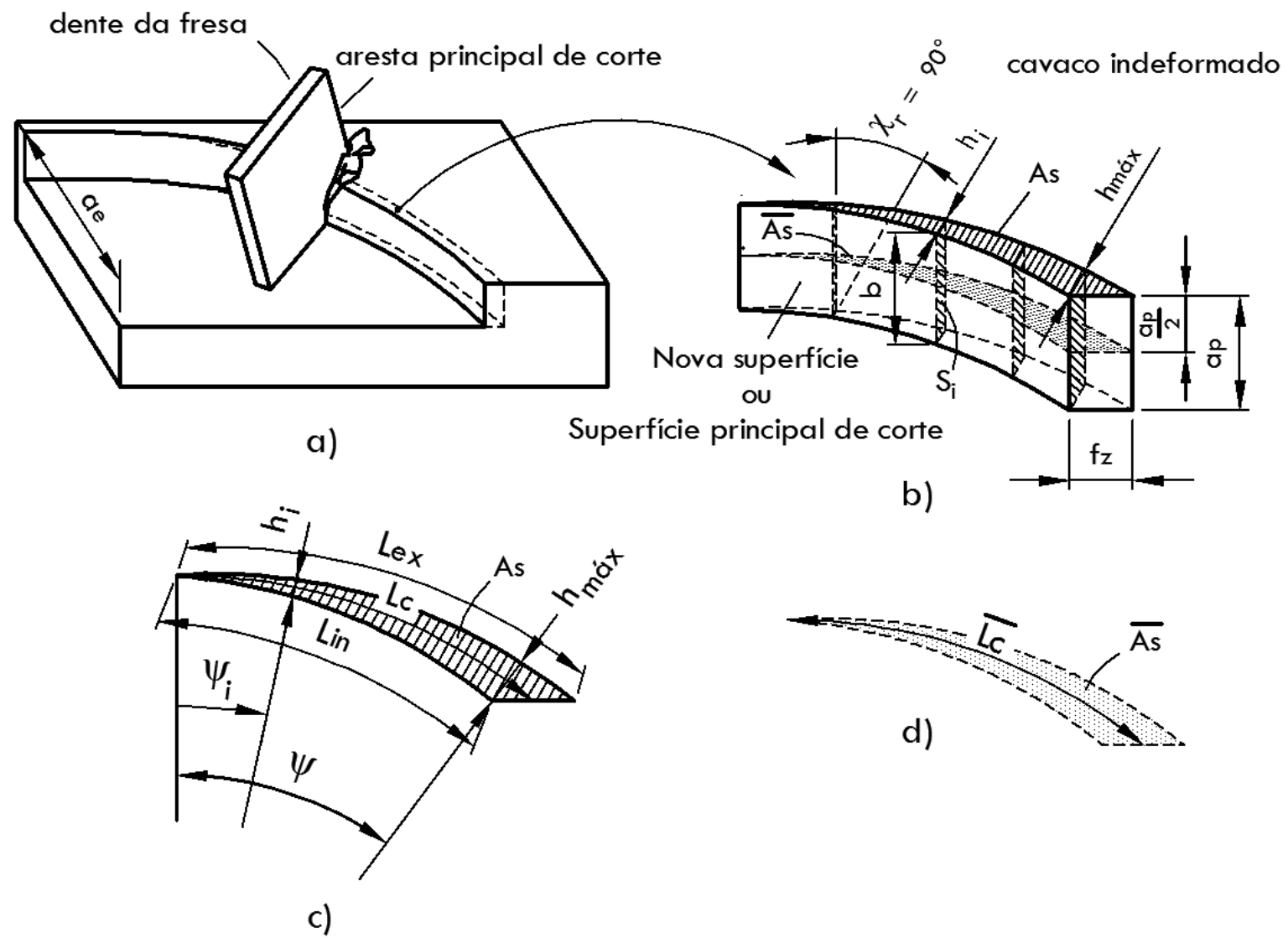

Figura 2.10 - Fresamento frontal parcial. a) movimento de corte. b) cavaco indeformado.

c) área superficial do cavaco indeformado. d) área superficial média do cavaco indeformado. Fonte: Modificado de Metals Handbook (1989). 
Foi demonstrado anteriormente que o movimento efetivo do dente da fresa percorre um percurso maior quando o movimento é discordante (arco mais alongado AB da Figura 2.6) e um percurso menor quando o movimento é concordante (arco menos alongado BC da Figura 2.6). Este fato interfere diretamente na espessura de corte.

A espessura de corte verdadeira para o movimento discordante é sensivelmente menor que a do corte concordante. Este fenômeno pode ser explicado pela relação de arcos: o arco mais alongado $\mathrm{AB}$ tem uma curvatura mais expandida, comparado com o arco menos alongado BC, o que proporciona uma espessura de corte sensivelmente menor. Porém, a espessura de corte no fresamento é em função do avanço por dente, e este é muito menor que o raio da fresa, assim sendo tal diferença torna-se desprezível. Portanto, a espessura de corte instantânea pode ser descrita como o produto do avanço por dente, o ângulo de contato instantâneo e o ângulo de posição da ferramenta, como mostra a Equação (2.1). A precisão desta formulação depende efetivamente da localização do ângulo de contato $\psi$ que é, para ambos os movimentos concordante e discordante, o ângulo central formado pelo centro da fresa com os pontos onde o dente penetra e sai do material em usinagem (FERRARESI, RUFFINO e PALLEROSI, 1974).

$$
h_{i}=f_{z} \cdot \operatorname{sen} \psi_{i} \cdot \operatorname{sen} \chi_{r}
$$

Ferraresi, Ruffino e Pallerosi (1974) assumem que o ângulo de contato $\psi$ é estático, e é determinado pela abertura da interseção inicial da área superficial até seu ponto final (ponto inicial e ponto final Figura 2. 11). O ponto final é o momento em que a ferramenta começa a sair da zona de usinagem. Na prática, se o ângulo de contato parte como referência do centro da fresa, este ângulo vai aumentando junto com o movimento de avanço e principalmente o de rotação da fresa, até alcançar seu valor máximo no ponto final da área superficial (zona de usinagem). A Figura 2. 11 representa de forma dinâmica o movimento de um dente de uma fresa, este por sua vez realiza um movimento de giro em torno do seu próprio eixo e ao mesmo tempo avança conforme o movimento de avanço da mesa. A ferramenta de linha tracejada da Figura 2. 11 demonstra um movimento anterior, e a ferramenta de linha continua demonstra um movimento subsequente; os dois círculos intercalados pelo avanço por dente $\mathrm{f}_{\mathrm{z}}$ representam a geometria simplificada, e as duas curvaturas que ligam as pontas das ferramentas representam o percurso efetivo de corte. 


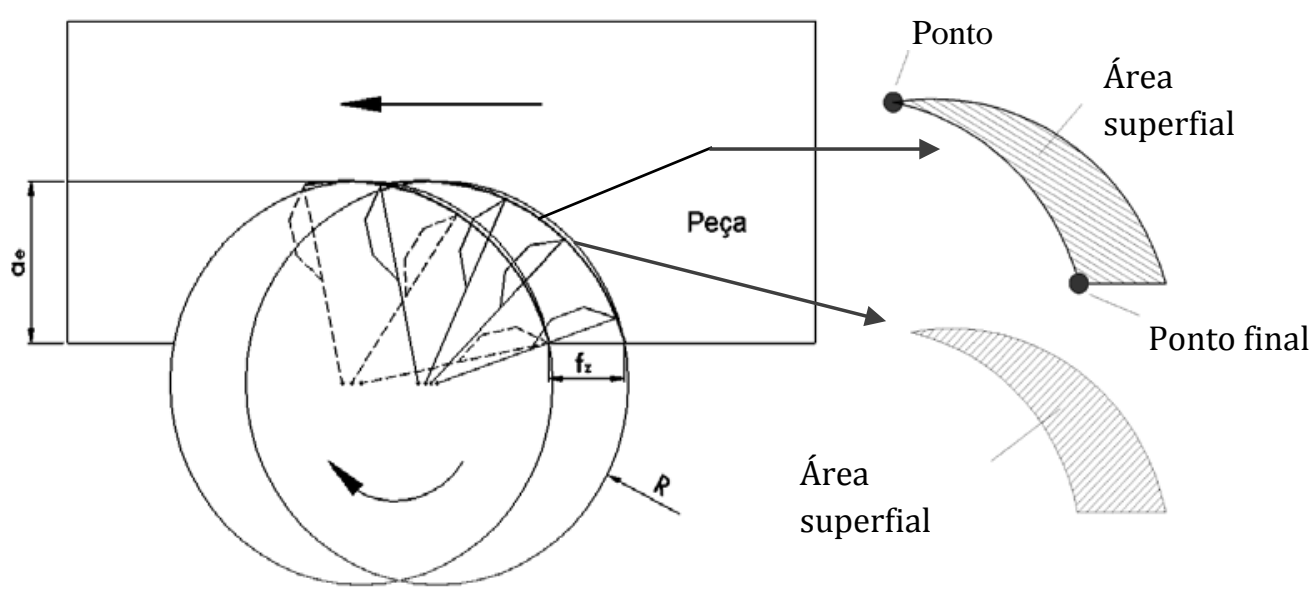

Figura 2. 11 - Geometria do movimento dinâmico efetivo de corte versus geometria simplificada.

Ferraresi, Ruffino e Pallerosi (1974), Diniz, Marcondes e Coppini (2009) adotaram o ponto de referência do ângulo de contato $\psi$ no centro do raio da fresa antes de um corte subsequente como mostra a geometria da Figura 2. 12.

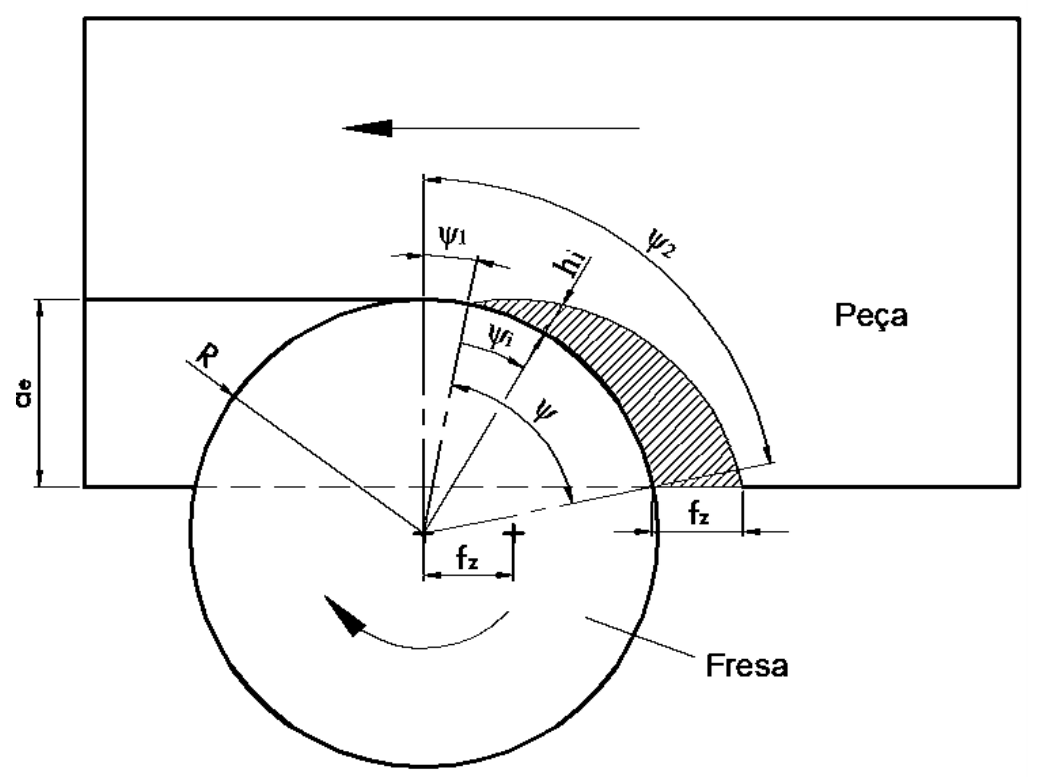

Figura 2. 12 - Ponto de referência do ângulo de contato segundo a literatura.

Fonte: Ferraresi (1977), Ruffino e Pallerosi (1974); Diniz, Marcondes e Coppini (2009).

Conforme o método geométrico da Figura 2. 12, chega-se ao cálculo da espessura de corte instantânea $h_{i}$, fornecido pela expressão da Equação (2.2). O ângulo de contato $\psi$ é determinado pela subtração de dois ângulos conforme a Equação (2.5).

$$
h_{i}=\left[f_{z} \cdot \operatorname{sen} \psi_{i}-R\left(1-\sqrt{1-\left(\frac{f}{R}\right)^{2} \cos ^{2} \psi_{i}}\right)\right] \operatorname{sen} \chi_{r} ; \quad 0 \leq \psi_{i} \leq \psi
$$




$$
\begin{gathered}
\psi_{1}=\operatorname{arctg}\left(\frac{\mathrm{f}_{\mathrm{z}}}{2 \mathrm{R}}\right) \\
\psi_{2}=\arccos \left(1-\frac{\mathrm{a}_{\mathrm{e}}}{\mathrm{R}}\right) \\
\psi=\psi_{2}-\psi_{1}
\end{gathered}
$$

Estes autores concluíram que a parcela $R\left(1-\sqrt{1-\left(f . R^{-1}\right)^{2} \cos ^{2} \psi_{\mathrm{i}}}\right)$ da Equação (2.2) é desprezível comparada a parcela $\mathrm{f}_{\mathrm{z}} \sin \psi_{\mathrm{i}}$. Portanto tal parcela é desconsiderada. Também desconsideram a porção angular $\psi_{1}$ por ser muito menor que a parcela angular $\psi_{2}$. De acordo com estas aproximações, a espessura de corte instantânea passa a ser determinada conforme as expressões:

$$
\begin{gathered}
h_{i}=f_{z} \cdot \operatorname{sen} \psi_{i} \cdot \operatorname{sen} \chi_{r} \\
\psi=\arccos \left(1-\frac{a_{e}}{R}\right)
\end{gathered}
$$

Ao fazer aproximações entre as equações (2.2 e (2.5 alterou-se diretamente a geometria representativa da espessura de corte e o ângulo que forma a mesma. Para obter exatamente as equações (2. 6 e (2. 7, a geometria deve obedecer às características da Figura 2. 13, em que o ângulo de contato $\psi$ parte da interseção da área superficial do cavaco indeformado até metade do avanço por dente.

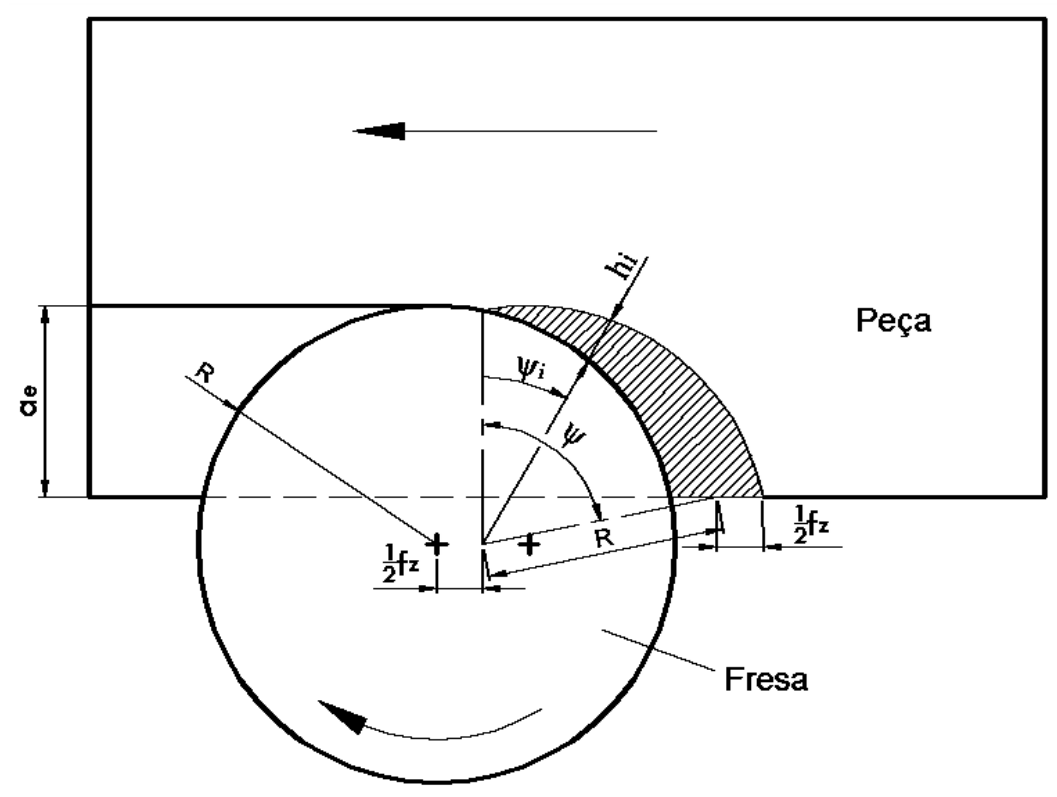

Figura 2. 13 - Ponto de referência do ângulo de contato $\psi$ (nova geometria devido às aproximações). 
Observa-se na Figura 2. 13 que o ponto de referência de onde partem as retas para formar o ângulo $\psi$ e determinar $h_{i}$, é excêntrico ao centro da fresa e encontra-se no eixo de simetria horizontal da mesma. Para se chegar à expressão matemática da espessura de corte $\mathrm{h}_{\mathrm{i}}$, deve-se saber a função que descreve o comprimento da reta que parte de um ponto excêntrico dentro de um círculo. Conforme a Figura 2.14-a este comprimento é dado por $\mathrm{C}_{\mathrm{i}}$.

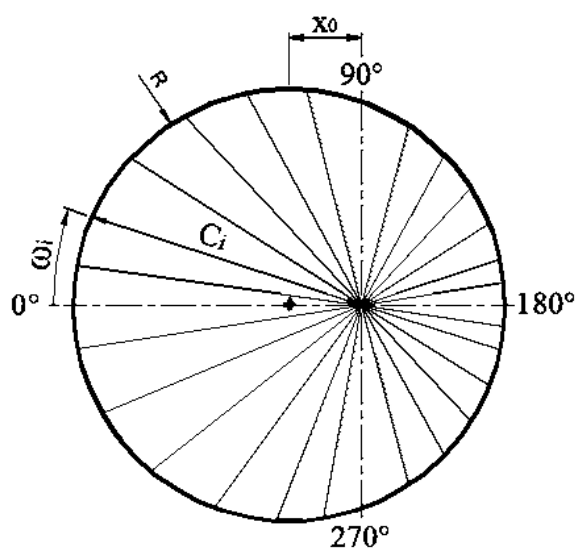

a)

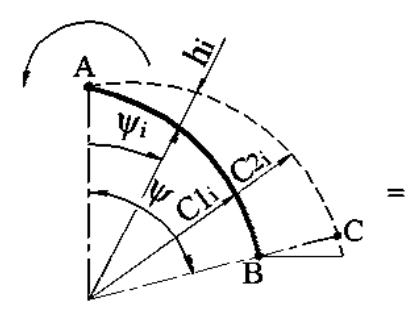

b)

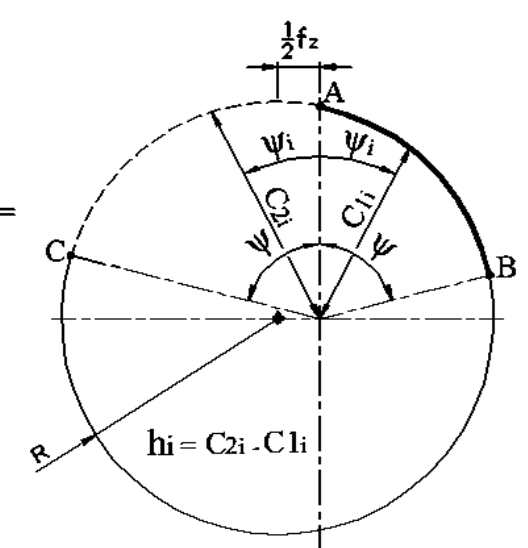

c)

Figura 2.14 - Princípio da espessura de corte instantânea.

Conforme adotado por este estudo, a função que descreve o comprimento da reta $\mathrm{C}_{\mathrm{i}}$, como mostra a Figura 2.14-a, partindo de um ponto excêntrico localizado no eixo horizontal de simetria de um círculo, será chamada de função circular excêntrica: $\mathrm{f}_{\mathrm{e}}\left(\omega_{\mathrm{i}}\right)$ :

$$
f_{e}\left(\omega_{i}\right)=\sqrt{R^{2}-x_{0}^{2} \operatorname{sen}^{2} \omega_{i}}+x_{0} \cos \omega_{i}
$$

Quando o ponto referencial se encontra exatamente na reta vertical que toca o ponto de interseção dos dois arcos conforme mostra o ponto A da Figura 2.14-b, pode-se espelhar o arco tracejado AC para o lado esquerdo para obter um círculo como mostra a Figura 2.14-c. Uma vez que os dois arcos estão determinados dentro de um mesmo ângulo de contato, a variação de $\psi$, que é o $\Psi_{\mathrm{i}}$, é a mesma parcela angular tanto para o arco AB quanto para o arco AC, assim sendo, conforme a função circular excêntrica dada pela Equação (2. 8), tem-se:

$$
\begin{aligned}
& C_{1_{i}}=\sqrt{R^{2}-\left(\frac{f}{2}\right)^{2} \operatorname{sen}^{2}\left(90+\psi_{i}\right)}+\left(\frac{f}{2}\right) \cos \left(90+\psi_{i}\right) \\
& C_{2 i}=\sqrt{R^{2}-\left(\frac{f}{2}\right)^{2} \operatorname{sen}^{2}\left(90-\psi_{i}\right)}+\left(\frac{f}{2}\right) \cos \left(90-\psi_{i}\right)
\end{aligned}
$$


Conforme a regra do quadrante, tem-se que $\operatorname{sen}\left(90-\psi_{\mathrm{i}}\right)=\cos \psi_{\mathrm{i}}, \operatorname{sen}\left(90+\psi_{\mathrm{i}}\right)=$ $\cos \psi_{\mathrm{i}}, \cos \left(90-\psi_{\mathrm{i}}\right)=\operatorname{sen}\left(\psi_{\mathrm{i}}\right)$ e $\cos \left(90+\psi_{\mathrm{i}}\right)=-\sin \left(\psi_{\mathrm{i}}\right)$. Portanto:

$$
\begin{gathered}
\mathrm{h}_{\mathrm{i}}=\mathrm{C}_{2 \mathrm{i}}-\mathrm{C}_{1_{\mathrm{i}}}=\mathrm{f}_{\mathrm{z}} \cdot \operatorname{sen} \psi_{\mathrm{i}} \quad \chi_{\mathrm{r}}=90^{\circ} \\
\psi=\arccos \left(1-\frac{\mathrm{a}_{\mathrm{e}}}{\mathrm{R}}\right)
\end{gathered}
$$

Por fim, a porção de material que antes era desconsiderada após a espessura máxima (Figura 2. 12), nesta nova característica geométrica proveniente das aproximações feitas por Ferraresi, Ruffino e Pallerosi (1974), Diniz, Marcondes e Coppini (2009), passa automaticamente a ser compensada por causa do ângulo de contato posicionado na interseção da área superficial, e por isto tal ângulo excede levemente a $\mathrm{h}_{\text {máx }}$ compensando a pequena parte desconsiderada. Esta compensação é demonstrada pela Figura 2.15, em que a pequena área “Ai” que restou é compensada na pequena parte abaixo da espessura máxima.

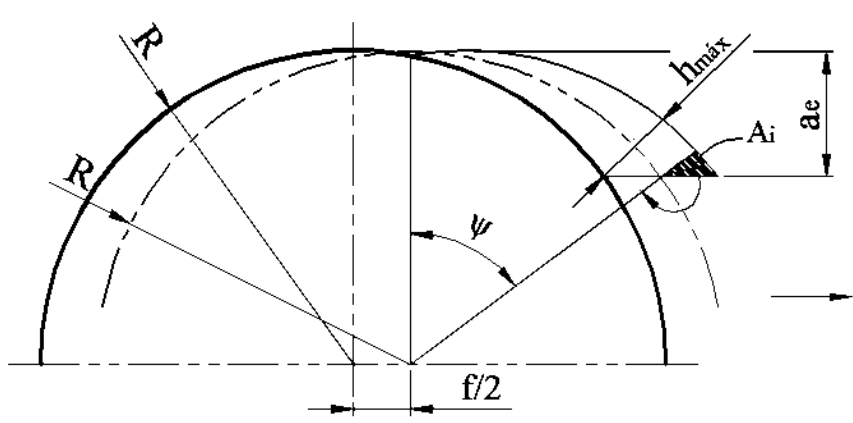

a)

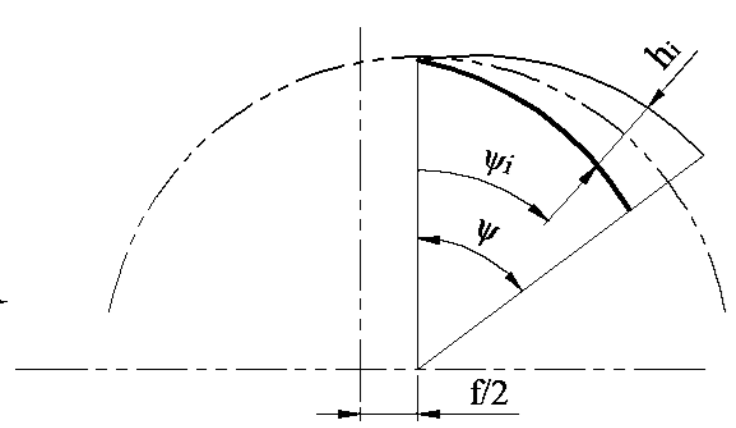

b)

Figura 2.15 - Representação do efeito de aproximação.

Das aproximações até aqui analisadas, uma desvantagem observada é que quando a espessura máxima é calculada, e esta é calculada na posição $\psi$, o valor de $\mathrm{h}_{\text {máx }}$ é sensivelmente maior que o real.

Pelo fato da espessura de corte $\left(\mathrm{h}_{\mathrm{i}}\right)$ ser instantaneamente variável, Diniz, Marcondes e Coppini (2009), propuseram representar a espessura de corte no processo de fresamento como sendo a média da variação de tal espessura instantânea, dita como espessura de corte média $\overline{\mathrm{h}}$. Para chegar-se a tal espessura estes autores aplicaram o teorema do valor médio. Este teorema busca encontrar o valor médio da variação de uma função, em que o resultado é o quociente entre a integral da função e seu intervalo. Para um fresamento frontal parcial à $90^{\circ}$ : 


$$
\bar{h}=\frac{1}{\psi-0} \int_{0}^{\psi} f_{z} \cdot \operatorname{sen} \psi \cdot d \psi=\frac{f_{z} \cdot(1-\cos \psi)}{\psi}
$$

sendo,

$$
\cos \psi=1-\frac{\mathrm{a}_{\mathrm{e}}}{\mathrm{R}}
$$

A Equação (2.13) pode ser escrita como:

$$
\overline{\mathrm{h}}=\frac{\mathrm{f}_{\mathrm{z}} \cdot \mathrm{a}_{\mathrm{e}}}{\text { R. } \psi} \quad \chi_{\mathrm{r}}=90^{\circ}
$$

Vale ressaltar que quando há um ângulo de posição menor que $90^{\circ}$, não basta multiplicar a $\bar{h}$ por sen $\chi_{\mathrm{r}}$ para chegar à espessura de corte média do cavaco. No caso de um ângulo de posição correspondente a $90^{\circ}$, a área superficial inferior possui as mesmas dimensões da área superficial superior. Portanto, se a espessura média de corte é calculada em qualquer uma das duas áreas superficiais, é encontrada a espessura de corte média do cavaco indeformado. Por outro lado, um cavaco indeformado com $\chi_{\mathrm{r}}$ menor que $90^{\circ}$ terá duas áreas superficiais diferentes, pois haverá diferentes diâmetros nos vários pontos da aresta principal de corte (vide Figura 2. 4). As dimensões da área superficial superior serão maiores que as dimensões da área superficial inferior devido à diferença de diâmetros, e a espessura de corte média da área superior também será maior que a da área inferior. Portanto, a espessura de corte média para $\chi_{\mathrm{r}}$ menor que $90^{\circ}$ deve ser calculada na área superficial média $\overline{\mathrm{A}_{\mathrm{s}}}$ (Figura 2.16), que corresponde exatamente à média das espessuras médias da área superficial superior e inferior, como mostra a figura a seguir:

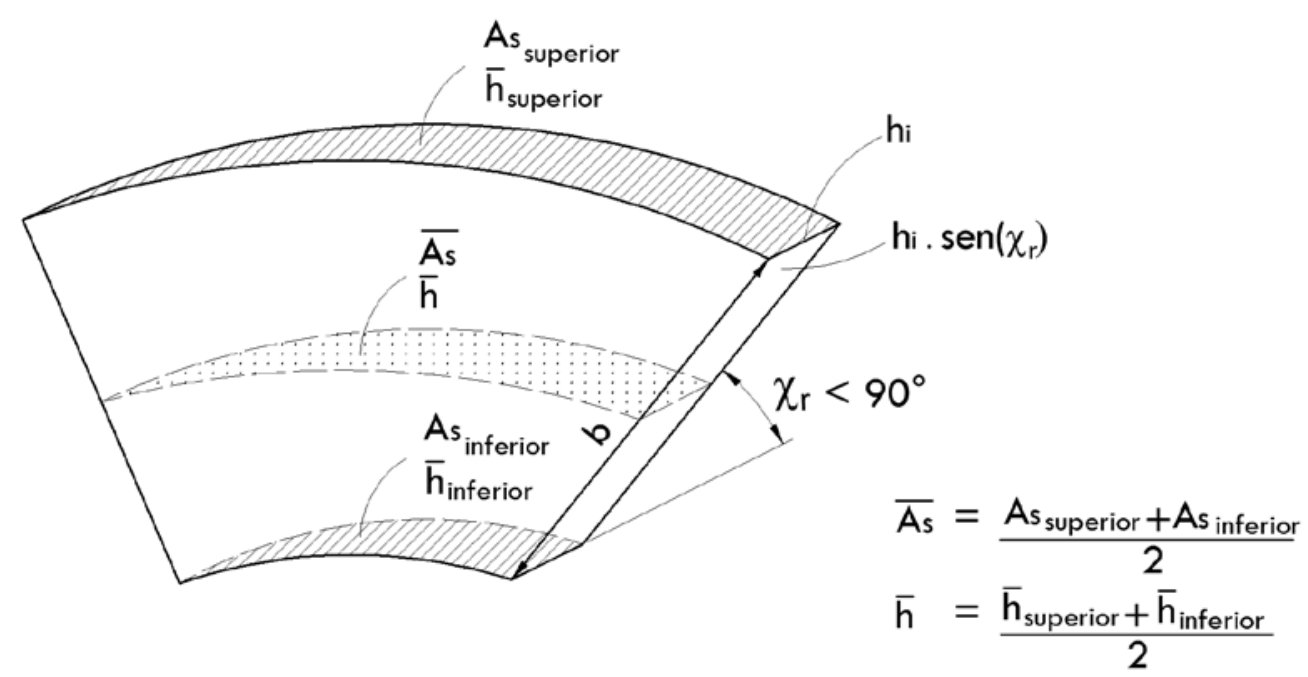

Figura 2.16 - Cavaco indeformado para um ângulo de posição menor que 90 . 
O cálculo da espessura de corte média para um cavaco indeformado com ângulo de posição menor que $90^{\circ}$ será examinado nos parágrafos seguintes.

Na representação fornecida pela Figura 2.10-b, pode-se observar que a área da seção de corte $\left(\mathrm{S}_{\mathrm{i}}\right)$ é variável conforme a espessura de corte $\mathrm{h}_{\mathrm{i}}$. A equação que descreve esta área é dada por:

$$
S_{i}=h_{i} \operatorname{sen} \chi_{r} \cdot b=h_{i} \operatorname{sen} \chi_{r} \cdot \frac{a_{p}}{\operatorname{sen} \chi_{r}}=h_{i} \cdot a_{p}
$$

Portanto, a média desta área pode ser calculada pela espessura de corte média da Equação (2.15), mesmo sendo para um ângulo de posição menor que $90^{\circ}$, pois no caso de $\chi_{\mathrm{r}}<$ $90^{\circ}$ o que importa para o cálculo da área da seção de corte média é a espessura de corte média da superfície superior. Assim, a área da seção de corte para $\chi_{\mathrm{r}}<90^{\circ}$ e $\chi_{\mathrm{r}}=90^{\circ}$ é:

$$
\overline{\mathrm{S}}=\overline{\mathrm{h}} \cdot \mathrm{a}_{\mathrm{p}}
$$

Para o caso do ângulo de posição igual a $90^{\circ}$ ou $\pi / 2 \mathrm{rad}$, o comprimento de corte $\mathrm{L}_{\mathrm{c}}$, demonstrado pela Figura 2.10-c é o comprimento intermediário entre o comprimento do arco externo $\mathrm{L}_{\mathrm{ex}}$ e o comprimento do arco interno $\mathrm{L}_{\mathrm{in}}$. O comprimento de corte pode ser dado pela média dos comprimentos $L_{e x}$ e $L_{i n}$ ou o produto entre o raio da fresa e o ângulo de contato em radianos:

$$
\mathrm{L}_{\mathrm{c}}=\frac{\mathrm{L}_{\mathrm{ex}}+\mathrm{L}_{\mathrm{in}}}{2}=\mathrm{R} \cdot \psi \mathrm{rad} \quad \chi_{\mathrm{r}}=90^{\circ}
$$

Uma vez que a área da seção de corte varia de um valor mínimo até um valor máximo, basta multiplicar a área da seção de corte média pelo comprimento de corte para obter o volume do cavaco indeformado:

$$
\mathrm{V}_{\mathrm{L}}=\overline{\mathrm{S}} \cdot \mathrm{L}_{\mathrm{c}}=\overline{\mathrm{h}} \cdot \mathrm{a}_{\mathrm{p}} \cdot \mathrm{L}_{\mathrm{c}} \quad \chi_{\mathrm{r}}=90^{\circ}
$$

Existem duas formas para determinar a área superficial do cavaco indeformado. Uma é a área exata:

$$
A_{s}=\frac{f_{z}}{4}\left[\sqrt{4 R^{2}-f_{z}^{2}}-4\left(R-a_{e}\right)\right]+R^{2} \operatorname{arcsen}\left(\frac{f_{z}}{2 R}\right) \operatorname{rad}
$$

E a outra é a aproximada: 


$$
A_{s}=f_{z} \cdot a_{e}
$$

A dedução das duas equações (2.20) e (2.21) se encontra no apêndice A. Por meio da Figura 2.17 é possível observar a diferença entre a área exata e a área aproximada em função do avanço por dente. Observa-se na figura que as duas equações começam a ter diferenças a partir de um avanço de $4 \mathrm{~mm} /$ dente que é um $\mathrm{f}_{\mathrm{z}}$ muito alto, e o máximo percentual de erro, para um avanço de $8 \mathrm{~mm} /$ dente, é de 5,8\%.

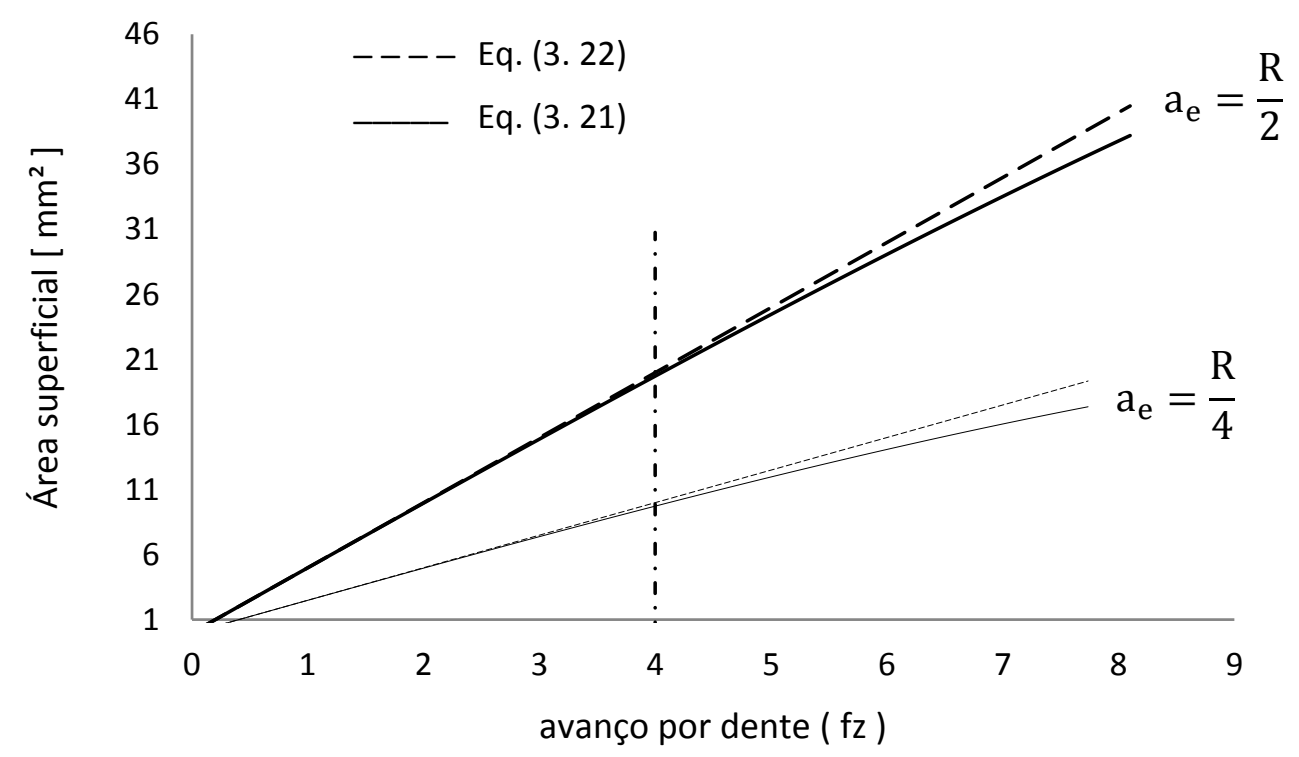

Figura 2.17 - Comparação entre as áreas dadas pelas equações (2.20) e (2.21).

Comparando a Equação (2.21) e (2.18) com a Equação (2.15), a espessura média de corte também pode ser obtida por:

$$
\overline{\mathrm{h}}=\frac{\mathrm{A}_{\mathrm{s}}}{\mathrm{L}_{\mathrm{c}}} \quad \chi_{\mathrm{r}}=90^{\circ}
$$

Substituindo a Equação (2.22) em (2.19) e sabendo que $\mathrm{L}_{c}=\mathrm{R}$. $\Psi$, o volume do cavaco indeformado também pode ser calculado por:

$$
\mathrm{V}_{\mathrm{L}}=\mathrm{f}_{\mathrm{z}} \cdot \mathrm{a}_{\mathrm{e}} \cdot \mathrm{a}_{\mathrm{p}} \quad \mathrm{\chi}_{\mathrm{r}}=90^{\circ}
$$

Para o caso do ângulo de posição menor que $90^{\circ}$, a área superficial superior do cavaco indeformado será maior que a área inferior, portanto o volume do cavaco indeformado deve ser calculado em função do comprimento de corte médio $\overline{\mathrm{L}_{\mathrm{c}}}$. A espessura de corte média deve ser 
calculada em função da área superficial média $\overline{\mathrm{A}_{\mathrm{s}}}$, pois a espessura de corte média na superfície superior do cavaco indeformado é maior que a da superfície inferior do mesmo. Conforme a Figura 2. 4, quando se tem ângulos de posição menores que $90^{\circ}$, a fresa é provida de dois raios, um é o raio nominal da fresa (R), o outro é o raio menor (r), decorrente do ângulo de posição menor que $90^{\circ}$. Assim sendo, tem-se que:

$$
\begin{array}{cc}
\overline{\mathrm{L}_{\mathrm{c}}}=\left(\mathrm{r}+\frac{\mathrm{a}_{\mathrm{p}}}{2 \operatorname{tg} \chi_{\mathrm{r}}}\right) \cdot \psi \mathrm{rad} & \chi_{\mathrm{r}}<90^{\circ} \\
\overline{\mathrm{A}_{\mathrm{s}}}=\mathrm{f}_{\mathrm{z}} \cdot\left(\mathrm{a}_{\mathrm{e}}-\frac{\mathrm{a}_{\mathrm{p}}}{2 \operatorname{tg} \chi_{\mathrm{r}}}\right) & \chi_{\mathrm{r}}<90^{\circ} \\
\overline{\mathrm{h}}=\frac{\overline{\mathrm{A}_{\mathrm{s}}}}{\overline{\mathrm{L}_{\mathrm{c}}}} & \chi_{\mathrm{r}}<90^{\circ} \\
\mathrm{V}_{\mathrm{L}}=\overline{\mathrm{h}} \cdot \mathrm{a}_{\mathrm{p}} \cdot \overline{\mathrm{L}_{\mathrm{c}}} & \chi_{\mathrm{r}}<90^{\circ}
\end{array}
$$

Com o intuito de validar as equações até aqui desenvolvidas, foi utilizado um software CAD de desenhos tridimensionais que fornece o volume dos mesmos e a área de qualquer superfície selecionada. A Tabela 2.2 mostra os resultados do cavaco indeformado de duas ferramentas. Uma possui ângulo de posição $\chi_{\mathrm{r}}=45^{\circ}$, diâmetro maior de $16 \mathrm{~mm}(\mathrm{R}=8)$ e diâmetro menor de $8 \mathrm{~mm}(\mathrm{r}=4)$. A outra ferramenta possui ângulo de posição $\chi_{\mathrm{r}}=90^{\circ}$ e diâmetro de $16 \mathrm{~mm}(\mathrm{R}=8 \mathrm{~mm})$. Ambas as ferramentas se encontram com apenas um dente. Os

\begin{tabular}{|c|c|c|c|c|}
\hline \multicolumn{3}{|c|}{$\chi_{r}=90^{\circ}$} & \multicolumn{2}{|c|}{$\chi_{r}=45^{\circ}$} \\
\hline \multicolumn{3}{|c|}{$A_{s}$} & \multicolumn{2}{|c|}{$\overline{A_{s}}$} \\
\hline Software & Eq. $(2.20)$ & Eq. (2.21) & Software & Eq. (2.25) \\
\hline $4,995 \mathrm{~mm}^{2}$ & $4,9947 \mathrm{~mm}^{2}$ & $5 \mathrm{~mm}^{2}$ & $3,492 \mathrm{~mm}^{2}$ & $3,5 \mathrm{~mm}^{2}$ \\
\hline \multicolumn{3}{|c|}{$\mathbf{V}_{\mathbf{L}}$} & \multicolumn{2}{|c|}{$\mathbf{V}_{\mathbf{L}}$} \\
\hline Software & Eq. (2.19) & Eq. (2. 23) & Software & Eq. (2.27) \\
\hline $14,984 \mathrm{~mm}^{3}$ & $14,984 \mathrm{~mm}^{3}$ & $15 \mathrm{~mm}^{3}$ & $10,477 \mathrm{~mm}^{3}$ & $10,5 \mathrm{~mm}^{3}$ \\
\hline
\end{tabular}
parâmetros estipulados foram: profundidade de usinagem $\mathrm{a}_{\mathrm{p}}=3 \mathrm{~mm}$, largura de corte $\mathrm{a}_{\mathrm{e}}=5$ $\mathrm{mm}$ e avanço por dente $\mathrm{f}_{\mathrm{z}}=1 \mathrm{~mm} /$ volta.

Tabela 2.2 - Comparação dos resultados fornecidos por um software e as equações apresentadas. 


\subsection{TAXA DE MATERIAL REMOVIDO}

Segundo Diniz, Marcondes e Coppini (2009), Stemmer (2007) e Fischer et al. (2008) a taxa de material removido $(\mathrm{Q})$ no fresamento é o quociente entre o volume de material removido para um determinado percurso da ferramenta na direção de avanço e o tempo deste percurso. De acordo com estes autores, o volume de material removido é calculado conforme a estrutura de um paralelepípedo retângulo (produto entre a penetração de trabalho $\mathrm{a}_{\mathrm{e}}$, a profundidade de usinagem $a_{p}$ e o deslocamento total na direção de avanço $L_{\mathrm{f}}$ ). A Figura 2.18 mostra a estrutura do volume de material removido (paralelepípedo retângulo) em que uma fresa realizou usinagem.

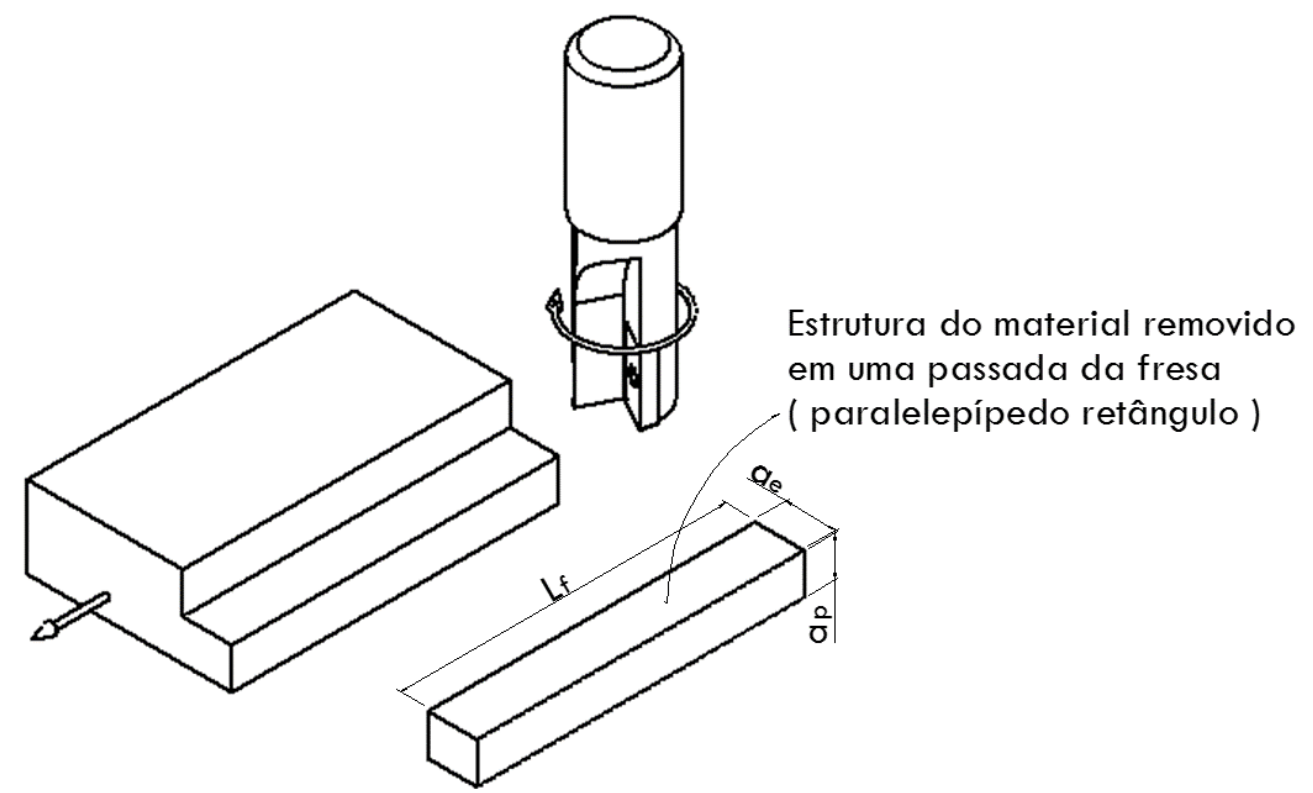

Figura 2.18 - Fresamento com ângulo de posição à $90^{\circ}$.

A relação entre o deslocamento total na direção de avanço $L_{f}$, e o tempo corrido necessário para a fresa percorrer tal deslocamento $\left(\mathrm{t}_{\mathrm{f}}\right)$ é conhecido como velocidade de avanço $\mathrm{V}_{\mathrm{f}}$. Assim sendo, a taxa de material removido é expressa por:

$$
\mathrm{Q}=\frac{\mathrm{a}_{\mathrm{e}} \cdot \mathrm{a}_{\mathrm{p}} \cdot \mathrm{L}_{\mathrm{f}}}{\mathrm{t}_{\mathrm{f}}}=\mathrm{a}_{\mathrm{e}} \cdot \mathrm{a}_{\mathrm{p}} \cdot \mathrm{V}_{\mathrm{f}}
$$

A velocidade de avanço $V_{f}$ também pode ser expressa pelo produto entre o avanço por dente, os números de dentes da fresa e a rotação da fresa:

$$
\mathrm{V}_{\mathrm{f}}=\mathrm{f}_{\mathrm{z}} \cdot \mathrm{Z} \cdot \mathrm{n}
$$


Entretanto, a Equação (2.28) não representa a taxa de material removido no processo de fresamento de modo geral, pois há duas situações que podem mascarar os resultados. A primeira se dá no fresamento frontal parcial quando o dente da fresa possui ângulo de posição menor que $90^{\circ}$ e a usinagem é realizada em uma única passada, como mostra a Figura 2. 19.

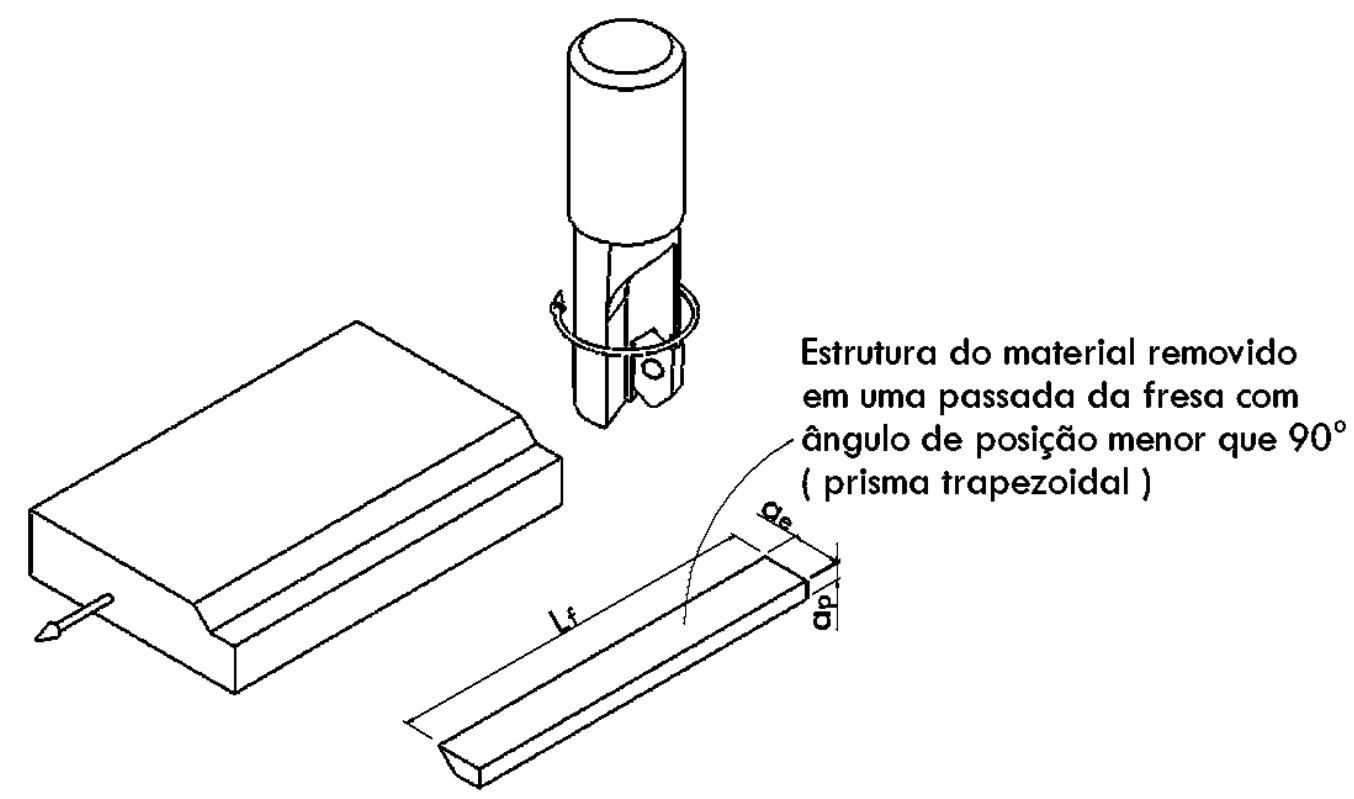

Figura 2. 19 - Fresamento com ângulo de posição menor que $90^{\circ}$.

No caso da Figura 2. 19 o volume da estrutura de material removido já não é mais correspondente a um paralelepípedo retângulo, e sim a um prisma trapezoidal. Assim, a taxa efetiva de material removido $\left(Q_{e}\right)$ é o quociente entre o volume trapezoidal e o tempo gasto para removê-lo:

$$
Q_{e}=\frac{a_{e} \cdot a_{p} \cdot L_{f}-\frac{a_{p}{ }^{2}}{2 \operatorname{tg} \chi_{r}} \cdot L_{f}}{t_{f}}=a_{p} \cdot\left(a_{e}-\frac{a_{p}}{2 \operatorname{tg} \chi_{r}}\right) V_{f}
$$

A segunda situação se dá quando o corte não é engajado. Uma vez que a ferramenta não remove material em um certo tempo, este tempo deve ser desconsiderado. Se as equações (2.28) ou (2.30) são usadas para calcular a taxa efetiva de material removido com tempo de movimento em vazio, os resultados são mascarados, pois estas duas equações consideram o tempo corrido. A Tabela 2.3 simula o movimento de uma volta da ferramenta. Nesta tabela é dado um exemplo do referido corte não engajado. $O$ tempo de corte $t_{c}$ é o tempo que o dente da fresa leva para passar pela zona de usinagem removendo material, e o tempo passivo $t_{p}$ é o tempo que o dente 
da fresa leva para completar o movimento até que o outro dente da fresa entre na zona de usinagem para remover outra camada de material.

Tabela 2.3 - Tempo de corte e tempo passivo para uma volta da ferramenta.

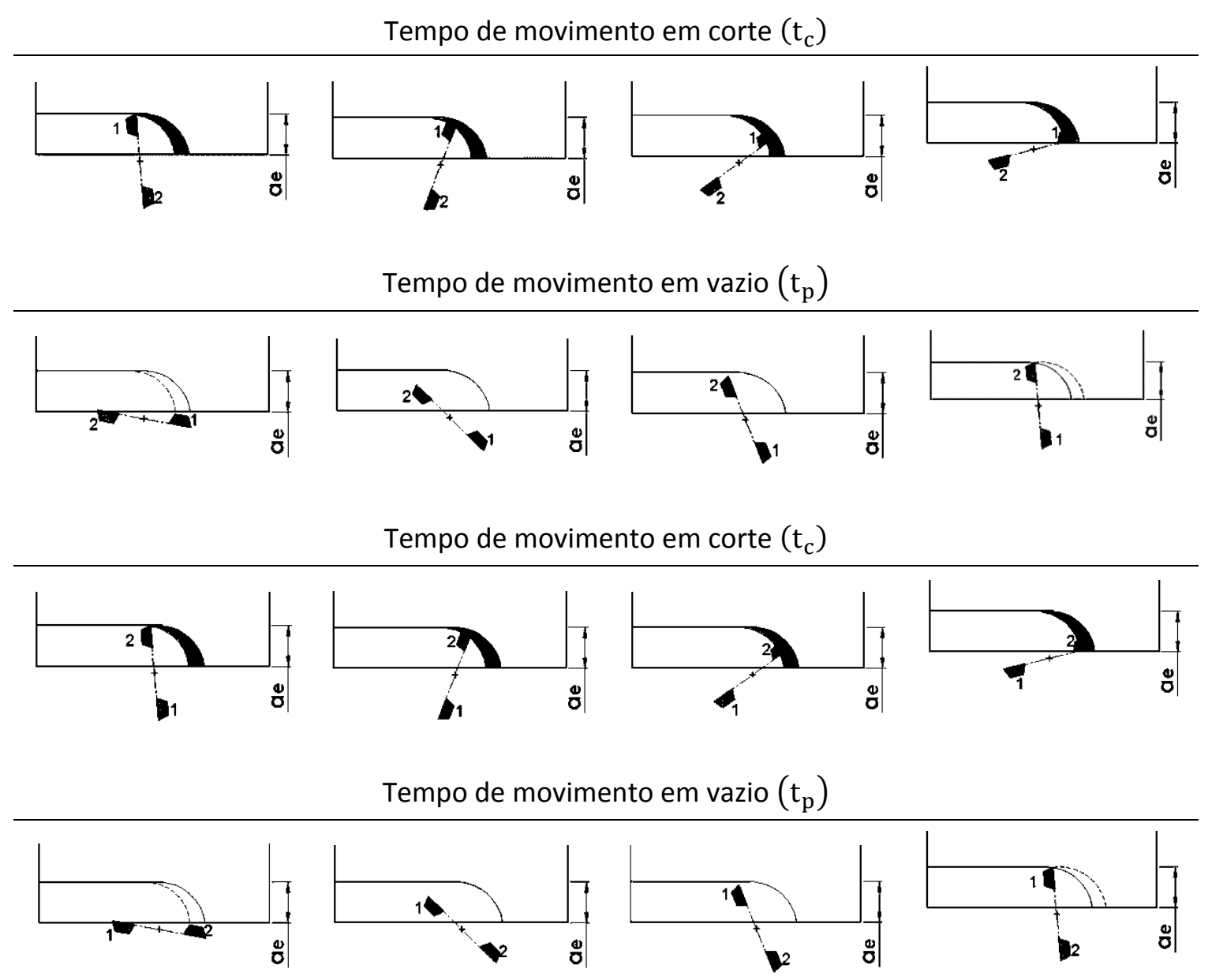

Considerando o método convencional para o cálculo da taxa de material removido, para uma volta da ferramenta, temos que Q é o quociente do volume de material removido em uma volta $\left(2 V_{L}\right)$ e o tempo corrido desta volta $\left(t_{f}=2 t_{c}+2 t_{p}\right)$, desta forma tem-se:

$$
Q=\frac{2 V_{L}}{t_{f}}=\frac{2 V_{L}}{2 t_{c}+2 t_{p}}=\frac{V_{L}}{t_{c}+t_{p}}
$$

Pode-se ver na Equação (2. 31) que o tempo durante o qual não houve remoção de material $\left(t_{p}\right)$ está mascarando os resultados, fazendo com que $Q$ tenha um valor menor que o efetivo. Portanto, se o corte não é engajado, o tempo corrido $t_{f}$ não pode ser usado nos cálculos da taxa de material removido. 
Desta forma, para calcular a taxa efetiva de material removido $Q_{e}$ no corte não engajado, o tempo passivo $t_{p}$ precisa ser tirado da equação. Sabendo que o volume do cavaco indeformado

é $\bar{h} \cdot a_{p} \cdot L_{c}$, e que o quociente entre o comprimento de corte $L_{c}$ e o tempo de corte $t_{c}$ é a velocidade de corte, têm-se:

$$
\mathrm{Q}_{\mathrm{e}}=\frac{\mathrm{V}_{\mathrm{L}}}{\mathrm{t}_{\mathrm{c}}}=\overline{\mathrm{h}} \cdot \mathrm{a}_{\mathrm{p}} \cdot \mathrm{V}_{\mathrm{c}} \quad \psi<\psi_{\mathrm{z}}
$$

Portanto, de modo geral, três equações devem ser consideradas para os cálculos da taxa de material removido no processo de fresamento: a primeira é a Equação (2.28), esta será usada quando o corte for engajado. A segunda é a Equação (2.30), esta será usada quando for realizado um fresamento em uma única passada, engajado, e com uma ferramenta que possui um ângulo de posição menor que $90^{\circ}$. Por fim, a terceira é a Equação (2.32), a qual será usada quando houver tempo de movimento em vazio, ou seja, corte não engajado.

\subsection{COMPONENTES DA FORÇA DE USINAGEM}

Conforme Ferraresi (1977) as componentes da força de usinagem são consideradas agindo em direção e sentido sobre a ferramenta, além disso, todas as componentes da força de usinagem projetados no plano de trabalho contribuem para a potência de usinagem.

Segundo a norma DIN 6584 (1982), as três componentes básicas, perpendiculares entre si, que somadas fornecem a força de usinagem $F_{u}$ são: a força de avanço $F_{f}$, força de apoio $F_{a p}$ e a força passiva $F_{p}$, onde $F_{f}$ e $F_{a p}$ se encontram no plano de trabalho, e $F_{p}$ é perpendicular a este plano. Outras três componentes da força de usinagem, que se encontram no plano de trabalho, são a força de corte $F_{c}$, a força de compressão $F_{n}$ e a força ativa $F_{T}$.

Segundo Ferraresi (1977), a força de avanço $\mathrm{F}_{\mathrm{f}}$, localiza-se sobre a direção de avanço; a força de apoio $\mathrm{F}_{\mathrm{ap}}$, se encontra sobre a direção perpendicular à direção de avanço, situada no plano de trabalho; a força passiva $\mathrm{F}_{\mathrm{p}}$, também conhecida por força de profundidade, é perpendicular ao plano de trabalho; a força de corte $\mathrm{F}_{\mathrm{c}}$, também conhecida como força principal de corte, localiza-se sobre a direção de corte (dada pela velocidade de corte); a força de compressão $\mathrm{F}_{\mathrm{n}}$, encontra-se na direção perpendicular à superfície principal de corte (superfície "arada" pela aresta principal de corte); e a força ativa $\mathrm{F}_{\mathrm{T}}$, se encontra sobre o plano de trabalho, sendo esta a resultante da força de apoio e de avanço. 
Estas componentes da força de usinagem podem ser visualizadas na Figura 2. 1.

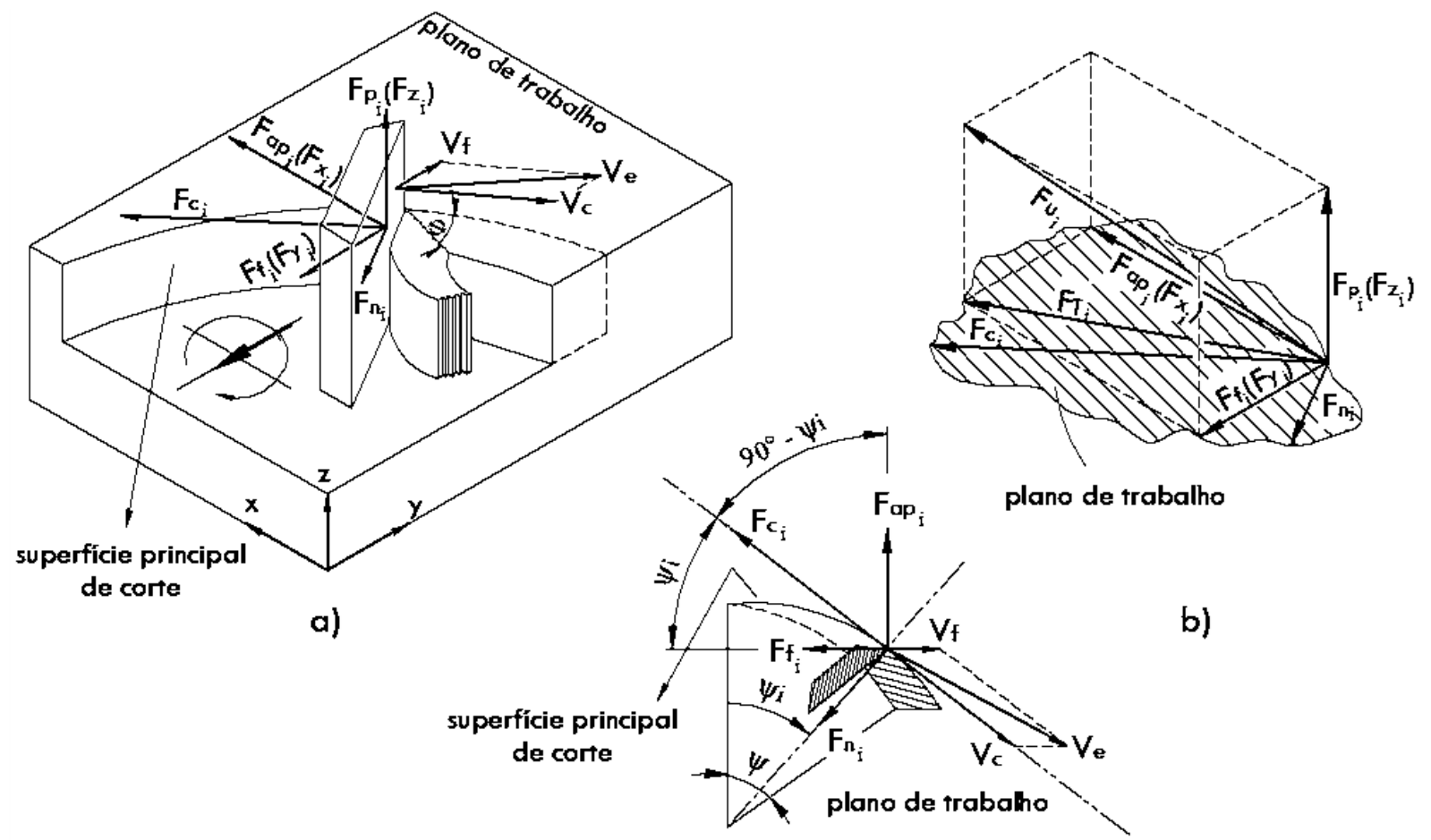

c)

Figura 2. 20 - Componentes da força de usinagem em fresamento frontal parcial discordante, fundamentadas na norma DIN 6584 (1982).

Do sistema geométrico da Figura 2. 20, pode-se chegar as seguintes equações:

$$
\begin{gathered}
\mathrm{F}_{\mathrm{u}_{\mathrm{i}}}=\sqrt{\mathrm{F}_{\mathrm{f}_{\mathrm{i}}}{ }^{2}+\mathrm{F}_{\mathrm{ap}_{\mathrm{i}}}{ }^{2}+\mathrm{F}_{\mathrm{p}_{\mathrm{i}}}{ }^{2}} \equiv \sqrt{\mathrm{F}_{\mathrm{c}_{\mathrm{i}}}{ }^{2}+\mathrm{F}_{\mathrm{n}_{\mathrm{i}}}{ }^{2}+\mathrm{F}_{\mathrm{p}_{\mathrm{i}}}{ }^{2}} \\
\mathrm{~F}_{\mathrm{T}_{\mathrm{i}}}=\sqrt{\mathrm{F}_{\mathrm{f}_{\mathrm{i}}}^{2}+\mathrm{F}_{\mathrm{ap}_{\mathrm{i}}}{ }^{2}} \equiv \sqrt{\mathrm{F}_{\mathrm{c}_{\mathrm{i}}}{ }^{2}+\mathrm{F}_{\mathrm{n}_{\mathrm{i}}}{ }^{2}} \\
\mathrm{~F}_{\mathrm{c}_{\mathrm{i}}}=\left|\mathrm{F}_{\mathrm{f}_{\mathrm{i}}} \cos \psi_{\mathrm{i}}\right|+\left|\mathrm{F}_{\mathrm{ap}_{\mathrm{i}}} \operatorname{sen} \psi_{\mathrm{i}}\right| \\
\mathrm{F}_{\mathrm{n}_{\mathrm{i}}}=\left|\mathrm{F}_{\mathrm{ap}_{\mathrm{i}}} \cos \psi_{\mathrm{i}}\right|-\left|\mathrm{F}_{\mathrm{f}_{\mathrm{i}}} \operatorname{sen} \psi_{\mathrm{i}}\right|
\end{gathered}
$$

Ressalta-se que, no processo de fresamento frontal parcial discordante, a força total de usinagem (força de usinagem $\mathrm{F}_{\mathrm{u}}$ ) varia de um valor mínimo até um valor máximo. Este fenômeno é decorrente da variação da espessura de corte h, que também varia de um valor mínimo até o máximo conforme o ângulo de contato $\psi$. Assim, todas as componentes da força de usinagem $\left(\mathrm{F}_{\mathrm{f}}, \mathrm{F}_{\mathrm{ap}}, \mathrm{F}_{\mathrm{p}}, \mathrm{F}_{\mathrm{c}}, \mathrm{F}_{\mathrm{n}}\right.$ e $\left.\mathrm{F}_{\mathrm{T}}\right)$ também variam conforme o ângulo de contato $\psi$. 


\subsection{PRESSÃO ESPECÍFICA DE CORTE EM FRESAMENTO}

Um dos componentes mais importantes da força de usinagem é a força de corte. Pelo fato de se localizar na direção do movimento de corte, é responsável pela maior parte da energia gasta e potência consumida pelo sistema. Pode-se chegar à força de corte com base na pressão exercida sobre a superfície de saída da ferramenta devido à camada de material removida da peça. A esta pressão é dado o nome de pressão específica de corte. Kronenberg (1966) acreditava que conforme o ensaio de resistência mecânica fornece tensões específicas para cada tipo de material independente da área, a pressão exercida sobre a ferramenta também deveria se comportar da mesma maneira, ou seja, para cada material, independente da área, haveria uma determinada pressão específica para rompê-lo. Tal pressão ficou designada como: Pressão específica de corte $\left(\mathrm{k}_{\mathrm{s}}\right)$. O termo pressão específica de corte vem da expressão, encontrada na literatura americana, "unit cutting force", algumas vezes também chamada de "specific cutting force"; por esse motivo, é comum encontrar em alguns livros traduzidos a denominação "força de corte específica”.

A pressão específica de corte, em fresamento, segue o mesmo princípio da espessura de corte na formação de um cavaco: varia a cada instante como mostra a Figura 2.21.

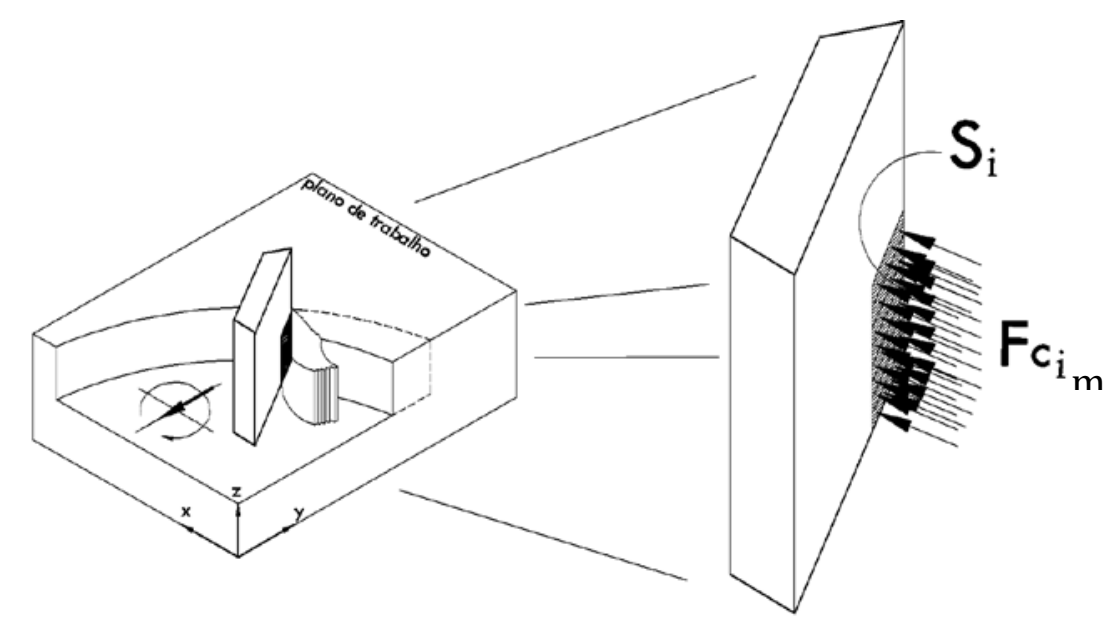

Figura 2.21 - Pressão exercida sobre o dente da fresa pela camada de material a ser removida.

Assim, para cada valor instantâneo da espessura de corte, dentro do ângulo de contato $\psi$, haverá uma pressão específica de corte correspondente. Esta pode ser expressa pelo quociente entre a força de corte medida de acordo com a posição da ferramenta dentro da zona de usinagem $\left(\mathrm{F}_{\mathrm{C}_{\mathrm{i}}}\right)$ e a seção de corte instantânea $\left(\mathrm{S}_{\mathrm{i}}\right)$ : 


$$
\mathrm{k}_{\mathrm{s}_{\mathrm{i}}}=\frac{\mathrm{F}_{\mathrm{c}_{\mathrm{m}}}}{\mathrm{S}_{\mathrm{i}}}=\frac{\mathrm{F}_{\mathrm{c}_{\mathrm{m}}}}{\mathrm{h}_{\mathrm{i}} \cdot \mathrm{a}_{\mathrm{p}}}
$$

Devido a variação da espessura de corte e consequentemente a variação da força de corte na formação de um cavaco, Ferraresi, Ruffino e Pallerosi (1974) se basearam no conceito da espessura de corte média. Com base neste conceito, a pressão específica de corte, no processo de fresamento, passa a ser reconhecida como uma média:

$$
\overline{\mathrm{k}_{\mathrm{s}}}=\frac{\overline{\mathrm{F}_{\mathrm{c}}}}{\overline{\mathrm{s}}}=\frac{\overline{\mathrm{F}_{\mathrm{c}}}}{\overline{\overline{\mathrm{h}} \cdot \mathrm{a}_{\mathrm{p}}}}
$$

Entretanto, a pressão específica de corte não se comporta como num ensaio de resistência mecânica, em que as tensões praticamente permanecem constantes para um mesmo material com áreas transversais distintas. Conforme Ferraresi (1977) e Ruffino (1971), vários pesquisadores e associações técnicas investigaram o comportamento da pressão específica de corte, e concluíram que esta é sensível a vários fatores.

Dentre os fatores que influenciam $\mathrm{k}_{\mathrm{s}}$, muitos proporcionam efeitos altamente significativos, e outros levemente significativos. Entre as propriedades do material da peça pode-se considerar para as formulações de $\mathrm{k}_{\mathrm{s}}$, a composição química e resistência ao cisalhamento do material da peça. Sobre a geometria e material da ferramenta, pode-se considerar para uma ferramenta nova, o raio de ponta para usinagem convencional, e o raio de aresta para microusinagem. A respeito dos ângulos, é possível realizar aproximações na força de corte, principalmente para os materiais dúcteis, em torno de 1\% quando o ângulo de saída varia $1^{\circ}$; o ângulo de posição $(\lambda)$ influi em $\mathrm{k}_{\mathrm{s}}$ quando é altamente negativo; o ângulo de folga principal $(\alpha)$ maior que $5^{\circ}$ não afeta o $\mathrm{k}_{\mathrm{s}}$; e o ângulo de posição $\left(\chi_{r}\right)$ modifica a espessura de corte, que consequentemente está relacionada com os parâmetros de usinagem. Dos parâmetros de usinagem que influem em $\mathrm{k}_{\mathrm{s}}$, o fator mais relevante é a espessura de corte. A velocidade em certo valor não influi em $\mathrm{k}_{\mathrm{s}}$, e o fluido de corte possui suas limitações (DINIZ, MARCONDES E COPPINI, 2010; FERRARESI, 1977; RODRIGUES, 2005; SANDVIK, 2006; KRONEMBERG, 1966; RUFFINO, 1971; BOOTHROYD e KNIGHT, 1989; ARNOLD, 1946; SHAW, 2005; DIB e JASINEVICIUS, 2012).

Assim $\mathrm{k}_{\mathrm{s}}$ pode ser calculado para um dado material a ser usinado com uma dada ferramenta em função da área e da forma da seção de corte. 


\subsubsection{Estimando as constante $\mathrm{k}_{\mathrm{s} 1}$ e $\mathrm{m}$ do material da peça}

Segundo Ferraresi (1977), vários pesquisadores, baseados em resultados experimentais, propuseram fórmulas analíticas, relacionando a pressão específica de corte com as diversas grandezas que a influenciam. Merecem particular interesse neste estudo os trabalhos dos seguintes autores: Taylor; Sociedade Americana de Engenharia Mecânica (ASME); Associação de Produção Econômica da Alemanha (AWF); Hucks; Kronemberg; e Kienzle. A tabela de equações a seguir fornece, em cada linha, as constantes e o modelo proposto por cada autor mencionado.

Tabela 2.4 - Formulações da pressão específica de corte.

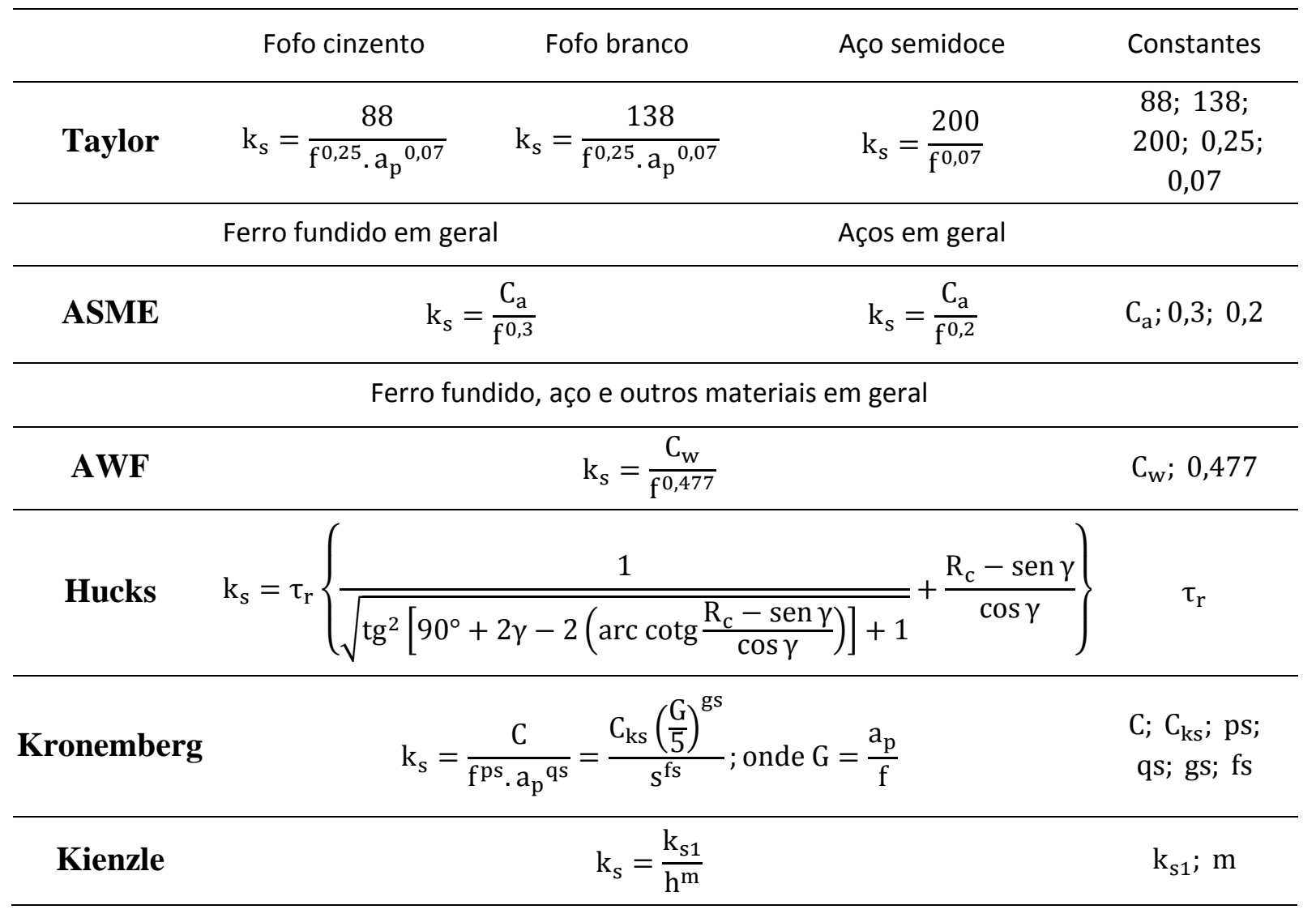

A fórmula de Kienzle é bastante simples e suficientemente precisa para os cálculos práticos da força de usinagem. Nesta, $\mathrm{k}_{\mathrm{s}}$ é dado em função da espessura de corte $\mathrm{h}$ e não em função do avanço f. Esta propriedade permite aplicar facilmente a fórmula de Kienzle a todas as operações de usinagem (FERRARESI, 1977). Por este motivo, no decorrer dos cálculos, a pressão específica de corte será tratada com base na equação geral de Kienzle. Dessa forma, é preciso determinar as constantes $\mathrm{k}_{\mathrm{s} 1}$ e $\mathrm{m}$ da função potência $\mathrm{k}_{\mathrm{s}}=\mathrm{k}_{\mathrm{s} 1} \mathrm{~h}^{-\mathrm{m}}$. 
A dispersão do par ordenado pressão específica de corte $\left(\mathrm{k}_{\mathrm{s}}\right)$ e espessura de corte $(\mathrm{h})$, segue uma tendência de função potência e o modelo proposto por Kienzle. Uma função potência pode ser linearizada. Para o caso de $\mathrm{k}_{\mathrm{s}}$ versus $\mathrm{h}$ é possível linearizar o comportamento destas duas quantidades fazendo $\ln \left(\mathrm{k}_{\mathrm{s}}\right)$ versus $\ln (\mathrm{h})$. Assim sendo, torna-se possível usar o método de regressão linear simples para encontrar as constantes $\mathrm{k}_{\mathrm{s} 1}$ e m.

A análise de regressão é uma técnica estatística para modelar e investigar o relacionamento entre duas ou mais variáveis. A análise de regressão pode ser usada para construir um modelo que expressa y em função de x. E também pode ser usada para otimização do processo ou controle do processo (HINES e MONTGOMERY, 1990).

Considerando duas variáveis $\mathrm{x}_{\mathrm{i}}=\ln \left(\mathrm{h}_{\mathrm{i}}\right)$ e $\mathrm{y}_{\mathrm{i}}=\ln \left(\mathrm{k}_{\mathrm{s}_{\mathrm{i}}}\right)$, para $\mathrm{N}$ observações $\left(\mathrm{x}_{1}, \mathrm{y}_{1}\right)$, $\left(\mathrm{x}_{2}, \mathrm{y}_{2}\right), \ldots,\left(\mathrm{x}_{\mathrm{N}}, \mathrm{y}_{\mathrm{N}}\right)$, pode-se estabelecer uma regressão linear simples cujo modelo estatístico é descrito pela Equação (2.39), em que $\beta_{0}$ é o intercepto ou coeficiente linear, $\beta_{1}$ é o coeficiente de regressão ou coeficiente angular e $\epsilon_{\mathrm{i}}$ é o erro experimental.

$$
\hat{y}_{i}=\beta_{0}+\beta_{1} x_{i}+\epsilon_{i}
$$

Pressupondo-se que a média do erro é nula, a equação pode ser representada por:

$$
\hat{y}_{i}=\beta_{0}+\beta_{1} x_{i}
$$

Os parâmetros $\beta_{0}$ e $\beta_{1}$ podem ser estimados pelo método dos mínimos quadrados, no qual a soma dos quadrados e desvios entre as observações e a linha de regressão é mínimo:

$$
\begin{gathered}
\beta_{0}=\bar{y}-\beta_{1} \bar{x} \\
\beta_{1}=\frac{S_{x y}}{S_{x x}}
\end{gathered}
$$

onde:

$$
\begin{aligned}
& \bar{y}=\frac{1}{n} \sum_{j=1}^{n} y_{j} \\
& \bar{x}=\frac{1}{n} \sum_{j=1}^{n} x_{j}
\end{aligned}
$$




$$
\begin{gathered}
S_{x y}=\sum_{j=1}^{n} x_{j} y_{j}-\frac{\left(\sum_{j=1}^{n} x_{j}\right)\left(\sum_{j=1}^{n} y_{j}\right)}{n} \\
S_{x x}=\sum_{j=1}^{n} x_{j}^{2}-\frac{\left(\sum_{j=1}^{n} x_{j}\right)^{2}}{n}
\end{gathered}
$$

Para verificar a exatidão do modelo de regressão, é preciso calcular o coeficiente de determinação linear $\left(\mathrm{R}^{2}\right)$, dado pela Equação (2.47). Quanto mais $\mathrm{R}^{2}$ se aproxima de 1 , maior é a precisão do modelo de regressão. O coeficiente de determinação linear $\mathrm{R}^{2}$ se encontra entre 0 e 1.

$$
\mathrm{R}^{2}=1-\frac{\mathrm{SSE}}{\mathrm{SST}}
$$

onde:

$$
\begin{gathered}
\text { SSE }=\sum_{j=1}^{n}\left(y_{j}-\hat{y}_{j}\right)^{2} \\
S S T=\sum_{j=1}^{n} y_{j}^{2}-\frac{\left(\sum_{j=1}^{n} y_{j}\right)^{2}}{n}
\end{gathered}
$$

Determinados os parâmetros $\beta_{0}$ e $\beta_{1}$, é necessário fazer a reversão da estratégia de linearização para se obter as constantes $\mathrm{k}_{\mathrm{s} 1}$ e $\mathrm{m}$. Na Equação (2.40), pode-se substituir diretamente as variáveis representativas $\hat{y}_{\mathrm{i}}$ e $\mathrm{x}_{\mathrm{i}}$ pelas variáveis originais $\ln \left(\hat{\mathrm{k}}_{\mathrm{s}_{\mathrm{i}}}\right)$ e $\ln \left(\mathrm{h}_{\mathrm{i}}\right)$ :

$$
\ln \left(\hat{\mathrm{k}}_{\mathrm{s}_{\mathrm{i}}}\right)=\beta_{0}+\beta_{1} \ln \left(\mathrm{h}_{\mathrm{i}}\right)
$$

Elevando-se o número natural aos termos dos dois lados da igualdade, e aplicando-se as regras de exponenciação:

$$
\hat{\mathrm{k}}_{\mathrm{si}}=\mathrm{e}^{\beta_{0}} \cdot \mathrm{h}_{\mathrm{i}}^{\beta_{1}}
$$

Da Equação (2.51), pode-se ver que: 


$$
\mathrm{k}_{\mathrm{s} 1}=\mathrm{e}^{\beta_{0}}
$$

e

$$
-\mathrm{m}=\beta_{1}
$$

No apêndice A é dado um exemplo numérico para determinação das constantes $\mathrm{k}_{\mathrm{s} 1}$ e m do material da peça SAE 1045 na operação de torneamento.

Uma vez estimado a pressão específica de corte, pode-se calcular a força de corte multiplicando $\mathrm{k}_{\mathrm{s}}$ pela área da seção de corte. Assim a equação da força de corte pode ser expressa por:

$$
\mathrm{F}_{\mathrm{c}_{\mathrm{i}}}=\mathrm{k}_{\mathrm{s}_{\mathrm{i}}} \cdot \mathrm{S}_{\mathrm{i}}=\mathrm{k}_{\mathrm{s} 1} \cdot \mathrm{h}_{\mathrm{i}}^{1-\mathrm{m}} \cdot \mathrm{a}_{\mathrm{p}}
$$

Força de corte média:

$$
\overline{\mathrm{F}_{\mathrm{c}}}=\overline{\mathrm{k}_{\mathrm{s}}} \cdot \overline{\mathrm{S}}=\mathrm{k}_{\mathrm{s} 1} \cdot \overline{\mathrm{h}}^{1-\mathrm{m}} \cdot \mathrm{a}_{\mathrm{p}} \quad \psi \leq \psi_{\mathrm{z}}
$$

A tabela a seguir fornece os valores de $\mathrm{k}_{\mathrm{s} 1}$ e m para vários tipos de material da peça.

Tabela 2. 5 - Constante específica de corte $\mathrm{k}_{\mathrm{s} 1}$ e o coeficiente angular m. (FERRARESI, 1977). Ferramenta utilizada nos ensaios para os aços

$$
\gamma=6^{\circ} \quad \lambda=-4^{\circ} \quad r_{\varepsilon}=1 \mathrm{~mm}
$$

Ferramenta utilizada nos ensaios para os ferros fundidos

\begin{tabular}{llccc}
\multicolumn{1}{c}{$\gamma=2^{\circ}$} & \multicolumn{3}{c}{$\mathrm{r}_{\varepsilon}=-4^{\circ}$} \\
\hline DIN & \multicolumn{1}{c}{ SAE } & $\tau_{\mathrm{r}}\left[\mathrm{N} / \mathrm{mm}^{2}\right]$ & $\mathrm{m}$ & $\mathrm{k}_{\mathrm{s} 1}\left[\mathrm{~N} / \mathrm{mm}^{2}\right]$ \\
\hline St 50.11 & $1030-1035$ & 510 & 0,26 & 1952 \\
St 60.11 & $1040-1045$ & 608 & 0,17 & 2070 \\
St 70.11 & 1060 & 706 & 0,30 & 2217 \\
Ck 45 & 1045 & 657 & 0,14 & 2178 \\
Ck 60 & 1060 & 755 & 0,18 & 2090 \\
16 MnCr 5 & 8620 & 755 & 0,26 & 2060 \\
18 CrNi 6 & - & 618 & 0,30 & 2217 \\
42 CrMo 4 & 4140 & 716 & 0,26 & 2453 \\
34 CrMo 4 & 4137 & 589 & 0,21 & 2198 \\
50 Cr V4 & 6150 & 589 & 0,26 & 2178 \\
55NiCrMo V6 & - & 922 & 0,24 & 1707 \\
55NiCrMo V7 & - & HB $=352$ & 0,24 & 1883 \\
EC Mo 80 & - & 579 & 0,17 & 2247 \\
Meehanite A & - & 353 & 0,26 & 1246 \\
FoFo duro & - & HRC $=46$ & 0,19 & 2021 \\
GG 26 & Fofo cinzento & HB $=200$ & 0,26 & 1138 \\
\hline
\end{tabular}




\subsection{FORÇA DE RISCAMENTO E O EFEITO DE ESCALA}

Segundo Boothroyd e Knight (1989), a força de usinagem (força resultante) no corte do metal, é distribuída sobre a área da ferramenta que está em contato com o cavaco e a peça, conforme é mostrado pela Figura 2.22. Esta distribuição se dá na interface cavaco-ferramenta que se encontra na superfície de saída da ferramenta, na interface peça-aresta localizada na região do raio de aresta, e na interface peça-ferramenta que se encontra na superfície de folga principal da ferramenta. Toda ferramenta de corte possui uma aresta de corte aproximadamente arredondada, e uma parte pequena da superfície de folga da ferramenta sempre vai estar em contato com a superfície da peça.

Por causa das altas pressões próximas da aresta de corte da ferramenta, deformações do material da peça podem ocorrer nesta região. Esta deformação pode causar um maior contato entre a ferramenta e a peça na superfície de folga principal. Deste modo, uma força de atrito atua na região da superfície de folga, que por sua vez forma uma pequena porção da força de corte.

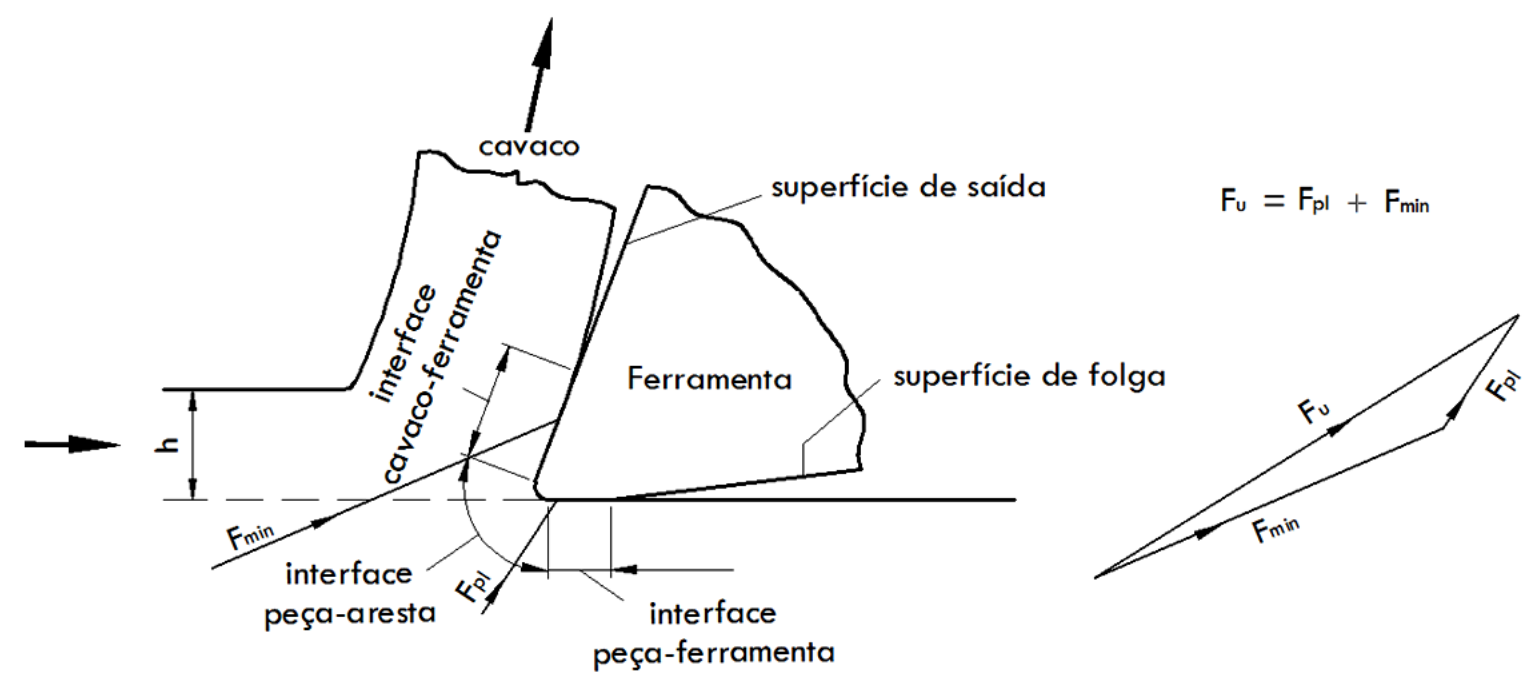

Figura 2.22 - Região de contato na ferramenta de corte. $\mathrm{F}_{\mathrm{u}}$ = força de usinagem, $\mathrm{F}_{\min }=$ força mínima para remover o cavaco, $\mathrm{F}_{\mathrm{pl}}=$ força de riscamento.

Fonte: Modificado de Boothroyd e Knight, 1989.

Nenhuma das forças que atua na aresta de corte da ferramenta, e que pode atuar na superfície de folga principal da ferramenta, contribui para remoção do cavaco. A estas forças é dado o nome de força de riscamento $\left(\mathrm{F}_{\mathrm{pl}}\right)$. A existência da força de riscamento pode explicar o efeito de escala (crescimento da pressão específica de corte com o decrescimento da espessura de corte). Em se tratando de valores relativamente pequenos da espessura de corte, a pressão 
específica de corte tende aumentar rapidamente com o decréscimo da espessura. Este fato induz à hipótese de que a força de riscamento torna-se uma grande porção da força de corte quando a espessura decresce. Quando a força de corte é dividida pela área da seção de corte para o conhecimento de $\mathrm{k}_{\mathrm{s}}$, a porção de $\mathrm{k}_{\mathrm{s}}$ contribuinte para remoção do cavaco permanecerá constante $\left(\mathrm{k}_{\mathrm{s}_{\text {min }}}\right)$, e a porção resultante da força de riscamento $\left(\mathrm{k}_{\mathrm{spl}_{\mathrm{pl}}}\right)$ aumentará com o decréscimo da espessura, pois deformações do material da peça começam a ter proporções maiores do que o cisalhamento. Assim, a pressão específica de corte é a soma de duas porções fenomenológicas do corte dos metais:

$$
\mathrm{k}_{\mathrm{s}_{\mathrm{i}}}=\mathrm{k}_{\mathrm{spl}_{\mathrm{i}}}+\mathrm{k}_{\mathrm{s}_{\min _{\mathrm{i}}}}
$$

Portanto, o $\mathrm{k}_{\mathrm{s}_{\text {min }}}$ sempre vai estar presente durante a remoção de material, porém o k $\mathrm{s}_{\mathrm{pl}}$ será mais proeminente conforme a quantidade de material sendo deformada. Quanto menor é a espessura de corte, maior é o fluxo lateral de material e maior é a força de riscamento. Por outro lado, quanto maior é a espessura de corte, menor é o fluxo lateral de material e menor é a força de riscamento. Pela Figura 2.23, pode-se observar que $\mathrm{k}_{\mathrm{spl}}$ aumenta de forma assintótica com o decréscimo da espessura. Disto resulta que o fluxo de material para lateral da ferramenta não é linear, com o decréscimo da espessura a quantidade de material deformada aumenta, mas não de forma progressiva, e sim como uma curva exponencial.

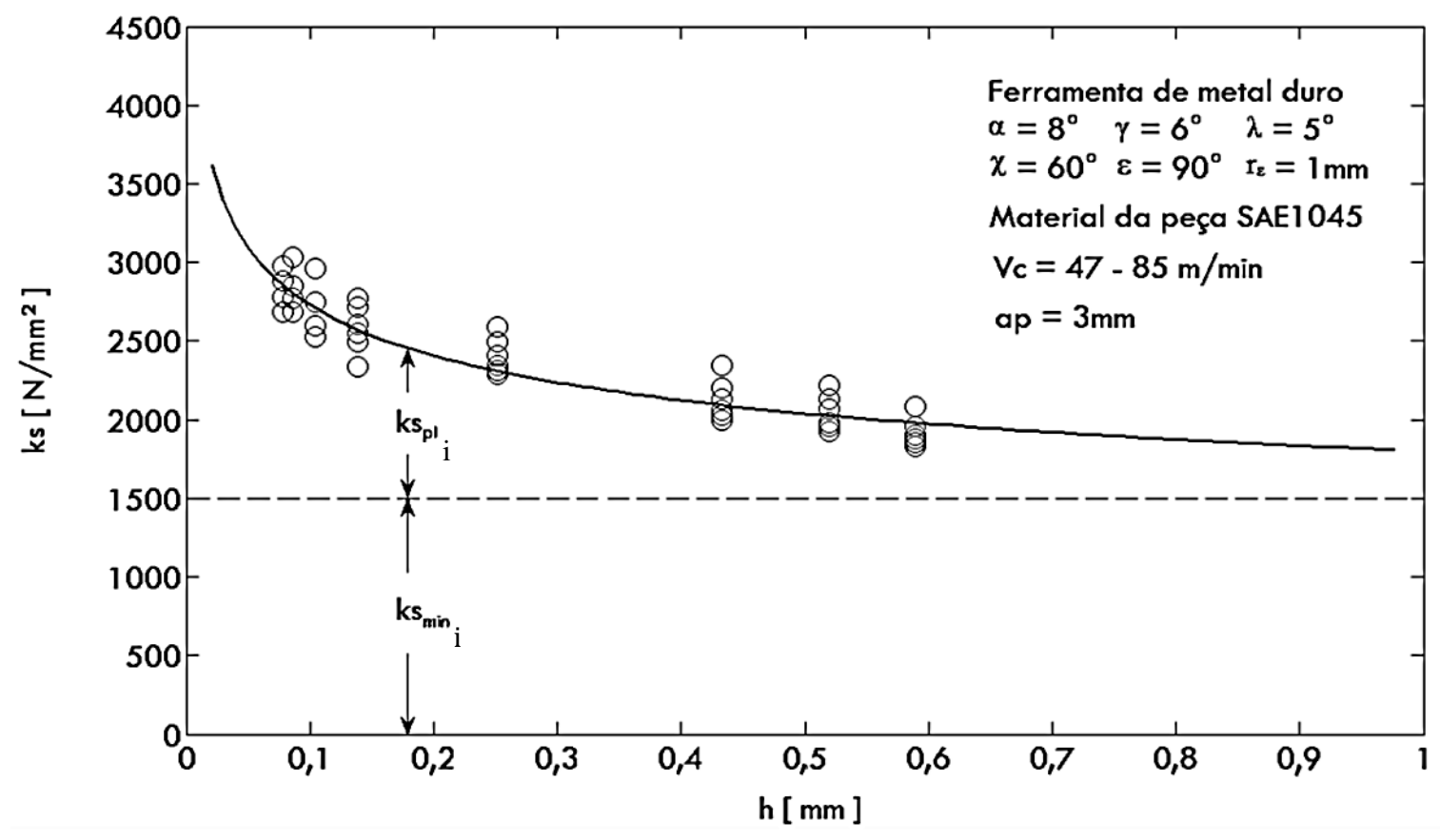

Figura 2.23 - Pressão específica de corte versus a espessura de corte.

Fonte: Dados de Ruffino (1971). 


\subsection{A FORÇA DE CORTE MÉDIA EM USINAGEM SIMULTÂNEA}

Até os parágrafos anteriores, a teoria da força de corte média, $\overline{\mathrm{F}_{\mathrm{c}}}$, foi correlacionada a uma fresa em que apenas um dente está presente na zona de usinagem. Contudo, se o corte for engajado, normalmente mais que um dente se encontra na zona de usinagem, e estes realizam o corte simultaneamente. Para estimar a força de corte média nesta interatividade de arestas de corte, é preciso saber qual é a espessura de corte média correspondente a cada zona de usinagem equivalente. Considera-se uma zona de usinagem equivalente, a relação que cada dente, presente na zona de usinagem, tem numa movimentação equivalente ao ângulo $\psi_{\mathrm{z}}$. A melhor forma de analisar este fato é observando, imediatamente, a saída de um dente da zona de usinagem.

De forma a ilustrar este fenômeno, será usado como exemplo uma fresa de oito dentes $(Z=8)$, em que a penetração de trabalho é três quartos do raio da fresa ( ae $=0,75 R$ ), consequentemente dois dentes vão trabalhar simultaneamente em um certo período. Observando a Figura 2.24-a, no exato momento que um dente sai da zona de usinagem (posição B'), há uma diminuição drástica da força de corte tendendo a uma força correspondente à força de corte exercida sobre o dente 1 na posição A' dentro da zona de usinagem. A força de corte começa a aumentar à medida que o dente 1 vai rotacionando e avançando; quando o dente 2 entra na zona de usinagem, ocorre uma sobreposição de forças, resultando em um somatório: a força de corte exercida sobre o dente 1 mais a força de corte sobre o dente 2. Esta sobreposição se mantém até que o dente 1 sai da zona de usinagem e se inicia um novo ciclo (Figura 2.24-b).

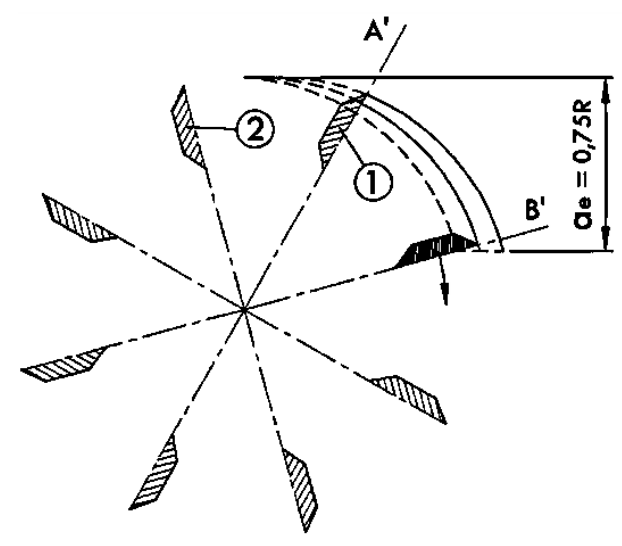

a)

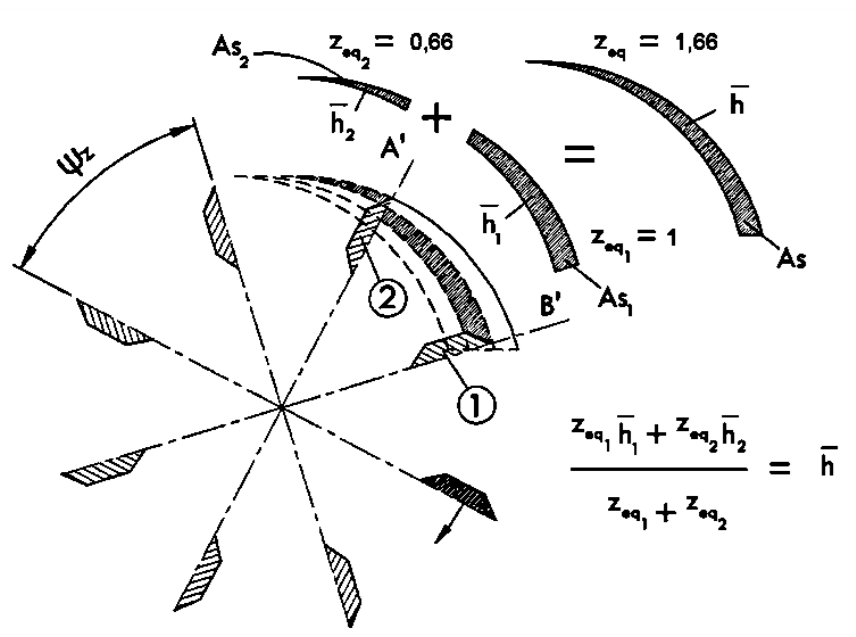

b)

Figura 2.24 - Sobreposição das forças de corte devido ao corte simultâneo. 
Conforme a Figura 2.24-b, a zona que contém a área superficial representativa $\mathrm{A}_{\mathrm{s}_{1}}$ obtida do movimento de corte realizado pelo dente 1 da posição A' até o B', é dita como uma zona de usinagem equivalente $\left(\mathrm{z}_{\mathrm{eq}_{1}}=1\right)$, pois equivale a um movimento correspondente ao ângulo $\Psi_{\mathrm{z}}$. Por outro lado, o dente 2 realiza um movimento simultâneo com o dente 1 , e entra na zona de usinagem um pouco depois, formando a área superficial representativa $A_{s_{2}}$ (consequentemente, o ângulo de abertura de $\mathrm{A}_{\mathrm{s}_{2}}$ é menor que $\psi_{\mathrm{z}}$ ). Assim, a zona de usinagem da área $\mathrm{A}_{\mathrm{s}_{2}}$ equivale a $66 \%\left(\mathrm{z}_{\mathrm{eq}_{2}}=0,66\right)$ de uma zona completa, pois o ângulo que forma a área $A_{\mathrm{s}_{2}}$ é em torno de $66 \%$ do ângulo entre os dentes da fresa $\left(\psi_{\mathrm{z}}\right)$.

Portanto, no caso específico da Figura 2.24, tem-se um número total de zonas de usinagem equivalentes correspondente a $1,66\left(\mathrm{z}_{\mathrm{eq}}=1,66\right)$, o que significa que 1,66 do ângulo formado entre os dentes da fresa corresponde ao ângulo de contato da zona de usinagem* $(\psi)$, assim $\mathrm{z}_{\text {eq }}$ pode ser calculado pela expressão:

$$
\mathrm{z}_{\mathrm{eq}}=\frac{\psi}{\psi_{\mathrm{z}}}
$$

Sendo,

$$
\begin{aligned}
& \psi_{\mathrm{z}}=\frac{2 \pi \mathrm{rad}}{\mathrm{Z}} \equiv \frac{360^{\circ}}{\mathrm{Z}} \\
& \mathrm{z}_{\mathrm{eq}}=\frac{\psi \cdot \mathrm{Z}}{2 \pi} \equiv \frac{\psi^{\circ} \cdot \mathrm{Z}}{360^{\circ}}
\end{aligned}
$$

Onde, $\Psi$ é o ângulo de contato*; Z é o número de dentes da fresa, e $\Psi_{z}$ é o ângulo entre os dentes da fresa.

Para o cálculo da força de corte média com dentes simultâneos em operação, é preciso somar a força de corte média exercida sobre o dente 1 na zona $\mathrm{z}_{\mathrm{eq}_{1}}$, e a força de corte média exercida sobre o dente 2 na zona $\mathrm{z}_{\mathrm{eq}_{2}}$. A espessura de corte média correspondente à zona $\mathrm{z}_{\mathrm{eq}_{1}}$ é $\overline{h_{1}}$, e da zona $\mathrm{z}_{\mathrm{eq}_{2}}$ é $\overline{\mathrm{h}_{2}}$ (vide Figura 2.24-b). Assim, a força de corte média estimada é:

$$
\overline{\mathrm{F}_{\mathrm{c}}}=\mathrm{k}_{\mathrm{s} 1} \cdot \overline{\mathrm{h}}^{-\mathrm{m}} \cdot\left(\overline{\mathrm{h}_{1}} \cdot \mathrm{a}_{\mathrm{p}}\right)+\mathrm{k}_{\mathrm{s} 1} \cdot \overline{\mathrm{h}}^{-\mathrm{m}} \cdot\left(\overline{\mathrm{h}_{2}} \cdot \mathrm{a}_{\mathrm{p}}\right)
$$

\footnotetext{
* No caso da Figura 2.24, o ângulo de contato $\psi$ é formado entre as áreas $\mathrm{A}_{\mathrm{s}_{1}}$ e $\mathrm{A}_{\mathrm{s}_{2}}$ que somadas correspondem exatamente a um movimento completo de um dente isolado, ou seja, o ângulo de contato é calculado pela mesma equação de um fresamento não engajado, dada pela Equação 2.7.
} 
Generalizando a Equação (2.60), a força de corte média no corte engajado é:

$$
\overline{F_{c}}=k_{s 1} \cdot a_{p} \cdot \sum_{j=1}^{n}{\overline{h_{j}}}^{1-m}
$$

Contudo, utilizar a Equação (2.61) torna-se uma tarefa complexa, uma vez que para cada zona de usinagem equivalente é preciso identificar os ângulos iniciais e finais e então calcular a espessura de corte média correspondente a cada zona.

A literatura alemã traz o seguinte conceito: a força de corte média, sem sobreposição, correspondente a um movimento de um dente da fresa do início ao final da zona de usinagem, multiplicada pela soma das zonas de usinagem equivalentes, fornece, aproximadamente, a força de corte média total correspondente à interação dos dentes na zona de usinagem (GIECK, 2001; FISCHER et al., 2008).

Após uma série de análises em busca da dedução deste conceito, chegou-se a seguinte aproximação matemática: a soma dos termos $a_{j}$ elevados a uma potência $q$, onde q é sempre menor que 1 , é aproximadamente o produto do número de termos $\mathrm{N}$ e a média dos termos $\mathrm{a}_{\mathrm{j}}$ elevada ao expoente q, conforme descreve a equação a seguir:

$$
\sum_{j=1}^{N} a_{j} q \cong N\left(\frac{1}{N} \sum_{j=1}^{N} a_{j}\right)^{q} \quad q \leq 1
$$

Existem dois casos (i e ii) que tornam a aproximação da Equação (2. 62) mais precisa; $\mathrm{i}$ : é quando os termos $\mathrm{a}_{\mathrm{j}}$ são progressivos $\left(\mathrm{a}_{\mathrm{j}}=1,2,3,4, \ldots\right)$; e ii: é quando apenas o primeiro termo difere dos outros $\left(a_{j}=0,5,1,1,1, \ldots\right)$. O caso ii é mais preciso do que o caso $i$.

Esta aproximação matemática, Equação (2.45), pode ser aplicada no somatório da Equação (2.61), porém a soma das zonas de usinagem equivalentes nem sempre é um número inteiro (conforme o caso ii). Desse modo, a média dos termos deve ser uma média ponderada. A soma das zonas de usinagem é $\mathrm{z}_{\text {eq }}$, e a média ponderada das espessuras de corte médias de cada zona de usinagem equivalente, é exatamente a espessura de corte média correspondente ao movimento de um dente da fresa do início ao final da zona de usinagem sem sobreposição (Figura 2.24-b). Assim sendo: 


$$
\sum_{j=1}^{n}{\overline{h_{j}}}^{1-m} \cong \sum_{j=1}^{n} z_{e q_{j}} \cdot\left(\frac{\sum_{j=1}^{n} z_{e q_{j}} \cdot \overline{h_{j}}}{\sum_{j=1}^{n} z_{e q_{j}}}\right)^{1-m}
$$

onde,

$$
\sum_{j=1}^{n} z_{e q_{j}}=z_{e q} \quad \text { e } \quad \frac{\sum_{j=1}^{n} z_{e q_{j}} \cdot \overline{h_{j}}}{\sum_{j=1}^{n} z_{e q_{j}}}=\bar{h}
$$

Portanto,

$$
\sum_{j=1}^{n}{\overline{h_{j}}}^{1-m} \cong z_{e q} \cdot \bar{h}^{1-m}
$$

Assim, substituindo a Equação (2.65) em (2.61), a força de corte, para mais que um dente na zona de usinagem, pode ser escrita conforme o conceito da literatura alemã:

$$
\overline{\mathrm{F}_{\mathrm{c}}} \cong \mathrm{k}_{\mathrm{s} 1} \cdot \mathrm{a}_{\mathrm{p}} \cdot \overline{\mathrm{h}}^{1-\mathrm{m}} \cdot \mathrm{z}_{\mathrm{eq}} \quad \psi>\psi_{\mathrm{z}}
$$

Para conhecimento do erro assumido pela aproximação da força de corte média para um corte com mais que um dente presente na zona de usinagem dada pela Equação (2.66), foi simulada ponto a ponto a variação da força de corte para um fresamento engajado (Figura 2.25-a), onde a parte hachurada representa a passagem da ferramenta com a respectiva remoção de material). O fresamento é o frontal parcial, e a ferramenta possui 20 dentes $\left(\psi_{\mathrm{z}}=18^{\circ}\right)$. A largura de penetração $\mathrm{a}_{\mathrm{e}}$ foi escolhida de tal modo que cinco dentes estavam atuando simultaneamente na zona de usinagem, para isso o $\mathrm{a}_{\mathrm{e}}$ foi correspondente ao raio $\mathrm{R}$ da fresa, e consequentemente o ângulo de contato $\psi$ foi de $90^{\circ}$ ou $\pi / 2 \mathrm{rad}$. O avanço de cada dente é de $0,5 \mathrm{~mm} /$ dente, e a profundidade de usinagem $\mathrm{a}_{\mathrm{p}}=3 \mathrm{~mm}$. O número total de zonas de usinagem equivalentes é cinco $\left(\mathrm{z}_{\mathrm{eq}}=5\right)$. As constantes $\mathrm{k}_{\mathrm{s} 1}$ e m utilizadas foram do material SAE $1045\left(\mathrm{k}_{\mathrm{s} 1}=2220 \mathrm{~N} / \mathrm{mm}^{2}\right.$ e $\left.\mathrm{m}=0,14\right)$. A Figura 2.25-a demonstra o exato momento em que a força de corte total é máxima, pois todos os dentes estão dentro da zona de usinagem e na espessura de corte máxima correspondente a cada zona de usinagem equivalente 1, 2, 3, 4 e 5 (Figura 2.25-c ponto A). A partir do momento em que o quinto dente sai da zona de 
usinagem, a força de corte cai drasticamente, tendendo a se estabilizar nas espessuras máximas 1, 2, 3 e 4 (Figura 2.25-c ponto B), e então um novo dente entra na zona de usinagem dando início a um novo ciclo (Figura 2.25-b e Figura 2.25-c ponto C).

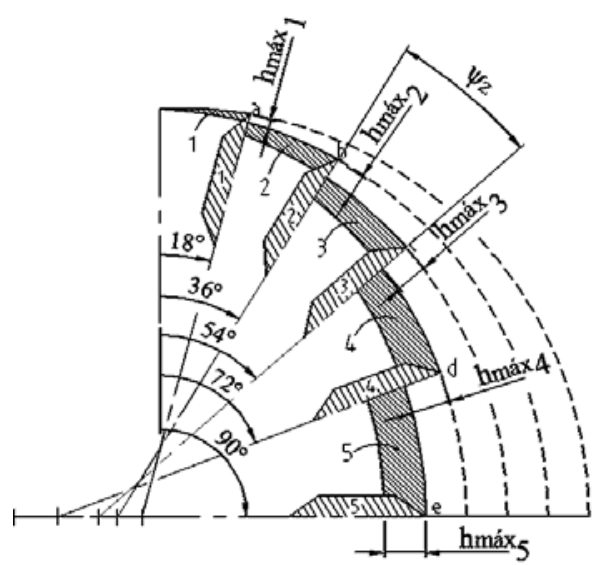

a)

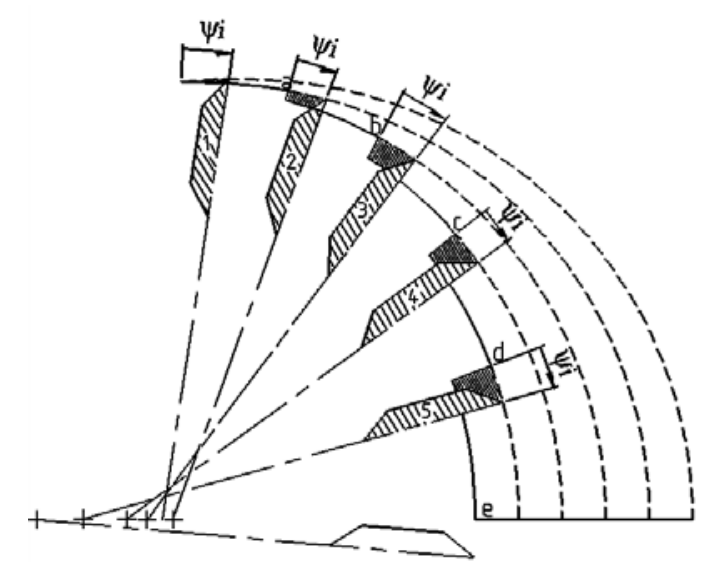

b)

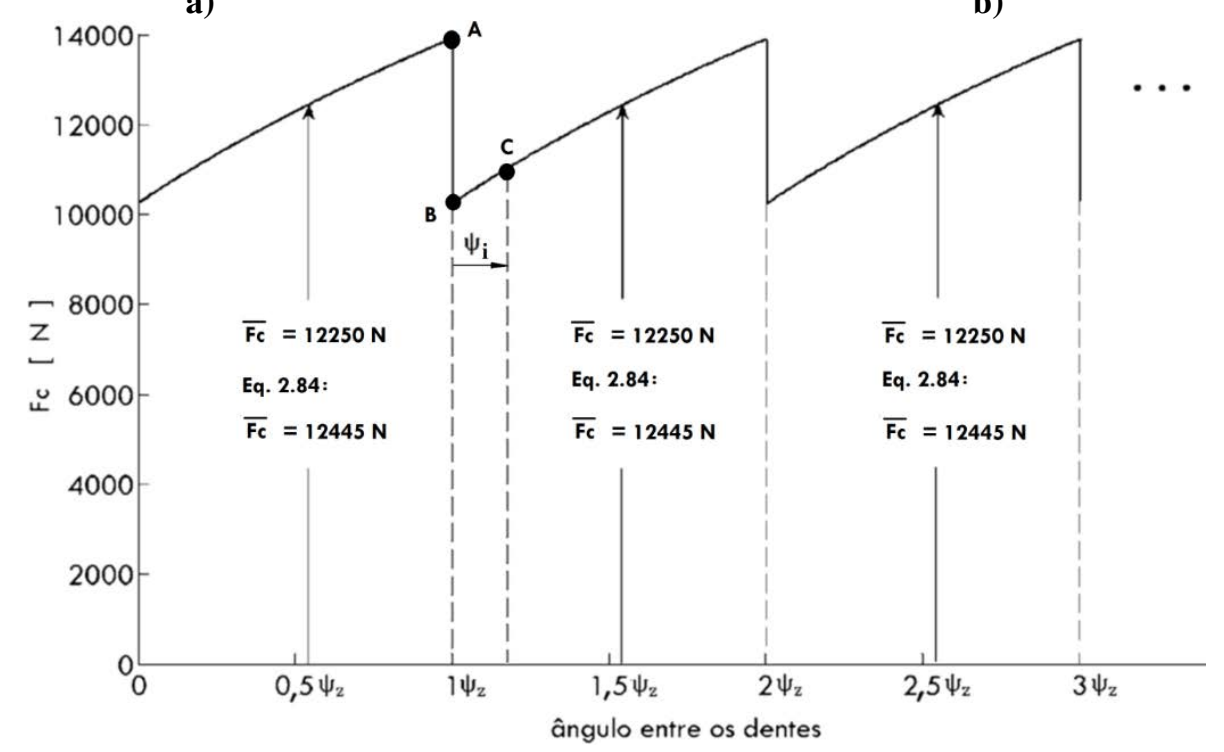

c)

Figura 2.25 - Simulação do corte para um movimento correspondente ao ângulo $\psi_{\mathrm{z}}$.

A simulação ponto a ponto da variação da força de corte é demonstrada pela Tabela 2.6. Nesta tabela é possível verificar o efeito de cada dente na zona de usinagem, por exemplo: para um movimento equivalente ao ângulo entre os dentes da fresa $\left(\psi_{z}=18^{\circ}\right)$, o dente 1 vai entrar na zona de usinagem e vai avançar até $18^{\circ}$, simultaneamente, o dente 2 vai avançar da posição $\psi_{\mathrm{i}}=18^{\circ}$ e vai avançar até $36^{\circ}$, e assim respectivamente até o dente 5 avançar da posição $\Psi_{\mathrm{i}}=$ $72^{\circ}$ até $\psi_{\mathrm{i}}=90^{\circ}$, e sair da zona de usinagem. Neste mesmo instante outro dente entra na zona de usinagem e inicia-se o ciclo. Pelo fato de todos os dentes estarem simultaneamente removendo material, haverá uma sobreposição de forças causadas pelos dentes 1, 2, 3, 4 e 5 como mostra a Tabela 2.6: 
Tabela 2.6 - Simulação da força de corte para cinco dentes na zona de usinagem (corte engajado).

\begin{tabular}{|c|c|c|c|c|c|c|c|c|c|c|}
\hline \multicolumn{2}{|c|}{ dente 1} & \multicolumn{2}{|c|}{ dente 2} & \multicolumn{2}{|c|}{ dente 3} & \multicolumn{2}{|c|}{ dente 4} & \multicolumn{2}{|c|}{ dente 5} & \multirow{2}{*}{$\begin{array}{c}\text { Sobreposição } \\
F_{c}[N]\end{array}$} \\
\hline $\boldsymbol{\Psi}_{\mathbf{i}}\left[^{\circ}\right]$ & $\mathbf{F}_{\mathbf{c}}[\mathbf{N}]$ & $\boldsymbol{\Psi}_{\mathbf{i}}\left[^{\circ}\right]$ & $\mathbf{F}_{\mathbf{c}}[\mathbf{N}]$ & $\Psi_{\mathbf{i}}\left[^{\circ}\right]$ & $\mathbf{F}_{\mathbf{c}}[\mathbf{N}]$ & $\Psi_{\mathbf{i}}\left[^{\circ}\right]$ & $\mathbf{F}_{\mathbf{c}}[\mathbf{N}]$ & $\boldsymbol{\Psi}_{\mathbf{i}}\left[^{\circ}\right]$ & $\mathbf{F}_{\mathbf{c}}[\mathbf{N}]$ & \\
\hline 0 & 0 & 18 & 1336.5 & 36 & 2323.4 & 54 & 3058.0 & 72 & 3514.4 & 10232.2 \\
\hline 2 & 204.8 & 20 & 1458.4 & 38 & 2417.8 & 56 & 3122.9 & 74 & 3546.8 & 10750.7 \\
\hline 4 & 371.6 & 22 & 1577.1 & 40 & 2509.1 & 58 & 3184.4 & 76 & 3575.4 & 11217.7 \\
\hline 6 & 526.2 & 24 & 1692.8 & 42 & 2597.3 & 60 & 3242.4 & 78 & 3600.3 & 11658.9 \\
\hline 8 & 673.0 & 26 & 1805.4 & 44 & 2682.3 & 62 & 3296.8 & 80 & 3621.4 & 12078.9 \\
\hline 10 & 814.2 & 28 & 1915.0 & 46 & 2764.1 & 64 & 3347.6 & 82 & 3638.6 & 12479.5 \\
\hline 12 & 950.5 & 30 & 2021.6 & 48 & 2842.6 & 66 & 3394.8 & 84 & 3652.1 & 12861.6 \\
\hline 14 & 1082.8 & 32 & 2125.2 & 50 & 2917.7 & 68 & 3438.4 & 86 & 3661.7 & 13225.8 \\
\hline 16 & 1211.4 & 34 & 2225.8 & 52 & 2989.6 & 70 & 3478.2 & 88 & 3667.4 & 13572.4 \\
\hline 18 & 1336.5 & 36 & 2323.4 & 54 & 3058.0 & 72 & 3514.4 & 90 & 3669.3 & 13901.5 \\
\hline \multicolumn{10}{|c|}{ média } & 12197.93 \\
\hline
\end{tabular}

Os resultados da força de corte total média ponto a ponto, fornecem, para uma variação de $\Psi$ mais refinada, um valor de 12250 Newton, enquanto que a Equação (2.66) fornece uma força de corte média total de 12445 Newton. A diferença percentual destes dois resultados é em torno de $1 \%$, e, portanto, estatisticamente desprezível. Assim sendo, pode-se concluir que a força de corte, para mais que um dente na zona de usinagem, calculada em função do número total de zonas equivalente $\mathrm{z}_{\mathrm{eq}}$, é estimada com boa precisão.

\subsection{ENERGIA DE CORTE EM FRESAMENTO}

Para uma ferramenta de corte realizar trabalho sobre a camada de material que será removida da peça, é necessário fornecer energia ao sistema que a move. A energia fornecida ao sistema, praticamente, é a soma de duas energias. Uma é a energia consumida para fazer com que o sistema funcione, a outra é a energia consumida para cortar o metal. Em usinagem, quando se calcula o trabalho realizado pela ferramenta de corte, automaticamente calcula-se a energia consumida para cortar o metal.

De maneira mais geral, o trabalho é o produto apenas da componente da força que atua na direção do movimento pela distância percorrida (HALLIDAY, 1996). Sendo a direção da força de corte, no fresamento, variável conforme o deslocamento não linear, a melhor forma de estudar tal energia é na sua forma diferencial. Assim, estudando uma camada infinitesimal de material removido, como mostra a figura a seguir: 


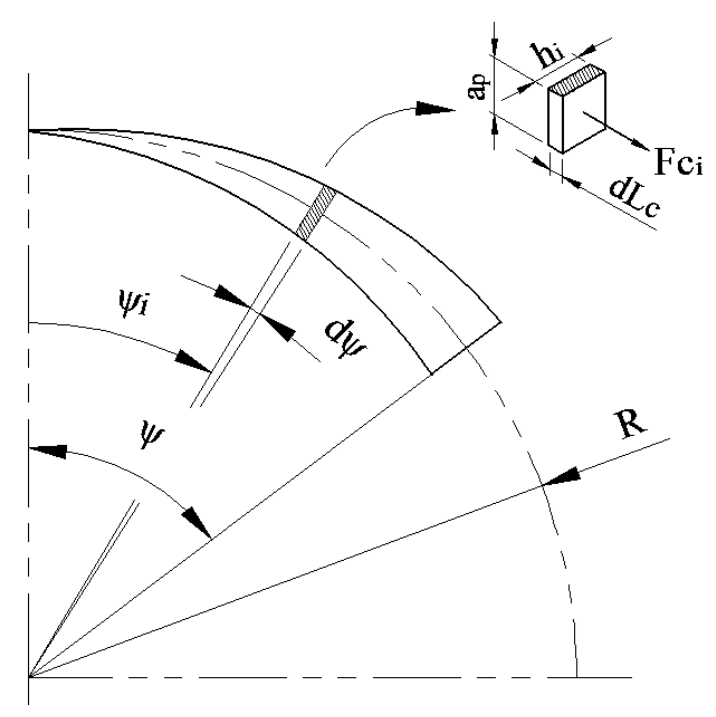

Figura 2.26 - Representação da equação diferencial da energia de corte.

A equação diferencial da energia de corte, sendo $d_{L_{c}}=R \cdot d \psi$ e $\psi$ representado em radianos, é dada por:

$$
\mathrm{du}_{\mathrm{c}}=\mathrm{F}_{\mathrm{c}_{\mathrm{i}}} \cdot \mathrm{dL}_{\mathrm{c}}=\mathrm{F}_{\mathrm{c}_{\mathrm{i}}} \cdot \mathrm{R} \cdot \mathrm{d} \psi \quad \psi<\psi_{\mathrm{z}}
$$

Portanto, a energia de corte é:

$$
\mathrm{u}_{\mathrm{c}}=\mathrm{R} \int_{0}^{\psi} \mathrm{F}_{\mathrm{c}} \mathrm{d} \psi \quad \psi<\psi_{\mathrm{z}}
$$

Se, e somente se, o corte for engajado, a Equação (2.68) pode ser escrita no domínio do tempo, pois $d \psi$ pode ser representado por $2 \pi$. n. $d t$ :

$$
u_{c}=2 \pi \cdot n \cdot R \int_{0}^{t} F_{c} d t=V_{c} \int_{0}^{t} F_{c} d t \quad \psi \geq \psi_{z}
$$

Conforme a Equação (2.68), sabendo que a força de corte pode ser estimada pelas constantes do material da peça $\left(\mathrm{F}_{\mathrm{c}_{\mathrm{i}}}=\mathrm{k}_{\mathrm{s} 1} \cdot \mathrm{h}_{\mathrm{i}}{ }^{1-\mathrm{m}} \cdot \mathrm{a}_{\mathrm{p}}\right)$, onde $\mathrm{h}_{\mathrm{i}}=\mathrm{f}_{\mathrm{z}}$ sen $\psi_{\mathrm{i}}$, a energia de corte pode ser estimada pela seguinte expressão:

$$
\mathrm{u}_{\mathrm{c}}=\mathrm{R} \cdot \mathrm{k}_{\mathrm{s} 1} \cdot \mathrm{a}_{\mathrm{p}} \int_{0}^{\psi}\left(\mathrm{f}_{\mathrm{z}} \operatorname{sen} \psi_{\mathrm{i}}\right)^{1-\mathrm{m}} \mathrm{d} \psi \quad \psi<\psi_{\mathrm{z}}
$$

O problema da Equação (2.70), é que não é possível integrar a função $\left(\mathrm{f}_{\mathrm{z}} \text { sen } \Psi_{\mathrm{i}}\right)^{1-\mathrm{m}}$, a única forma de resolver esta integral é numericamente por meio de um somatório. A solução da integral por meio de um somatório será chamada de M. Considerando a seguinte equivalência: 


$$
\int_{a}^{b} f(x) d x=\lim _{\Delta_{x} \rightarrow 0}\left[\sum_{x=\frac{a}{\Delta_{x}}}^{\frac{b}{\Delta_{x}}} f\left(x \Delta_{x}\right) \Delta_{x}\right] ; \quad x=\left[\frac{a}{\Delta_{x}}, \frac{a}{\Delta_{x}}+1, \frac{a}{\Delta_{x}}+2, \ldots, \frac{b}{\Delta_{x}}\right]
$$

A solução numérica da integral $\left(\mathrm{f}_{\mathrm{z}} \operatorname{sen} \psi_{\mathrm{i}}\right)^{1-\mathrm{m}}$ é dada por:

$$
M=\int_{0}^{\psi}\left(f_{\mathrm{z}} \operatorname{sen} \psi_{\mathrm{i}}\right)^{1-\mathrm{m}} \mathrm{d} \psi=\lim _{\Delta_{\Psi} \rightarrow 0}\left[\sum_{\mathrm{x}=0}^{\frac{\psi}{\Delta_{\psi}}}\left[\mathrm{f}_{\mathrm{z}} \operatorname{sen}\left(\psi_{\mathrm{i}} \cdot \Delta_{\psi}\right)\right]^{1-\mathrm{m}} \cdot \Delta_{\psi}\right]
$$

Com o intuito de conhecer melhor a integral solucionada apenas pelo método numérico, foi montado um gráfico como mostra a Figura 2.27. Nesta figura $\psi$ varia de 0 até $\pi$ rad $\left(180^{\circ}\right)$ com um incremento de $0,01745 \mathrm{rad}\left(1^{\circ}\right)$, e também a constante $\mathrm{m}$ varia de 0 até 1 com um incremento de 0,05 . Para cada combinação de $\psi$ com a constante m, é feito um somatório para $\Delta_{\mathrm{x}}=1.10^{-4}$.

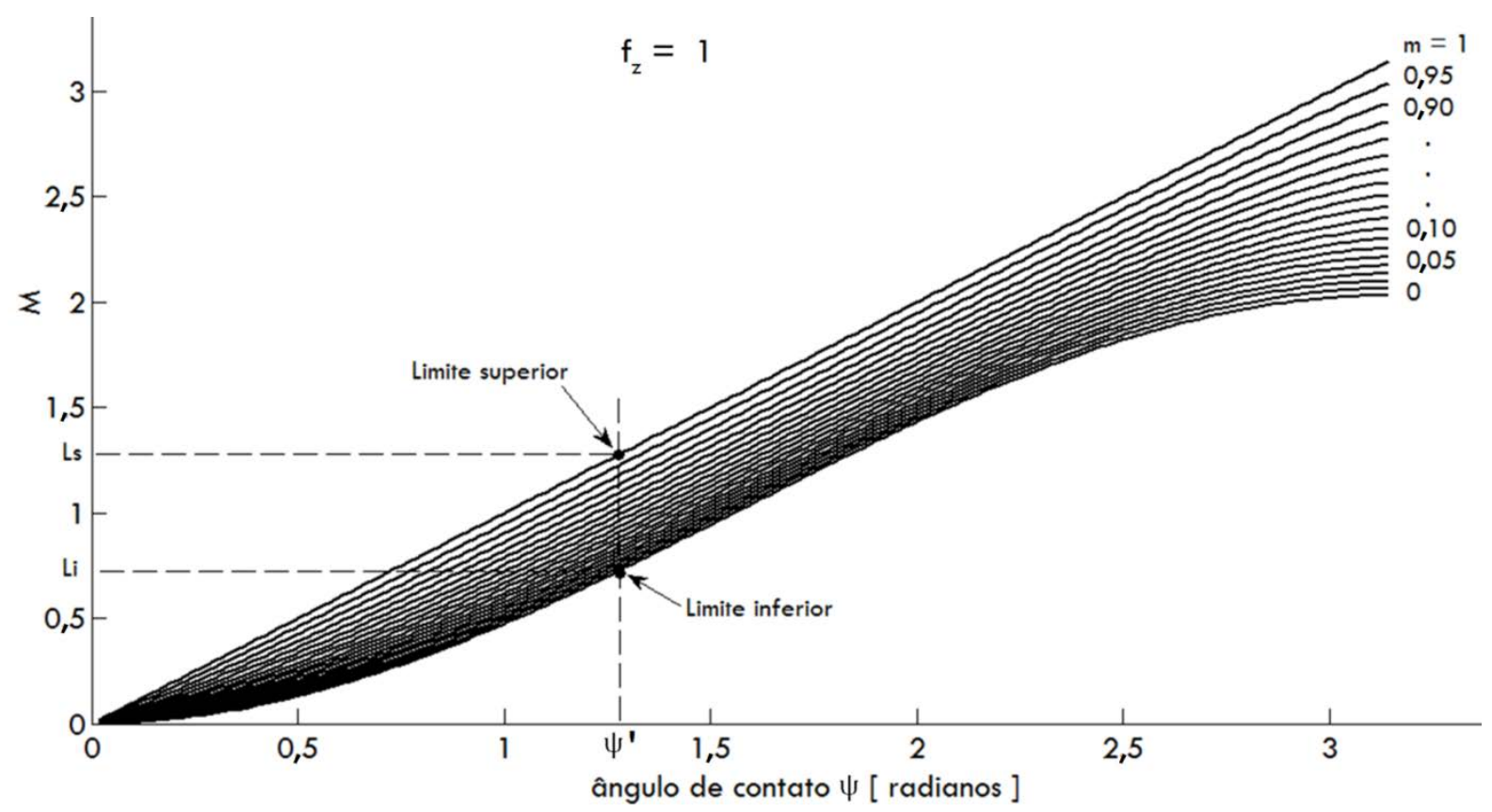

Figura 2.27 - Apresentação da solução da integral pelo método numérico.

Os únicos pontos possíveis de serem resolvidos sem o auxílio do somatório, são os pontos no limite superior e inferior (vide Figura 2.27), pois quando $\mathrm{m}=1$ e $\mathrm{m}=0$ :

$$
M=\int_{0}^{\psi}\left(f_{z} \operatorname{sen} \psi_{i}\right)^{1-1} d \psi=\int_{0}^{\psi} d \psi=\psi
$$




$$
M=\int_{0}^{\psi}\left(f_{z} \operatorname{sen} \psi_{i}\right)^{1-0} d \psi=f_{z} \int_{0}^{\psi} \operatorname{sen} \psi_{i} d \psi=f_{z}(1-\cos \psi)
$$

Assim sendo, têm-se duas condições de contorno:

$$
\begin{gathered}
y(0)=f_{z}(1-\cos \psi) \\
y(1)=\psi
\end{gathered}
$$

Conforme a Figura 2.27, se o ponto do eixo horizontal $\psi^{\prime}$ é analisado, pode-se conhecer o comportamento de $\mathrm{M}$ quando $\mathrm{m}$ varia de 0 até 1 . Este comportamento é mostrado pela figura a seguir:

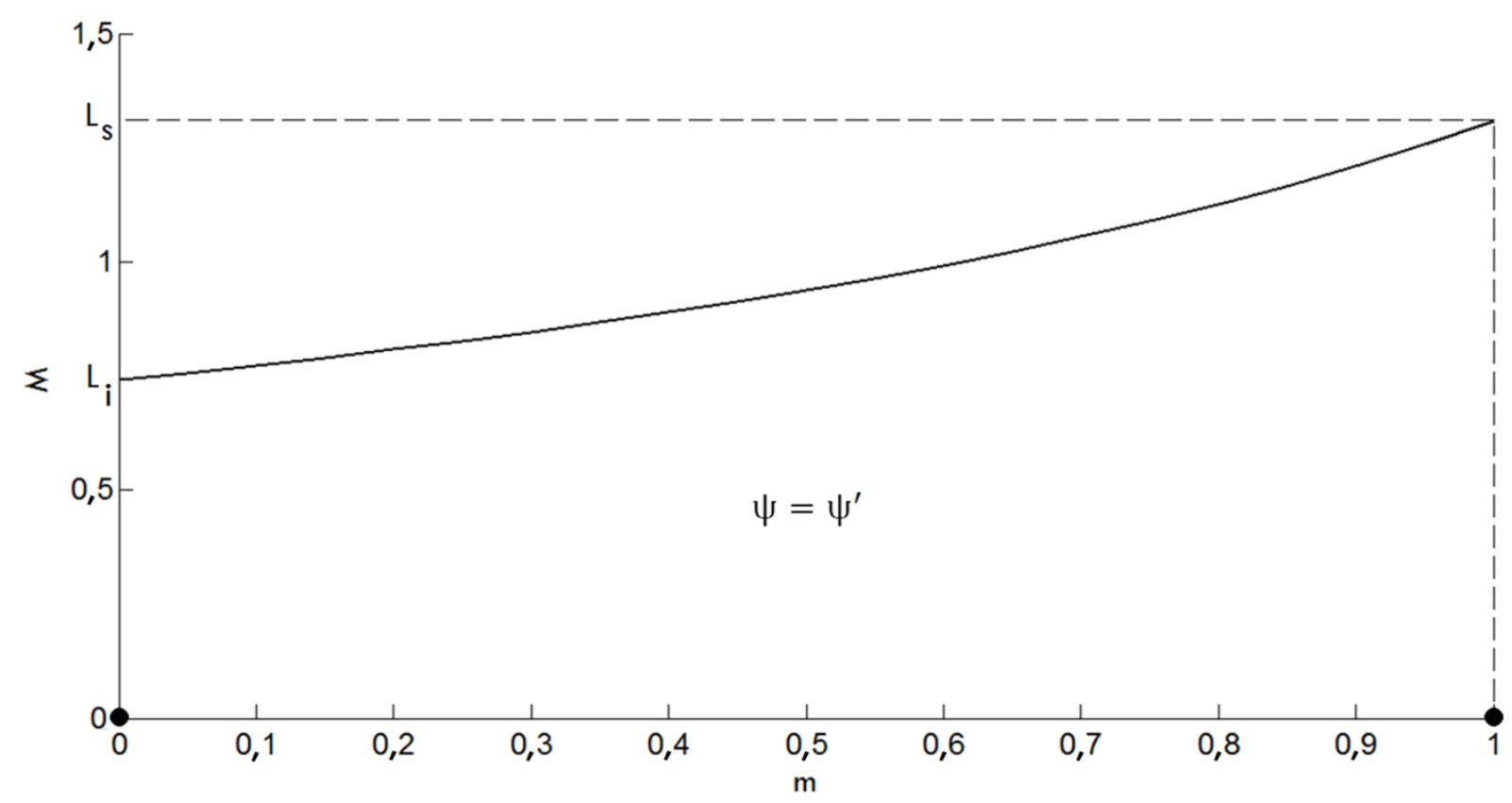

Figura 2.28 - Comportamento do M versus m, para o ângulo $\psi^{\prime}$ da Figura 2.25.

Conforme demonstra a Figura 2.28, é possível visualizar a variação de $\mathrm{M}$ do limite inferior até o limite superior para um determinado ângulo $\psi$ (no caso da Figura 2.28 o ângulo é $\psi^{\prime}$ ). Duas possíveis equações gerais se ajustam a essa variação, uma é a equação polinomial $y(x)=A x^{2}+B x+C$; a outra é a equação exponencial $y(x)=A e^{k x}$.

A solução da equação polinomial requer no mínimo três condições de contorno para determinar as constantes A, B e C; e a solução da equação exponencial é satisfeita com duas 
condições de contorno para determinar as constantes A e k. Assim sendo, é tomada como equação geral da variação de $\mathrm{M}$, a equação exponencial. De acordo com a equação exponencial e pelas condições de contorno:

$$
\begin{gathered}
y(0)=f_{z}(1-\cos \psi)=A e^{k 0} \quad \therefore A=f_{z}(1-\cos \psi) \\
y(1)=\psi=A e^{k 1} \quad \therefore \quad k=\ln \left[\frac{\psi}{f_{z}(1-\cos \psi)}\right]
\end{gathered}
$$

Logo, a equação que se ajusta ao somatório $M$, é a equação exponencial conforme apresenta expressão a seguir:

$$
M \cong A e^{k m}=f_{z}(1-\cos \psi) e^{\ln \left[\frac{\psi}{f_{z}(1-\cos \psi)}\right] \cdot m}=f_{z}(1-\cos \psi) \cdot\left[\frac{\psi}{f_{z}(1-\cos \psi)}\right]^{m}
$$

De modo a comparar o $\mathrm{M}$ real, dado pela integral representada pelo somatório da Equação (2.72), com o M aproximado, dado pelo ajuste da equação exponencial da Equação (2.79), será usada a constante $\mathrm{m}=0,5$, pois é exatamente neste ponto entre 0 e 1 que ocorre o maior erro dado pelo ajuste da equação exponencial. Quando m tende a 1, os resultados tendem ao limite superior que é o resultado de $\mathrm{M}$ real. Por outro lado, quando $\mathrm{m}$ tende à 0 , os resultados tendem ao limite inferior que também é o resultado de $\mathrm{M}$ real. Por isso, o valor de $\mathrm{m}$ correspondente a 0,5 é o maior erro alcançado pelo ajuste, pois tal valor está com um deslocamento máximo do limite superior e inferior. A Figura 2.29 mostra tal comparação.

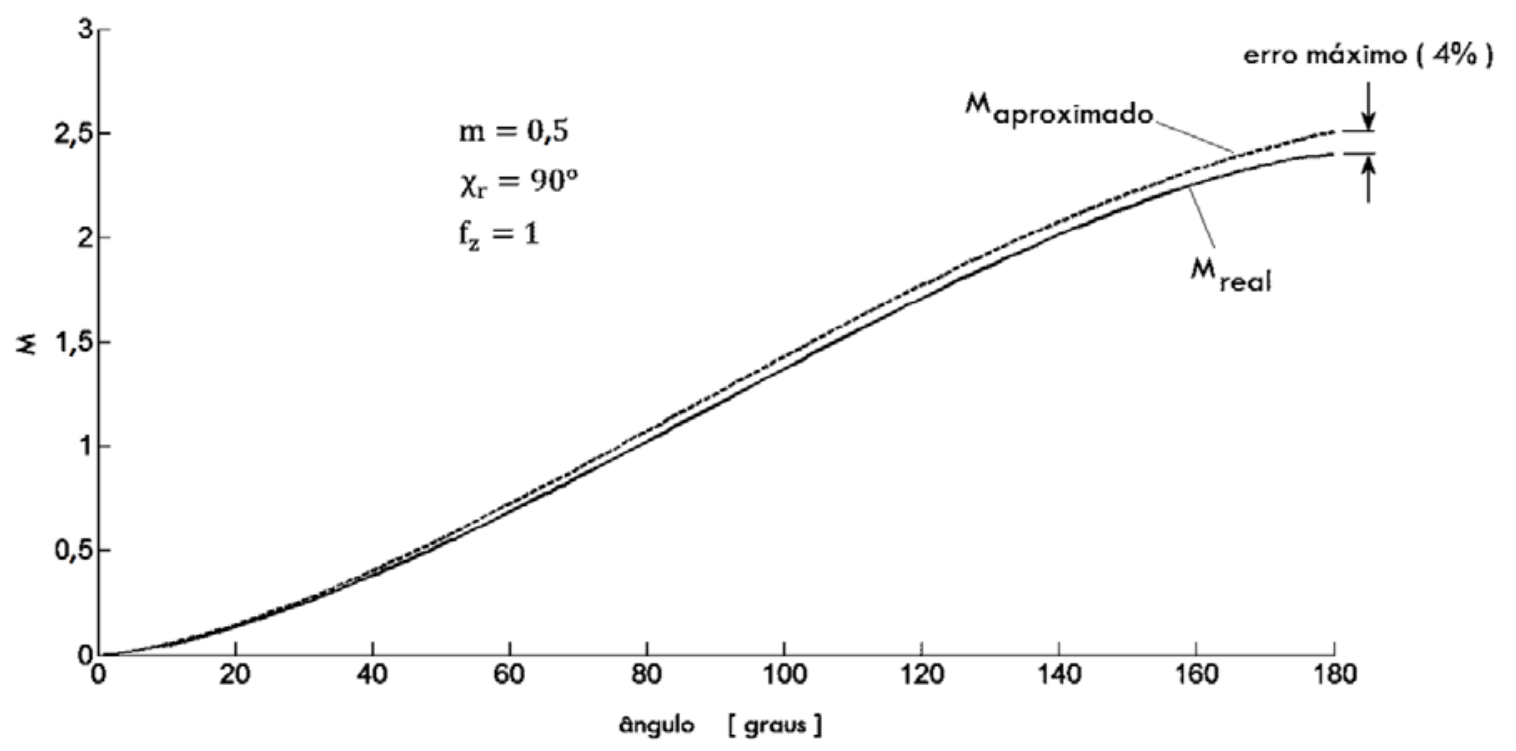

Figura 2.29 - $\mathrm{M}_{\text {real }}$ versus $\mathrm{M}_{\text {aproximado }}$. 
No processo de fresamento $\psi$ nunca será maior que $180^{\circ}$, assim sendo, a diferença percentual máxima dos resultados de $M_{\text {real }}$ versus $M_{\text {aproximado é dada pelos valores mais }}$ extremos que são $\mathrm{m}=0,5$ e $\psi=180^{\circ}$, e conforme mostra a Figura 2.29, tal percentual foi de 4\%. Portanto, como o percentual da diferença máxima é menor que 5\%, a Equação (2.79) representa com grande precisão a integral da função $\left(\mathrm{f}_{\mathrm{z}} \operatorname{sen} \Psi_{\mathrm{i}}\right)^{1-\mathrm{m}}$.

Substituindo a Equação (2.7) ( $\left.\cos \psi=1-\mathrm{a}_{\mathrm{e}} / \mathrm{R}\right)$ em (2.79) e rearranjando:

$$
M=\frac{(R \cdot \psi)^{m} \cdot\left(f_{z} \cdot a_{e}\right)^{1-m}}{R} \quad \chi_{r}=90^{\circ}
$$

Assim sendo, substituindo M no lugar da integral da Equação (2.70), a energia de corte no processo de fresamento passa a ser estimada por:

$$
u_{c}=k_{s 1} \cdot a_{p} \cdot(R \cdot \psi)^{m} \cdot\left(f_{z} \cdot a_{e}\right)^{1-m} \quad \chi_{r}=90^{\circ}
$$

Comparando a Equação (2.81) com (2.18) e (2.21), $\mathrm{u}_{\mathrm{c}}$ também pode ser expresso por:

$$
\mathrm{u}_{\mathrm{c}}=\mathrm{k}_{\mathrm{s} 1} \cdot \mathrm{a}_{\mathrm{p}} \cdot \mathrm{L}_{\mathrm{c}}{ }^{\mathrm{m}} \cdot \mathrm{A}_{\mathrm{s}}{ }^{1-\mathrm{m}} \quad \chi_{\mathrm{r}}=90^{\circ}
$$

Assim sendo, para uma ferramenta que possui ângulo de posição menor que $90^{\circ}$, a energia de corte $u_{c}$ deve ser calculada em função das dimensões na área superficial média, e, portanto, $\mathrm{u}_{\mathrm{c}}$ para $\chi_{\mathrm{r}}<90^{\circ}$ é expresso por:

$$
\mathrm{u}_{\mathrm{c}}=\mathrm{k}_{\mathrm{s} 1} \cdot \mathrm{a}_{\mathrm{p}} \cdot \overline{\mathrm{L}}_{\mathrm{c}}^{\mathrm{m}} \cdot{\overline{\mathrm{A}_{\mathrm{s}}}}^{1-\mathrm{m}} \quad \chi_{\mathrm{r}}<90^{\circ}
$$

Segundo o conceito da literatura sobre desenvolver os cálculos do fresamento referentes à espessura de corte média, a energia de corte no fresamento é reconhecida como energia de corte média. Esta por sua vez, pode ser determinada pelo produto entre a força de corte média e o comprimento de corte.

$$
\overline{\mathrm{u}_{\mathrm{c}}}=\overline{\mathrm{F}_{\mathrm{c}}} \cdot \mathrm{L}_{\mathrm{c}} \quad \psi \leq \psi_{\mathrm{z}}
$$

Conforme as constantes $\mathrm{k}_{\mathrm{s} 1}$ e $\mathrm{m}$ a energia de corte média pode ser estimada por:

$$
\overline{\mathrm{u}_{\mathrm{c}}}=\mathrm{k}_{\mathrm{s} 1} \cdot(\overline{\mathrm{h}})^{1-\mathrm{m}} \cdot \mathrm{a}_{\mathrm{p}} \cdot \mathrm{L}_{\mathrm{c}} \quad \psi \leq \psi_{\mathrm{z}}
$$


Conforme a Equação (2.13), em que $\overline{\mathrm{h}}=\left(\mathrm{f}_{\mathrm{z}} \cdot \mathrm{a}_{\mathrm{e}}\right) /(\mathrm{R} \cdot \psi)$, e de acordo com a Equação (2.18), em que $L_{c}=R . \psi$, substituindo estas duas em (2.85) e rearranjando:

$$
\overline{\mathrm{u}_{\mathrm{c}}}=\mathrm{k}_{\mathrm{s} 1} \cdot \mathrm{a}_{\mathrm{p}} \cdot(\mathrm{R} \cdot \psi)^{\mathrm{m}} \cdot\left(\mathrm{f}_{\mathrm{z}} \cdot \mathrm{a}_{\mathrm{e}}\right)^{1-\mathrm{m}} \quad \psi \leq \psi_{\mathrm{z}}
$$

A Equação (2.86) mostra que no processo de fresamento não há diferenças entre a energia de corte e a energia de corte média, pois as duas representam exatamente a energia de corte consumida para o dente da fresa remover uma camada de material da peça com espessura de corte variável. Este fato pode ser explicado justamente pela espessura de corte variável, pois esta varia de forma progressiva de zero até um valor máximo (discordante parcial até o meio da fresa). Com base nesta espessura média e o comprimento de corte total, tal resultado médio representa o resultado total. Por exemplo, sabe-se que a área de um triangulo retângulo é o quociente entre o produto do comprimento da base e sua altura, e o valor dois. A altura dividida por dois é justamente a altura média, pois a altura varia de zero até a altura máxima no comprimento da base máxima. Multiplicando a altura média pelo comprimento total da base, obtém-se a área total do triângulo. Este mesmo princípio se aplica à variação da espessura de corte no fresamento.

Portanto, em fresamento:

$$
\mathrm{u}_{\mathrm{c}}=\overline{\mathrm{u}_{\mathrm{c}}}=\overline{\mathrm{F}_{\mathrm{c}}} \cdot \mathrm{L}_{\mathrm{c}} \quad \psi \leq \psi_{\mathrm{z}}
$$

\subsubsection{Energia de corte em usinagem simultânea}

Conforme a Figura 2.24-b, o comprimento de corte correspondente à primeira zona, que possui uma força de corte média $\overline{\mathrm{F}_{\mathrm{c}_{1}}}$, é $\mathrm{L}_{\mathrm{c}_{1}}=\mathrm{R} \cdot \Psi_{z} \cdot \mathrm{z}_{\mathrm{eq}_{1}}$; e o comprimento de corte da segunda zona, que possui uma força de corte média $\overline{\mathrm{F}_{\mathrm{c}_{2}}}$, é $\mathrm{L}_{\mathrm{c}_{2}}=\mathrm{R} \cdot \Psi_{z} \cdot \mathrm{z}_{\mathrm{eq}_{2}}$. Assim sendo, a energia de corte, para o corte engajado da Figura 2.24, pode ser expressa por:

$$
\mathrm{u}_{\mathrm{c}}=\overline{\mathrm{F}_{\mathrm{c}_{1}}} \cdot \mathrm{L}_{\mathrm{c}_{1}}+\overline{\mathrm{F}_{\mathrm{c}_{2}}} \cdot \mathrm{L}_{\mathrm{c}_{2}}=\mathrm{R} \cdot \psi_{\mathrm{z}} \cdot\left(\overline{\mathrm{F}_{\mathrm{c}_{1}}} \cdot \mathrm{z}_{\mathrm{eq}_{1}}+\overline{\mathrm{F}_{\mathrm{c}_{2}}} \cdot \mathrm{z}_{\mathrm{eq}_{2}}\right)
$$

A soma ponderada da força de corte média do dente 1 e 2 da fresa $\left(\overline{\mathrm{F}_{\mathrm{c}_{1}}} \cdot \mathrm{z}_{\mathrm{eq}_{1}}+\right.$ $\overline{\mathrm{F}_{\mathrm{c}_{2}}} \cdot \mathrm{z}_{\mathrm{eq}_{2}}$ ), corresponde exatamente à força de corte média de apenas um dente, sem 
sobreposição do início ao final da zona de usinagem determinada por $\psi$. Assim sendo, a Equação (2.88) pode expressa por:

$$
\mathrm{u}_{\mathrm{c}} \cong \mathrm{R} \cdot \psi_{\mathrm{z}} \cdot \overline{\mathrm{F}_{\mathrm{c}}} \cdot \mathrm{z}_{\mathrm{eq}} \quad \psi>\psi_{\mathrm{z}}
$$

\subsubsection{Energia específica de corte em fresamento}

Energia específica de corte é uma grandeza quantitativa que caracteriza a resistência ao corte oferecida pelo material, assim como a tensão de tração e a dureza caracterizam a força e a resistência à deformação plástica do material, respectivamente (SHAW, 2005).

Pode-se interpretar a energia específica de corte como a energia necessária para remover uma unidade de volume do material da peça $\left(\mathrm{J} / \mathrm{mm}^{3}\right)$, ou seja, energia de corte por unidade de volume (STEMMER, 2007).

Em fresamento, a energia específica de corte pode ser descrita pelo quociente entre a energia de corte média e o volume do cavaco indeformado, assim:

$$
\mathrm{u}=\frac{\mathrm{u}_{\mathrm{c}}}{\mathrm{V}_{\mathrm{L}}}=\frac{\overline{\mathrm{F}_{\mathrm{c}}} \cdot \mathrm{L}_{\mathrm{c}}}{\overline{\overline{\mathrm{h}} \cdot \mathrm{a}_{\mathrm{p}} \cdot \mathrm{L}_{\mathrm{c}}}}=\frac{\overline{\mathrm{F}_{\mathrm{c}}}}{\overline{\overline{\mathrm{h}} \cdot \mathrm{a}_{\mathrm{p}}}} \quad \psi \leq \psi_{\mathrm{z}}
$$

Por meio da Equação (2.90) pode-se ver que a energia específica de corte é equivalente à pressão específica de corte média, Equação (2.38). Ressalta-se que os dois conceitos são distintos, mas os resultados são equivalentes.

Na literatura americana, a energia específica de corte é conhecida como "specific cutting power". Deste termo surge a tradução literal, encontrada em alguns livros, potência específica de corte. Esta é determinada pela relação entre a potência de corte consumida e a taxa efetiva de material removido, Equação (2.91), sendo sua unidade hp/in $3 / \mathrm{min}$ ou $\mathrm{kW} / \mathrm{cm}^{3} / \mathrm{min}$. A potência de corte consumida (que será vista mais adiante) pode ser obtida pelo produto entre a força de corte e a velocidade de corte. Assim,

$$
\mathrm{u}=\frac{\mathrm{P}_{\mathrm{c}}}{\mathrm{Q}_{\mathrm{e}}} \equiv \frac{\overline{\mathrm{F}_{\mathrm{c}}} \cdot \mathrm{V}_{\mathrm{c}}}{\overline{\mathrm{h}} \cdot \mathrm{a}_{\mathrm{p}} \cdot \mathrm{V}_{\mathrm{c}}} \equiv \frac{\overline{\mathrm{F}_{\mathrm{c}}}}{\overline{\mathrm{h} \cdot \mathrm{a}_{\mathrm{p}}}}
$$


Das equações (2.90) e (2.91) conclui-se que os termos energia específica de corte e potência específica de corte são equivalentes.

\subsubsection{Energia específica de corte em usinagem simultânea}

No corte engajado a energia específica de corte também sofre uma sobreposição devido à interação simultânea entre os dentes da fresa presentes na zona de usinagem. A soma das energias específicas de corte, de acordo com o sistema da Figura 2.24, pode ser calculada da seguinte forma:

$$
\mathrm{u}=\frac{\overline{\mathrm{F}_{\mathrm{c}_{1}}}}{\overline{\mathrm{h}_{1}} \cdot \mathrm{a}_{\mathrm{p}}}+\frac{\overline{\mathrm{F}_{\mathrm{c}_{2}}}}{\overline{\mathrm{h}_{2}} \cdot \mathrm{a}_{\mathrm{p}}}=\mathrm{k}_{\mathrm{s} 1} \cdot \overline{\mathrm{h}}^{-\mathrm{m}}+\mathrm{k}_{\mathrm{s} 1} \cdot \overline{\mathrm{h}}^{-\mathrm{m}}
$$

Generalizando-se a Equação (2.92):

$$
\mathrm{u}=\mathrm{k}_{\mathrm{s} 1} \cdot \sum_{\mathrm{j}=1}^{\mathrm{n}}{\overline{\mathrm{h}_{\mathrm{j}}}}^{-\mathrm{m}} \quad \psi>\psi_{\mathrm{z}}
$$

Conforme a aproximação do somatório da Equação (2.63), a Equação (2.93) pode ser aproximada por:

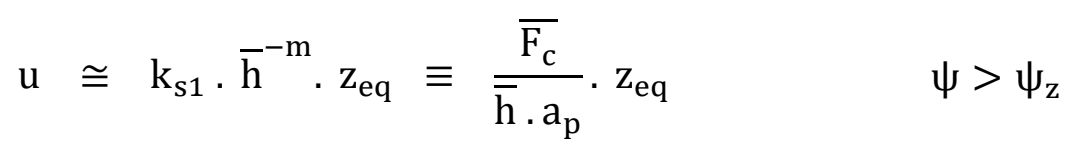

\subsection{POTÊNCIA DE CORTE EM FRESAMENTO}

Potência é igual à quantidade de trabalho realizado pelo tempo que levou para realizálo (HEWITT, 2001). Em usinagem, a potência de corte é o trabalho realizado pela ferramenta de corte durante o tempo de corte, ou seja, energia de corte por unidade de tempo em corte:

$$
P_{c}=\frac{u_{c}}{t_{c}}=\frac{\overline{F_{c}} \cdot L_{c}}{t_{c}}=\overline{F_{c}} \cdot V_{c} \quad \psi \leq \psi_{z}
$$


A potência de corte também pode ser calculada de acordo com a literatura americana, sendo esta o produto da energia específica de corte (specific cutting power) e a taxa efetiva de material removido:

$$
\mathrm{P}_{\mathrm{c}}=\mathrm{u} \cdot \mathrm{Q}_{\mathrm{e}} \equiv \overline{\mathrm{k}_{\mathrm{s}}} \cdot \mathrm{Q}_{\mathrm{e}} \quad \psi \leq \psi_{\mathrm{z}}
$$

\subsubsection{Potência de corte em usinagem simultânea}

Conforme a Figura 2.24, a potência de corte consumida também sofre sobreposição quando mais que um dente se encontra na zona de usinagem. Para os parâmetros específicos desta figura, o somatório é:

$$
\mathrm{P}_{\mathrm{c}}=\overline{\mathrm{F}_{\mathrm{c}_{1}}} \cdot \mathrm{V}_{\mathrm{c}}+\overline{\mathrm{F}}_{\mathrm{c}_{2}} \cdot \mathrm{V}_{\mathrm{c}}=\mathrm{k}_{\mathrm{s} 1} \cdot \mathrm{a}_{\mathrm{p}} \cdot \mathrm{V}_{\mathrm{c}} \cdot\left({\overline{\mathrm{h}_{1}}}^{1-\mathrm{m}}+{\overline{\mathrm{h}_{2}}}^{1-\mathrm{m}}\right)
$$

Generalizando-se a Equação (2.97):

$$
P_{c}=k_{s 1} \cdot a_{p} \cdot v_{c} \sum_{j=1}^{n} \bar{h}_{j}^{1-m} \quad \psi>\psi_{z}
$$

Conforme a aproximação do somatório da Equação (2.63), a Equação (2.98) pode ser aproximada por:

$$
P_{c}=k_{s 1} \cdot a_{p} \cdot V_{c} \cdot \bar{h}^{1-m} \cdot z_{e q} \equiv \overline{F_{c}} \cdot V_{c} \cdot z_{e q} \quad \psi>\psi_{z}
$$

E seguindo o princípio da literatura americana e do número de zonas equivalente:

$$
\mathrm{P}_{\mathrm{c}}=\mathrm{u} \cdot \mathrm{Q}_{\mathrm{e}} \cdot \mathrm{z}_{\mathrm{eq}} \quad \psi>\psi_{\mathrm{z}}
$$

A equação geral da taxa efetiva de material removido de apenas um cavaco individual é $\mathrm{Q}_{\mathrm{e}}=\overline{\mathrm{h}} \cdot \mathrm{a}_{\mathrm{p}} \cdot \mathrm{V}_{\mathrm{c}}$. Sabendo-se que $\overline{\mathrm{h}}=\mathrm{f}_{\mathrm{z}} \cdot \mathrm{a}_{\mathrm{e}} / \mathrm{R} \cdot \psi, \mathrm{V}_{\mathrm{c}}=2 \pi$. R. n e $\mathrm{z}_{\text {eq }}=\psi \cdot \mathrm{Z} / 2 \pi$, a parte da Equação (2.100) - $Q_{e} \cdot z_{e q}$ - pode ser escrita como:

$$
Q_{e} \cdot z_{e q}=\left(\frac{f_{z} \cdot a_{e}}{R \cdot \psi}\right) \cdot a_{p} \cdot 2 \pi \cdot R \cdot n \cdot \frac{\psi \cdot Z}{2 \pi}=a_{e} \cdot a_{p} \cdot f_{z} \cdot z \cdot n=Q \quad \psi>\psi_{z}
$$


Portanto, a Equação (2.100) pode ser escrita como:

$$
P_{c}=u \cdot a_{e} \cdot a_{p} \cdot f_{z} \cdot Z \cdot n=u \cdot Q \quad \psi>\psi_{z}
$$

\subsection{RAZÃO ENTRE AS FORSÇAS DE USINAGEM NO FRESAMENTO}

No fresamento frontal parcial, quatro regiões (A, B, C e D) são consideradas fonte de calor como mostra Figura 2. 30-a. A região A se encontra no plano de cisalhamento do material $r_{\phi}$, a região $B$ se encontra na superfície de saída da ferramenta $r_{\gamma}$, a região $C$ na superfície de folga principal $r_{\alpha}$, e por último a região $D$ na superfície de folga secundária $r_{\alpha_{2}}$. As razões entre as forças são dadas de acordo com as equações (2.103), (2.104), (2.105) e (2.106), Estas equações foram desenvolvidas com base na decomposição das forças principais $F_{c_{i}}, F_{n_{i}}$ e $F_{p_{i}}$, na direção perpendicular e paralela ao plano estudado (A, B, C ou D), conforme o diagrama composto da Figura 2. 30-b e c.

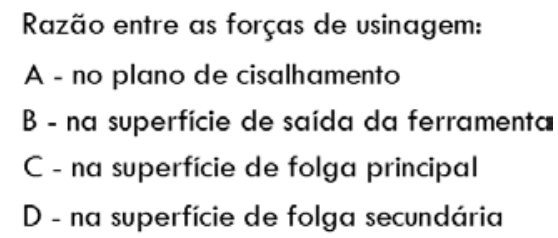

Razão entre as forças de usinagem:

A - no plano de cisalhamento

B - na superfície de saida da ferramenta

C - na superfície de folga principal

D - na superfície de folga secundária

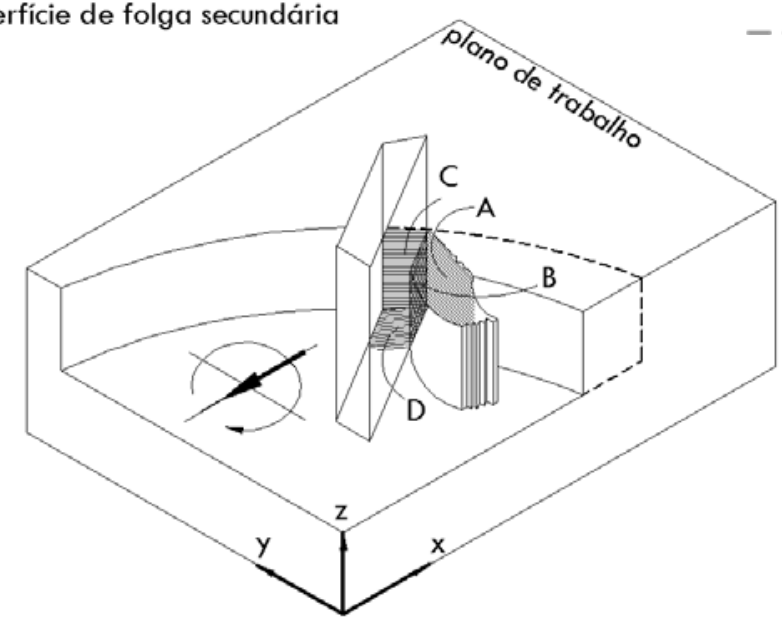

a)
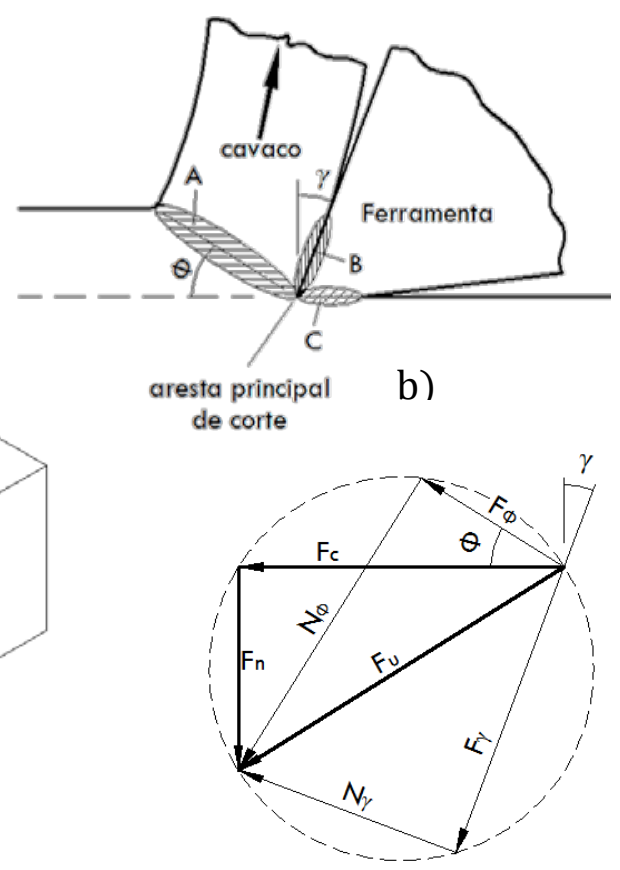

c)

Figura 2. 30 - Razão entre as forças de usinagem: a) processo de fresamento frontal; b) plano de trabalho; c) diagrama composto do plano de trabalho .

Fonte: Modificado de Black (1961).

$$
r_{\phi_{i}}=\frac{F_{\phi_{i}}}{N_{\phi_{i}}}=\frac{\left|F_{c_{i}} \cos \phi-F_{n_{i}} \operatorname{sen} \phi\right|}{\left|F_{c_{i}} \operatorname{sen} \phi+F_{n_{i}} \cos \phi\right|}
$$




$$
\begin{gathered}
\mathrm{r}_{\gamma_{i}}=\frac{\mathrm{F}_{\gamma_{i}}}{\mathrm{~N}_{\gamma_{\mathrm{i}}}}=\frac{\left|\mathrm{F}_{\mathrm{c}_{\mathrm{i}}} \operatorname{sen} \gamma+\mathrm{F}_{\mathrm{n}_{\mathrm{i}}} \cos \gamma\right|}{\left|\mathrm{F}_{\mathrm{c}_{\mathrm{i}}} \cos \gamma-\mathrm{F}_{\mathrm{n}_{\mathrm{i}}} \operatorname{sen} \gamma\right|}=\frac{\left|\mathrm{F}_{\mathrm{n}_{\mathrm{i}}}+\mathrm{F}_{\mathrm{c}_{\mathrm{i}}} \operatorname{tg} \gamma\right|}{\left|\mathrm{F}_{\mathrm{c}_{\mathrm{i}}}-\mathrm{F}_{\mathrm{n}_{\mathrm{i}}} \operatorname{tg} \gamma\right|} \\
\mathrm{r}_{\alpha_{\mathrm{i}}}=\frac{\mathrm{F}_{\mathrm{c}_{\mathrm{i}}}}{\mathrm{F}_{\mathrm{n}_{\mathrm{i}}}} \\
\mathrm{r}_{\alpha_{2_{\mathrm{i}}}}=\frac{\mathrm{F}_{\mathrm{c}_{\mathrm{i}}}}{\mathrm{F}_{\mathrm{p}_{\mathrm{i}}}}
\end{gathered}
$$

\subsection{ESPESSURA MÍNIMA DE CORTE}

Os príncipios da microusinagem são similares aos da usinagem convencional. Na microusinagem, a camada de material removida da peça é feita por uma microferramenta. A diferença entre a macro-usinagem e a micro-usinagem é a redução significativa de escala. Em microusinagem, quando a espessura de corte h, estipulada para uma ferramenta de corte, está abaixo de uma espessura de corte crítica (determinada como espessura mínima de corte $\mathrm{h}_{\text {min }}$ ), pode não ocorrer a formação de cavaco durante o processo de corte, e o material da peça pode ser deformado elasticamente. A Figura 2.31 mostra o conceito da espessura mínima de corte. Para uma espessura de corte ou avanço menor que a espessura mínima de corte, não haverá remoção de cavaco, apenas deformação elástica como mostra a Figura 2.31-a. Para uma espessura de corte correspondente a espessura mínima de corte, haverá uma tendência a formação de cavaco, em que a porção de material removido e a porção de recuperação elástica são praticamente proporcionais uma a outra como demonstra a Figura 2.31-b. Para uma espessura de corte maior que a espessura mínima de corte, haverá formação de cavaco, em que a porção de material removido será bem maior que a porção de recuperação elástica do material da peça, conforme mostra a Figura 2.31-c ( CHAE, et. al., 2006).
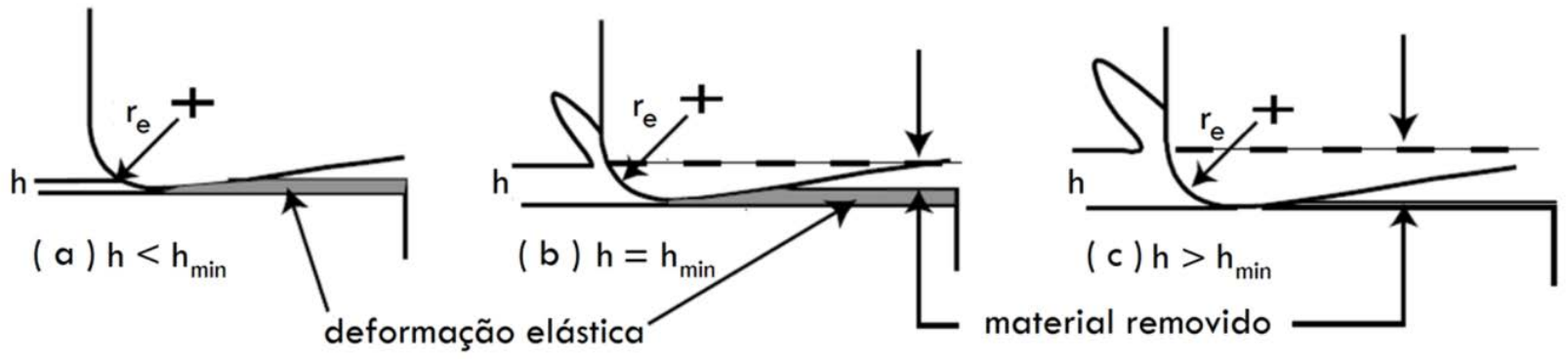

Figura 2. 31 - Esquema da mínima espessura de corte. ( $\mathrm{r}_{\mathrm{e}}$ : raio da aresta principal) Fonte: Modificado de Chae (2006). 
A espessura de corte tem sido investigada por diferentes pesquisadores, entre eles Yuan et al. (1996), os quais analisaram experimentalmente a espessura mínima de corte em uma liga de alumínio, utilizando ferramenta de diamante. Por meio da medição das componentes da força de usinagem, a relação entre o raio de aresta $\left(\mathrm{r}_{\mathrm{e}}\right)$ e a mínima espessura de corte $\left(\mathrm{h}_{\mathrm{min}}\right)$ é descrita pelas Equações (2.107), (2.108) e (2.109)obtidas a partir da geometria fornecida pela Figura 2.32 .

$$
h_{\min }=r_{e}\left[1-\frac{F_{n}+r_{\theta} \cdot F_{c}}{\sqrt{\left(F_{c}^{2}+F_{n}^{2}\right) \cdot\left(1+r_{\theta}^{2}\right)}}\right]
$$

Onde,

$$
\begin{gathered}
\operatorname{tg} \theta=\frac{F_{c}-r_{\theta} F_{n}}{r_{\theta} F_{c}+F_{n}} \\
r_{\theta}=\frac{F_{\theta}}{N_{\theta}}=\frac{F_{c} \cos \theta-F_{n} \operatorname{sen} \theta}{F_{n} \cos \theta+F_{c} \operatorname{sen} \theta}=\frac{F_{c}-F_{n} \operatorname{tg} \theta}{F_{n}+F_{c} \operatorname{tg} \theta}
\end{gathered}
$$

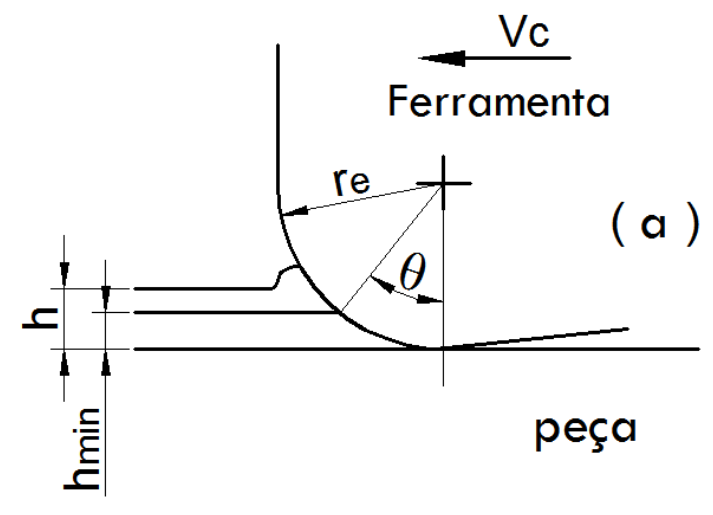

Figura 2.32 - Relação da espessura mínima e o raio da aresta principal. Fonte: Modificado de Yuan et al. (1996).

Yaun et al. (1996) concluíram que a espessura mínima de corte é em torno de 25 a 30\% do raio da aresta principal ( $\mathrm{h}_{\min }=0,25 \mathrm{r}_{\mathrm{e}}$ à $0,3 \mathrm{r}_{\mathrm{e}}$ ), portanto o ângulo $\theta$ é em torno de $41,4^{\circ}$ à 45,6 $6^{\circ}$, e o ângulo efetivo de saída $\gamma^{\prime}$ é em torno de - $69^{\circ}$ à $-67^{\circ}$.

Son et al. (2005), também deduzem uma equação, Equação (2.110), com base na teoria de Merchant, para a mínima espessura de corte considerando o coeficiente de atrito entre a peça e a ferramenta. Para esta equação assume-se que o ângulo $\theta$ é constante: 


$$
\mathrm{h}_{\min }=\mathrm{r}_{\mathrm{e}}\left[1-\left(\frac{\pi}{4}-\frac{\beta}{2}\right)\right]
$$

onde,

$$
\beta=\operatorname{arctg}\left(\mu_{\theta}\right)
$$

Son et al. (2005) investigaram o comportamento da espessura mínima de corte nos materiais cobre eletrolítico, alumínio e latão. A ferramenta utilizada foi a de diamante. Conforme os experimentos, eles verificaram que a mínima espessura de corte se comportou entre $20 \%$ e $25 \%$ do raio da aresta principal de corte, portanto $\theta$ é em torno de $36,9^{\circ}$ à $41,4^{\circ}$, e $\gamma^{\prime}$ em torno de $-71,5^{\circ}$ à $-69^{\circ}$.

Basuray et al. (1977) também investigaram a mínima espessura de corte no corte ortogonal. Estes autores afiaram ferramentas de aço rápido com arestas exageradas (raio de aresta entre $0,75 \mathrm{~mm}$ e $1,5 \mathrm{~mm}$ ) para simular a microusinagem na macrousinagem. Eles constataram que o ângulo $\theta$ varia em torno de $28^{\circ}$ a $33^{\circ}$, sendo que o calculado foi de $37,6^{\circ}$. Assim sendo, para uma variação do ângulo $\theta$ de $28^{\circ}$ até $33^{\circ}$, a espessura mínima de corte variou de $0,12 . r_{\mathrm{e}}$ a 0,16. $\mathrm{r}_{\mathrm{e}}$ (conforme mostra a Figura 2.33), e portanto o ângulo $\gamma^{\prime}$ variou de $-76^{\circ}$ a $-73,5^{\circ}$.
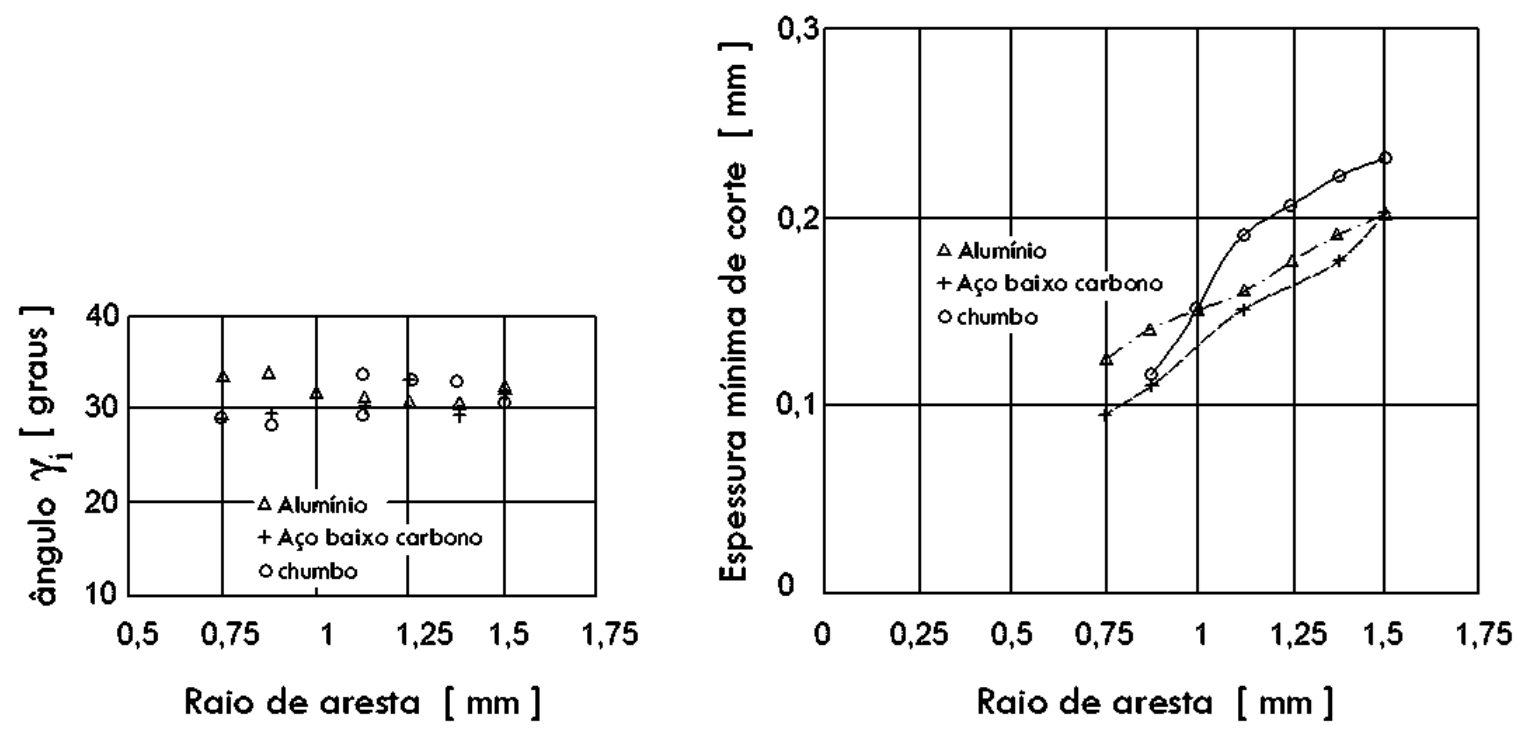

Figura 2.33 - Variação do ângulo $\gamma^{\prime}$ e da espessura mínima com o raio de aresta. Fonte: Modificado de Basuray et al., 1977.

Weule et al. (2001), declara que a espessura mínima de corte depende do raio de aresta e das propriedades do material. Uma vez que se trabalha com uma espessura de corte acima desta espessura crítica $\left(\mathrm{h}_{\min }\right)$, haverá remoção de material. Conforme este autor, para um dado 
material, é possível estimar a mínima espessura em torno de $29,3 \%$ o raio da aresta de corte. Portanto $\theta$ é de $45^{\circ}$ e $\gamma^{\prime}$ é $-67,5^{\circ}$.

Ducobu et al. (2012), utiliza o método dos elementos finitos com uma ferramenta de raio de aresta $20 \mu \mathrm{m}$, ângulo de saída $15^{\circ}$ e ângulo de folga $2^{\circ}$ e velocidade de corte de 75 m/min. O material da ferramenta é o carbeto de tungstênio (ferramenta de metal duro), e o material da peça é a liga de titânio Ti6Al4V. A Tabela 2.7 mostra a simulação da formação do cavaco com o decréscimo da espessura de corte.

Tabela 2.7 - Formação do cavaco com o decréscimo da espessura de corte (Ducobu et al.,2012)
$\mathrm{h}=14 \cdot \mathrm{r}_{\mathrm{e}}$
$\mathrm{h}=5 \cdot \mathrm{r}_{\mathrm{e}}$
$\mathrm{h}=2 \cdot \mathrm{r}_{\mathrm{e}}$
$\mathrm{h}=1 \cdot \mathrm{r}_{\mathrm{e}}$
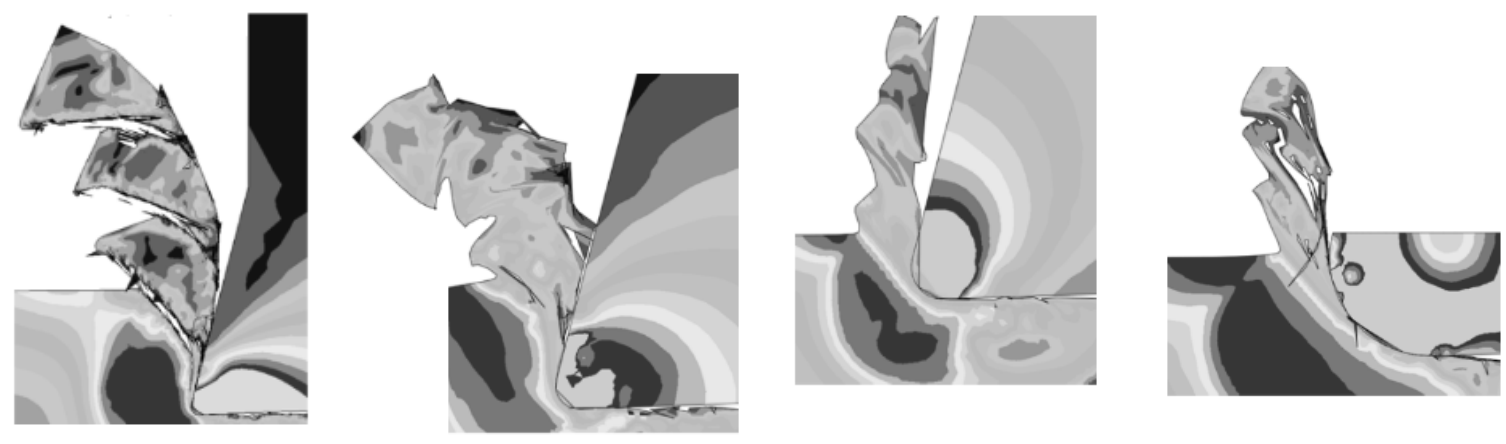

$\mathrm{h}=0,5 \cdot \mathrm{r}_{\mathrm{e}}$

$\mathrm{h}=0,25 \cdot \mathrm{r}_{\mathrm{e}}$

$\mathrm{h}=0,125 \cdot \mathrm{r}_{\mathrm{e}}$

$\mathrm{h}=0,05 \cdot \mathrm{r}_{\mathrm{e}}$
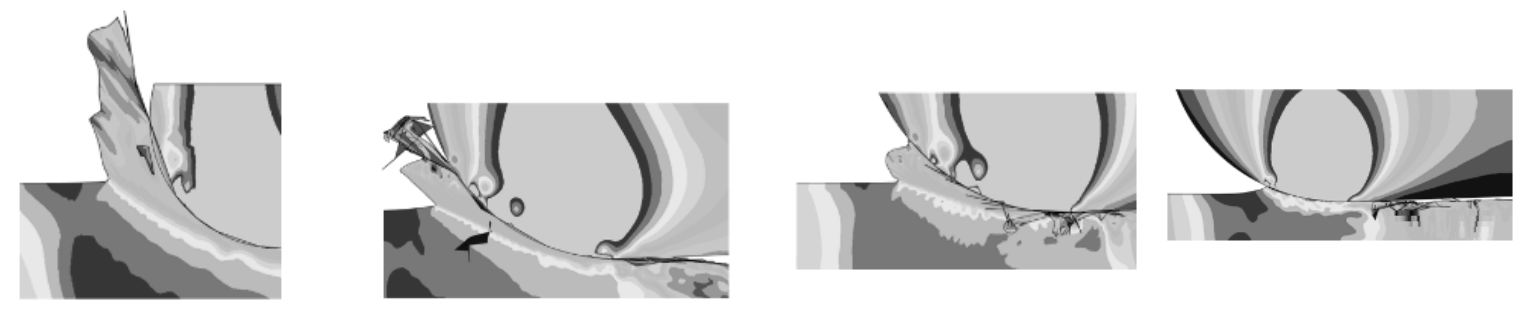

Ducobu et al. (2012), verificaram que a espessura mínima de corte variou entre 12,5\% do raio de aresta $\left(\theta\right.$ de $30^{\circ}$ e $\gamma^{\prime}$ de $\left.-75,5^{\circ}\right)$ até $50 \%$ do raio de aresta $\left(\theta\right.$ de $60^{\circ}$ e $\gamma^{\prime}$ de $\left.-60^{\circ}\right)$, com um valor médio de $25 \%$ do raio de aresta ( $\theta$ de $41,4^{\circ}$ e $\gamma^{\prime}$ de $-69^{\circ}$ ). 
Para finalizar este capítulo, uma síntese das equações, para o fresamento frontal, é fornecida pela Tabela 2.8 .

Tabela 2.8 - Síntese de equações em fresamento frontal (ângulos das equações em radianos).

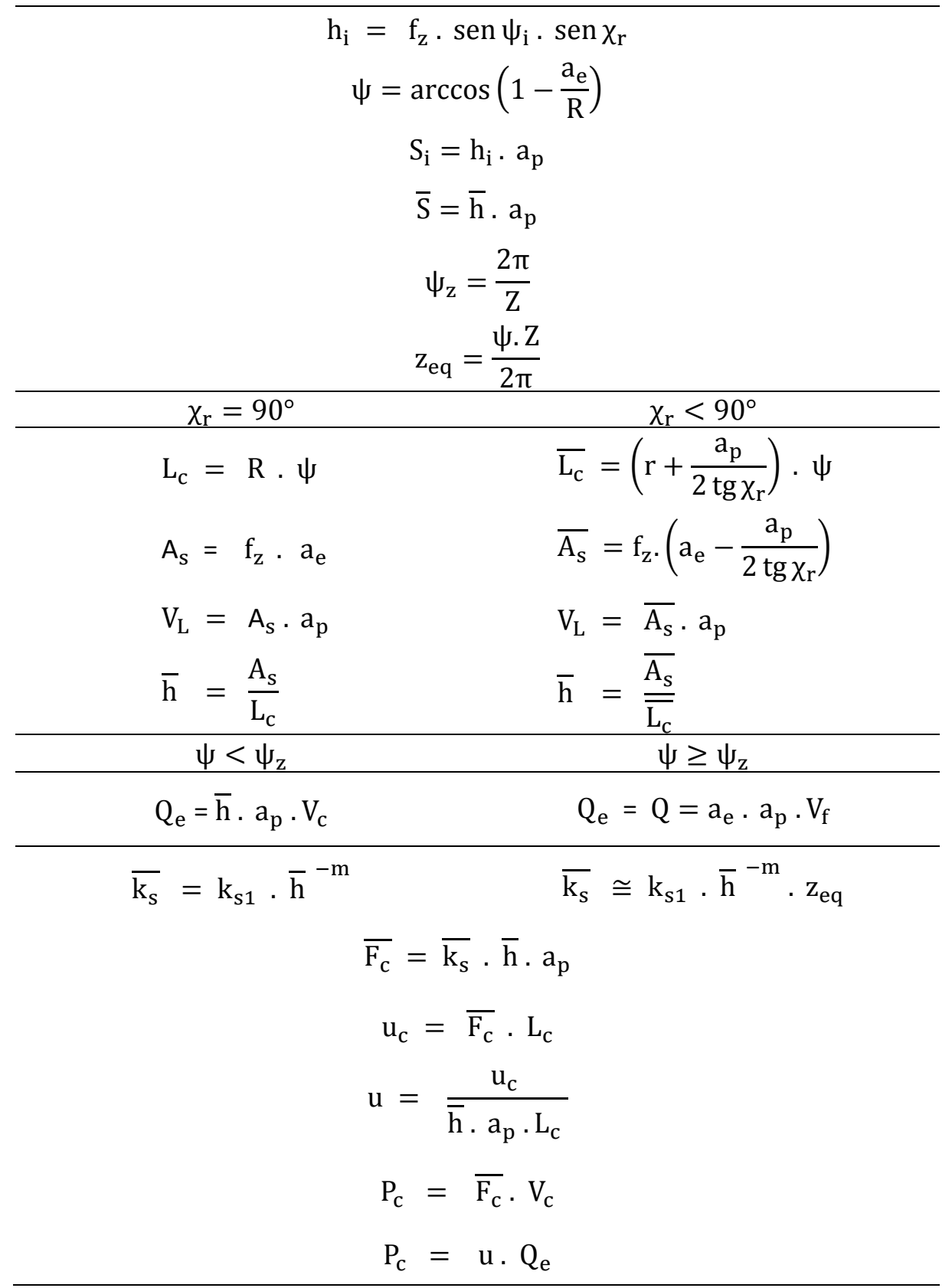




\section{MATERIAIS E MÉTODOS}

As informações sobre os procedimentos para aquisição do sinal, medições das componentes da força de usinagem, força de corte, pressão específica de corte, energia de corte, energia específica de corte, potência de corte, potência específica de corte, razão entre as forças de usinagem, rugosidade e formação dos cavacos são descritas na sequência. Os tópicos abordados são planejamento experimental, bancos de ensaios, especificação do corpo de prova, ferramentas de corte e o procedimento experimental.

\subsection{PLANEJAMENTO EXPERIMENTAL}

Para os ensaios decidiu-se, por duas razões, optar pelo fresamento frontal parcial discordante com tempo de movimento em vazio. Primeiramente, o fresamento discordante proporcionará uma variação da espessura de corte crescente, assim facilitando os estudos experimentais; e segundo, por meio de um fresamento parcial com tempo de movimento em vazio, tem-se a certeza que apenas um dente estará em contato com a peça durante a usinagem, assim não haverá interferência de outros dentes na análise das forças.

As operações de usinagem foram realizadas em um centro de usinagem vertical CNC marca Hermle, sem aplicação de fluido lubrificante ou refrigerante.

Os parâmetros de corte adotados como as variáveis de entrada foram o avanço por dente $\mathrm{f}_{\mathrm{z}}$ e a penetração de trabalho $\mathrm{a}_{\mathrm{e}}$. A velocidade de corte e a profundidade de usinagem $\mathrm{a}_{\mathrm{p}}$ foram mantidas constantes em todos os ensaios de usinagem.

Foram usadas duas fresas novas de topo inteiriças de metal duro sem cobertura (diâmetro de $0,8 \mathrm{~mm}$ e dois dentes cada). A primeira fresa foi utilizada no ensaio e a segunda fresa foi utilizada na réplica. A escolha das variáveis de entrada foi realizada a fim de investigar a força, energia e potência no processo de corte; a espessura mínima de corte e o tempo de movimento em vazio.

A análise do processo de formação do cavaco e a rugosidade do fresamento foram realizadas para contribuir com os resultados principais. A Tabela 3.1 apresenta os fatores de controle ou variáveis de entrada e as respectivas condições (níveis) seguidas da ordem de execução. Procurou-se executar os procedimentos em uma ordem aleatória. 
Tabela 3.1 - Parâmetro de ensaio (uma réplica).

\begin{tabular}{|c|c|c|c|c|}
\hline \multirow{2}{*}{$\begin{array}{l}\text { Parâmetros } \\
\text { Condições }\end{array}$} & \multicolumn{4}{|c|}{ Microfresamento } \\
\hline & $\mathrm{C} 1$ & $\mathrm{C} 2$ & $\mathrm{C3}$ & $\mathrm{C4}$ \\
\hline Ordem de execução & $1 \underline{a}$ & $3 \underline{a}$ & $2 \mathrm{a}$ & $4 \underline{a}$ \\
\hline $\mathrm{a}_{\mathrm{e}}[\mathrm{mm}]$ & 0,4 & 0,2 & 0,4 & 0,2 \\
\hline $\mathrm{f}_{\mathrm{z}}[\mathrm{mm} /$ dente $]$ & & & & \\
\hline $\mathrm{a}_{\mathrm{p}}[\mathrm{mm}]$ & \multicolumn{4}{|c|}{0,05} \\
\hline $\mathrm{V}_{\mathrm{c}}[\mathrm{m} / \mathrm{min}]$ & \multicolumn{4}{|c|}{50} \\
\hline
\end{tabular}

\subsection{BANCO DE ENSAIOS}

Todos os ensaios foram realizados em um centro de usinagem vertical CNC marca Hermle, modelo C800U, com potência de 18 kw. A rotação máxima do CNC é de 24000 RPM, as rotações fixadas possuem uma tolerância de \pm 3 RPM. A resolução de posicionamento da máquina é de $\pm 5 \mu \mathrm{m}$.

O posicionamento da ferramenta de corte, referente ao plano de trabalho da peça, foi realizado por meio de um dispostivo de calibração da marca dot-zero ${ }^{\circledR}$ que possui altura calibrada de $30 \mathrm{~mm}$, com precisão de $1 \mu \mathrm{m}$.

A aquisição dos dados das três componentes ortogonais da força de usinagem foi realizada por meio de um dinamômetro piezelétrico da marca Kistler ${ }^{\circledR}$, modelo 9256C2, faixa de trabalho na direção $\mathrm{x}, \mathrm{y}$ e z de -250 à $250 \mathrm{~N}$, frequência natural de $4 \mathrm{kHz}$, rigidez de 250 N/ $\mu \mathrm{m}$; e por um amplificador de carga de três canais da marca Kistler ${ }^{\circledR}$, modelo 5233A.

A conversão e transmissão dos sinais analógicos para o digital foi realizada por uma placa de aquisição de dados da marca National Instruments ${ }^{\circledR}$, PCI, blocos de conectores e o software labVIEW ${ }^{\circledR}$. O tratamento do sinal foi realizado por meio do software Matlab ${ }^{\circledR}$.

O dinamômetro foi fixado em um gabarito que por sua vez foi fixado à mesa da máquina por grampos. O dinamômetro foi conectado ao amplificador de carga, o qual foi conectado à placa de aquisição. Esta, por sua vez, foi conectada à placa mãe de um notebook munido do software labVIEW ${ }^{\circledR}$, como mostra o esquema da Figura 3.1. 


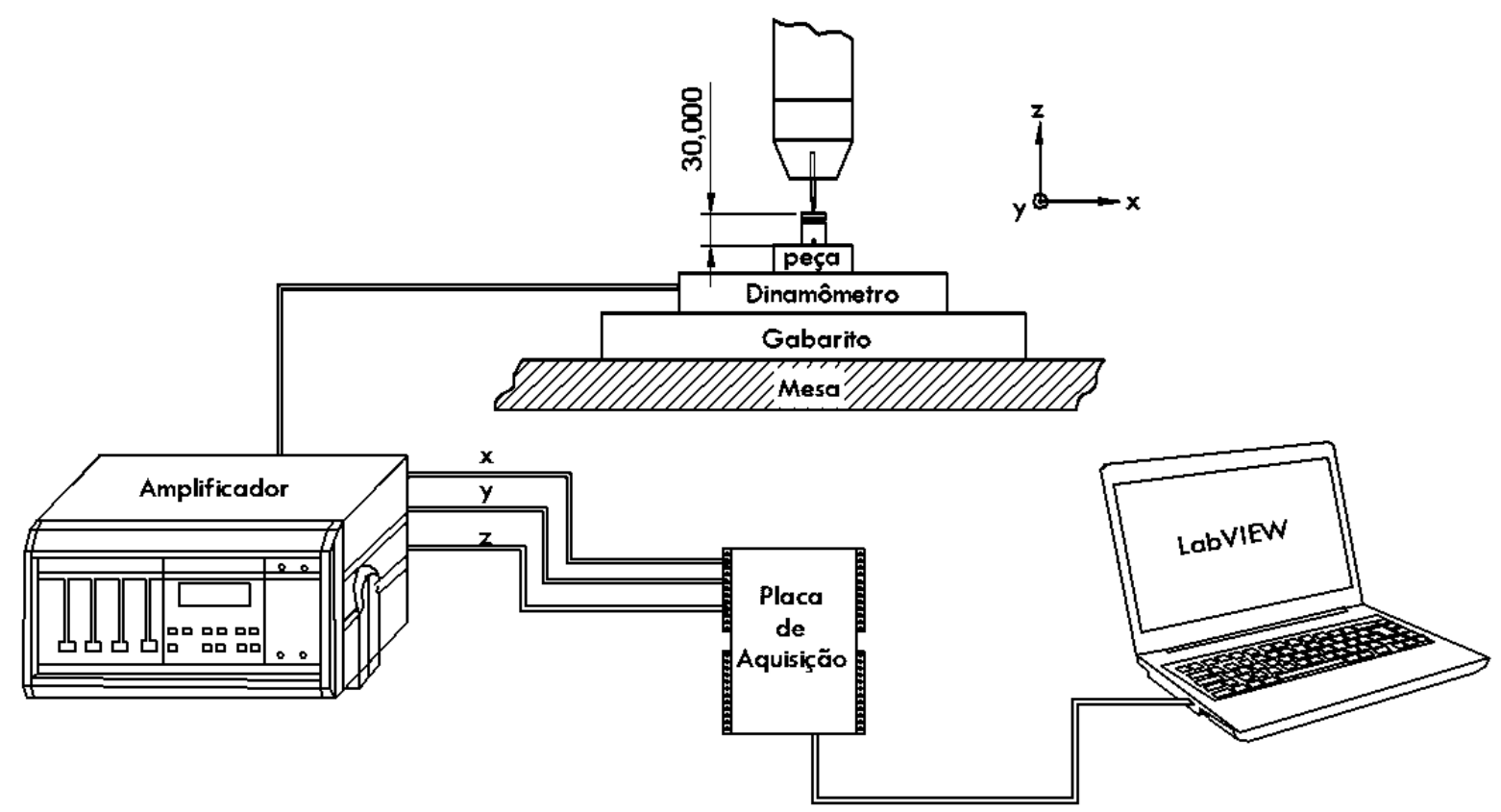

Figura 3.1 - Conjunto para análise das componentes da força de usinagem.

A caracterização microestrutural do material foi realizada utilizando um microscópio óptico. O raio de aresta da microfresa foi medido utilizando um microscópio confocal Olympus OLS4000 (cortesia Arotec S/A). A análise do processo de formação do cavaco foi realizada no microscópio eletrônico de varredura Zeiss LEO 440. A rugosidade e as dimensões efetivas após o fresamento foram analisadas em um perfilômetro sem contato de alta resolução da marca Vecco modelo WYKO NT1100.

\subsection{CORPO DE PROVA}

O material do corpo de prova, denominado comercialmente como RSA 6061, foi obtido a partir de uma barra cilíndrica extrudada de alumínio de grãos ultrafinos (em média 1 $\mu \mathrm{m}$ ). A composição química de tal material foi analisada por EDS conforme apresenta a Tabela 3.2. As propriedades físicas e mecânicas do material, obtidas junto ao fabricante, são mostradas pela Tabela 3.3 e Tabela 3.4. A microestrutura do material é apresentada pela Figura 3.2.

Tabela 3. 2 - Composição química do material usado nos experimentos (\%).

\begin{tabular}{ccc}
\hline $\mathbf{A l}$ & $\mathbf{S i}$ & $\mathbf{M g}$ \\
98,2 & 0,3 & 0,5 \\
\hline
\end{tabular}


Tabela 3.3 - Propriedades físicas do material usado nos experimentos.

\begin{tabular}{ccccc}
\hline \multirow{2}{*}{ Densidade } & $\begin{array}{c}\text { Dilatação } \\
\text { Térmica }\end{array}$ & \multicolumn{2}{c}{ Módulo de elasticidade } & Condutividade térmica \\
\hline $2,7\left[\mathrm{gr} / \mathrm{cm}^{3}\right]$ & $23\left[10^{-6} / \mathrm{K}\right]$ & $70[\mathrm{GPa}]$ & $26[\mathrm{GPa}]$ & $160[\mathrm{~W} / \mathrm{m} . \mathrm{k}]$ \\
\hline
\end{tabular}

Tabela 3.4 - Propriedades mecânicas do material usado nos experimentos.

\begin{tabular}{cccc}
\hline Tensão de escoamento & Limite de resistência & Alongamento & Dureza \\
\hline $295 \mathrm{MPa}$ & $330 \mathrm{MPa}$ & $12 \%$ & $117 \mathrm{HV}$ \\
\hline
\end{tabular}

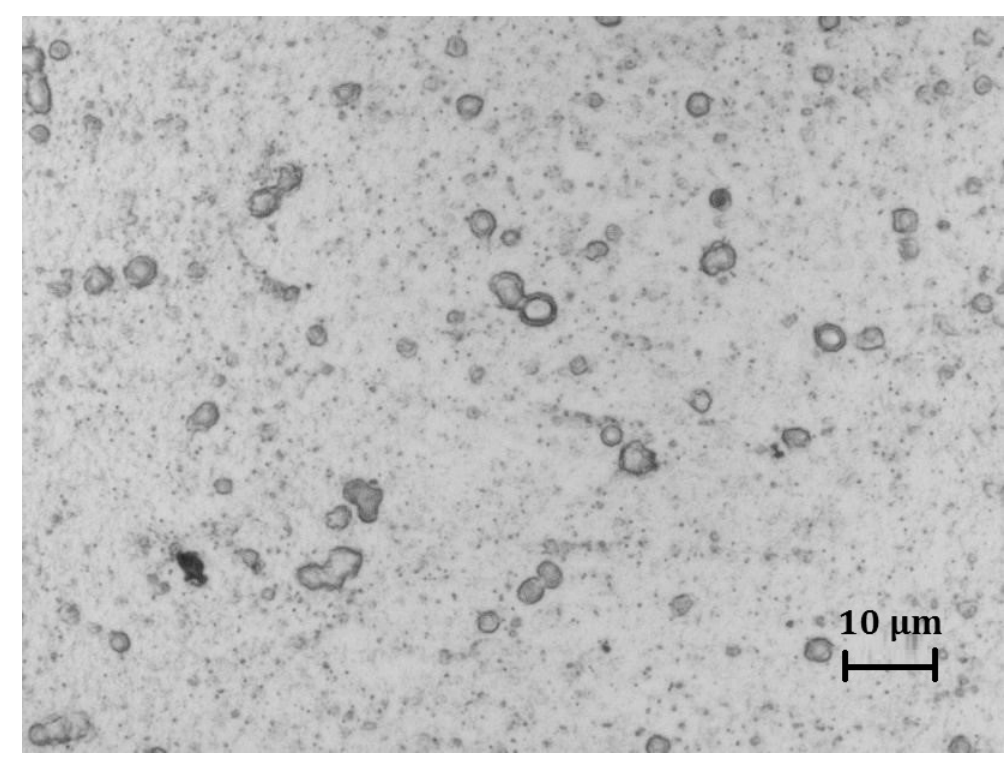

Figura 3.2 - Microestrutura do material usado nos experimentos.

Antes de realizar os ensaios de usinagem principais, o corpo de prova foi submetido a uma pré-usinagem por meio de um processo convencional de fresamento, visando a uma dimensão prismática de dimensões 12 x 25 x 50 mm.

\subsection{FERRAMENTA DE CORTE}

A ferramenta de corte utilizada nos ensaios foi uma microfresa inteiriça de metal duro da Swisstool ${ }^{\circledR}$, código $\varnothing 0.8 / 423757$. Tal fresa possui diâmetro de $0,8 \mathrm{~mm}$, duas arestas de corte, em que o canal de alívio de topo é descentralizado (esta técnica permite que a fresa realize corte no seu centro), conforme mostra a figura a seguir: 

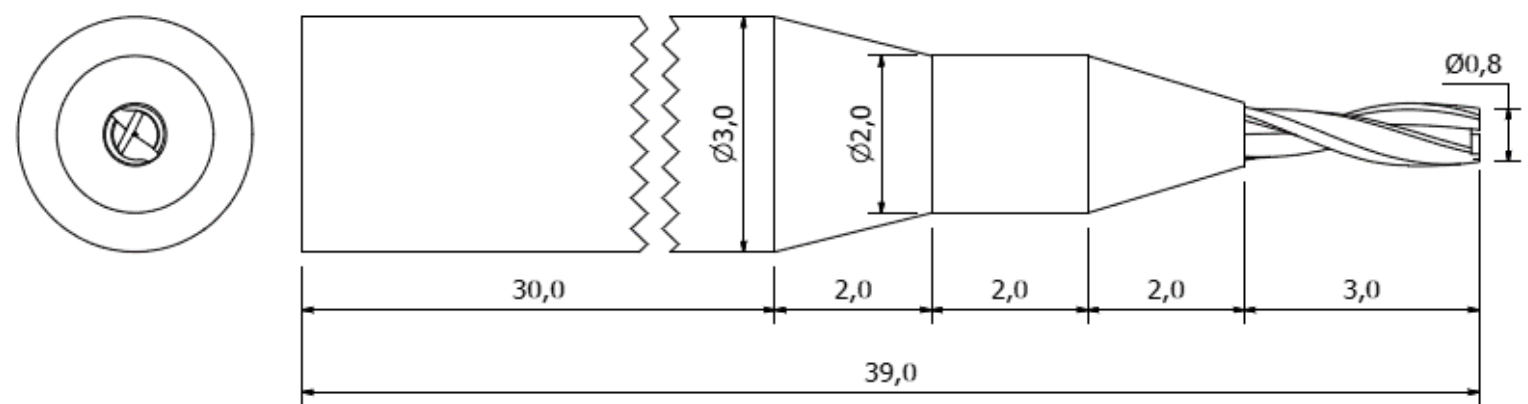

Figura 3.3 - Medidas da ferramenta de corte (escala do desenho 20:1)

A geometria da ferramenta foi determinada por meio das imagens obtidas do MEV e do microscópio confocal conforme apresenta a Figura 3. 4. Os dentes da fresa possuem ângulo de saída de $17^{\circ}$, ângulo de folga principal de $15^{\circ}$, raio de ponta em torno de $5 \mu \mathrm{m}$ e raio de aresta em torno de $2 \mu \mathrm{m}$ e $3 \mu \mathrm{m}$. O ângulo de posição da fresa é de $90^{\circ}$ e o ângulo de hélice é de $30^{\circ}$. A Tabela 3.5 apresenta todas as características geométricas das microfresas.

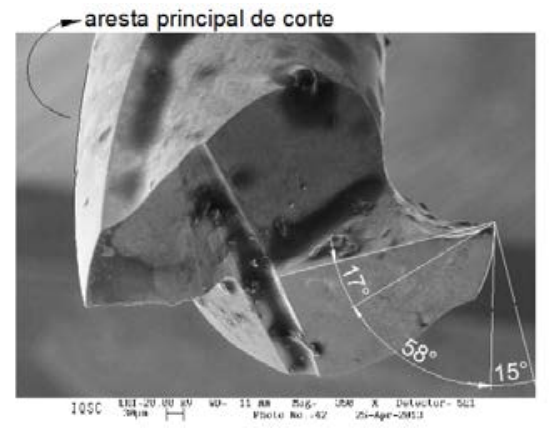

a)

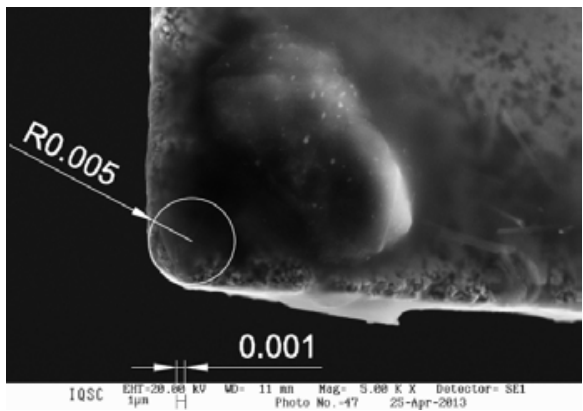

b)

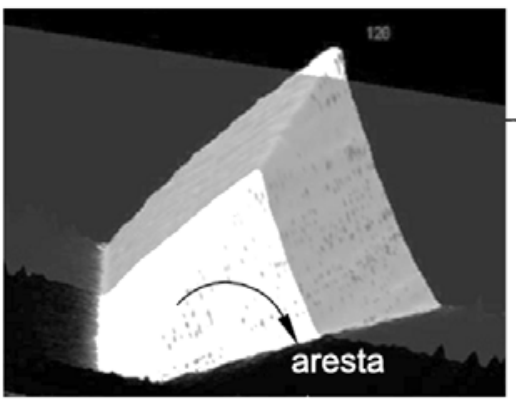

Plano de corte

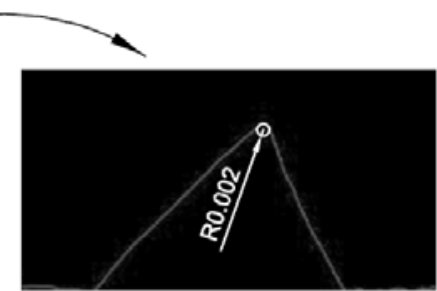

c)

Figura 3. 4 - Geometria da ferramenta, a) ângulos do dente da fresa (MEV), b) raio de ponta (MEV), c) raio da aresta principal de corte de uma fresa nova (microscópio confocal, cortesia Arotec S/A).

Tabela 3.5. Geometria da ferramenta de corte.

\begin{tabular}{cccccccc}
\hline \multicolumn{8}{c}{ Ferramenta de Metal Duro [ mm ] } \\
\hline Diâmetro & $\mathbf{Z}$ & $\boldsymbol{\alpha}$ & $\boldsymbol{\gamma}$ & $\lambda$ & $\chi_{\mathbf{r}}$ & $\mathbf{r}_{\boldsymbol{\varepsilon}}$ & $\mathbf{r}_{\mathbf{e}}$ \\
0,8 & 2 & $15^{\circ}$ & $17^{\circ}$ & $30^{\circ}$ & $90^{\circ}$ & 0,005 & $0,0018-0,0033$ \\
\hline
\end{tabular}




\subsection{PROCEDIMENTO EXPERIMENTAL}

Os procedimentos para obtenção dos resultados serão apresentados a seguir, na seguinte ordem: ensaio de usinagem, aquisição do sinal, componentes da força de usinagem, força de corte, tempo de movimento em vazio, pressão específica de corte, energia de corte, potência de corte, potência específica de corte volumétrica, razão entre as forças de usinagem, rugosidade e cavacos.

\subsubsection{Ensaio de usinagem}

Inicialmente foram realizados pré-testes em condições de microusinagem com o intuito de conhecer o comportamento das micro ferramentas quanto aos parâmetros de corte, o comportamento do sinal das componentes da força de usinagem e as condições da máquina perante tais parâmetros e condições de microusinagem.

Após os pré-testes, deu-se início aos ensaios de microfresamento. O corpo de prova foi fixado cuidadosamente no dinamômetro por meio de parafusos e pequenas barras de aço. Uma barra de aço de seção quadrada foi posicionada e fixada no dinamômetro, o corpo de prova foi pressionado contra esta barra por meio de outra barra de seção circular, a qual exercia pressão no corpo de prova por meio de três parafusos. Este método de fixação da peça assegurou que a peça estivesse bem assentada sobre o dinamômetro conforme demonstra a ilustração a seguir:

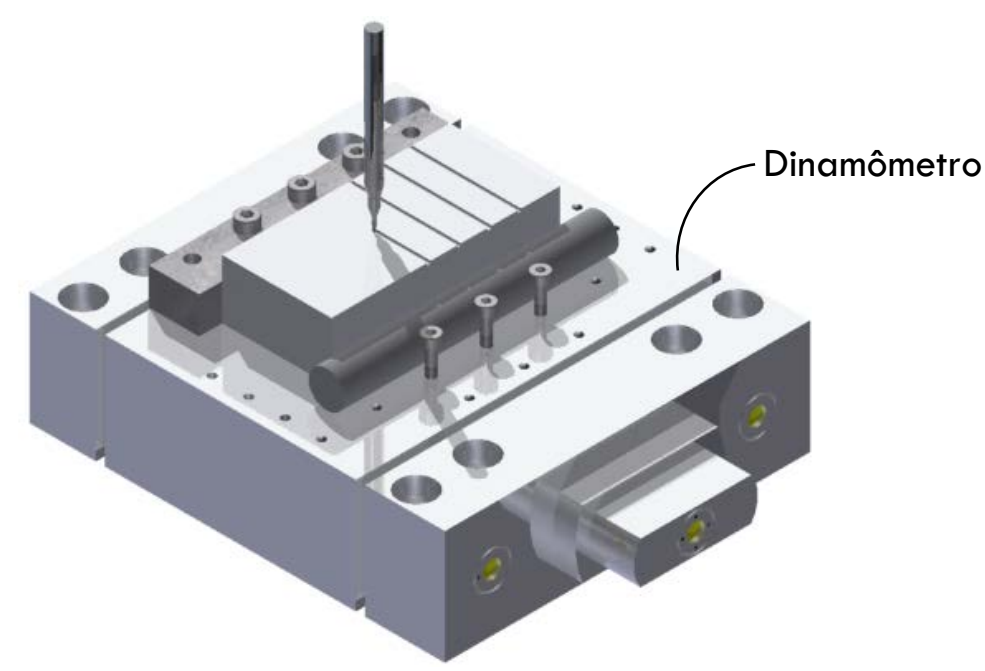

Figura 3.5 - Método de fixação do corpo de prova no dinamômetro. 
Em seguida uma fresa de diâmetro 16 mm, com dois insertos de metal duro revestidos, fresaram a parte frontal da peça com o intuito de alcançar uma superfície plana para execução das condições de microfresamento.

As condições de microusinagem foram realizadas da seguinte maneira: o fresamento foi iniciado pelo fresamento em cheio (para abertura de um canal), em seguida a ferramenta foi deslocada lateralmente de modo a conseguir um fresamento parcial e então foi iniciado o corte. Em seguida, foram feitas as medições das componentes da força de usinagem nas direções ortogonais x, y e z. Os deslocamentos na direção do avanço e penetração de trabalho foram realizados nas direções paralelas ao plano de trabalho, ou seja, todos os movimentos eram paralelos as direções x e y referentes ao dinamômetro. A Figura 3.6 simboliza os canais feitos pelos cortes em cheio e parciais, sentido de rotação e dos avanços. Todos os fresamentos possuem tempo de movimento em vazio.
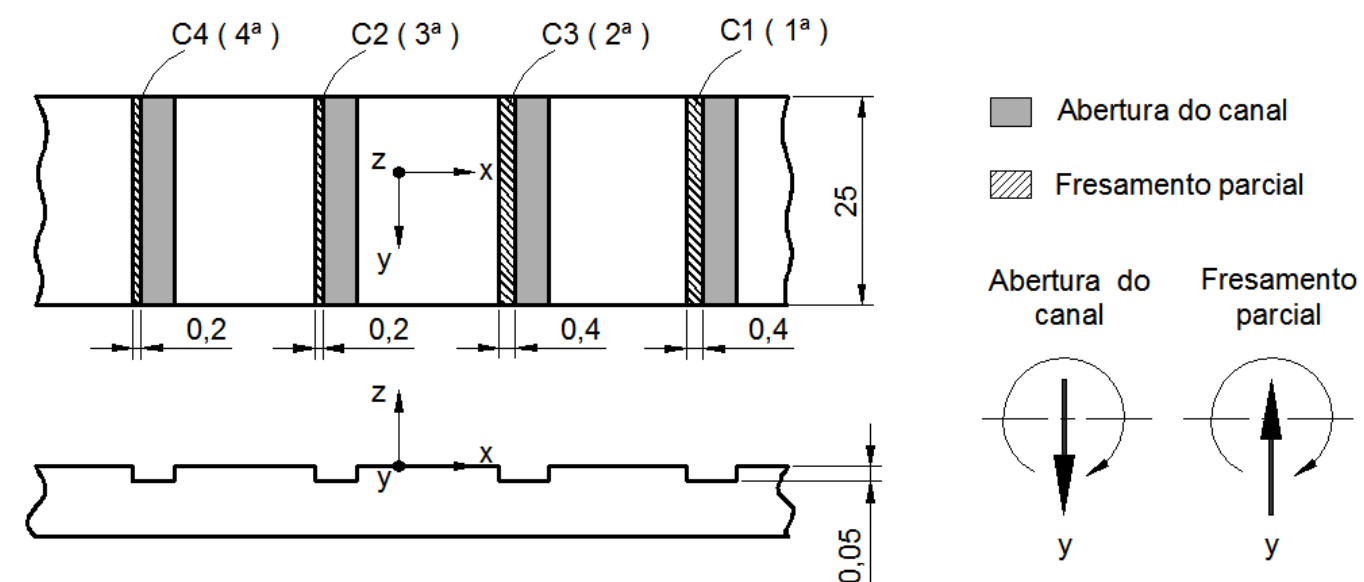

Figura 3.6 - Sequência da ordem de execução das condições de microfresamento.

A cada condição realizada, o processo foi parado e os cavacos coletados para futuras análises. Por meio de ar com alta pressão e vazão a superfície da peça e a ferramenta eram limpas para execução da próxima condição, e assim sucessivamente. Ao término das condições, a ferramenta foi trocada por um nova para realização de uma réplica.

\subsubsection{Aquisição do sinal}

Antes de determinar a frequência de aquisição é preciso primeiro conhecer a frequência de excitação do sistema. No caso do fresamento, frequência de excitação corresponde ao número de vezes que os dentes da fresa passam pelo material da peça em um determinado 
tempo. A Figura 3.7, apresenta uma transformada discreta de Fourier (FFT) do sinal da força, sem filtro no amplificador, de um pré-teste de microfresamento com base em uma das condições de usinagem. Nesta figura pode-se observar a frequência de excitação do eixo árvore (para uma rotação de 20000 RPM) e a frequência de excitação dos dentes da fresa passando pela peça $(Z=2)$. As frequências subsequentes não fazem parte da usinagem.

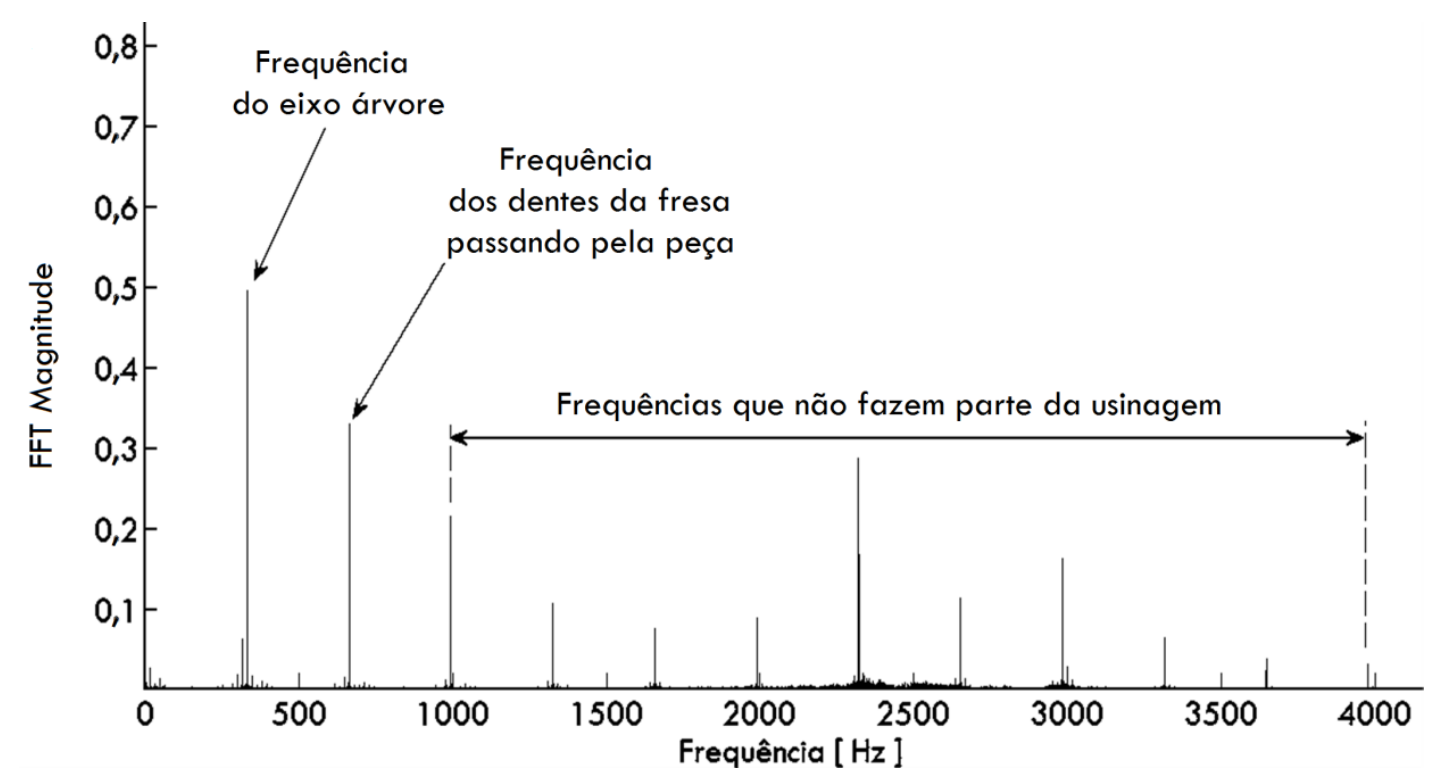

Figura 3.7 - Transformada discreta de Fourier do sinal da força no microfresamento.

Com o intuito de evitar que as frequências que não fazem parte da usinagem não interfiram nos resultados, o amplificador foi programado para deixar passar na aquisição do sinal apenas frequências de excitação que estivessem abaixo de $1000 \mathrm{~Hz}$.

Determinada a frequência de excitação que será estudada, passa-se para a frequência de aquisição do sinal, ou seja, o número de amostras em um determinado tempo. No caso do fresamento, em que a aquisição do sinal se deve ao eixo árvore da máquina, é de praxe pensar em um determinado número de amostras por volta. A força gerada no processo de usinagem é decorrente da camada de material que se deseja remover. Assim sendo, de modo a discretizar a força de corte, basta estudá-la ponto a ponto na formação do cavaco.

Segundo Rigatti (2010) a frequência de aquisição mínima deve ser duas vezes a frequência de excitação para que não ocorra aliasing no sinal (que consiste na aquisição de um sinal distorcido ou falso). Corroborando esta ideia, a frequência de aquisição mínima também pode ser determinada com base na formação do cavaco, em que para cada cavaco deve-se no mínimo obter duas amostras. 
Conhecendo o ângulo correspondente ao tamanho do cavaco (ângulo de contato $\psi$ ), pode-se estimar o número de amostras por volta em função do número de amostras por cavaco. Por exemplo, se o ângulo correspondente ao tamanho do cavaco é $90^{\circ}$, conforme mostra a Figura 3.8-a, com o intuito de conseguir duas amostras por cavaco, é preciso oito amostras por volta. Sendo a rotação do eixo árvore 20000 rpm (333,33 Hz) o tempo de uma volta corresponde a 0,003 segundos, e, portanto, o quociente entre o número de amostras por volta e o tempo de uma volta, corresponde a uma frequência de aquisição de 2667 Hz. Esta frequência de aquisição garantirá, para um eixo à 20000 rpm, duas amostras da força por cavaco. Conforme a Figura 3.8-b, pode-se observar que dependendo do número de amostras que se deseja por cavaco, a discretização das forças registradas podem não fornecer os dados de toda extensão da variação da força. Por isso, quanto maior o número de amostras por cavaco, melhor é a resolução da força analisada.

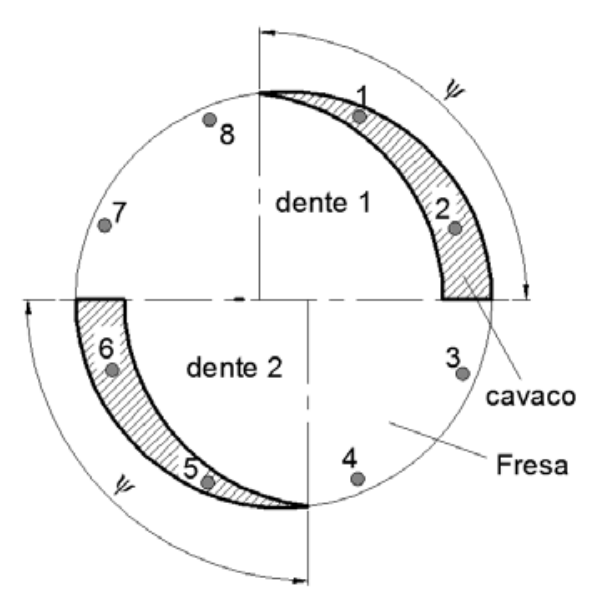

a)

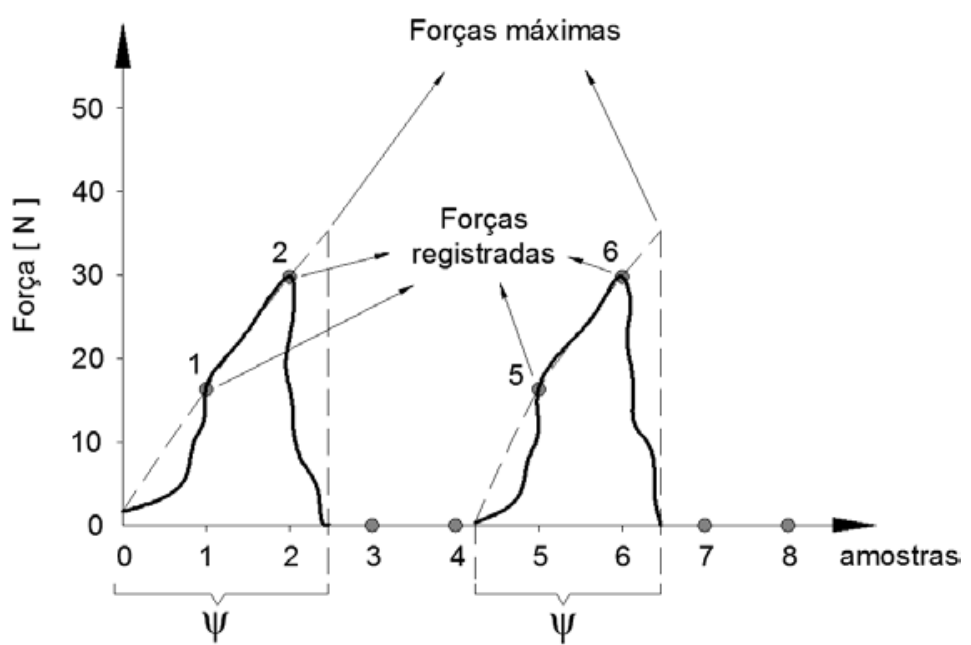

b)

Figura 3.8 - Frequência de aquisição no fresamento não engajado. A fresa utilizada possui dois dentes.

Assim sendo, a Equação (3.1) indica uma frequência de aquisição $\left(F_{\text {aq }}\right)$ em função do número de amostras por cavaco $(\mathrm{N})$ conforme o comprimento total angular do cavaco $(\psi)$ e a rotação (n) do eixo árvore da máquina, para um fresamento que possui tempo de movimento em vazio.

$$
\mathrm{F}_{\mathrm{aq}}=\frac{2 \pi \cdot \mathrm{n} \cdot \mathrm{A}}{\psi} \equiv \frac{360^{\circ} \cdot \mathrm{n} \cdot \mathrm{A}}{\psi^{\circ}} \quad \psi<\psi_{\mathrm{z}}
$$

Como um dos objetivos deste trabalho é analisar, por meio da força de corte, a mínima espessura de corte, a frequência de aquisição adotada foi a máxima suportada pela placa de 
aquisição: 130 kHz. Esta alta frequência de aquisição fornecerá ponto a ponto a variação da força de corte com alta resolução. Assim as amostras por cavaco chegarão mais próximo possível da força de corte mínima e máxima.

\subsubsection{Componentes da força de usinagem}

Os sinais das componentes da força de usinagem salvos em arquivo formato txt, foram formatados por uma matriz de três colunas. A primeira coluna corresponde ao eixo x, a segunda coluna ao eixo y e a terceira ao eixo z. Conforme o sentido de rotação horário da fresa e de avanço da mesa, os eixos x, y e z do dinamômetro, correspondem, respectivamente, as forças de apoio, avanço e passiva:

$$
\begin{aligned}
& \mathrm{F}_{\mathrm{x}}=\mathrm{F}_{\mathrm{ap}} \\
& \mathrm{F}_{\mathrm{y}}=\mathrm{F}_{\mathrm{f}} \\
& \mathrm{F}_{\mathrm{z}}=\mathrm{F}_{\mathrm{p}}
\end{aligned}
$$

As etapas do tratamento do sinal foram feitas da seguinte maneira: primeiro foi analisado o sinal bruto como mostra a Figura 3.9. Nesta figura pode-se observar as componentes da força de usinagem $F_{a p}, F_{f}$ e $F_{p}$, a região de aproximação da ferramenta até a peça, a região de usinagem e a região de afastamento após usinagem. Nas regiões de aproximação, pode-se notar um pequeno ruído causado, talvez, pela rede elétrica.
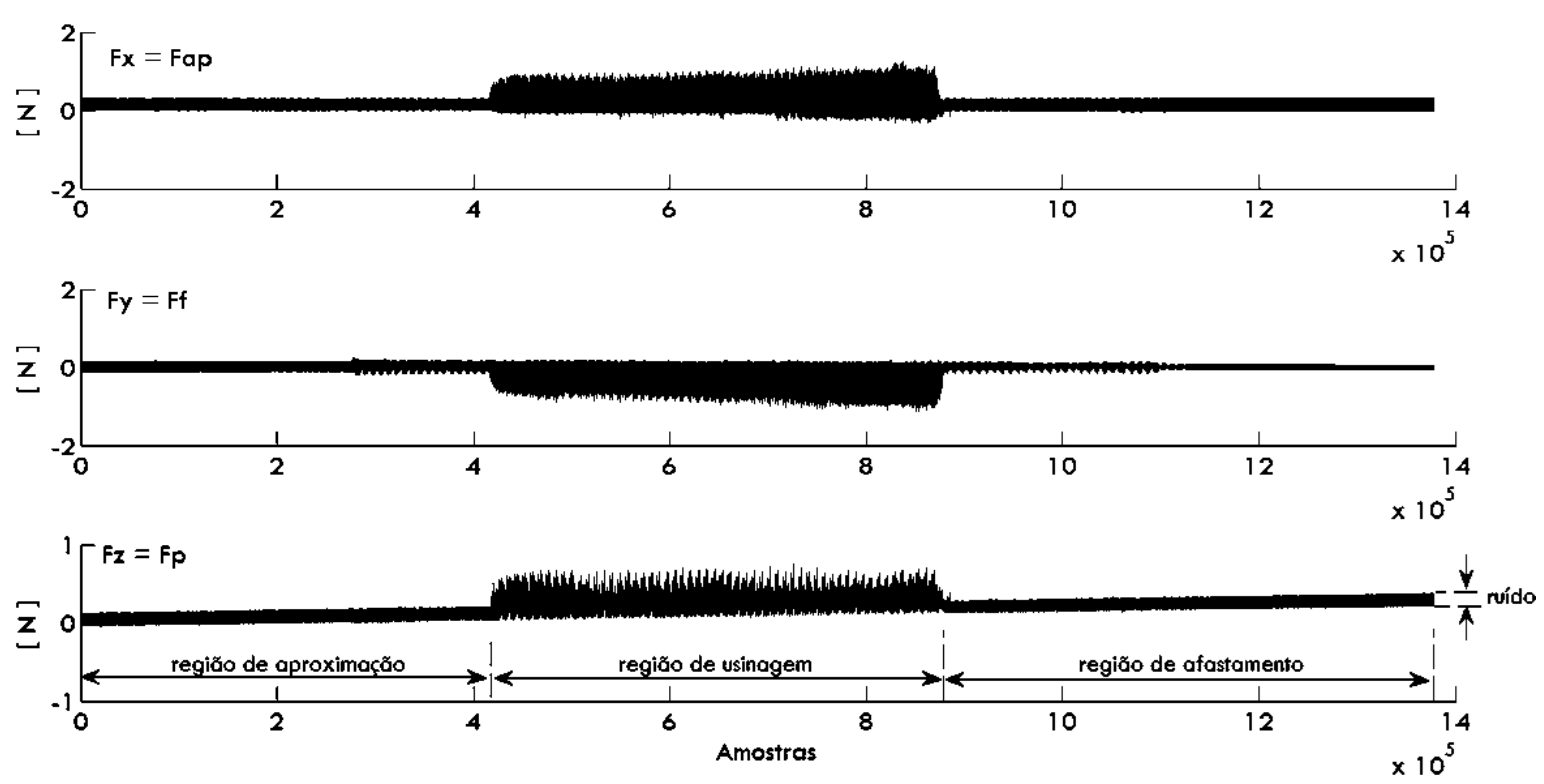

Figura 3.9 - Sinal das componentes da força de usinagem 
Após análise verificou-se que era preciso corrigir a inclinação da curva (drift), como pode ser visto na força passiva $F_{p}$ da Figura 3.9. Após a correção de drift, as regiões de aproximação e de afastamento eram excluídas, de modo a analisar apenas a região de usinagem.

Conforme visto no tópico fundamentos do fresamento, as médias das variações do fresamento bem como a espessura de corte, a força de corte, a energia de corte, dentre outros, representam o fresamento como um todo. Estudar um sinal com uma frequência de aquisição de $130 \mathrm{kHz}$ é muito demorado. Portanto, a metodologia adotada foi descobrir o intervalo do sinal na região de usinagem e determinar quantos períodos possíveis estão presentes neste intervalo e então calcular uma média das forças destes períodos para obter um período médio que represente o sinal por inteiro, conforme demonstrado pelas equações (3.3) (primeiro período), (3.4) (segundo período), (3.5) (último período) e (3.6) (média das forças dos períodos).

$$
\begin{aligned}
& P_{1}=\left\{F_{1_{1}}, F_{1_{2}}, F_{1_{3}}, F_{14}, F_{1_{5}}, F_{1_{6}}, F_{17}, F_{1_{8}}, \ldots, F_{1_{j}}\right\} ; \quad j \text { é o último termo do período } \\
& P_{2}=\left\{F_{2_{1}}, F_{2_{2}}, F_{2_{3}}, F_{2_{4}}, F_{2_{5}}, F_{2_{6}}, F_{27}, F_{2_{8}}, \ldots, F_{2_{j}}\right\} \\
& \cdot \\
& P_{k}=\left\{F_{k_{1}}, F_{k_{2}}, F_{k_{3}}, F_{k_{4}}, F_{k_{5}}, F_{k_{6}}, F_{k_{7}}, F_{k_{8}}, \ldots, F_{k_{j}}\right\} ; \quad k \text { é o último período } \\
& \bar{P}=\left\{\frac{1}{k} \sum_{i=1}^{k} F_{i_{1}}, \frac{1}{k} \sum_{i=1}^{k} F_{i_{2}}, \frac{1}{k} \sum_{i=1}^{k} F_{i_{3}}, \ldots, \frac{1}{k} \sum_{i=1}^{k} F_{i_{j}}\right\}
\end{aligned}
$$

Inicialmente procurou-se encontrar o período da força de apoio e de avanço separadamente, porém estas duas componentes são defasadas entre si e por isto tal método não funcionava separadamente. Porém, como a força ativa é a soma vetorial destas duas componentes, encontrando o período da força ativa, automaticamente será encontrado o período das componentes força de apoio e força de avanço. Sabendo que na espessura de corte máxima a força ativa é máxima, o pico do período da força ativa se dá exatamente neste momento e entre dois picos tem-se um período.

As forças ativas máximas correspondentes a cada período subsequente são os picos do sinal. Para encontrar os picos do sinal, foi criada uma rotina que realiza uma busca iterativa do 
sinal (neste caso na região de usinagem). Com base no ponto $\mathrm{P}_{\mathrm{i}}$ da Figura 3.10, é dado um exemplo da busca iterativa. Este ponto, por meio da rotina, é comparado com um ponto (ou amostra) anterior e com um ponto subsequente; se este ponto for menor que um destes dois, a rotina pula para o próximo ponto. Caso o ponto seja o do pico, nenhum ponto anterior ou subsequente será maior que este ponto dentro do período. Neste caso, conforme já programado para a rotina, o ponto será comparado com todos os pontos correspondentes, a meio período para frente e meio período para trás; se este ponto é maior que todos, é identificado o pico e início de um período. Este tipo de busca iterativa garante que 99\% dos picos, contidos no sinal, sejam identificados.

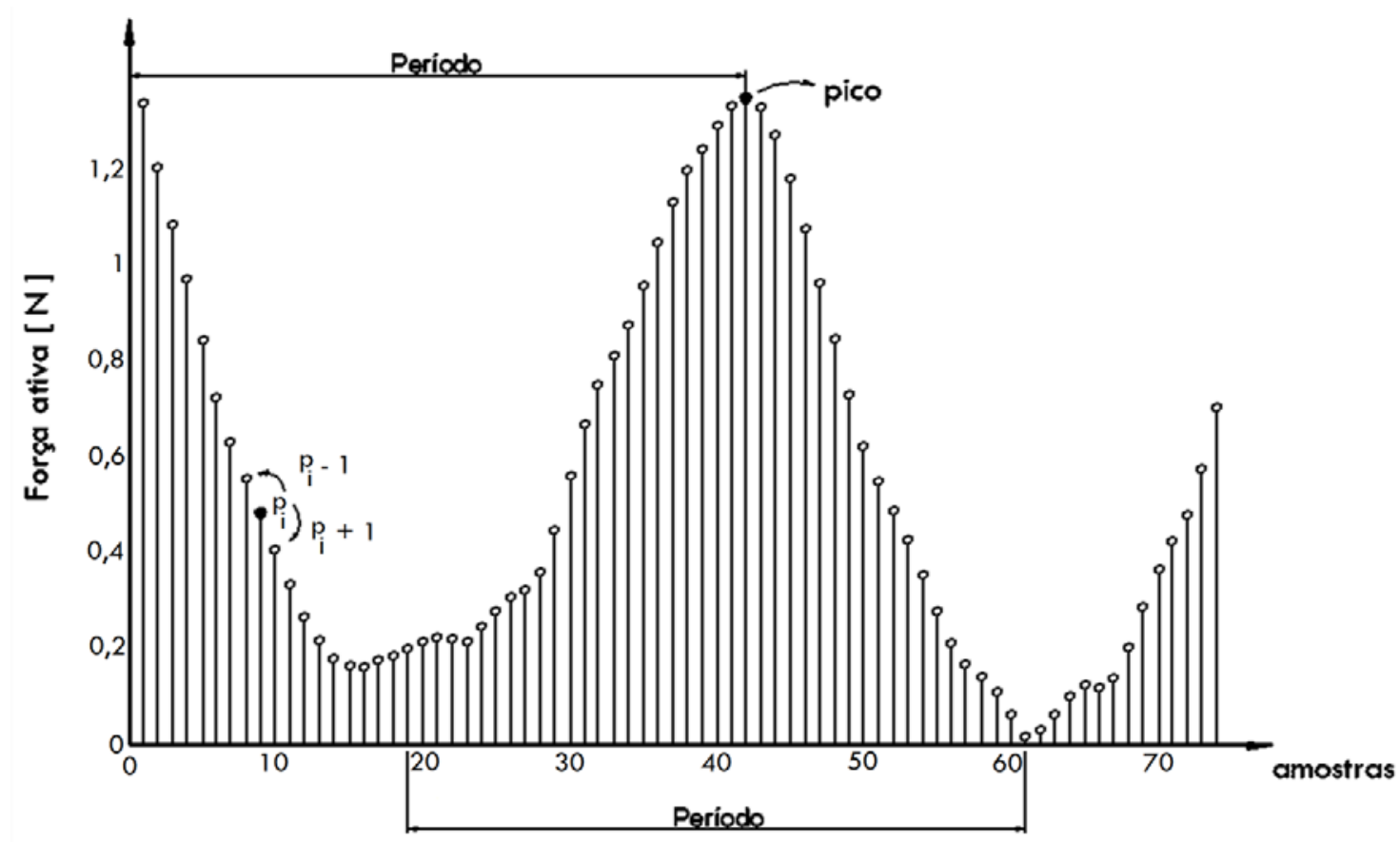

Figura 3.10 - Busca iterativa dos picos e início dos períodos.

Identificados, todos os picos e períodos do sinal na região de usinagem, é então calculado o período médio, conforme a Equação (3.6). Sendo o período determinado pela força ativa máxima (decorrente da espessura de corte máxima), tal período está entre 0 e $180^{\circ}$ (para o caso de uma fresa com dois dentes) e as amostras contidas dentro deste período médio possui um incremento correspondente a uma pequena porção angular, em que a soma destas será sempre $180^{\circ}$. Portanto, após estas identificações, a força de corte pôde ser determinada dentro do sinal. 


\subsubsection{Força de corte e a pressão específica de corte}

Com base no período médio, foram obtidas duas espessuras de corte máximas, dentro do período de $180^{\circ}$, conforme mostra a Figura 3.11. Uma vez que é conhecido o número de amostras por cavaco, é possível determinar a região de formação do cavaco (extensão da letra $\psi$ da Figura 3.11). Pode-se observar ainda, que um pouco antes do início da formação do cavaco, há um aumento considerável da força. A hipótese assumida para este efeito é a sobreposição causada pelo ruído.

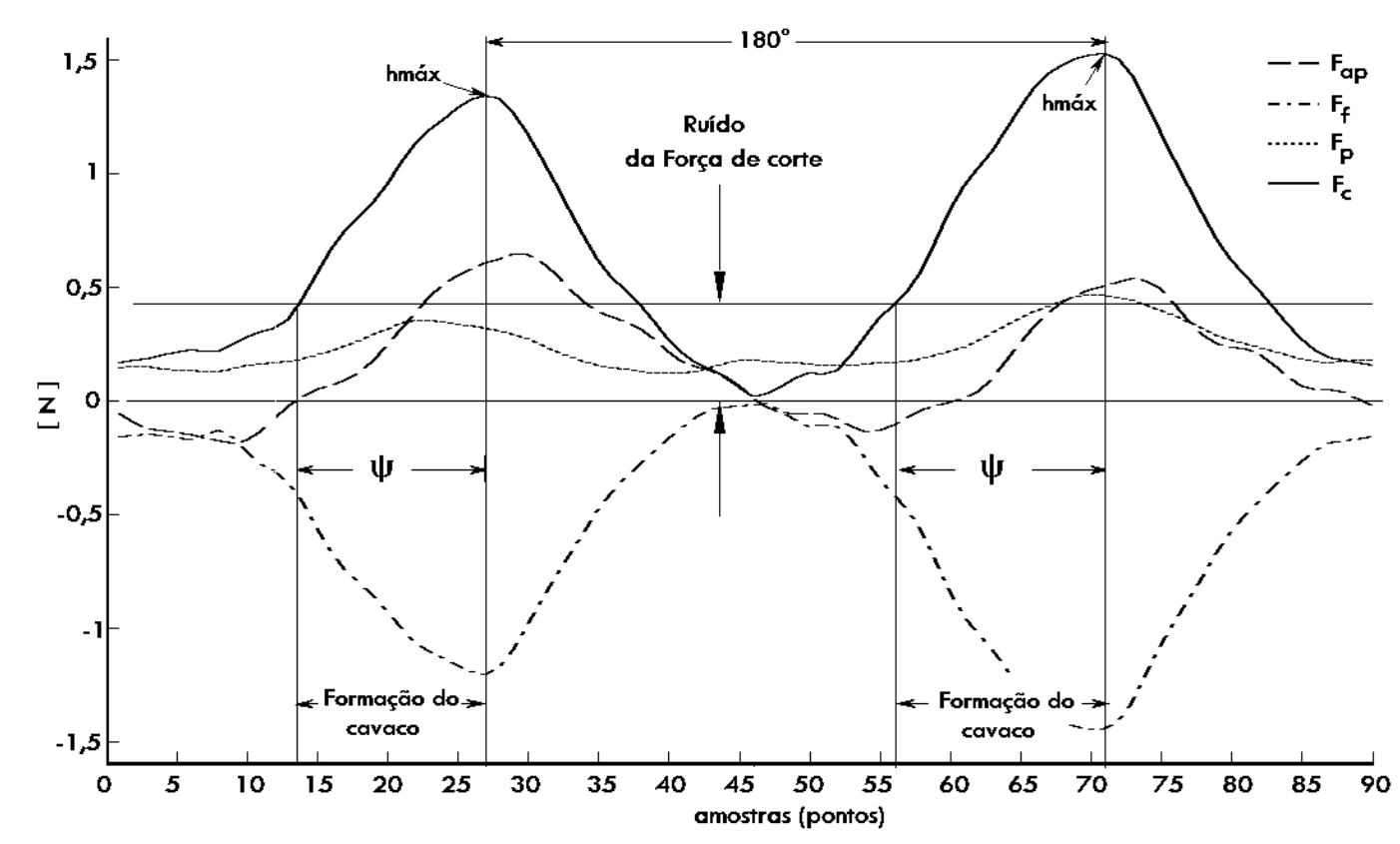

Figura 3.11 - Período médio do sinal, fresamento discordante: força de corte crescente.

Se o período (um período está entre dois picos) comporta, por exemplo, 45 amostras, o intervalo angular de cada amostra será exatamente 180\%/45 que corresponde a um incremento de $4^{\circ}$. Conforme a penetração de trabalho $\mathrm{a}_{\mathrm{e}}$ e o raio da fresa $\mathrm{R}$ é possível calcular o ângulo de contato ou comprimento angular do cavaco. Para uma penetração de trabalho correspondente a metade do raio da fresa $\left(\mathrm{a}_{\mathrm{e}}=0,5 \mathrm{R}\right)$ o ângulo de contato $\psi$ corresponde a $60^{\circ}$, por meio do incremento angular de $4^{\circ}$, dado pelo número de amostras dentro do período, o número de amostras contidos dentro da zona de formação do cavaco é 15.

Partindo do pico para trás, tem-se exatamente a região em que houve a formação do cavaco. Nesta região encontram-se 15 amostras e cada uma corresponde a um intervalo angular de $4^{\circ}$, totalizando o ângulo de contato $\psi=60^{\circ}$. Com isto, torna-se possível decompor as forças 
de avanço e apoio em função de cada incremento angular somado ao anterior $\left(\psi_{\mathrm{i}}\right)$ para obtenção da variação da força de corte $F_{c_{i}}\left(F_{c_{i}}=F_{f_{i}} \cos \psi_{i}+F_{a p_{i}}\right.$ sen $\left.\psi_{i}\right)$ e então calcular a força de corte média que será calculada da seguinte maneira:

$$
\overline{\mathrm{F}_{\mathrm{c}}}=\frac{1}{\mathrm{~N}} \sum_{\mathrm{i}=1}^{\mathrm{N}} \mathrm{F}_{\mathrm{c}_{\mathrm{i}}} ; \quad \mathrm{N} \text { é o número de amostras por cavaco }
$$

Conhecida a força de corte média do sinal, pode-se determinar a pressão específica de corte com base na área da seção de corte média:

$$
\overline{\mathrm{k}_{\mathrm{s}}}=\frac{\overline{\mathrm{F}_{\mathrm{c}}}}{\overline{\mathrm{S}}}=\frac{\overline{\mathrm{F}_{\mathrm{c}}}}{\overline{\mathrm{h}} \cdot \mathrm{a}_{\mathrm{p}}}
$$

\subsubsection{Energia de corte e a energia específica de corte}

A energia de corte por sua vez pode ser calculada, conforme o sinal da força de corte, de duas maneiras: em função da força de corte média e o comprimento de corte; ou em função da integral numérica do sinal da força na região de formação do cavaco. A primeira será calculada da seguinte forma:

$$
\mathrm{u}_{\mathrm{c}}=\overline{\mathrm{F}_{\mathrm{c}}} \cdot \mathrm{L}_{\mathrm{c}}=\overline{\mathrm{F}_{\mathrm{c}}} \cdot \mathrm{R} \cdot \psi
$$

E a segunda será calcula por integração numérica pelo método do trapézio. Primeiro o ruído será atenuado deslocando as forças de corte na zona de formação do cavaco para o eixo zero como mostra a figura a seguir:
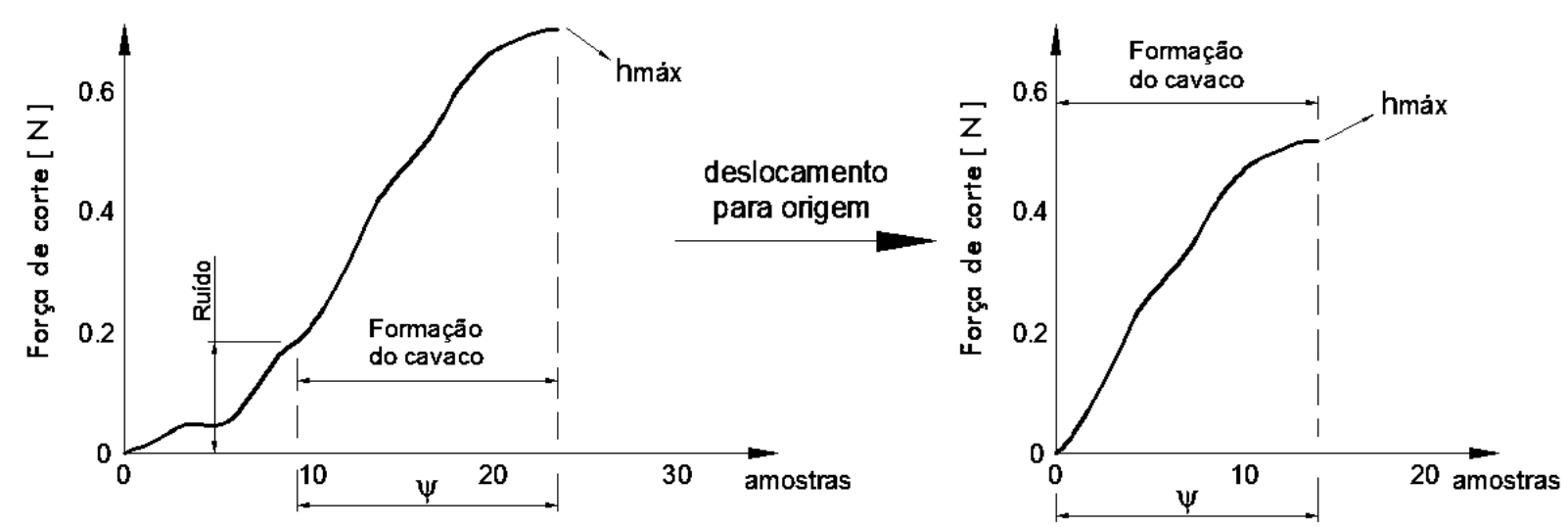

Figura 3.12 - Deslocamento da força de corte para origem (eliminando o ruído). 
Em seguida a energia de corte será calculada pelo somatório das áreas formadas por um trapézio. Os números de trapézios serão conforme o número de amostra por cavaco. A Figura 3.13 apresenta a integração numérica pelo método do trapézio.

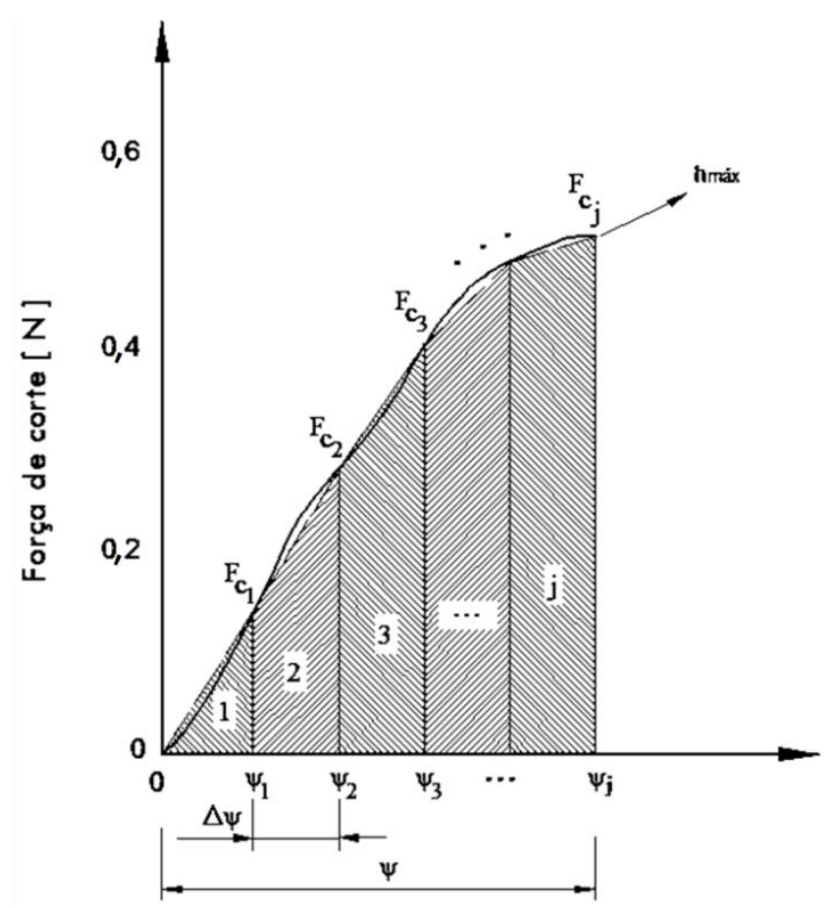

Figura 3.13 - Integração numérica do sinal da força de corte pelo método do trapézio.

Assim sendo a energia de corte, pelo método do trapézio, será:

$$
\mathrm{u}_{\mathrm{c}}=\mathrm{R} \cdot \sum_{\mathrm{i}=1}^{\mathrm{j}} \frac{\left(\mathrm{F}_{\mathrm{c}_{\mathrm{i}}}+\mathrm{F}_{\mathrm{ci}_{\mathrm{i}-1}}\right) \Delta_{\psi}}{2}
$$

Para obter a energia específica de corte, basta dividir a energia de corte pelo volume removido:

$$
\mathrm{u}=\frac{\mathrm{u}_{\mathrm{c}}}{\mathrm{a}_{\mathrm{e}} \cdot \mathrm{a}_{\mathrm{p}} \cdot \mathrm{f}_{\mathrm{z}}}
$$

\subsubsection{Potência de corte}

A potência de corte também será determinada, conforme o sinal da força de corte de duas maneiras: a primeira será determinada conforme a força de corte média $\overline{F_{c}}$ e a velocidade 
de corte $V_{c}$, conforme a Equação (3.12), e a outra será determinada de acordo com a energia específica de corte média u e a taxa de material removido efetiva $Q_{e}$, Equação (3.13):

$$
\begin{aligned}
& P_{c}=\overline{F_{c}} \cdot V_{c} \\
& P_{c}=u \cdot Q_{e}=u \cdot \bar{h} \cdot a_{p} \cdot V_{c}
\end{aligned}
$$

\subsubsection{Rugosidade}

Para análise da rugosidade, foi utilizado um perfilômetro óptico da marca Vecco modelo WYKO NT1100. As amostras foram posicionadas no equipamento e alinhadas de modo que as superfícies fresadas ficassem perpendiculares ao feixe de luz. Imagens planas e tridimensionais com escala de cores foram obtidas em diversas regiões representativas de cada condição de usinagem. Por meio do perfilômetro, também foi feita uma análise das dimensões efetivas dos parâmetros de corte, como penetração de trabalho e a profundidade de usinagem.

\subsubsection{Cavacos}

Os cavacos coletados durante a usinagem das condições de fresamento foram dispostos aleatoriamente sobre uma superfície de fita condutora de eletricidade e levados ao microscópio eletrônico de varredura (MEV). O objetivo desta análise foi verificar, conforme os parâmetros de corte, se houve a formação de cavacos. Também, como parte do objetivo, foi observado o ângulo de cisalhamento do material e se o mecanismo de formação dos cavacos foi constituído de lamelas justapostas contínuas, segmentadas ou de ruptura. 


\section{RESULTADOS E DISCUSSÕES}

A seguir são apresentados os resultados referentes à análise da aquisição do sinal das componentes da força de usinagem. Todos os resultados do sinal das componentes da força de usinagem (força de apoio, força de avanço e força passiva) foram tratados estatisticamente, considerando um intervalo de confiança de 99\% com base nos desvios padrões. As seções a seguir têm por objetivo avaliar as forças e energias despendidas no processo de microfresamento, atrito e a mínima espessura de corte, o mecanismo de formação do cavaco e a rugosidade.

\subsection{PARÂMETROS DE CORTE}

Por meio de um perfilômetro óptico e um microscópio confocal, foi possível derterminar, conforme a precisão de posicionamento da máquina-ferramenta e o erro experimental, os parâmetros efetivos de cada condição de microfresamento. Foram feitas três medidas, uma na parte inferior da peça (corte AA'), a outra no meio da peça (corte BB') e a outra medida foi feita na parte superior da peça (corte CC'), conforme mostra a Figura 4.1.
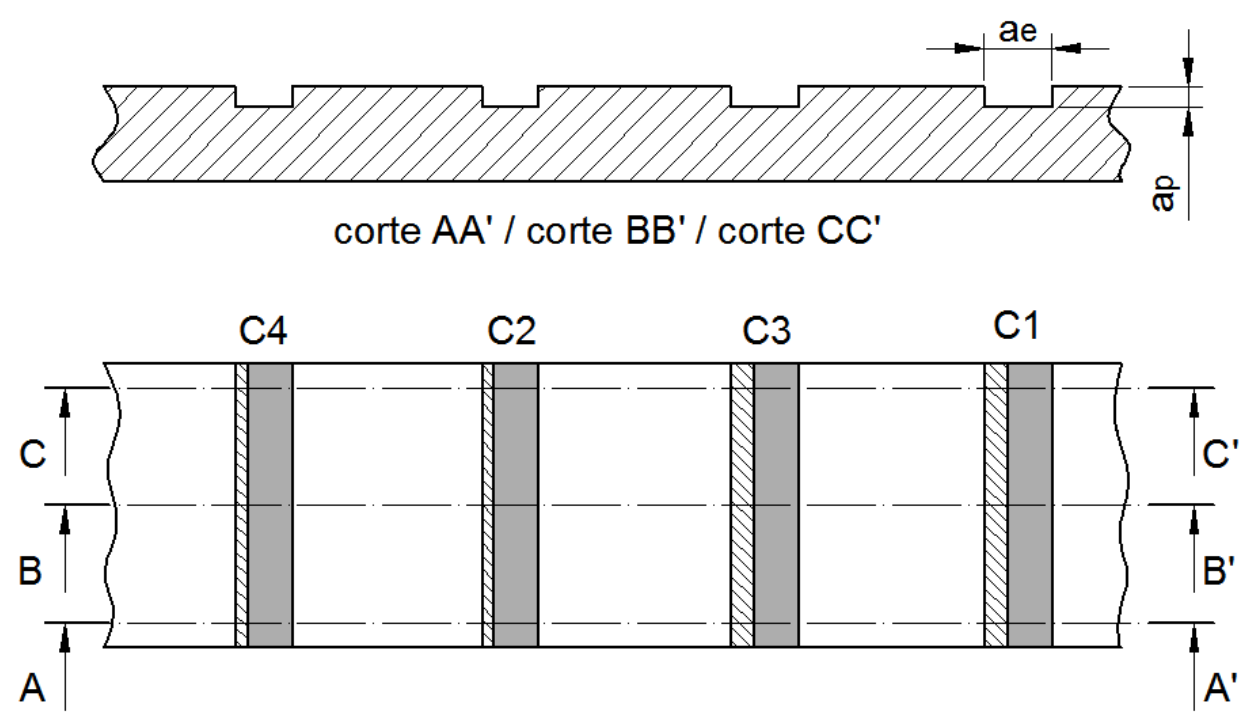

Figura 4.1 - Regiões de cortes para medição do $a_{e}$ e do $a_{p}$. 
Uma amostra da condição C3 do primeiro ensaio na região de corte BB', coletada por meio do perfilômetro óptico, é mostrada pela Figura 4.2. Esta imagem ilustra a estratégia de fresamento usada para realização dos experimentos. Primeiro a microfresa realizou a abertura do canal com fresamento em cheio (largura correspondente ao diâmetro da fresa: 0,8 mm) com movimento de avanço na direção do eixo y. Após o fim da abertura do canal, a fresa foi deslocada na direção do eixo x para realizar o fresamento conforme os parâmetros de usinagem da condição C3 (largura correspondente a 0,4 mm).

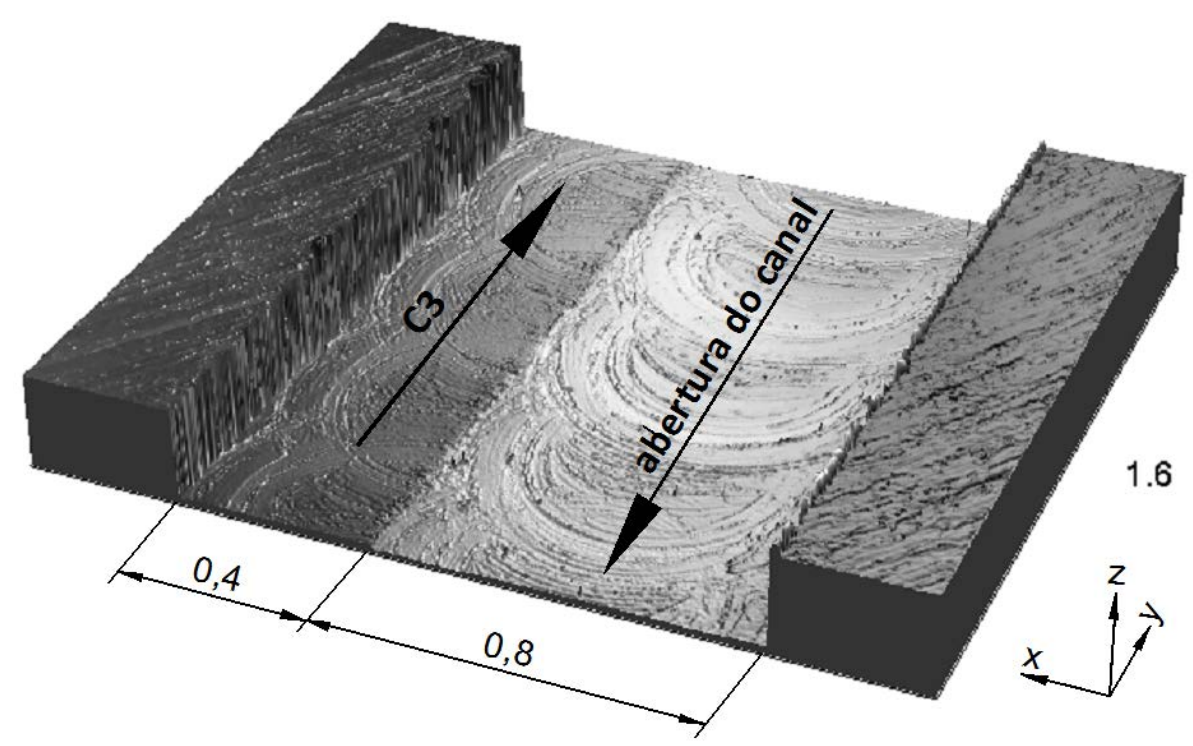

Figura 4.2 - Ilustração da estratégia de fresamento, exemplo da condição C3 do Ensaio 1.

A Figura 4.3-a apresenta o método de verificação dos parâmetros efetivos obtidos de acordo com a resolução dos movimentos da máquina ferramenta e da preparação experimental. A imagem mostra a parte em que houve a abertura do canal (fresamento em cheio) e em seguida o fresamento parcial. Assim sendo, foram medidas as dimensões deixadas pelos dois fresamentos (profundidade de usinagem $\mathrm{a}_{\mathrm{p}}$ e penetração de trabalho total $\mathrm{a}_{\mathrm{e}_{\text {total }}}$ ). Os diâmetros das ferramentas de corte usadas nos experimentos também foram medidos para obter a medida efetiva da penetração de trabalho $\mathrm{a}_{\mathrm{e}}$ dos fresamentos parcias (Figura 4.3-b: ferramenta do primeiro ensaio, Figura 4.3-c: ferramenta do segundo ensaio). A efetiva penetração de trabalho $a_{e}$ foi obtida por meio da largura total do canal e do raio da fresa $\left(a_{e}=a_{e_{t o t a l}}-2 R\right)$. 


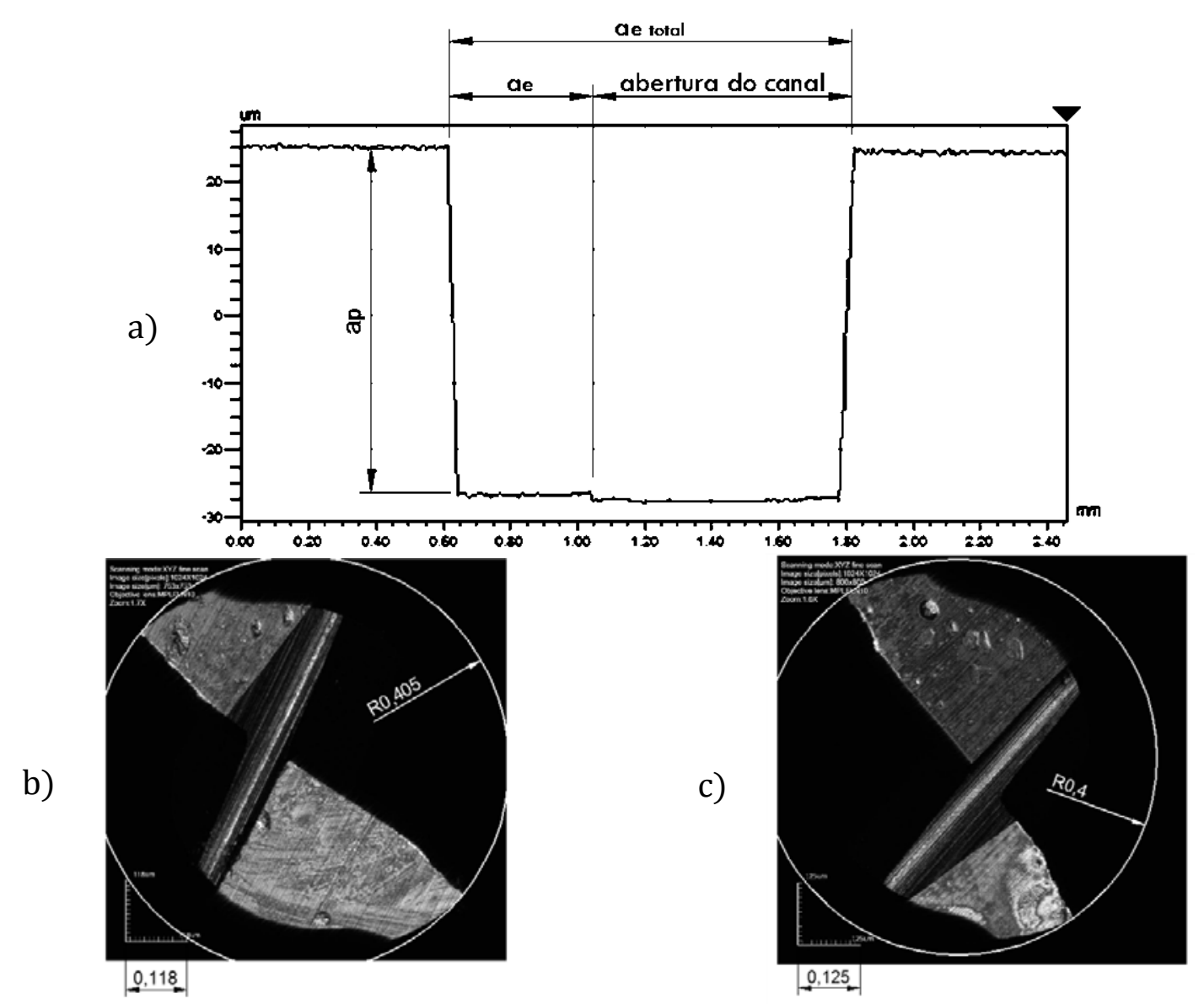

Figura 4.3 - Medição das condições de fresamento e das penetrações de trabalho parciais: a) imagem do perfilômetro óptico; b) imagem do microscópio confocal (cortesia Arotec S/A).

Para Condição 1 (C1) do primeiro ensaio, tem-se a medida da largura total do canal, $\mathrm{a}_{\mathrm{e}}=1,2048 \mathrm{~mm}$, como mostra a Figura 4.4-a. Sendo o raio da fresa de 0,405 mm, a penetração de trabalho correspondente ao fresamento parcial é de 0,3948 $\mathrm{mm}$. E a medida da profundidade de usinagem efetiva da condição 1 (C1) é $a_{p}=50,9472$, como mostra a Figura $4.4-b$.

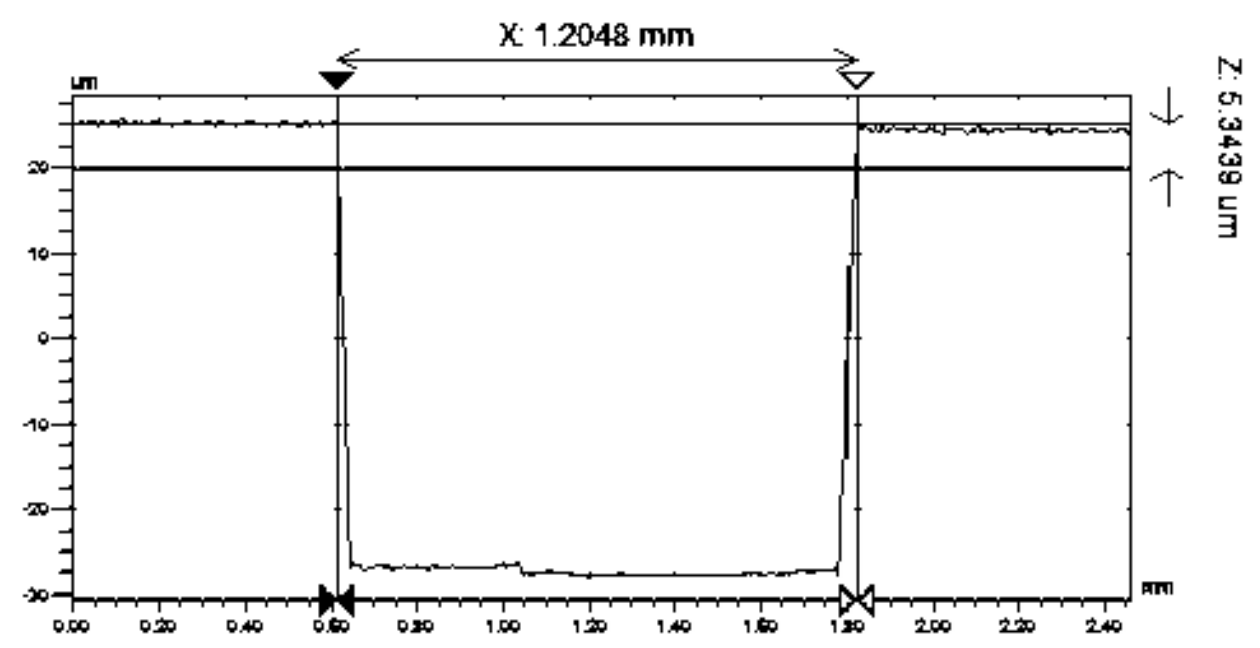

a) 


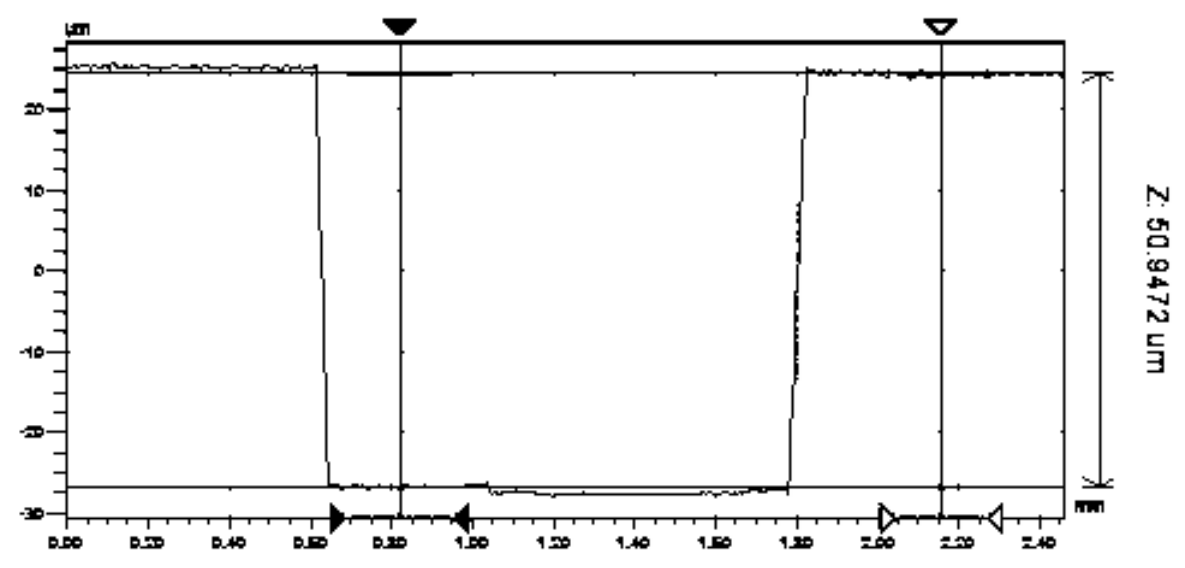

b)

Figura 4.4 - Parâmetros de corte efetivos: a) Penetração de trabalho da condição 1 (C1); b) Profundidade de usinagem das condição 1 (C1: fresamento parcial)

Desta forma, todos os canais das respectivas condições foram medidos, a Tabela 4.1 mostra as medidas efetivas e suas médias. Pode-se observar na Tabela 4.1 que a precisão de posicionamento da máquina CNC nas direções x e z (deslocamentos na direção de penetração de trabalho e profundidade de usinagem respectivamente) variou entre 7 e $25 \mu \mathrm{m}$. As medidas efetivas da Tabela 4.1 serão usadas nos cálculos da energia e potência despendidas no microfresamento, como em qualquer outro cálculo ou análise que as envolvam.

Tabela 4.1. Perfilometria óptica das medidas efetivas das condições de fresamento.

\begin{tabular}{|c|c|c|c|c|c|c|c|c|}
\hline & \multicolumn{4}{|c|}{ Ensaio 1} & \multicolumn{4}{|c|}{ Ensaio 2 (réplica) } \\
\hline & C1 & C2 & C3 & C4 & C1 & $\mathrm{C2}$ & C3 & C4 \\
\hline \multicolumn{9}{|c|}{ penetração de trabalho ae [ um ] } \\
\hline $\mathrm{AA}^{\prime}$ & 395 & 190 & 398 & 181 & 378 & 174 & 385 & 200 \\
\hline $\mathrm{BB}^{\prime}$ & 361 & 190 & 385 & 201 & 385 & 191 & 408 & 191 \\
\hline $\mathrm{CC}^{\prime}$ & 368 & 190 & 395 & 181 & 375 & 174 & 391 & 197 \\
\hline Média & 375 & 190 & 393 & 187 & 379 & 179 & 395 & 196 \\
\hline Setup* & 400 & 200 & 400 & 200 & 400 & 200 & 400 & 200 \\
\hline Erro $^{* *}$ & $6 \%$ & $5 \%$ & $2 \%$ & $6 \%$ & $5 \%$ & $10 \%$ & $1 \%$ & $2 \%$ \\
\hline \multicolumn{9}{|c|}{ Profundidade de usinagem ap [ um ] } \\
\hline $\mathrm{AA}^{\prime}$ & 51 & 44 & 40 & 44 & 41 & 42 & 43 & 40 \\
\hline $\mathrm{BB}^{\prime}$ & 58 & 51 & 44 & 51 & 48 & 46 & 46 & 44 \\
\hline $\mathrm{CC}^{\prime}$ & 67 & 60 & 54 & 61 & 57 & 57 & 58 & 53 \\
\hline Média & 59 & 52 & 46 & 52 & 49 & 48 & 49 & 46 \\
\hline Setup* & 50 & 50 & 50 & 50 & 50 & 50 & 50 & 50 \\
\hline Erro $^{* *}$ & $18 \%$ & $4 \%$ & $8 \%$ & $4 \%$ & $2 \%$ & $4 \%$ & $2 \%$ & $8 \%$ \\
\hline alor do pa & ajus & na $m$ & & & erro d & ido e & lação & o setu \\
\hline
\end{tabular}




\subsection{AMOSTRAS DA AQUISIÇÃO DO SINAL}

A Tabela 4.2 fornece a aquisição do sinal conforme os parâmetros de usinagem adotados. Pode-se observar diferenças entre os números de amostra total do sinal para cada condição específica. Este fato se deve aos dois avanços por dente adotados. Para as condições C1 e C2 o avanço por dente da fresa estipulado foi de 5 $\mu$ m; para as condições C3 e C4 o avanço por dente foi de $10 \mu \mathrm{m}$. Para velocidades de avanço maiores, a taxa de aquisição será coletada em um tempo menor e consequentemente um menor número de amostras serão registradas.

Tabela 4.2 - Amostras da aquisição do sinal na região de usinagem.

\begin{tabular}{ccccc}
\hline \multicolumn{5}{c}{ Microfresamento } \\
\hline Condições & $\begin{array}{c}\text { Amostras } \\
\text { total do sinal }\end{array}$ & $\begin{array}{c}\text { número de picos } \\
\text { (períodos) }\end{array}$ & $\begin{array}{c}\text { amostras por volta } \\
\text { (2 períodos) }\end{array}$ & $\begin{array}{c}\text { amostras por comprimento } \\
\text { de contato }(\boldsymbol{\Psi})^{*}\end{array}$ \\
\hline C1 & 910812 & 4647 & 392 & 97 \\
C2 & 896058 & 4458 & 402 & 64 \\
C3 & 441980 & 2255 & 392 & 97 \\
C4 & 438648 & 2238 & 392 & 64 \\
${ }^{*}$ Amostras por comprimento de contato $(\psi)$ equivale ao número de amostras por cavaco. \\
\hline
\end{tabular}

As diferenças entre as amostras na formação do cavaco de cada condição se deve ao comprimento de contato da ferramenta com a peça na região de usinagem (região de formação do cavaco, determinada pelo ângulo de contato $\psi$ ), o qual está diretamente ligado à penetração de trabalho $\mathrm{a}_{\mathrm{e}}$. Para as condições C2 e C4, a penetração de trabalho foi um quarto do diâmetro da fresa $\left(\mathrm{a}_{\mathrm{e}}=0,2 \mathrm{~mm}\right)$ e, portanto, o comprimento de contato foi de 0,42 $\mathrm{mm}$. Para as condições C1 e C3 a penetração de trabalho foi metade do diâmetro da fresa $\left(a_{e}=0,4 \mathrm{~mm}\right), \log o$ o comprimento de contato foi de $0,63 \mathrm{~mm}$.

A fresa usada nos experimentos possui dois dentes. Assim, o número de amostras por volta é correspondente a dois períodos, pois o primeiro período está entre a espessura máxima do primeiro dente e a espessura máxima do segundo dente, e o segundo período está entre a espessura máxima do segundo dente e a espessura máxima do primeiro dente novamente completando uma volta.

A transformada discreta de Fourier do sinal da força dos experimentos realizados, comportou-se conforme mostra a Figura 4.5, em que é possível observar que usando um filtro no amplificador para coletar frequências abaixo de $1000 \mathrm{~Hz}$, o sinal não foi atenuado em comparação com o sinal sem o filtro (Figura 3.7). 


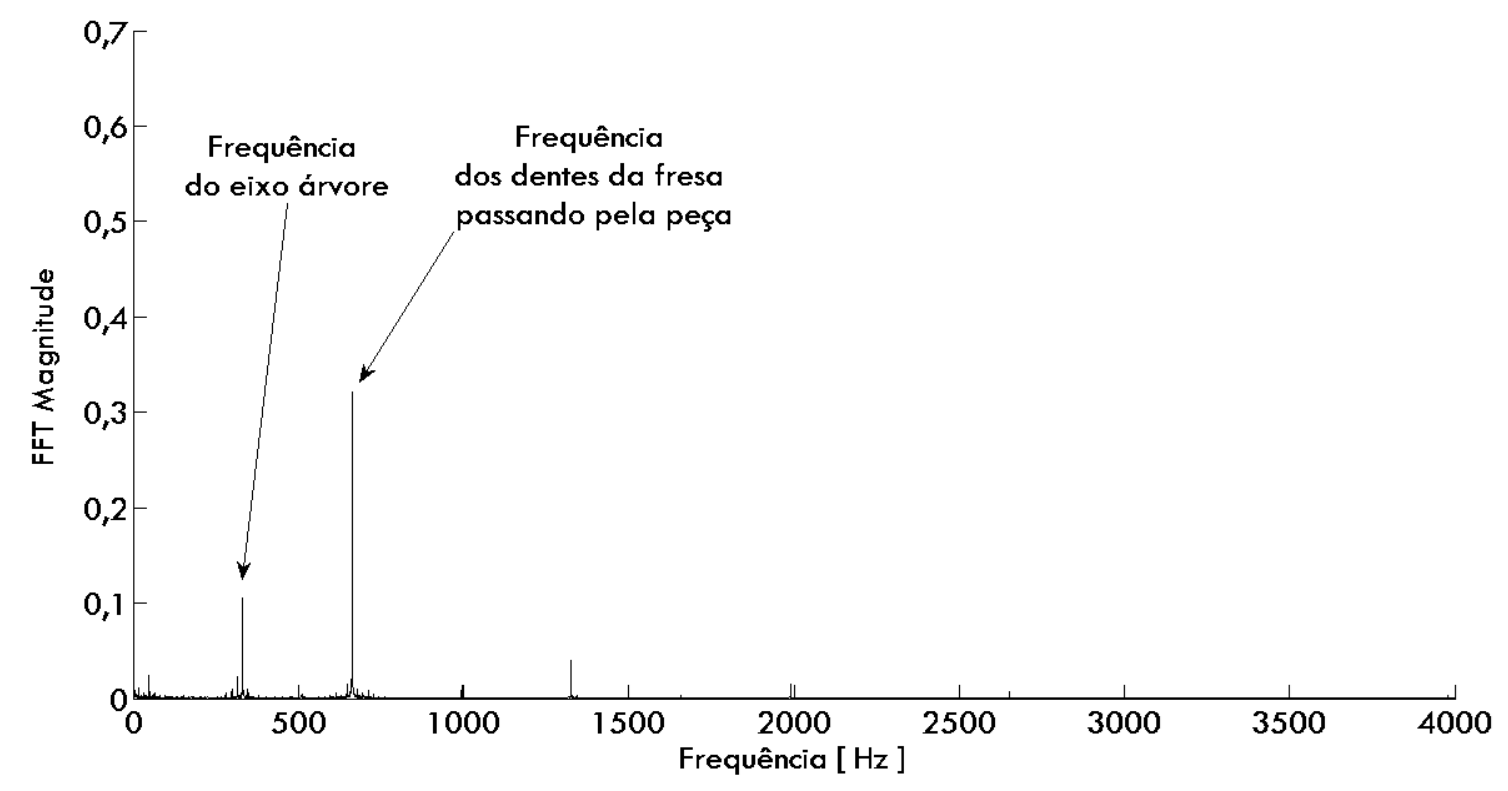

Figura 4.5 - Transformada discreta de Fourier do sinal da força das condições de microfresamento.

\subsection{SINAL MÉDIO DAS COMPONENTES DA FORÇA DE USINAGEM}

Conforme Filiz et. al. (2007), as forças de usinagem contêm informações importantes do mecanismo e dinâmica dos processos de usinagem. A qualidade das superfícies usinadas é determinada conforme as características estáticas e dinâmicas das forças de usinagem. Além disso, as forças de usinagem são um ponto importante para se determinar as ferramentas de corte, assim como para determinar a potência consumida e a produtividade do processo.

Em microusinagem, a amplitude das forças pode ser afetada por qualquer variação externa. Portanto, a análise deve ser minuciosa desde a realização dos experimentos até as determinações matemáticas do sinal.

As forças encontradas durante o microfresamento se comportam conforme é mostrado pela Figura 4.6. O número de pontos amostrados deste sinal varia de 0, com incremento de 1, até aproximadamente 500.000 pontos. Tomou-se um intervalo visível entre as amostras, de 100.000 até 103.500 pontos amostrados. Pode-se observar neste intervalo que o número de períodos é 18 (do $\mathrm{P}_{\mathrm{i}}$ até $\mathrm{P}_{\mathrm{i}+17}$ ), conforme mostra a Figura 4.6-a. As forças $\mathrm{F}_{\mathrm{f}}$ e $\mathrm{F}_{\mathrm{p}}$ mostram que os períodos estão sendo formados de forma assimétrica, pois o sinal de um período comparado com outro subsequente (um dente depois o outro) mostra uma diferença de amplitude das forças (Figura 4.6-b e c). Este fato pode ser correlacionado ao efeito do ruído no sinal da força, que 
será visto mais adiante. Conforme a Figura 4.6-d, pode-se ver que os períodos são determinados de acordo com as espessuras de corte máximas, $\mathrm{h}_{\text {máx}}$.
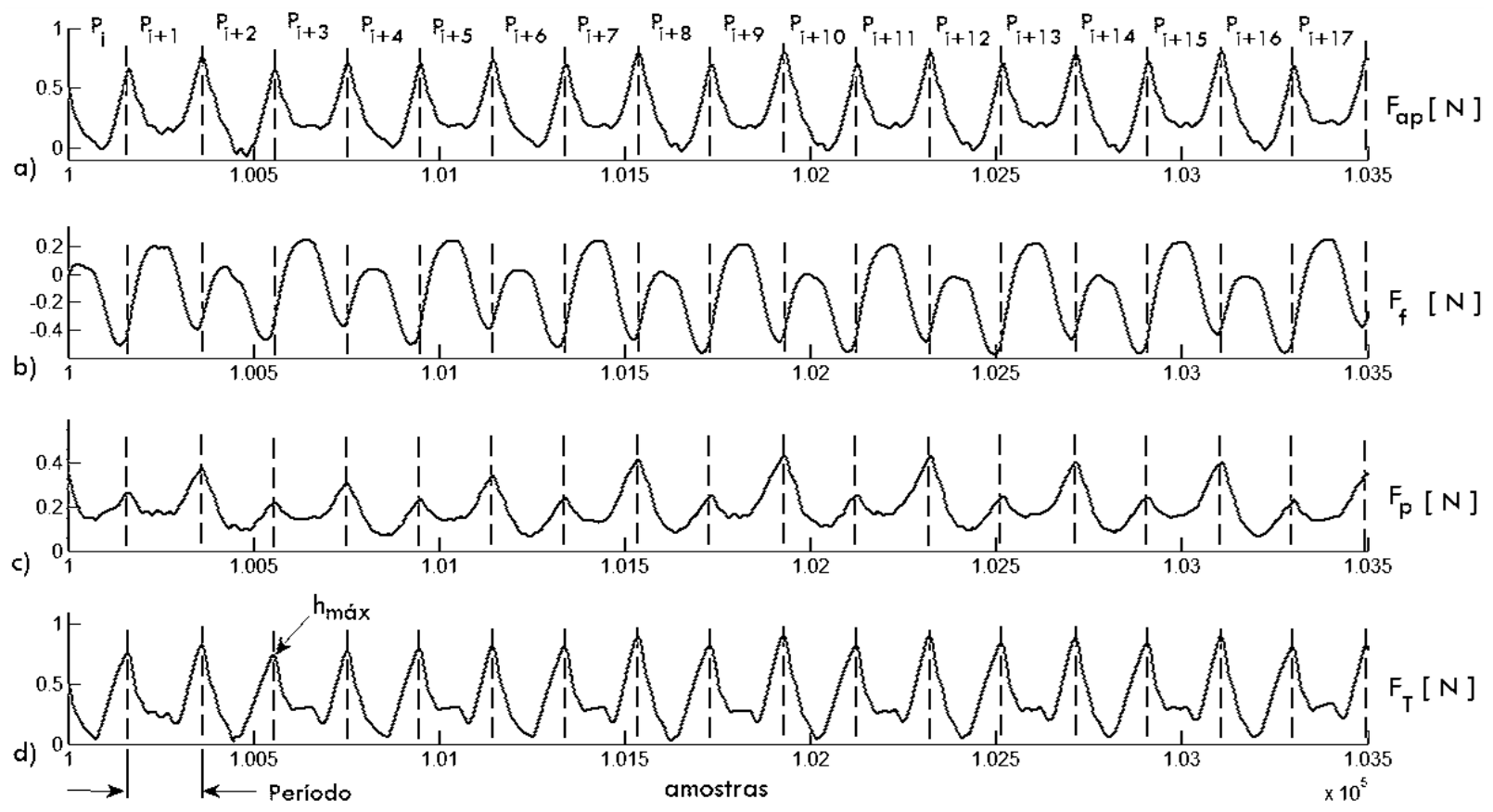

Figura 4.6 - Forças sem tratamento em microfresamento, $V_{c}=50 \mathrm{~m} / \mathrm{min}, \mathrm{f}_{\mathrm{z}}=10 \mu \mathrm{m} /$ dente, $\mathrm{a}_{\mathrm{e}}=0,393$ $\mathrm{mm}, \mathrm{a}_{\mathrm{p}}=46 \mu \mathrm{m}, \mathrm{R}=0,4 \mathrm{~mm}$ e $\psi=90^{\circ}$ : a) força de apoio, $\mathrm{F}_{\mathrm{ap}}$; b) força de avanço, $\mathrm{F}_{\mathrm{f}}$; c) força passiva, $\mathrm{F}_{\mathrm{p}}$; d) força ativa, $\mathrm{F}_{\mathrm{T}}$.

Para determinar o período médio do sinal, todos os períodos foram armazenados em uma matriz, em que as linhas são os números de períodos e as colunas são o números de forças em cada período. Por exemplo, se o número de períodos corresponde a k, em que a variação de k são as linhas da matriz; e se o número de forças de cada período correspondem a j, em que a variação de j são as colunas da matriz, tem-se uma matriz [k X j]:

$$
\mathrm{F}_{\mathrm{k}, \mathrm{j}}=\left[\begin{array}{ccccc}
\mathrm{F}_{1,1} & \mathrm{~F}_{1,2} & \mathrm{~F}_{1,3} & \cdots & \mathrm{F}_{1, \mathrm{j}} \\
\mathrm{F}_{2,1} & \mathrm{~F}_{2,2} & \mathrm{~F}_{2,3} & \cdots & \mathrm{F}_{2, \mathrm{j}} \\
\vdots & \vdots & \vdots & \ddots & \vdots \\
\mathrm{F}_{\mathrm{k}, 1} & \mathrm{~F}_{\mathrm{k}, 2} & \mathrm{~F}_{\mathrm{k}, 3} & \cdots & \mathrm{F}_{\mathrm{k}, \mathrm{j}}
\end{array}\right]
$$

Visualmente tal matriz pode ser demonstrada conforme a Figura 4.7. Nesta figura podese observar todos os períodos do sinal partindo da origem dos eixos x e y. No caso da Figura 4.7 foram apresentados apenas 40 períodos e 200 amostras das forças por período, sendo que de acordo com a Tabela 4.2, os períodos podem chegar a 5.000 e as amostras das forças por 
período a 200. Assim sendo, por meio dos períodos, calcula-se a média destes conforme demonstra a linha média da Figura 4.7.

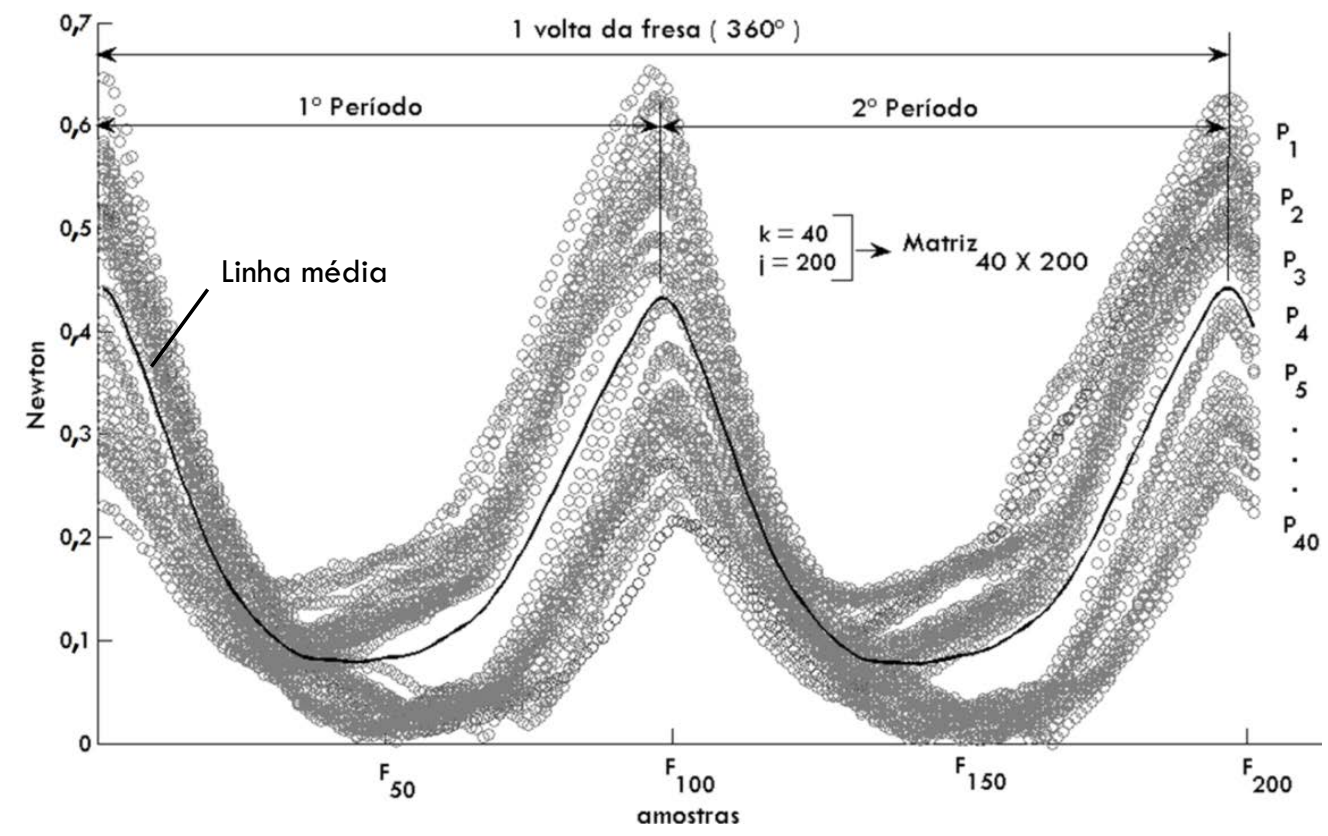

Figura 4.7 - Linha média da Força ativa, $\mathrm{F}_{\mathrm{T}}$, do microfresamento: $\mathrm{V}_{\mathrm{c}}=50 \mathrm{~m} / \mathrm{min}, \mathrm{f}_{\mathrm{z}}=5 \mu \mathrm{m} /$ dente, $\mathrm{a}_{\mathrm{e}}$ $=0,2 \mathrm{~mm}, \mathrm{a}_{\mathrm{p}}=50 \mu \mathrm{m}, \mathrm{R}=0,4 \mathrm{~mm}$ e $\psi=60^{\circ}$.

Com base em um intervalo de confiança de 99\%, que é o intervalo dentro do qual um parâmetro populacional tem maior probabilidade de ser encontrado, a Figura 4.8 apresenta o intervalo da linha média da Figura 4.7. Todas as linhas médias das condições de fresamento se comportaram conforme apresentado pela Figura 4.8.

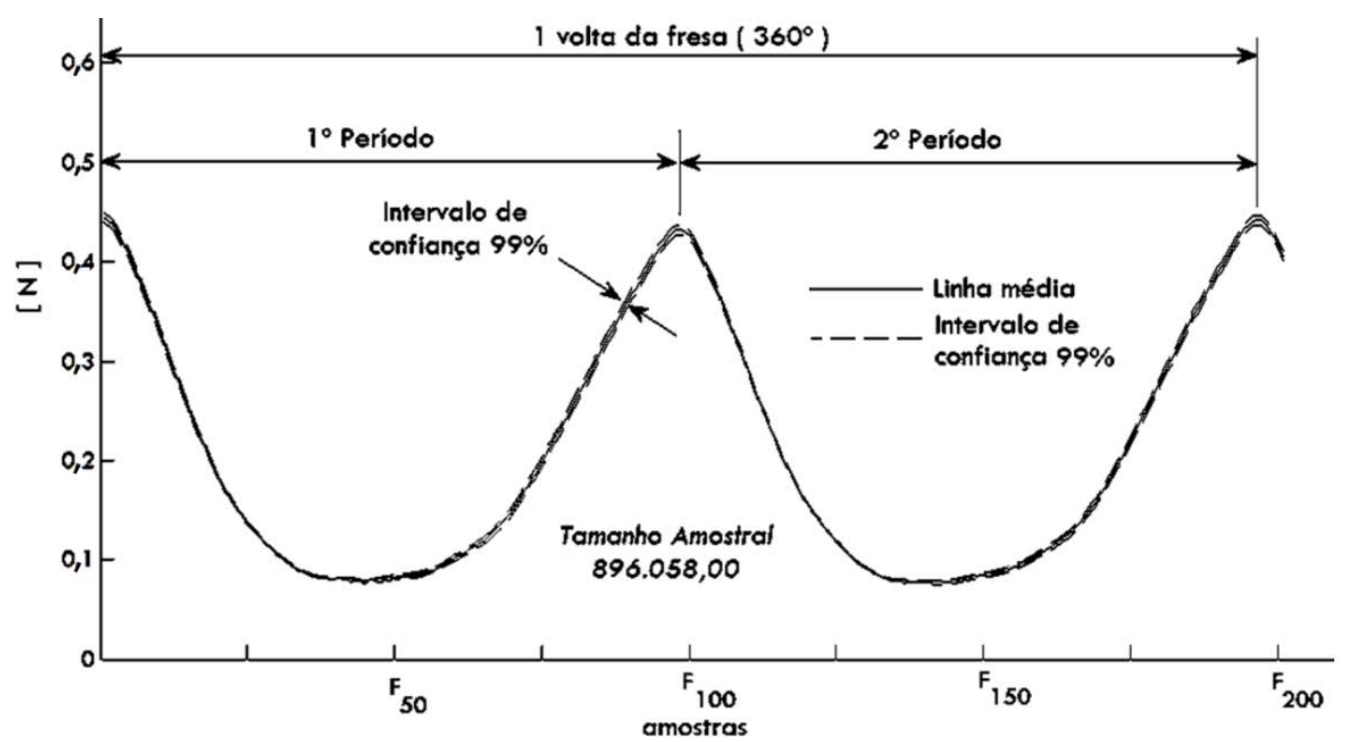

Figura 4.8 - Intervalo de confiança da Força ativa, $F_{T}$, do microfresamento: $V_{c}=50 \mathrm{~m} / \mathrm{min}, \mathrm{f}_{\mathrm{z}}=5$ $\mu \mathrm{m} /$ dente, $\mathrm{a}_{\mathrm{e}}=0,2 \mathrm{~mm}, \mathrm{a}_{\mathrm{p}}=50 \mu \mathrm{m}, \mathrm{R}=0,4 \mathrm{~mm}$ e $\psi=60^{\circ}$. 
Pode-se observar na Figura 4.8 que a linha média da força ativa não toca o eixo x. Este fato pode ser explicado observando-se a linha média do ruído desta mesma força em análise. Existem três regiões durante a realização dos experimentos: região de aproximação, de usinagem e de afastamento (vide Figura 3.9, na página 66). Com base na região de aproximação, pode-se notar o ruído do sinal. Descobrindo-se o período deste ruído, é possível determinar a linha média do ruído, conforme é apresentado pela Figura 4.9. Nesta figura pode-se observar que o ponto máximo do ruído é de 0,2 N. Na Figura 4.8 o deslocamento vertical da força ativa $\mathrm{F}_{\mathrm{T}}$ é aproximadamente $0,1 \mathrm{~N}$. O motivo pelo qual a força ativa não se deslocou 0,2 N pode ser explicado pelo comprimento de onda do ruído e da força ativa. Conforme a Tabela 4.2 o comprimento máximo de uma onda (um período) é de 200 amostras, por outro lado o comprimento de onda do ruído, como pode ser observado na Figura 4.9, é de 400 amostras. Assim sendo, a sobreposição do ruído na força ativa pode não ser no pico da variação do ruído, mas possivelmente no meio deste, ou um quarto, entre outros. Portanto, o deslocamento da linha média da força ativa irá depender do instante desta sobreposição que está diretamente ligada ao exato momento que o primeiro dente da fresa entra em contato com a peça e o instante da variação do ruído.

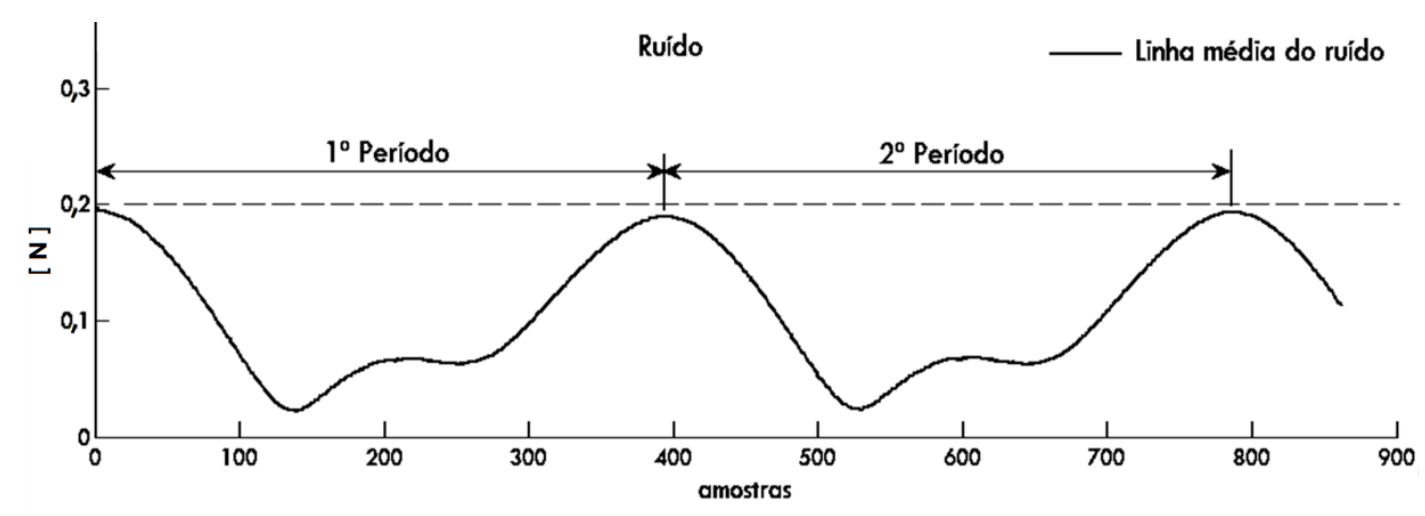

Figura 4.9 - Ruído do sinal da força ativa, $\mathrm{F}_{\mathrm{T}}$, da Figura 4.9.

A Figura 4.10 fornece uma simulação do efeito do ruído no sinal da força ativa. A linha vertical tracejada da Figura 4.10-a mostra uma interferência do pico do ruído com o vale do sinal da força ativa. O resultado desta interferência é mostrado pela linha contínua da Figura 4.10-b. Uma simulação da sequência de períodos do sinal da força ativa com interferência do ruído pode ser visto pela Figura 4.10-c. A Figura 4.10-d mostra um dos sinais coletados das condições de usinagem, em que é possível correlacionar o perfil deste sinal real com o simulado, mostrando que a hipótese assumida para explicação do efeito do ruído (assimetria do sinal) pode ser verdadeira. 


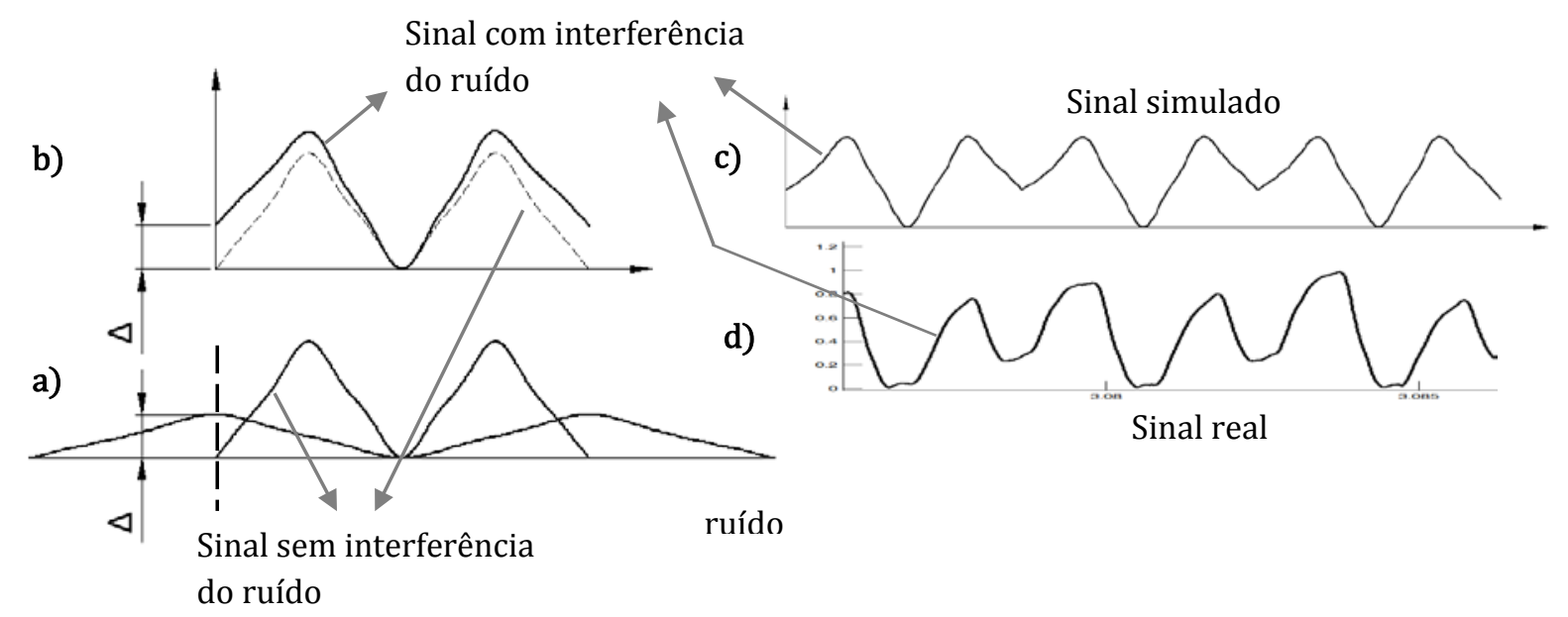

Figura 4.10 - Efeito do ruído: pico do ruído com o vale do sinal da força ativa

Outra possível combinação da sobreposição do ruído com o sinal da força ativa, assim como várias outras, pode ser mostrada pela Figura 4.11. Neste caso há uma interferência do pico do ruído com o pico do sinal da força ativa.

b)

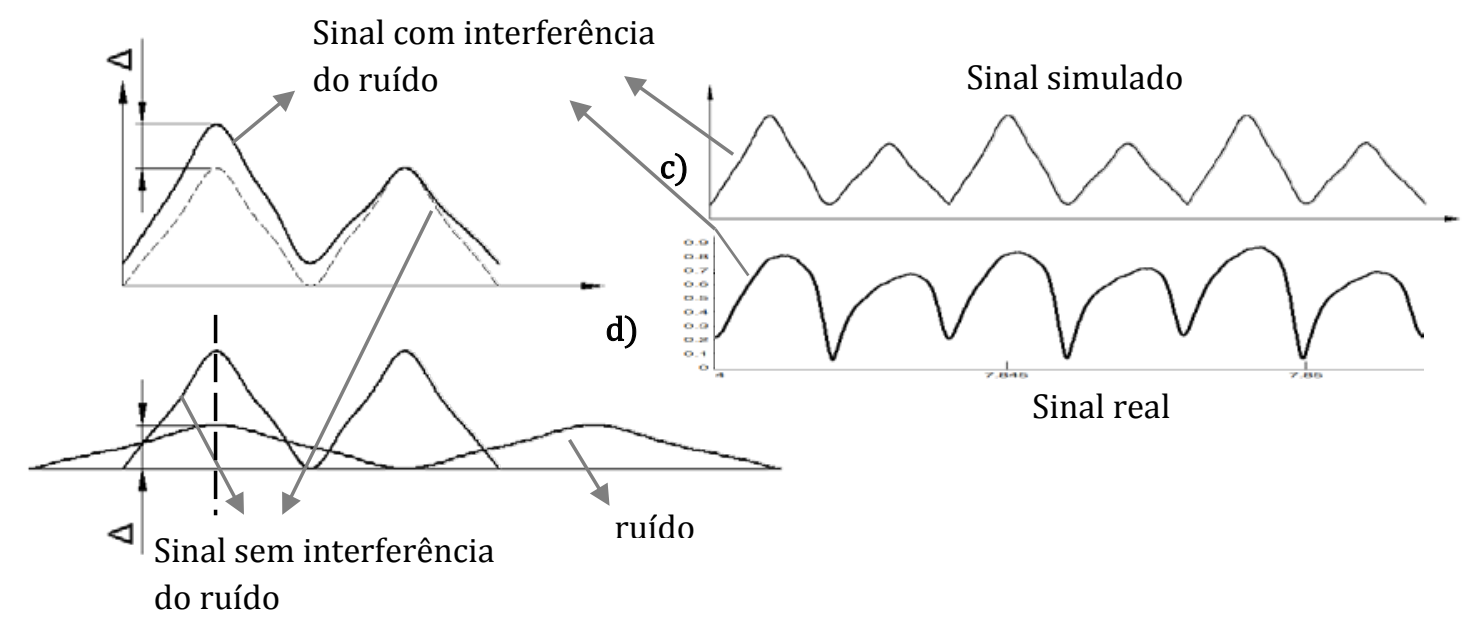

Figura 4.11 - Efeito do ruído: pico do ruído com o pico do sinal da força ativa

Com isso, assumindo-se que o deslocamento da linha média da força ativa é decorrente do ruído presente no sinal, basta deslocar a linha média da força ativa até o eixo x para atenuar o efeito do ruído. Uma vez determinado o período médio da força ativa $\mathrm{F}_{\mathrm{T}}$, é possível determinar os períodos médios da força de apoio, $\mathrm{F}_{\mathrm{ap}}$, força de avanço, $\mathrm{F}_{\mathrm{f}}$ e da força passiva, $\mathrm{F}_{\mathrm{p}}$ com base no comprimento amostral do período médio da força ativa. Desta forma, em uma volta completa da fresa na região de usinagem, o comportamento das componentes da força de usinagem são apresentados pela Figura 4.12. 


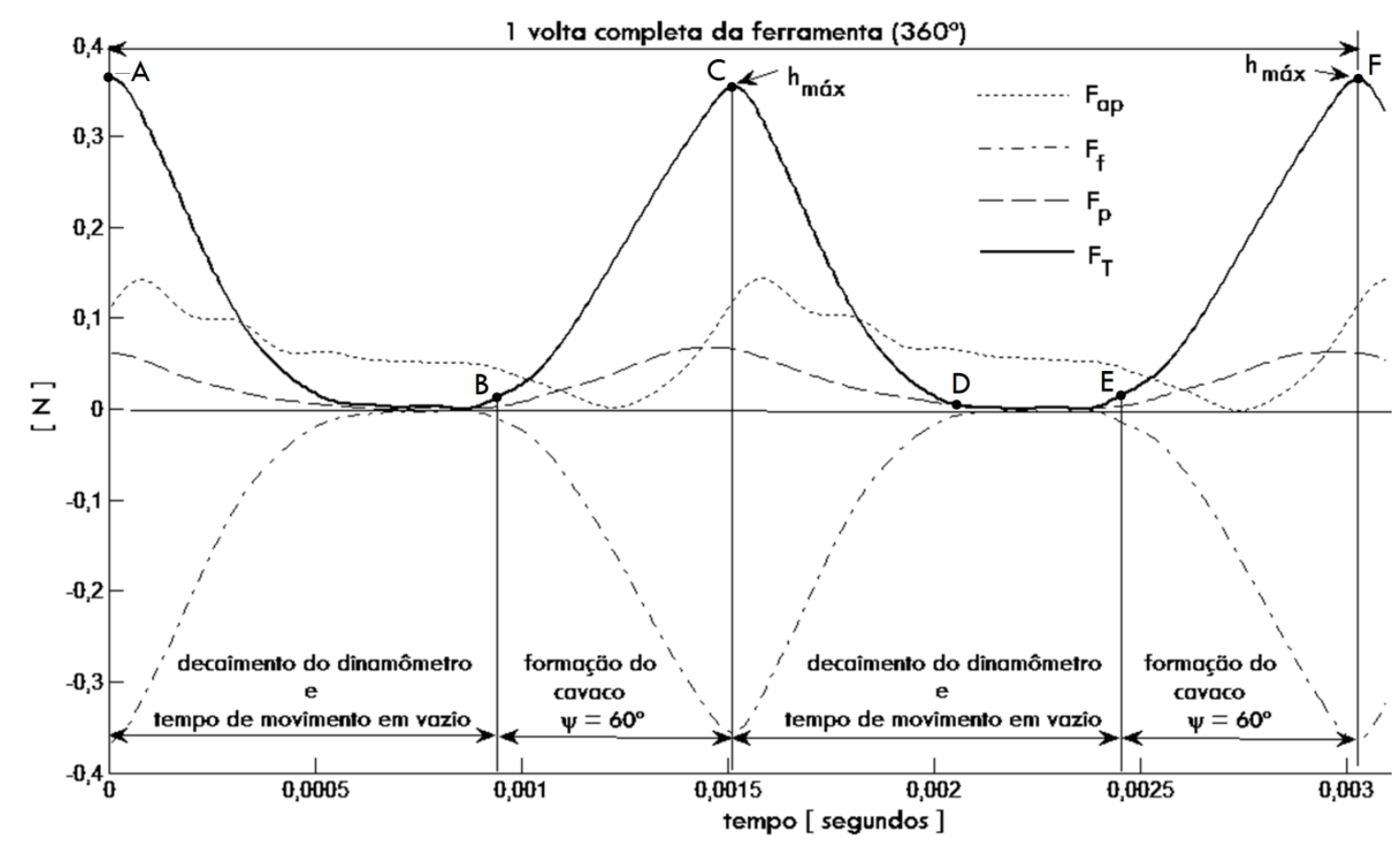

Figura 4.12 - Componentes da força de usinagem em microfresamento frontal parcial: $V_{c}=50 \mathrm{~m} / \mathrm{min}$, $\mathrm{f}_{\mathrm{z}}=5 \mu \mathrm{m} /$ dente, $\mathrm{a}_{\mathrm{e}}=0,2 \mathrm{~mm}, \mathrm{a}_{\mathrm{p}}=50 \mu \mathrm{m}, \mathrm{R}=0,4 \mathrm{~mm}, \psi=60^{\circ}$ e $\mathrm{Z}=2$.

A Figura 4.12 apresenta os resultados das forças de usinagem em um fresamento frontal parcial. Pode-se observar, por meio da figura, que após a espessura máxima, $\mathrm{h}_{\text {máx }}$, (ponto A) - que é o momento em que o primeiro dente da fresa sai da zona de usinagem - transcorre um tempo de decaimento em torno de 0,5 milésimo de segundo para uma recuperação completa de descarregamento do dinamômetro. Após o decaimento, transcorre mais um tempo para o segundo dente entrar na zona de usinagem (ponto B).

O tempo de movimento em vazio da Figura 4.12 compreende o momento do término da usinagem do primeiro dente da fresa (ponto A) até o início da usinagem do próximo dente (ponto B), pois neste espaço de tempo não há remoção de material. Quando o segundo dente entra em contato com a peça (tratando do fresamento discordante), as forças começam a aumentar progressivamente conforme o aumento, também progressivo, da espessura de corte. Desta forma, a distância entre os pontos B e C compreende o tempo durante o qual ocorre a formação de cavaco. Quando o segundo dente da fresa chega à espessura de corte máxima (ponto C), o cavaco é expelido da peça pelo movimento rotativo da ferramenta de corte e, neste exato momento, não há mais remoção de material. Portanto, as forças, novamente, começam a decair até zero (do ponto $\mathrm{C}$ até o ponto D) e inicia-se um novo ciclo de fresamento (compreendido do ponto E ao ponto F) após o tempo de movimento em vazio. 
Para corroborar a ideia do tempo de movimento em vazio, foi feito um ensaio, sem vínculo com o planejamento deste trabalho, apenas para efeito de comparação do tempo de movimento em vazio. Para tal ensaio, foi realizado um fresamento em cheio com uma fresa que possui dois dentes $(Z=2)$, assim sendo, não haverá tempo de movimento em vazio, pois assim que um dente sai da zona de usinagem, outro imediatamente entra $\left(\psi=\psi_{\mathrm{Z}}\right)$. Este fenômeno pode ser visualizado na Figura 4.13. O ponto A desta figura é o instante em que o primeiro dente da fresa entra na zona de usinagem. Por outro lado, o ponto B é o instante que o primeiro dente sai da zona de usinagem e o segundo dente imediatamente entra. Já o ponto C é o instante que o segundo dente da fresa sai da zona de usinagem e a fresa completa um giro em torno do seu próprio eixo. A partir do ponto C, o primeiro dente entra na zona de usinagem novamente e o ciclo continua até o fim da usinagem. Neste tipo de fresamento, como pode ser observado pelo gráfico da Figura 4.13, não há tempo de movimento em vazio, ou seja, o fresamento é engajado.

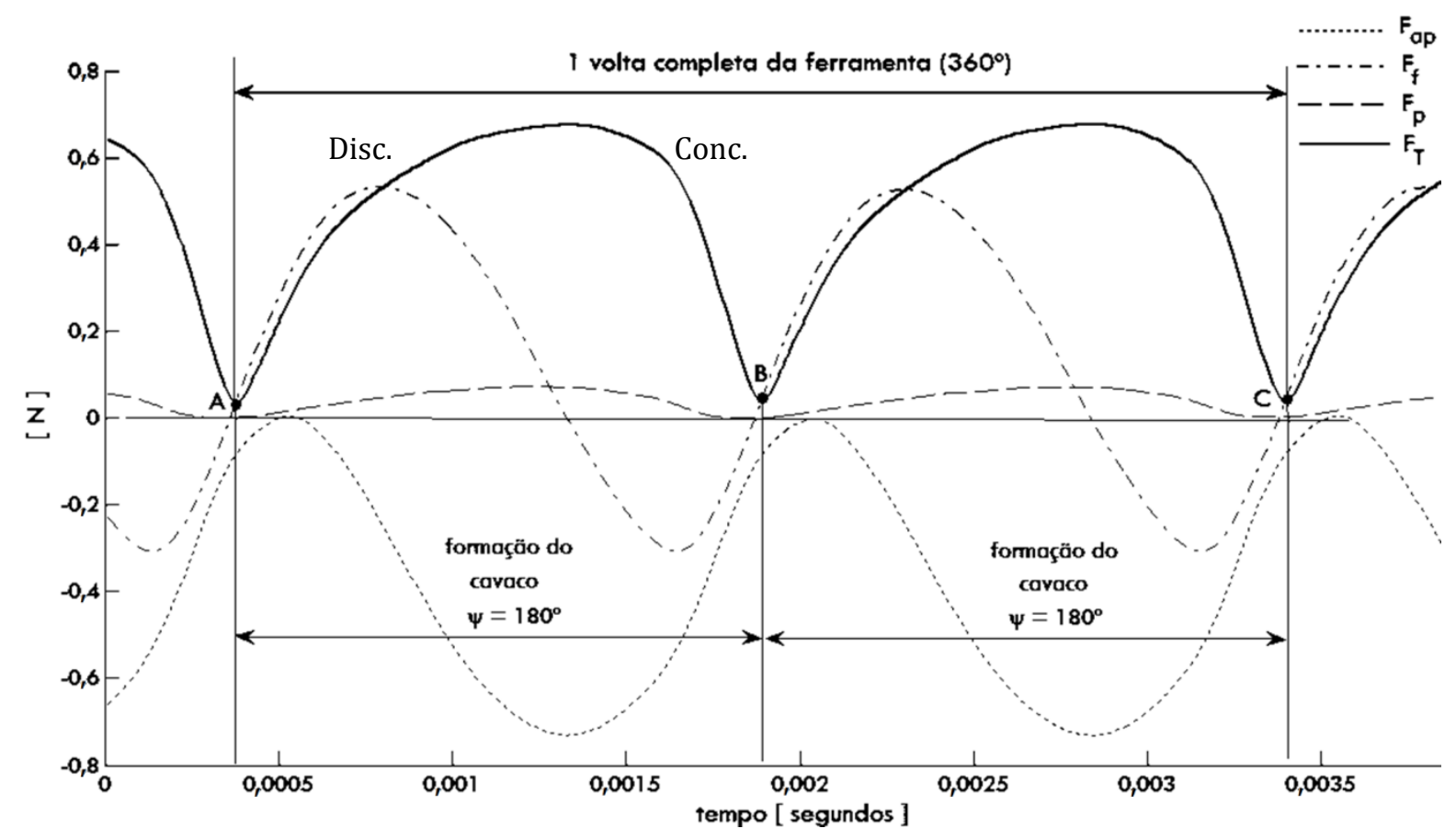

Figura 4.13 - Componentes da força de usinagem em microfresamento, Vc $=50 \mathrm{~m} / \mathrm{min}, \mathrm{fz}=5$ $\mu \mathrm{m} /$ dente, $\mathrm{R}=0,4 \mathrm{~mm}$, ae $=2 . \mathrm{R}$, ap $=50 \mu \mathrm{m}, \psi=180^{\circ}$ e $\mathrm{Z}=2$.

\subsection{FORÇA DE CORTE}

Determinado o período médio das componentes força de apoio e força de avanço com base na força ativa, o número de pontos amostrados na formação do cavaco correspondente ao 
ângulo de contato $\Psi$ (zona de usinagem), foi possível determinar a componente força de corte dentro da zona de usinagem pela soma da decomposição das forças de apoio e avanço. A zona de usinagem é a região em que ocorre a formação de cavaco, a qual é determinada pelo ângulo de contato $\psi$. No fresamento discordante, conforme o aumento progressivo de $\psi$ (a progressão de $\psi$ é representada por $\psi_{\mathrm{i}}$ ) a espessura de corte $\mathrm{h}$ também aumenta de forma progressiva (a progressão de $\mathrm{h}$ é representada por $\mathrm{h}_{\mathrm{i}}$ ). Assim sendo, a variação da espessura de corte está diretamente ligada à variação angular do dente da fresa. Com o aumento da espessura, também há um aumento da força de corte e esta por sua vez será mínima quando a espessura de corte for mínima, e máxima quando a espessura de corte for máxima.

Portanto, para encontrar a força de corte média, basta encontrar no sinal a força de corte correspondente à espessura de corte média. A Figura 4.14 fornece a variação da força de corte em função da espessura de corte e do ângulo de contato. Considerando-se os dados desta figura e calculando-se a média da variação da espessura de corte e da variação da força de corte, separadamente, têm-se $\overline{\mathrm{h}}=2,442 \mu \mathrm{m}$ e $\overline{\mathrm{F}_{\mathrm{c}}}=0,163 \mathrm{~N}$. Conforme a variação da força de corte, a força de corte instântanea correspondente à $h_{i}=\bar{h}=2,442 \mu$ m é $F_{c_{i}}=0,16 \mathrm{~N}$. Portanto, a força de corte instântanea na espessura de corte média corresponde a força de corte média.

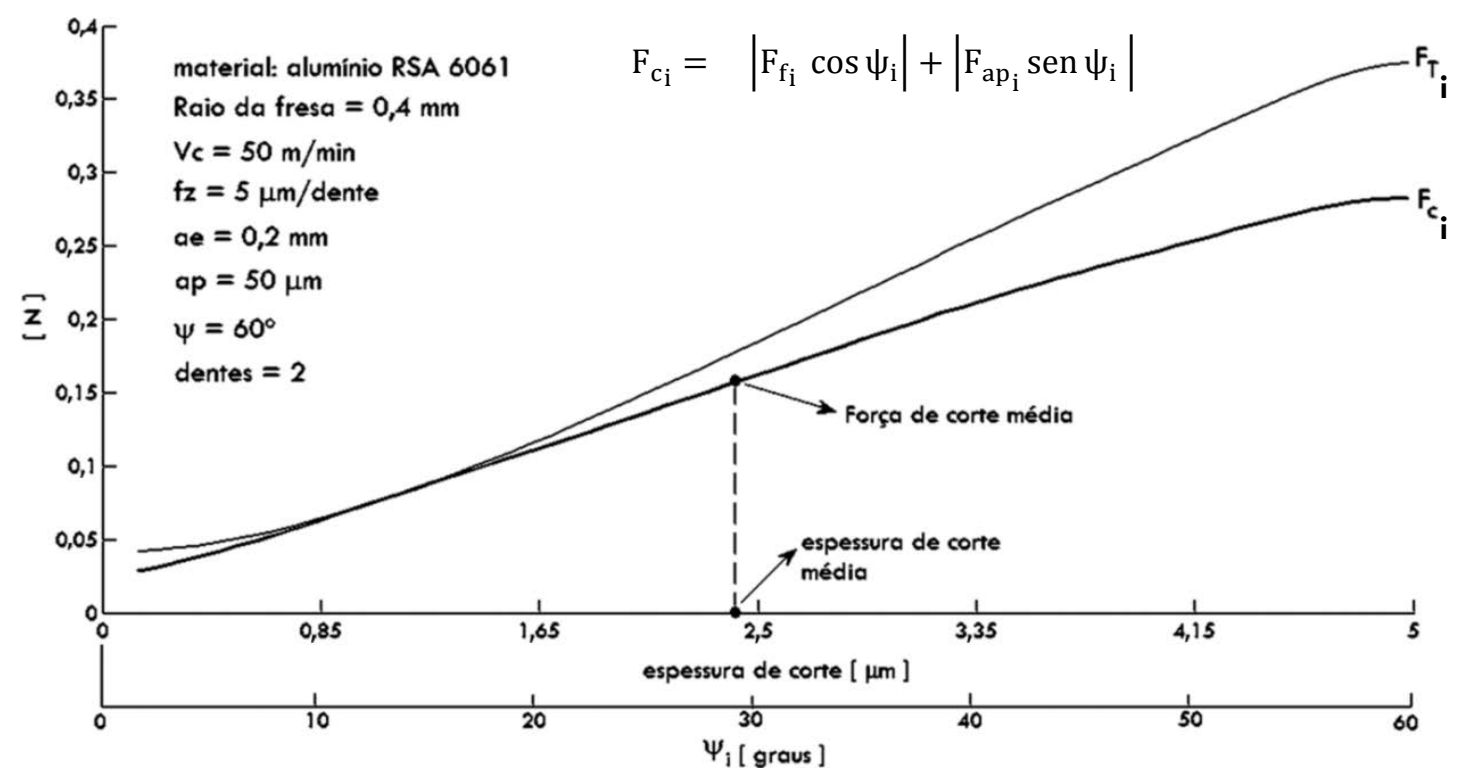

Figura 4.14 - Força de corte em microfresamento frontal parcial.

Por fim, a Figura 4.15 apresenta as forças de corte médias de cada condição de fresamento, obtidas conforme a Equação (3.7), da página 70. Observa-se pelo gráfico da Figura 
4.15 que as forças de corte médias dos ensaios (Ensaio $1^{*}$ ) tiveram valores maiores que os das réplicas (Ensaio $2^{*}$. Existem duas causas para isto: uma delas é que as profundidades médias de usinagem efetivas obtidas no Ensaio 1 foram maiores que as do Ensaio 2 (Tabela 4.1, da página 76). A segunda causa são os raios das arestas das ferramentas de corte usadas. O raio de aresta do dente da fresa usada nos ensaios é de 3,287 $\mu \mathrm{m}$ (medições realizadas em um microscópio confocal OLS4000 - cortesia Arotec S/A). O raio de aresta do dente da fresa usada na réplica é de $2,368 \mu \mathrm{m}$.

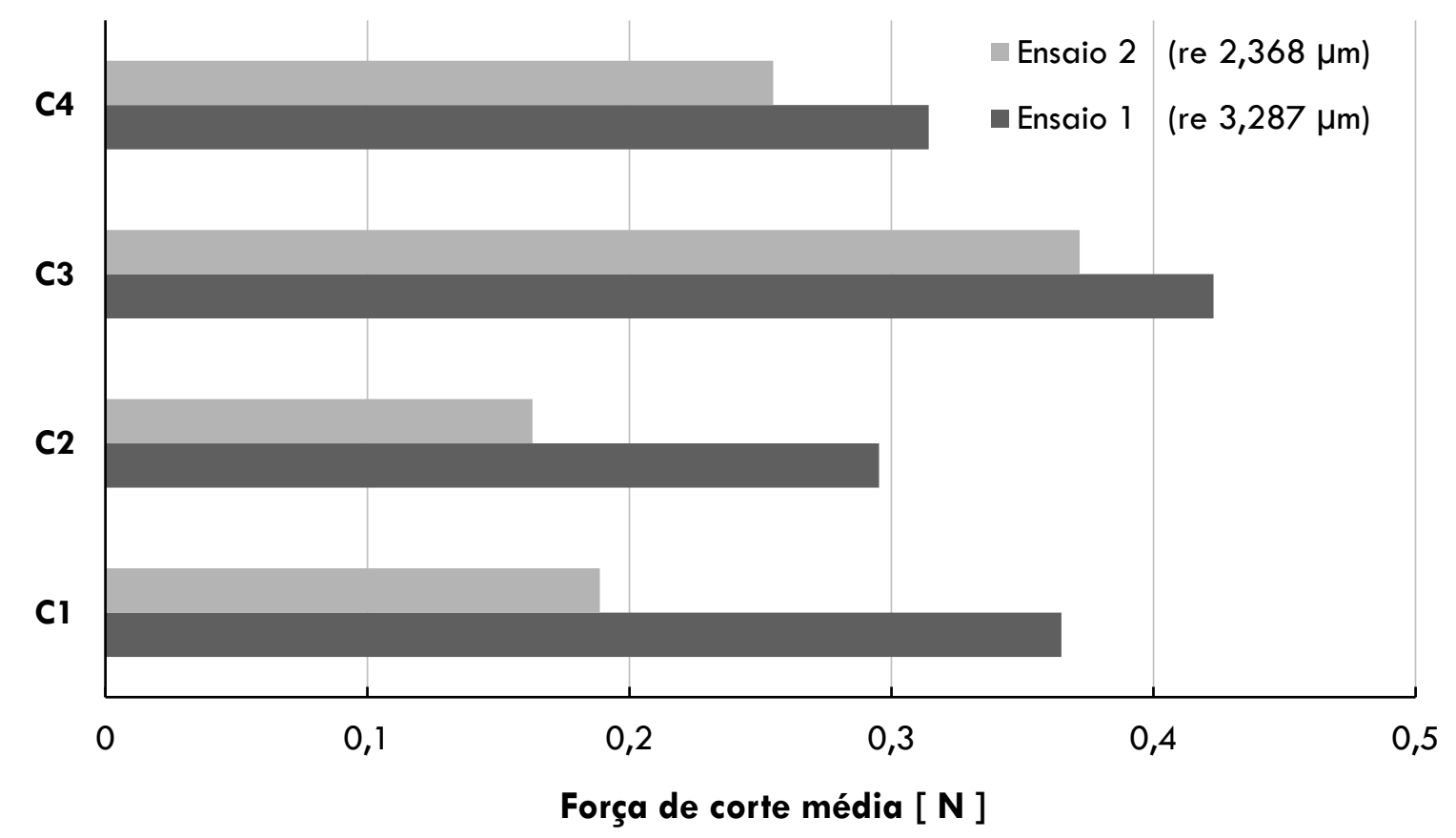

Figura 4.15 - Forças de corte médias das condições de fresamento.

Portanto, sendo o raio de aresta da ferramenta usada nos ensaios (Ensaio 1) maior que o raio de aresta da ferramenta usada nas réplicas (Ensaio 2), as forças de corte médias dos ensaios são maiores que as das réplicas, devido ao maior atrito para o raio de aresta maior (Figura 4.15). A grande discrepância das réplicas em relação aos ensaios nas condições C1 e C2 deve-se ao fato das profundidades médias de usinagem efetivas terem sido em torno de $10 \%$ a $20 \%$ menores que as profundidades das condições C1 e C2 dos ensaios, e também ao fato do raio de aresta da ferramenta usada nas réplicas ser em torno de $28 \%$ menor que a dos ensaios. As condições C3 e C4 apresentam resultados mais próximos devido as mesmas profundidades médias de usinagem efetivas, restando apenas o efeito da diferença entre os raios de arestas.

\footnotetext{
* Ensaio 1: primeiro ensaio realizado.

* Ensaio 2: réplica do primeiro ensaio.
} 


\subsection{A ESPESSURA MÍNIMA DE CORTE}

Quando se trabalha com microusinagem, os avanços $\left(f_{z}\right)$ podem chegar na escala do raio da aresta principal de corte. (YAUN et al., 1996).

Quando a espessura de corte instantânea é menor que a espessura de corte mínima, não há formação de cavaco, pelo fato de a maioria dos materiais se recuperam elasticamente após a ferramenta de corte passar sobre a região de usinagem (FILIZ et. al, 2007).

Portanto, sendo o raio da aresta principal de corte da primeira ferramenta 3,287 $\mu \mathrm{m}$ e o raio da aresta principal de corte da segunda ferramenta 2,368 $\mu \mathrm{m}$, para um avanço por dente de $5 \mu \mathrm{m}$ e de $10 \mu \mathrm{m}$, evidentemente a espessura mínima de corte $\left(\mathrm{h}_{\text {mín }}\right)$ será proeminente neste processo de microfresamento.

Para analisar o fenômeno da espessura mínima de corte, será tomada como base a força ativa, pois, por se tratar de uma força resultante da força de avanço e apoio, esta é mais sensível a qualquer fenômeno durante a usinagem.

O efeito da espessura mínima de corte, no fresamento, pode ser explicado pela Figura 4.16. Primeiramente, considerando-se o início de um corte qualquer, como mostra a Figura 4.16-a, sem nenhum vestígio deixado pelo corte anterior, a variação da força ativa na passada da ferramenta nesta camada (zona de usinagem - $\psi$ ) é descrita, teoricamente, pela Figura 4.16b. Sabendo-se que não haverá remoção de material antes da espessura mínima de corte $\left(\mathrm{h}_{\text {min }}\right)$, apenas deformação elástica, uma pequena camada de material permanecerá na peça como mostra a Figura 4.16-c. Conforme esta figura, pode-se ver que a partir da $h_{\min }$, ocorre o cisalhamento do material e o cavaco é formado.

Quando o próximo dente da fresa entrar na zona de usinagem, este irá se deparar com a pequena camada de material não cisalhada, deixada pelo corte anterior (Figura 4.16-d). Por consequência, haverá uma sobreposição de espessuras até a espessura mínima de corte do corte anterior. Este fato fará com que a força ativa aumente nesta pequena região, como mostra a Figura 4.16-e. A soma da pequena camada deixada pelo corte anterior e a nova camada de material que será removida, proporcionará uma espessura maior que a espessura mínima de corte, assim sendo, uma camada menor ainda será deixada neste corte subsequente, como mostra a Figura 4.16-f. 


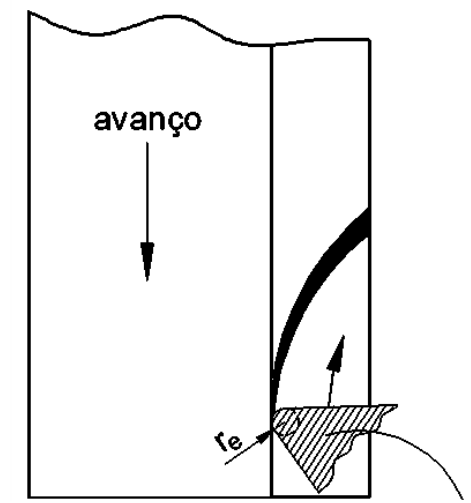

a)

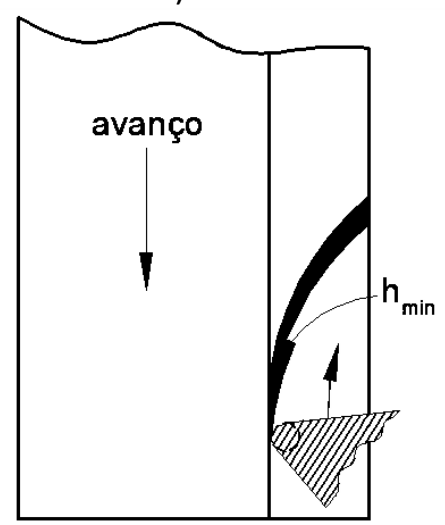

d)

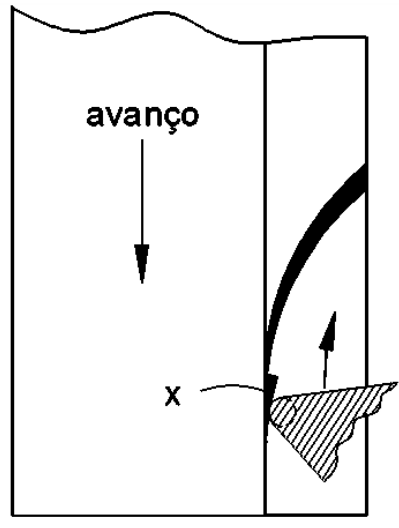

g)

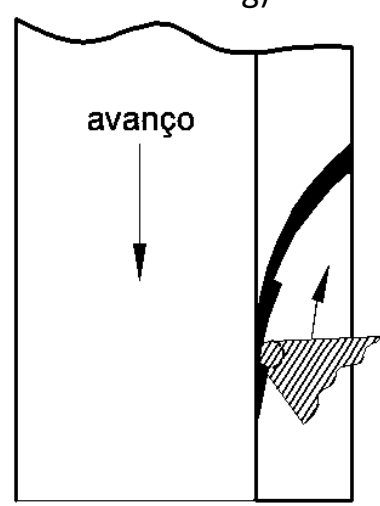

j)

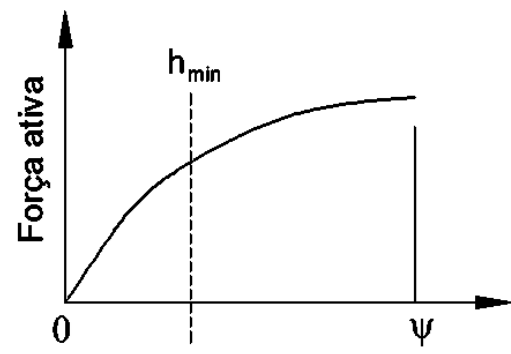

b)

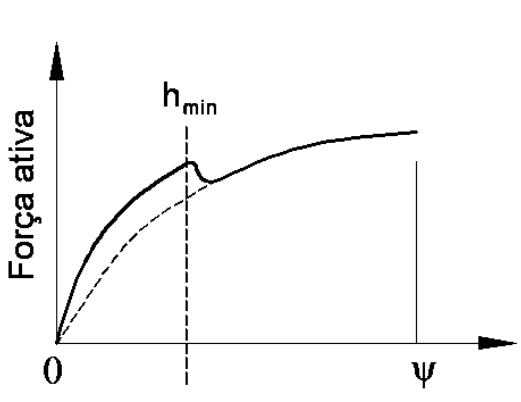

e)

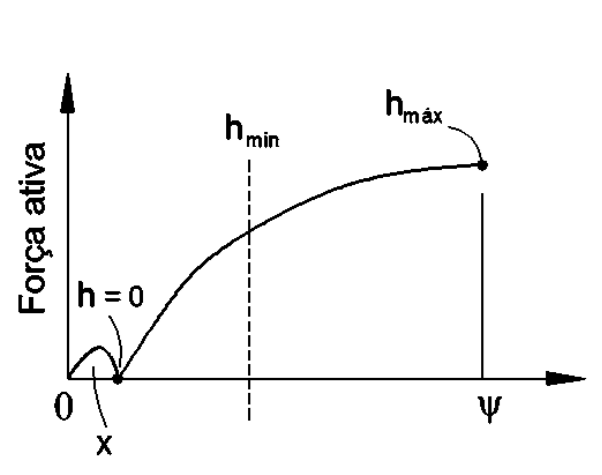

h)

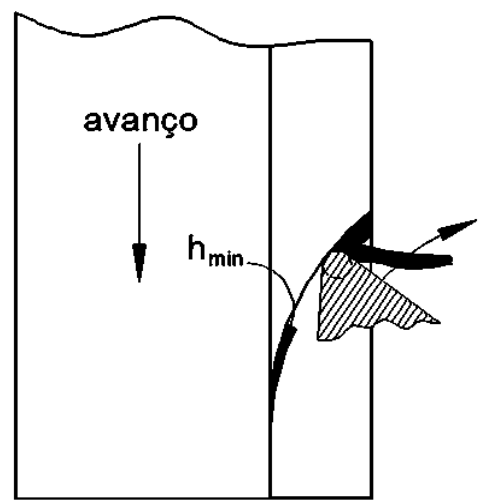

c)

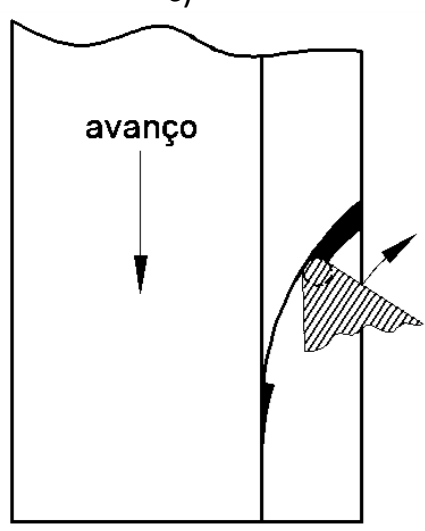

f)

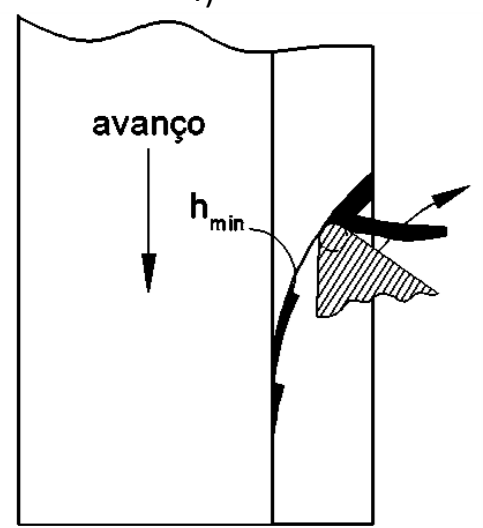

i)

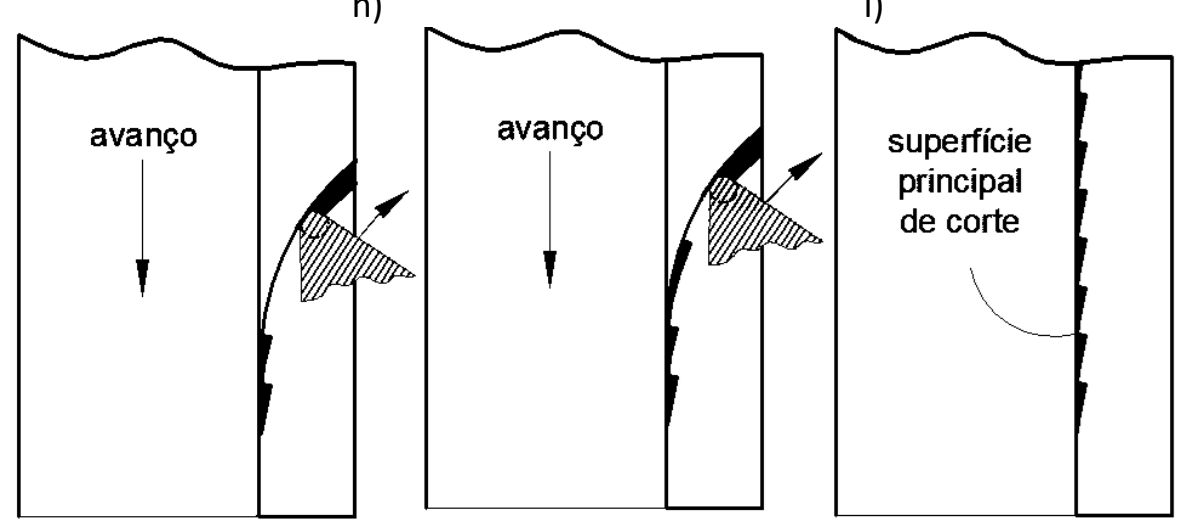

k)

L)

m)

Figura 4.16 - Esquematização da espessura mínima de corte no processo de fresamento. 
Quando o primeiro dente retorna a uma nova zona de usinagem (nova camada de material que será removida), primeiramente este dente passa pela pequena sobra de material deixada pelas sobreposições de camadas (Figura 4.16-g: letra “X”). Nesta região não haverá uma sobreposição de espessuras, porque o início da próxima camada de material a ser removida se encontra no fim desta sobra e, portanto, só haverá deformação elástica. Assim sendo, a ferramenta de corte deformará elasticamente esta pequena camada, pois tal camada de material é menor que a espessura mínima de corte, e, portanto, a força ativa poderá sofrer uma leve variação, como mostra a pequena extensão determinada pela letra “X” da Figura 4.16-h.

Após a ferramenta de corte passar pela pequena sobra de material, a espessura de corte torna a zero e inicia-se uma variação normal da espessura de corte (sem sobreposição de espessuras), como mostra o gráfico da Figura 4.16-h, do ponto em que $\mathrm{h}=0$ até a $\mathrm{h}_{\text {máx }}$. Mais uma vez, enquanto a variação da espessura de corte for menor que a espessura mínima de corte, haverá apenas deformação elástica, e a formação do cavaco somente se iniciará após este ponto, conforme apresenta a Figura 4.16-i.

Assim sendo, o ciclo de fresamento se repete como mostra as Figura 4.16 - j, k e l. Por fim, em microfresamento, é de se esperar uma superfície principal de corte como mostra a Figura 4.16-m. Para visualizar tal superfície, dois canais do corpo de prova (C1 e C4 do Ensaio 1) foram serrados ao meio e a peça foi posicionada no perfilômetro óptico de forma que foi possível obter uma imagem da superfície principal de corte como mostram as Figura 4.17, Figura 4.18, Figura 4.19-a e Figura 4.19-b. Não é possível medir $\mathrm{h}_{\text {mín }}$ por meio destas figuras porque uma série de deformações plásticas ocorrem durante o processo de remoção de material e tais valores podem não corresponder ao momento exato da ruptura da camada de material removida.

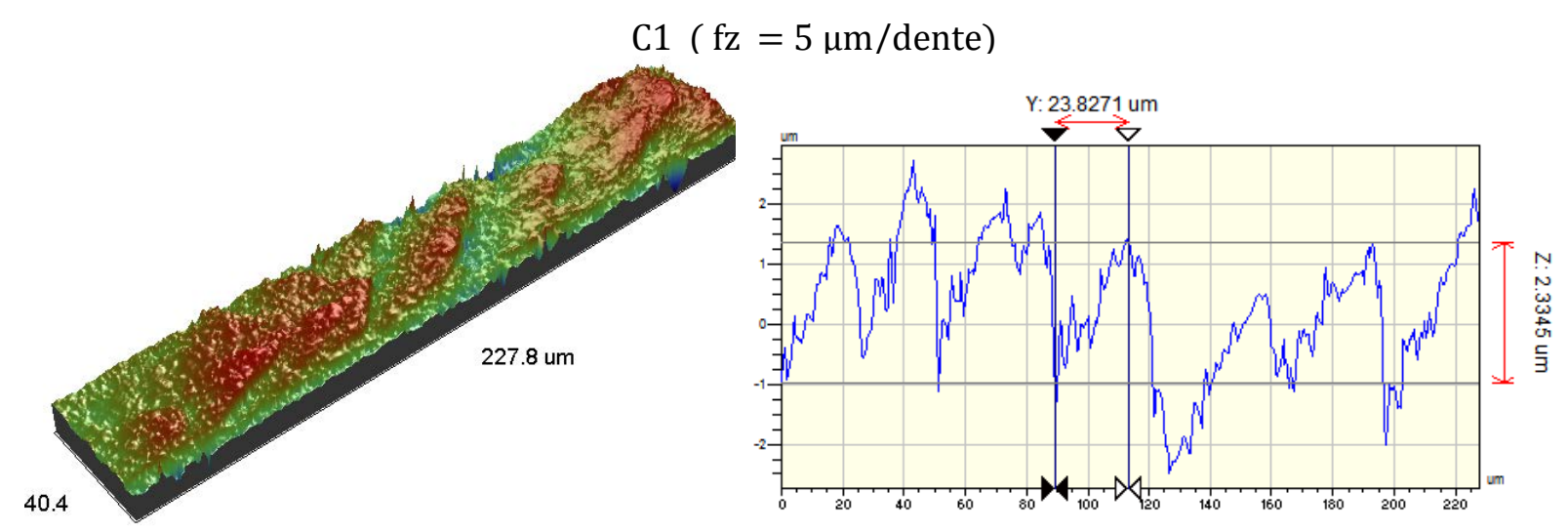

Figura 4.17 - Superfície principal de corte, ampliação 20 vezes. 


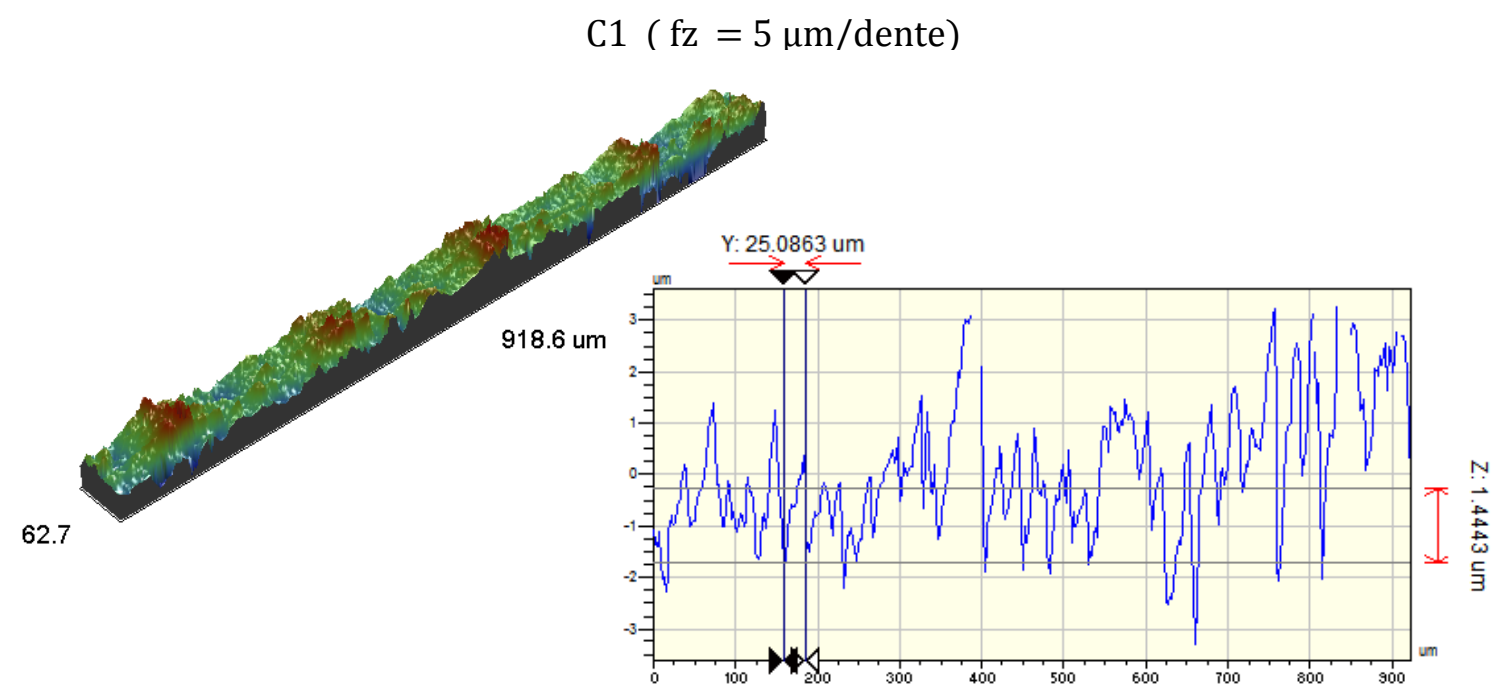

Figura 4.18 - Superfície principal de corte, ampliação 5 vezes

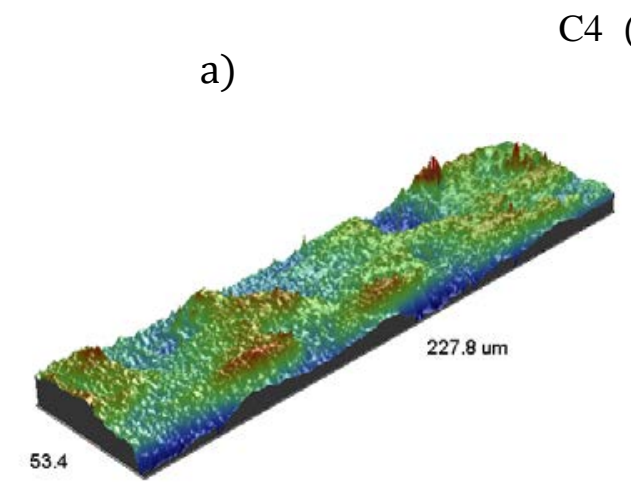

$$
\text { C4 }(\mathrm{fz}=10 \mu \mathrm{m} / \text { dente })
$$

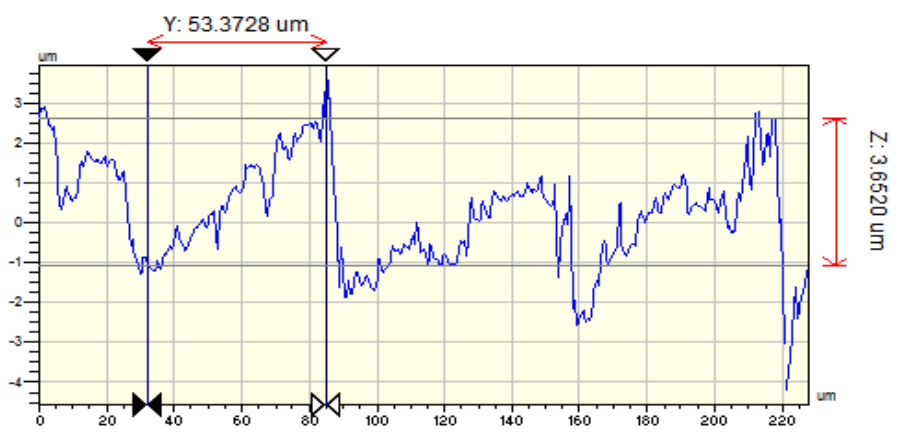

C4 $(\mathrm{fz}=10 \mu \mathrm{m} /$ dente $)$

b)
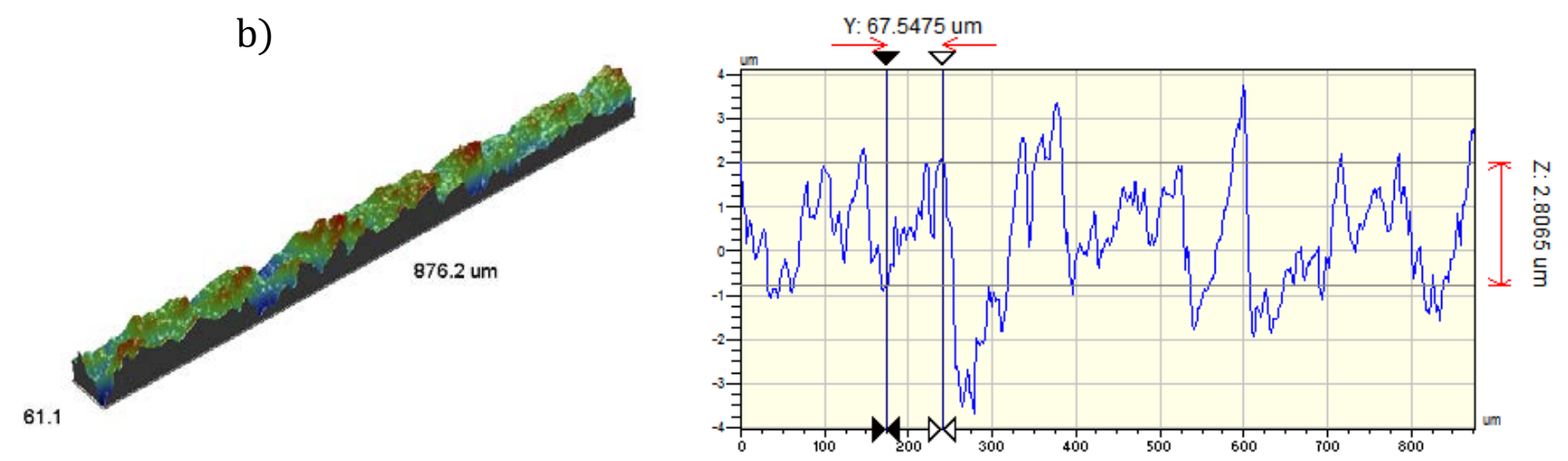

Figura 4.19 - Superfície principal de corte: a) ampliação 20 vezes; b) ampliação 5 vezes.

Constatou-se dois efeitos, no sinal das forças, decorrentes do fenômeno da espessura mínima de corte. Primeiro, a força de corte e a força ativa são semelhantes antes da espessura 
mínima de corte. Este fato é reafirmado por Kim et. al $^{1}$ (2002 apud Filiz et. al, 2007). Também verificou-se que as forças tendem a um mesmo valor na espessura mínima de corte, conforme demonstra a variação das forças da Figura 4.20.

O segundo efeito, que mostra o fenômeno da mínima espessura de corte, foi o valor e o comportamento da força ativa e de corte antes da espessura mínima de corte, em que a variação da espessura de corte, naquela pequena região, demonstra uma sobreposição de espessuras, pois as forças são maiores que as forças estimadas sem sobreposição (esta estimação parte de uma linha spline das linhas $\mathrm{F}_{\mathrm{T}}$ e $\mathrm{F}_{\mathrm{c}}$ depois da $\mathrm{h}_{\text {mín }}$ até o eixo horizontal: linha tracejada da Figura 4.20 na região antes da $h_{\text {mín }}$ ).

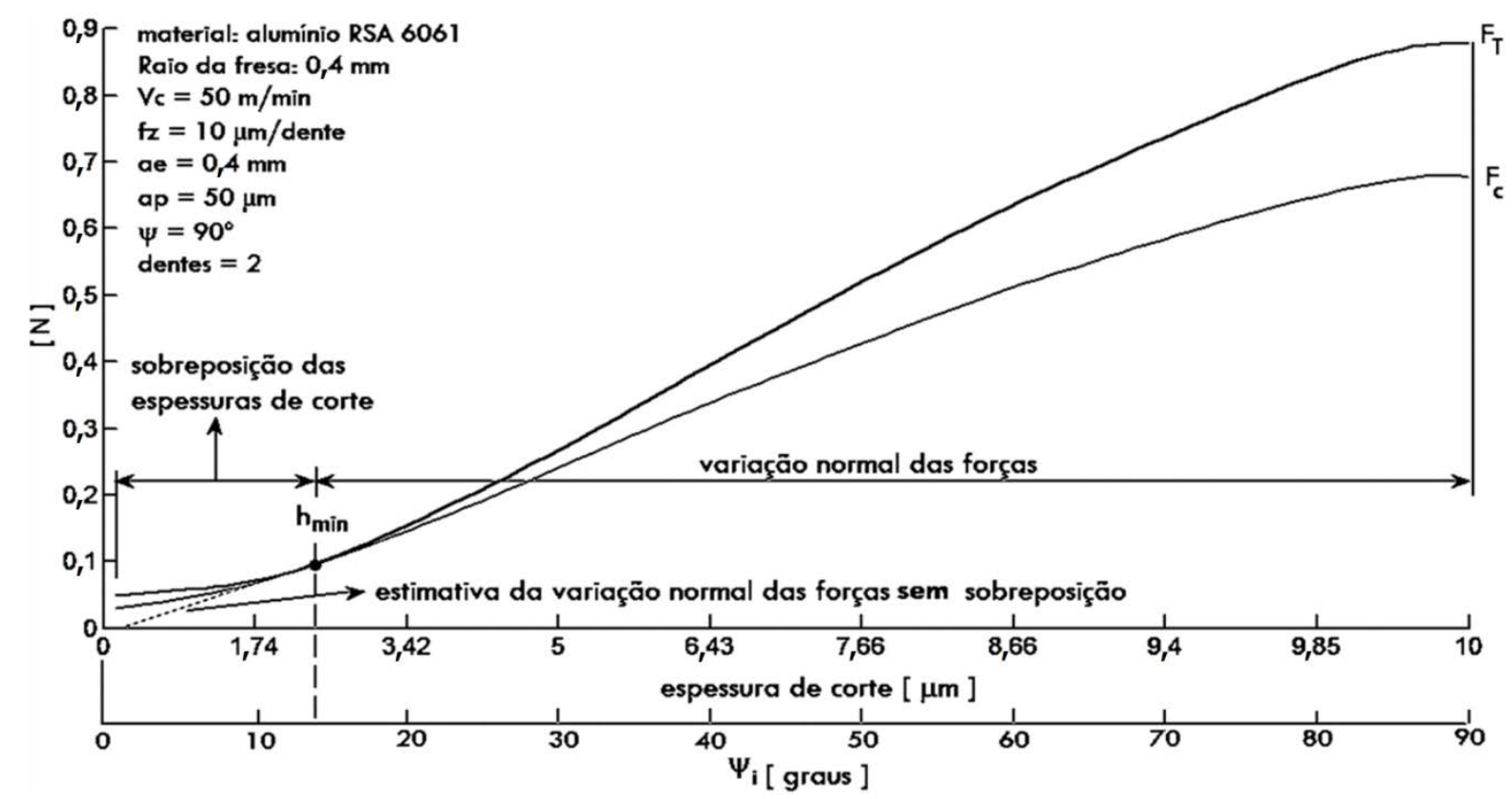

Figura 4.20 - Indício da espessura mínima de corte na força ativa e de corte.

Portanto, conforme a Figura 4.20, considerando que o ponto de encontro das forças corresponde a espessura mínima de corte $\left(h_{\text {mín }}\right)$, percebe-se que o comportamento das forças antes deste ponto é diferente do comportamento das forças depois deste ponto, decorrente do comportamento apenas de deformação antes da $h_{\text {min }}$ e de cisalhamento depois da $h_{\text {min }}$.

Assim sendo, foi possível determinar a espessura mínima de corte de cada condição, consequentemente, o ângulo efetivo de saída $\gamma_{i}$ (Figura 4.21) e também a relação percentual entre a espessura mínima de corte e o raio da aresta principal, conforme apresenta a Tabela 4.3.

\footnotetext{
${ }^{1}$ C.-J. Kim, M. Bono, J. Ni, Experimental analysis of chip formation in micro-milling, Transaction of NAMRI/SME XXX (2002) 247-254.
} 
Tabela 4.3 - Espessuras mínimas de corte.

\begin{tabular}{llcccc}
\hline & & C1 & C2 & C3 & C4 \\
\hline \multirow{2}{*}{ Ensaio 1 } & $\mathrm{h}_{\min }[\mu \mathrm{m}]$ & 1,2 & 1,2 & 2,2 & 2 \\
$\mathrm{r}_{\mathrm{e}}=\mathbf{3 , 2 8 7}$ & $\gamma_{\mathrm{i}}$ & $-64,5^{\circ}$ & $-64,5^{\circ}$ & $-54,6^{\circ}$ & $-56,5^{\circ}$ \\
& $\%$ do $\mathrm{r}_{\mathrm{e}}$ & $37 \%$ & $37 \%$ & $67 \%$ & $61 \%$ \\
\hline \multirow{2}{*}{ Ensaio 2 } & $\mathrm{h}_{\min }$ & 1,1 & 1,1 & 2,2 & 1,9 \\
$\mathrm{r}_{\mathrm{e}}=\mathbf{2 , 3 6 8}$ & $\gamma_{\mathrm{i}}$ & $-66^{\circ}$ & $-66^{\circ}$ & $-54,6^{\circ}$ & $-57,4^{\circ}$ \\
& $\%$ do $\mathrm{r}_{\mathrm{e}}$ & $33 \%$ & $33 \%$ & $67 \%$ & $58 \%$ \\
\hline
\end{tabular}

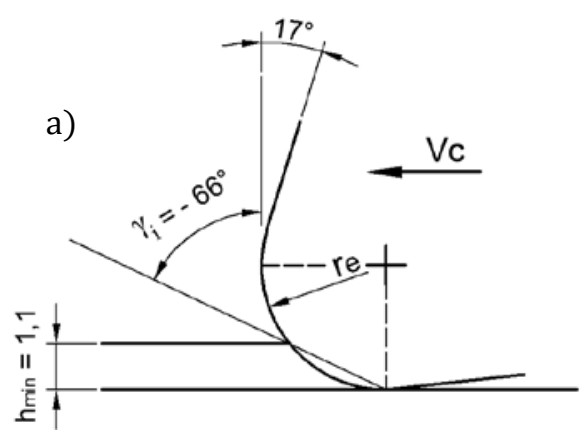

b)

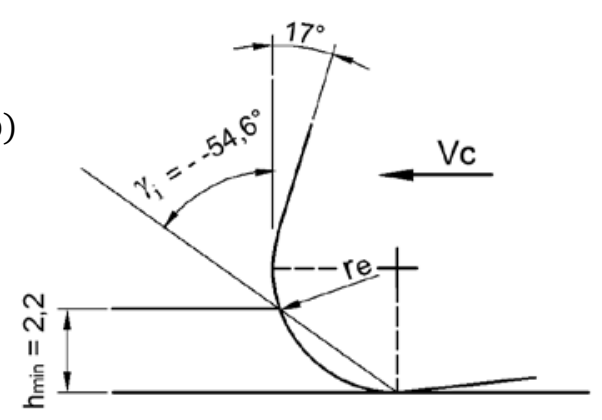

Figura $4.21-\mathrm{h}_{\min }$ e o ângulo efetivo de saída $\gamma_{\mathrm{i}}$ : a) Ensaio 2, C1; b) Ensaio 1, C3.

Segundo Sedriks e Mulhearn (1964) existe um ângulo de saída crítico para que a ferramenta de corte remova material. Se o ângulo de saída da ferramenta for menor que este valor, não haverá formação de cavaco. Estes autores determinaram tal ângulo para alguns materiais, a tabela a seguir fornece uma comparação destes materiais com o material usado neste trabalho.

Tabela 4.4 - Ângulos de saída críticos para alguns materiais (Sedriks e Mulherarn, 1964).

\begin{tabular}{cccc}
\hline & Limite de resistência [ Mpa] & Dureza & $\gamma_{\mathrm{i}}$ \\
\hline Cobre & 196 & $120 \mathrm{HV}$ & $-45 \pm 5$ \\
Latão & 333 & $180 \mathrm{HV}$ & $-55 \pm 5$ \\
RSA 6061 & $\mathbf{3 3 0}$ & $\mathbf{1 1 7} \mathrm{HV}$ & $-\mathbf{6 0} \pm \mathbf{5}$ \\
Nickel & 520 & $350 \mathrm{HV}$ & $-65 \pm 5$ \\
Alumínio & 88 & $35 \mathrm{HV}$ & $-85 \pm 5$ \\
\hline
\end{tabular}

O alumínio de grãos ultrafinos (RSA 6061) se encontra, em termos de dureza e limite de resistência, entre o latão e o alumínio comum, pois não é tão duro quanto o latão nem tão dúctil quanto o alumínio comum. Portanto, conforme apresenta a Tabela 4.4, os valores do ângulo de saída efetivo da mínima espessura de corte do material RSA 6061 variou em torno de $60^{\circ}$, tal valor está entre os valores do latão e alumínio.

Com base nos parâmetros das condições de fresamento e dos resultados da Tabela 4.3, montou-se um gráfico da variação da espessura mínima de corte em relação à penetração de trabalho $a_{e}$, avanço por dente $f_{z}$ e o raio da aresta principal $r_{e}$, conforme apresenta a Figura 
4.22. Com base nesta análise estatística, observa-se que a espessura mínima de corte aumentou com o avanço:

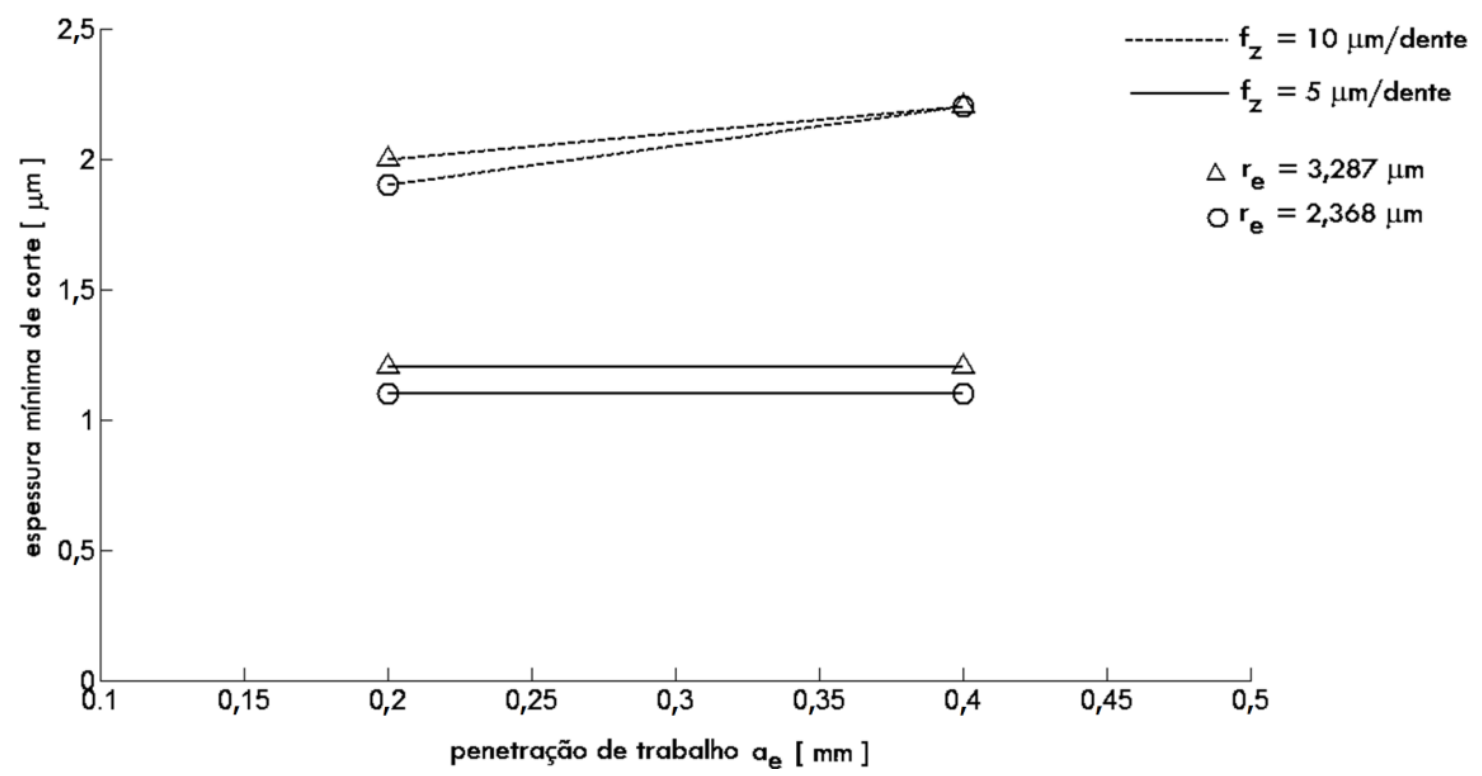

Figura 4.22 - Espessura mínima de corte em função do $\mathrm{a}_{\mathrm{e}}, \mathrm{f}_{\mathrm{z}}$ e $\mathrm{r}_{\mathrm{e}}$.

De modo a analisar estatisticamente a resposta da espessura mínima de corte com os parâmetros mencionados na Figura 4.22, uma análise de variância (ANOVA) foi realizada, adotando uma confiabilidade de 99\%, ou equivalente a um nível de significância de 1\%, gerando assim o denominado quadro ANOVA dos fatores de controle, seus níveis e a resposta. A Tabela 4.5 fornece o quadro ANOVA.

Tabela 4.5 - Quadro ANOVA sobre as respostas da espessura mínima de corte.

\begin{tabular}{ccccccc}
\hline fator & $\begin{array}{c}\text { grau de } \\
\text { liberdade }\end{array}$ & $\begin{array}{c}\text { soma dos } \\
\text { quadrados }\end{array}$ & $\begin{array}{c}\text { soma dos quadrados } \\
\text { ajustados }\end{array}$ & $\begin{array}{c}\text { quadrado médio } \\
\text { ajustado }\end{array}$ & $\begin{array}{c}\text { teste } \\
\mathrm{F}\end{array}$ & $\begin{array}{c}\text { teste } \\
\mathrm{P}\end{array}$ \\
\hline $\mathrm{fz}$ & 1 & 1,71125 & 1,71125 & 1,71125 & 195,57 & 0,000 \\
$\mathrm{ae}$ & 1 & 0,03125 & 0,03125 & 0,03125 & 3,57 & 0,132 \\
re & 1 & 0,01125 & 0,01125 & 0,01125 & 1,29 & 0,320 \\
erro & 4 & 0,03500 & 0,03500 & 0,00875 & & \\
Total & 7 & 1,78875 & & & & \\
\hline
\end{tabular}

A interpretação do quadro ANOVA é feita através da análise do valor da probabilidade P. Níveis menores que o de significância estabelecido previamente ( $\alpha=0,01$ ou 1\%) indicam que a hipótese inicial de normalidade para esses casos foi rejeitada, ou seja, as variâncias não são iguais e esses fatores causaram significativa variação na resposta da espessura mínima de corte. Assim, analisando os resultados obtidos, com base nos experimentos realizados, 
depreende-se que o avanço foi o fator que mais influenciou significativamente na espessura mínima de corte.

Uma avaliação gráfica, fornecida pela análise do efeito das médias, pode caracterizar a influência de cada fator na variável de resposta espessura mínima de corte. Por meio da Figura 4.23, pode-se concluir que o avanço por dente teve maior variação em torno da média e, portanto, exerce maior influência na espessura mínima de corte, seguido da penetração de trabalho e do raio da aresta principal de corte.

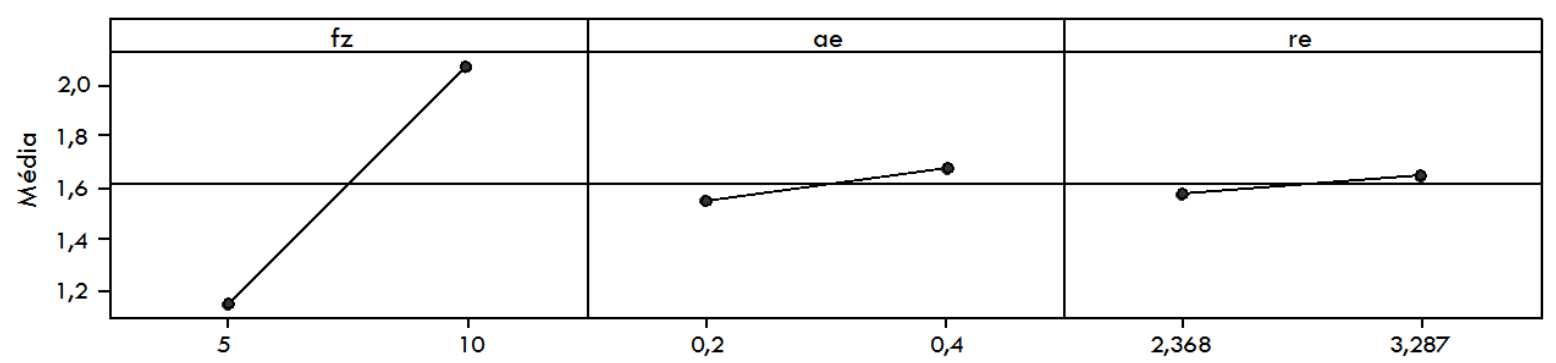

Figura 4.23 - Efeito das médias correspondente a variável de resposta espessura mínima de corte.

A maior influência na espessura mínima de corte foi causado pelo avanço, este fato não é esperado e leva à hipótese de que não somente o raio de aresta pode influenciar na espessura mínima de corte, mas também o avanço. Porém, não é possível afirmar tal hipótese com base nos experimentos realizados.

\subsection{RAZÃO ENTRE AS FORÇAS DE USINAGEM}

Sendo conhecida a variação das componentes da força de usinagem conforme a variação da espessura de corte, torna-se possível analisar o comportamento da razão entre as forças de usinagem. Quatro regiões são consideradas fonte de calor durante o fresamento: a primeira encontra-se no plano de cisalhamento, a segunda na superfície de saída da ferramenta, a terceira na superfície de folga principal do dente da fresa e a quarta na superfície de folga secundária do dente da fresa.

Para determinar a razão entre as forças na superfície de saída é preciso conhecer o ângulo de saída da ferramenta, o qual foi apresentado no tópico materiais e métodos (Figura 3.4, da página 61). Para o cálculo da razão entre as forças no plano de cisalhamento é preciso conhecer o ângulo formado entre tal plano e a superfície principal de corte (ângulo de cisalhamento - $\Phi$ ). 
Considerando-se que o ângulo de cisalhamento seja constante, dois métodos de análise podem ser usados para estimar tal ângulo. O primeiro método, determinou o ângulo de cisalhamento por meio das medições angulares da imagem do cavaco obtida por um microscópio eletrônico de varredura (MEV). Com o auxílio de um software CAD, foi possível verificar o ângulo formado entre as lamelas e a região de contato da superfície de saída da ferramenta com o cavaco (Figura 4.24-a), que deu um valor em torno de $73^{\circ}$. Fazendo uma analogia deste ângulo com o mecanismo de corte, conforme apresenta a Figura 4.24-b, foi possível identificar de onde surge tal ângulo. Construindo um arranjo das medidas angulares, conforme apresenta a Figura 4.24-c, o ângulo de cisalhamento foi determinado pela diferença entre $90^{\circ}$ e o ângulo da imagem, assim sendo, $\Phi=17^{\circ}$.
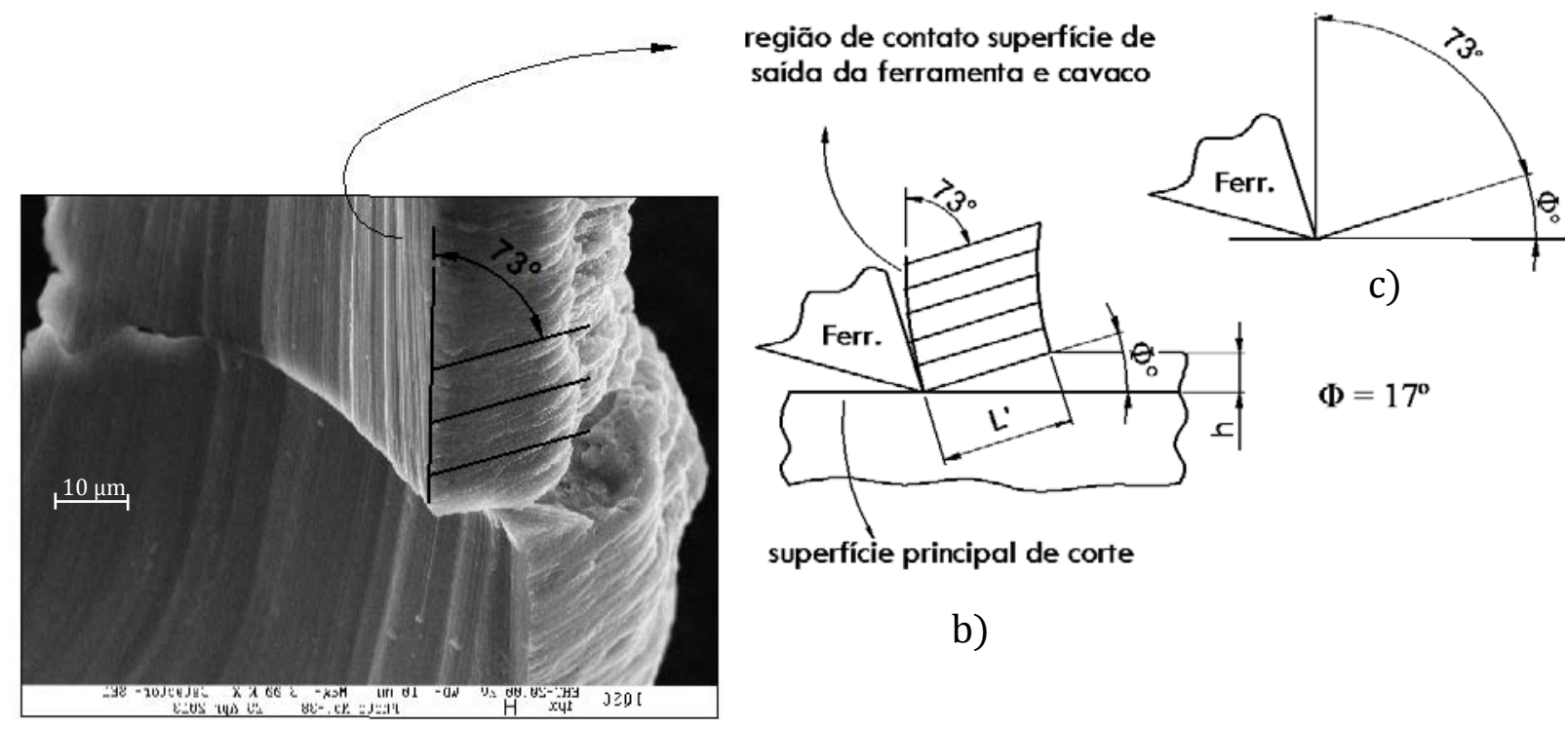

b)

a)

Figura 4.24 - Ângulo de cisalhamento determinado pelo cavaco (MEV): $\mathrm{f}_{\mathrm{z}}=10 \mu \mathrm{m} /$ dente.

O outro método para determinar o ângulo de cisalhamento utilizou também a análise das imagens do cavaco no MEV, porém ao invés das medições angulares, mediu-se a espessura do cavaco $h^{\prime}$.

Para um avanço por dente de $5 \mu \mathrm{m}$ e uma penetração de trabalho correspondente ao raio da fresa, tem-se uma espessura de corte máxima de $5 \mu \mathrm{m}\left(\mathrm{h}_{\text {máx }}=5 \mu \mathrm{m}\right)$. Com base em uma imagem de cavaco gerado por tal avanço (Figura 4.25), constatou-se uma espessura de cavaco máxima de 16,8 $\mu \mathrm{m} \quad\left(\mathrm{h}_{\text {máx }}^{\prime}=16,8 \mu \mathrm{m}\right)$. Segundo Ferraresi (1977), pela relação trigonométrica dada pela Equação 4.1, pode-se chegar ao ângulo de cisalhamento. Sendo o ângulo de saída da ferramenta de corte de $17^{\circ}$, e o grau de recalque $\mathrm{R}_{\mathrm{c}}=\mathrm{h}^{\prime}$ máx $/ \mathrm{h}_{\text {máx }}$, o ângulo 
de cisalhamento $\Phi$ corresponde a $17,3^{\circ}$. Portanto, o razão entre as forças no plano de cisalhamento será determinada em função do ângulo de cisalhamento correspondente a $17^{\circ}$.

$$
\operatorname{tg} \Phi=\frac{\cos \gamma}{\mathrm{R}_{\mathrm{c}}-\sin \gamma}
$$

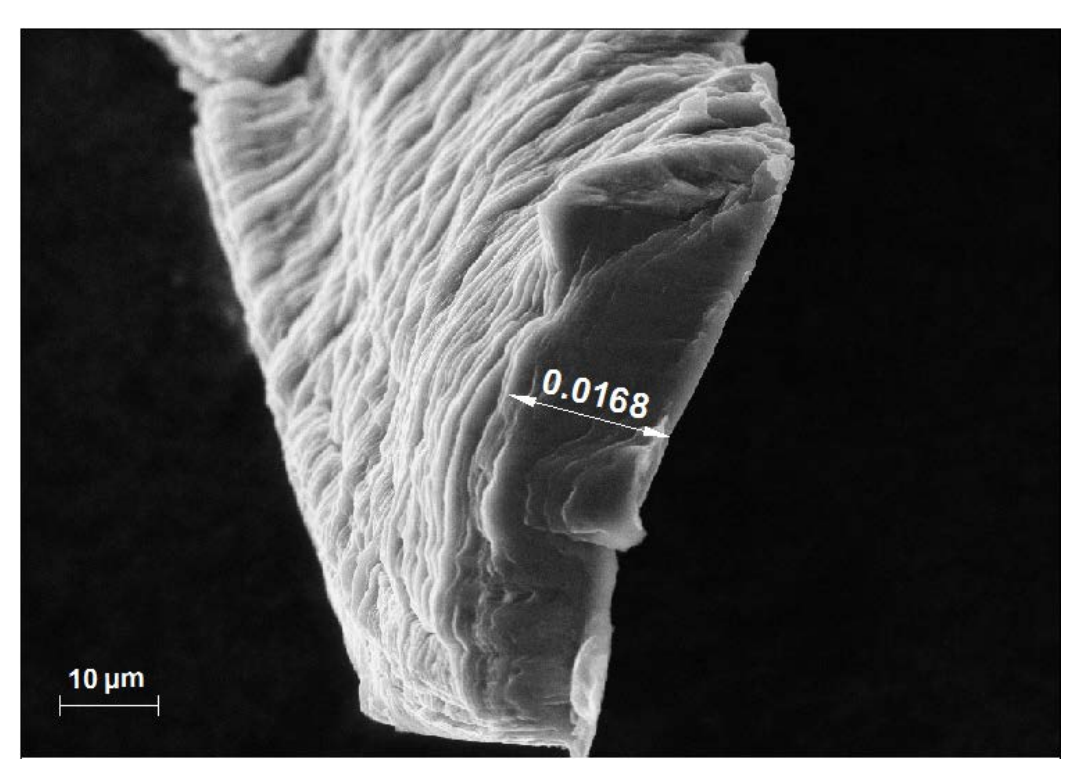

Figura 4.25 - Imagem do cavaco $(\mathrm{MEV}): \mathrm{f}_{\mathrm{z}}=5 \mu \mathrm{m} /$ dente e $\mathrm{a}_{\mathrm{e}}=$ raio da fresa.

Asssim, conforme as expressões para as razões nas quatro regiões:

$$
\begin{gathered}
\mathrm{r}_{\phi_{\mathrm{i}}}=\frac{\mathrm{F}_{\phi_{\mathrm{i}}}}{\mathrm{N}_{\phi_{\mathrm{i}}}}=\frac{\left|\mathrm{F}_{\mathrm{c}_{\mathrm{i}}} \cos \phi-\mathrm{F}_{\mathrm{n}_{\mathrm{i}}} \operatorname{sen} \phi\right|}{\left|\mathrm{F}_{\mathrm{c}_{\mathrm{i}}} \operatorname{sen} \phi+\mathrm{F}_{\mathrm{n}_{\mathrm{i}}} \cos \phi\right|} \\
\mathrm{r}_{\gamma_{\mathrm{i}}}=\frac{\mathrm{F}_{\gamma_{\mathrm{i}}}}{\mathrm{N}_{\gamma_{\mathrm{i}}}}=\frac{\left|\mathrm{F}_{\mathrm{c}_{\mathrm{i}}} \operatorname{sen} \gamma+\mathrm{F}_{\mathrm{n}_{\mathrm{i}}} \cos \gamma\right|}{\left|\mathrm{F}_{\mathrm{c}_{\mathrm{i}}} \cos \gamma-\mathrm{F}_{\mathrm{n}_{\mathrm{i}}} \operatorname{sen} \gamma\right|}=\frac{\left|\mathrm{F}_{\mathrm{n}_{\mathrm{i}}}+\mathrm{F}_{\mathrm{c}_{\mathrm{i}}} \operatorname{tg} \gamma\right|}{\left|\mathrm{F}_{\mathrm{c}_{\mathrm{i}}}-\mathrm{F}_{\mathrm{n}_{\mathrm{i}}} \operatorname{tg} \gamma\right|} \\
\mathrm{r}_{\alpha_{\mathrm{i}}}=\frac{\mathrm{F}_{\mathrm{c}_{\mathrm{i}}}}{\mathrm{F}_{\mathrm{n}_{\mathrm{i}}}} \\
\mathrm{r}_{\alpha_{2_{\mathrm{i}}}}=\frac{\mathrm{F}_{\mathrm{c}_{\mathrm{i}}}}{\mathrm{F}_{\mathrm{p}_{\mathrm{i}}}}
\end{gathered}
$$

A Figura 4.26 apresenta a variação da razão entre as forças, na zona de usinagem, conforme a variação do ângulo de contato $\psi_{\mathrm{i}}$ e, consequentemente, da espessura de corte $\mathrm{h}_{\mathrm{i}}$. 


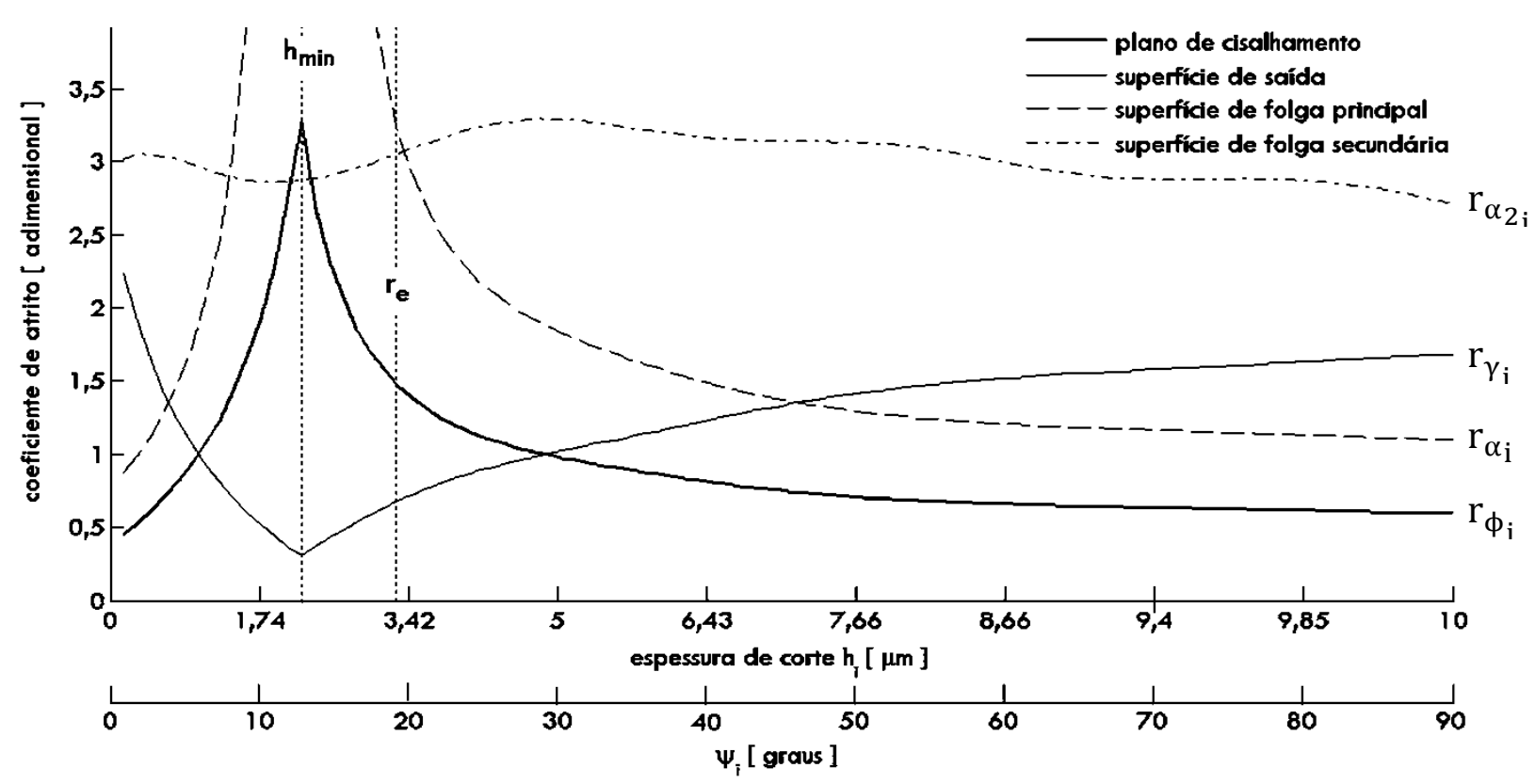

Figura 4.26 - Razão entre as forças de usinagem: $V_{c}=50 \mathrm{~m} / \mathrm{min}, \mathrm{f}_{\mathrm{z}}=10 \mu \mathrm{m} /$ dente, $\mathrm{R}=0,4 \mathrm{~mm}$, $\mathrm{a}_{\mathrm{e}}=\mathrm{R}, \mathrm{a}_{\mathrm{p}}=50 \mu \mathrm{m}, \psi=90^{\circ}$ e $\mathrm{Z}=2$.

Pode-se observar, na Figura 4.26, que quando a ferramenta de corte se encontra antes da espessura mínima de corte, a razão entre as forças na superfície de saída da ferramenta, no plano de cisalhamento e na superfície de folga principal, se comporta de forma diferente do que a razão entre as forças após a espessura mínima de corte. Isto ocorre porque antes do $\mathrm{h}_{\text {min }}$ não há cisalhamento da camada de material a ser removida, e, portanto, nesta região, consiste apenas a deformação do material..

O fato da razão entre as forças na superfície de folga principal tender a um valor elevado em $\mathrm{h}_{\min }$, é decorrente da decomposição das forças de apoio e avanço para obter a força de compressão. A equação da força de compressão é dada por $F_{n}=\left|F_{a p} \cos \psi_{\mathrm{i}}\right|-\left|F_{\mathrm{f}} \operatorname{sen} \psi_{\mathrm{i}}\right|$. A força $F_{a p}$ no início do corte é muito pequena, enquanto a força $F_{f}$ é maior. Porém, o seno de um ângulo pequeno fornece um valor próximo de zero, por outro lado o cosseno de um ângulo pequeno fornece um valor próximo de 1 . Assim, mesmo a força de avanço sendo maior que a força de apoio, esta torna-se pequena porque é multiplicada pelo seno de um $\psi_{\text {i }}$ pequeno, e a força de apoio continua pequena porque é multiplicada pelo cosseno do mesmo $\Psi_{\mathrm{i}}$. Portanto, quando se subtrai uma decomposição da outra, $\mathrm{F}_{\mathrm{n}}$ tende a 0 . Pelo fato de a razão entre as forças na superfície de folga principal ser o quociente entre $F_{c}$ e $F_{n}$, em que $F_{n}$ é o denominador , tal razão tende a um valor elevado. 
O mesmo acontece para a razão entre as forças no plano de cisalhamento e na superfície de saída, porém a $F_{n}$ se encontra no denominador ou no numerador com o acréscimo do valor de outras componentes.

Observa-se na Figura 4.26, que depois de um certo valor da espessura de corte (7,66 $\mu \mathrm{m})$, a razão entre as forças tende a ser constante. Desta forma, determinou-se a razão entre as forças na espessura de corte máxima* $\left(h_{i}=h_{\max }\right)$, como apresenta a Tabela 4. 6 .

Tabela 4. 6 - Razão entre as forças de usinagem das condições de fresamento

\begin{tabular}{llcccc}
\hline & & C1 & C2 & C3 & C4 \\
\hline \multirow{2}{*}{ Ensaio 1 } & plano de cisalhamento & 0,4570 & 0,5852 & 0,5966 & 0,6408 \\
$r_{\mathrm{e}}=\mathbf{3 , 2 8 7}$ & superfície de saída & 2,1880 & 1,7090 & 1,6760 & 1,5610 \\
& superfície de folga principal & 0,8866 & 1,0850 & 1,1040 & 1,1770 \\
& superfície de folga secundária & 4,2420 & 4,4800 & 2,7110 & 3,6900 \\
\hline \multirow{2}{*}{ Ensaio 2 } & plano de cisalhamento & 0,4700 & 0,6241 & 0,6650 & 0,7243 \\
$\mathbf{r}_{\mathbf{e}}=\mathbf{2 , 3 6 8}$ & superfície de saída & 2,1270 & 1,4900 & 1,5040 & 1,3810 \\
& superfície de folga principal & 0,9060 & 1,6020 & 1,2190 & 1,3230 \\
& superfície de folga secundária & 3,7690 & 4,3000 & 3,6970 & 4,0650 \\
\hline
\end{tabular}

Com base da Tabela 4. 6, construiu-se um gráfico da variação da razão entre as forças em relação as condições de fresamento, conforme apresenta a Figura 4.27. Pode-se observar por meio desta figura que, mesmo variando o avanço (C1 = $5 \mu \mathrm{m} /$ dente e C2 = $10 \mu \mathrm{m} /$ dente), a razão entre as forças no plano de cisalhamento, na superfície de saída da ferramenta e na superfície de folga principal, praticamente, tenderam ao mesmo valor na espessura máxima de corte. Na superfície de folga principal secundária, a razão entre as forças alcançaram valores bem diferentes, porém para um intervalo de confiança de 99\%, com base no desvio padrão, é possível observar que os intervalos podem se encontrar e, portanto, não há uma diferença significativa entre as condições.

\footnotetext{
* No fresamento parcial discordante, a espessura de corte instantânea varia de zero até um valor máximo, este é dito como espessura de corte máxima , $\mathrm{h}_{\max }$ (vide Figura 2.10-b).
} 


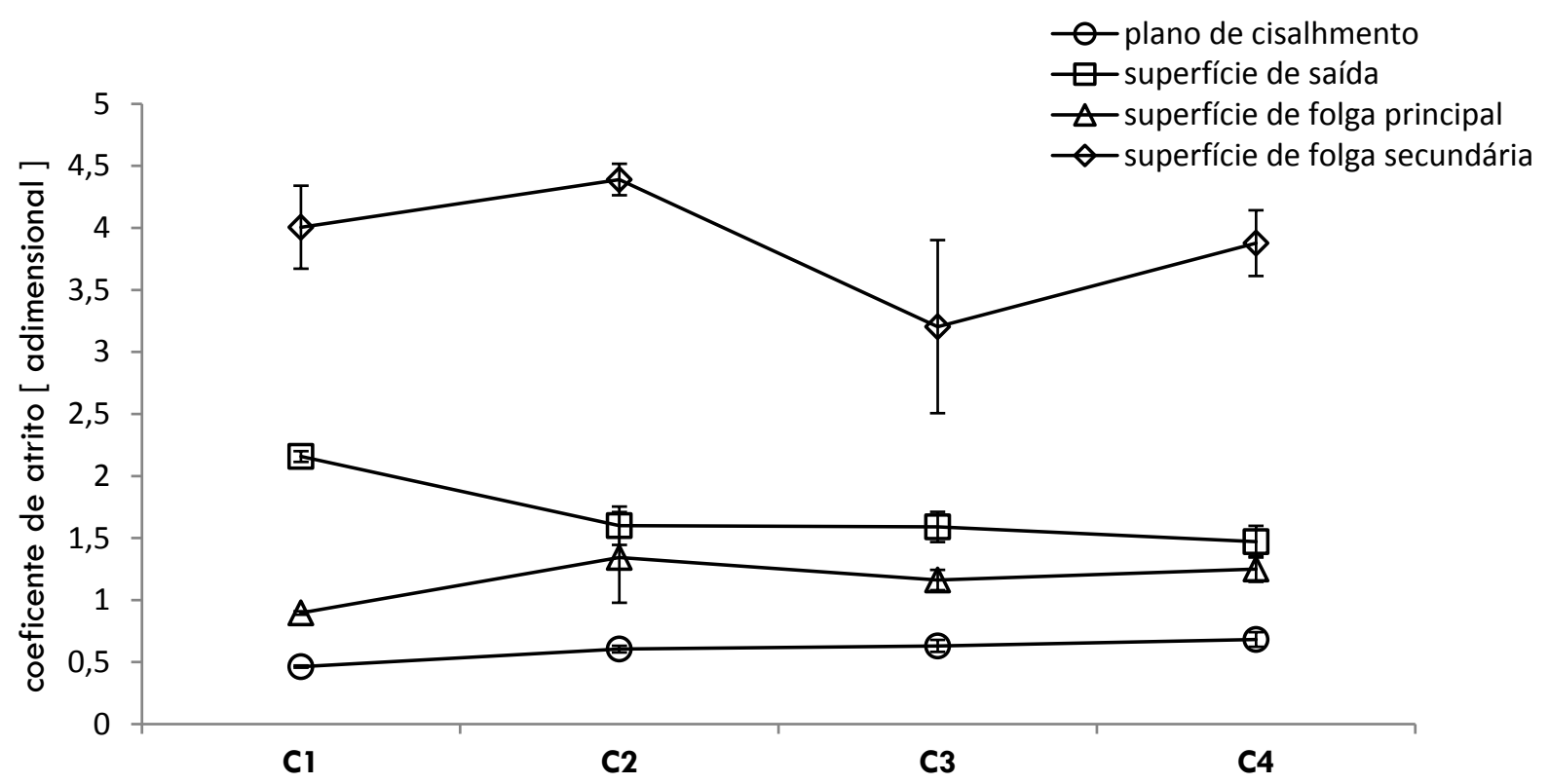

Figura 4.27 - Razão entre as forças de usinagem, determinada na espessura de corte máxima.

\subsection{PRESSÃO ESPECÍFICA DE CORTE}

Uma vez determinada a variação da força de corte no fresamento, torna-se possível a análise da pressão específica de corte. A variação da pressão específica de corte (calculada pela equação $\mathrm{k}_{\mathrm{s}_{\mathrm{i}}}=\mathrm{F}_{\mathrm{c}_{\mathrm{i}}} / \mathrm{h}_{\mathrm{i}} \cdot \mathrm{a}_{\mathrm{p}}$ ) nos ensaios de microfresamento, comportou-se conforme demonstra a Figura 4. 28, na qual pode-se observar o alto fator de escala da pressão específica de corte antes da $\mathrm{h}_{\text {min }}$, decorrente da alta porção da força de riscamento (força plowing) como parte da pressão específica de corte, causada pela deformação elástica e plástica do material - fluxo lateral (BOOTHROYD; KNIGHT, 1989).

A medida que o material tende a cisalhar, o fluxo lateral de material diminui e uma pequena quantidade de material tende a formar o cavaco. Consequentemente, a porção da força de riscamento diminui, mas não deixa de existir, e, em contrapartida, a força necessária para cisalhar o material torna-se mais proeminente. Assim, com o aumento da espessura de corte, a porção da pressão específica de corte, responsável por deformar o material $\left(\mathrm{k}_{\mathrm{spl}}\right)$, diminui; e a porção responsável por cisalhar o material $\left(\mathrm{k}_{\mathrm{s}_{\min }}\right)$ começa a ficar mais aparente. A Figura 4. 28 está dividida em três partes: deformação elástica, deformação plástica e cisalhamento. Assume-se que a primeira parte seja apenas deformação elástica por causa do decaimento linear da pressão específica de corte nesta região. Por outro lado, na região de 
deformação plástica o decaimento é não-linear. Por fim, na região de cisalhamento o decaimento da pressão específica de corte tende a um valor constante.

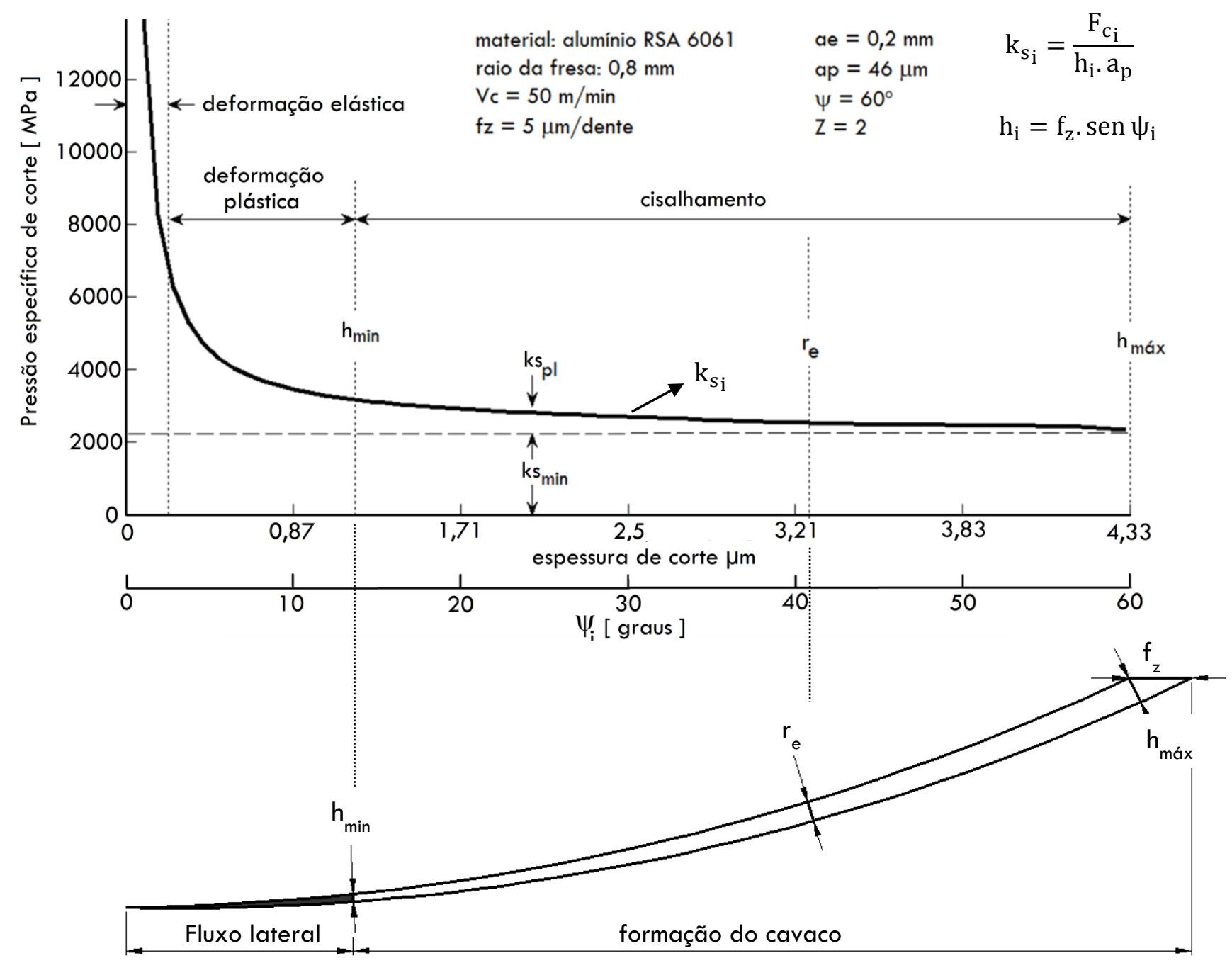

Figura 4. 28 - Pressão Específica de Corte Instantânea na formação do cavaco em microfresamento.

Por fim, a Figura 4.29 apresenta as pressões específicas de corte médias das condições de microfresamento, assim como os valores de $\mathrm{k}_{\mathrm{s} 1}$ e m para o par material alumínio RSA 6061 e ferramenta de metal duro. A pressão específica de corte média foi calculada com base na relação entre força de corte média $\left(\overline{F_{c}}\right)$ e a seção de corte média $\left(\bar{h} . a_{p}\right)$. As constantes do material $\left(\mathrm{k}_{\mathrm{s} 1}\right.$ e $\left.\mathrm{m}\right)$ foram determinadas conforme o método de regressão linear simples. 

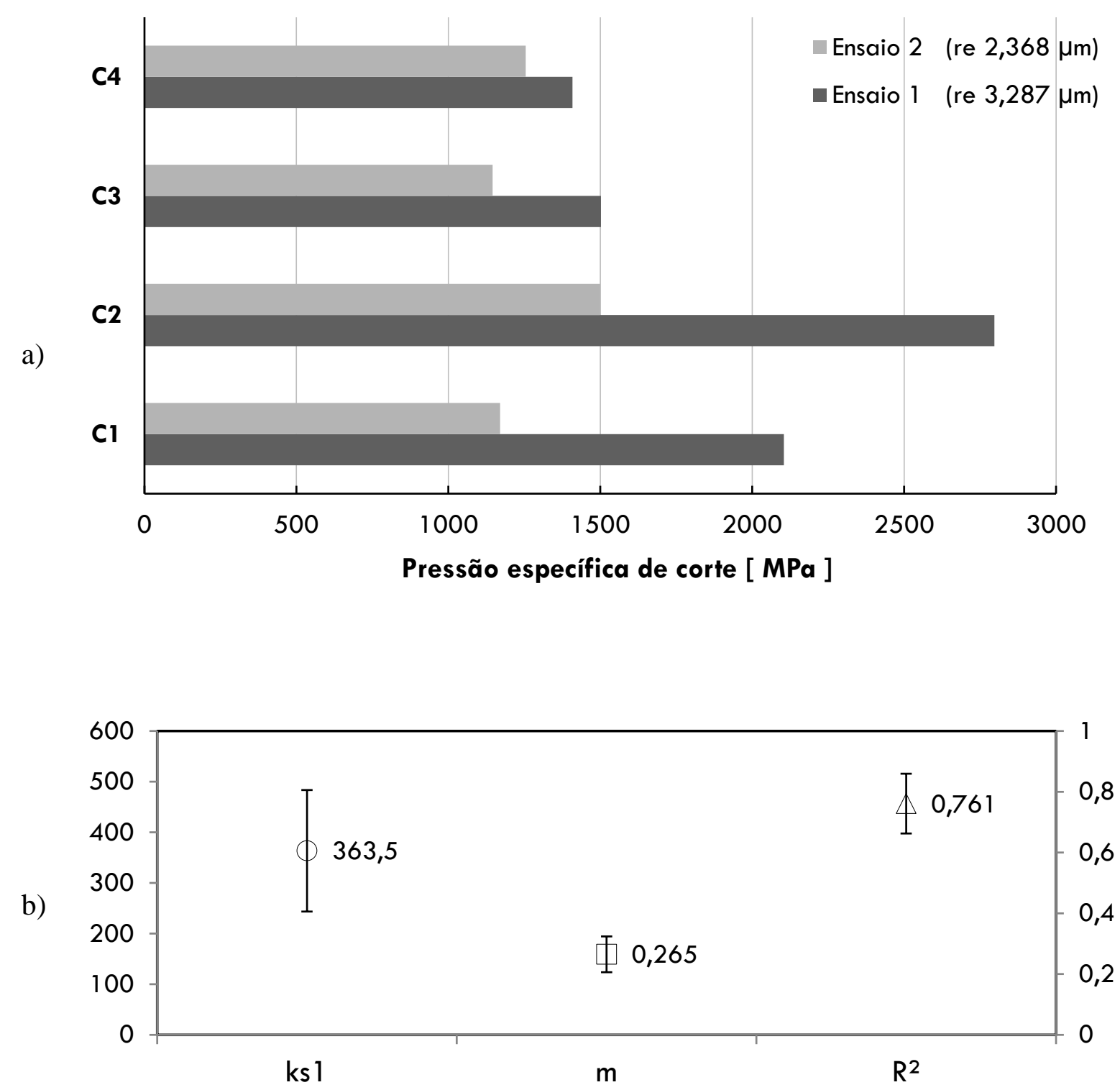

Figura 4.29 - Pressão específica de corte: a) valores médios de $\mathrm{k}_{\mathrm{s}}$, b) $\mathrm{k}_{\mathrm{s} 1}$ e m estimados.

Para validar os valores de $\mathrm{k}_{\mathrm{s} 1}$ e m encontrados em microfresamento para o material RSA 6061, foi feita uma comparação com a literatura conforme demonstra a Tabela 4. 7. Verifica-se que a constante do material da peça e o coeficiente angular da reta ficaram dentro da faixa de variação das diversas ligas de alumínio. 
Tabela 4. 7 - ks1 e m (STEMMER, 2007; ÁLISSON et al.,2009; SANDVIK, 2013; DORMER, 2013)

\begin{tabular}{cllc}
\hline & & ks1 & m \\
\hline \multirow{2}{*}{ AWF - 158 } & Alumínio puro & 360 & 0,46 \\
& Alumínio or: 300 MPa & 388 & 0,47 \\
& Alumínio or: 300-420 MPa & 460 & 0,48 \\
\hline RSA 6061 & Al 98,2 Si0,3 Mg0,5 or: 330 MPa & $\mathbf{3 6 4}$ & $\mathbf{0 , 2 7}$ \\
\hline Kienzle & Al Si 10 Mg a & 400 & 0,27 \\
\hline \multirow{2}{*}{ Sandvik } & Ligas de alumínio 13 - 22\% Si & 613 & 0,29 \\
& Ligas de alumínio & 383 & 0,29 \\
& Ligas de alumínio fundidas & 600 & 0,25 \\
\hline \multirow{2}{*}{ Dormer } & Al, Mg e não ligados & 250 & 0,22 \\
& Ligas de Al, Si<0,5\% & 450 & 0,18 \\
\hline
\end{tabular}

Portanto, para o espaço amostral dos experimentos realizados (penetração de trabalho de $0,2 \mathrm{~mm}$ e $0,4 \mathrm{~mm}$, avanço por dente entre $5 \mu \mathrm{m}$ e $10 \mu \mathrm{m}$, e profundidade de corte em torno de $50 \mu \mathrm{m}$ ), a equação que estima a pressão específica de corte é descrita pela Equação (4.6), e a força de corte pode ser estimada pela Equação (4.7).

$$
\begin{array}{ll}
\mathrm{k}_{\mathrm{s}_{\mathrm{i}}}=364 \cdot \mathrm{h}_{\mathrm{i}}^{-0,27} \quad\left[\mathrm{~N} / \mathrm{mm}^{2}\right] ; & \mathrm{h}_{\mathrm{i}} \text { : espessura de corte instantânea [mm] } \\
\mathrm{F}_{\mathrm{c}_{\mathrm{i}}}=364 \cdot \mathrm{h}_{\mathrm{i}}^{-0,27} \cdot \mathrm{S}_{\mathrm{i}} \quad[\mathrm{N}] ; & \mathrm{S}_{\mathrm{i}} \text { : seção de corte instantânea [mm²] }
\end{array}
$$

\subsection{ENERGIA DE CORTE E A ENERGIA ESPECÍFICA DE CORTE}

A energia de corte foi calculada de duas formas. Uma foi obtida pelo produto entre a força de corte média e o comprimento de corte, Equação (3.9). A outra, foi adquirida pelo somatório do produto entre a força de corte instantânea, o raio da fresa e o incremento $\Delta_{\psi}$, Equação (3.10). Ambas as energias foram obtidas do sinal* da força de corte.

A energia de corte média, calculada em função da força de corte média, será representada por $u_{c}\left(F_{c}\right.$ médio ). A energia de corte total despendida na usinagem, calculada por meio da integral discreta, será representada por $\mathrm{u}_{\mathrm{c}}(\Sigma)$.

A Figura 4. 30-a apresenta os valores da energia de corte média e da energia de corte total, para cada condição de usinagem e suas réplicas. A diferença entre o ensaio (Ensaio 1) e a

\footnotetext{
${ }^{*}$ O sinal da força de corte refere-se aos dados coletados pelo dinamômetro piezoelétrico durante o fresamento.
} 
réplica (Ensaio 2) se dá pelos mesmos fatores observados nas forças de corte médias (página 87, último parágrafo). Nota-se que não há uma diferença significativa entre a energia de corte média e a energia de corte total despendida, devido à variação progressiva da espessura de corte. Para melhor demonstrar este efeito, foi feita uma análise estatística do intervalo de confiança (99\%) das médias obtidas da energia de corte média, $u_{c}\left(F_{c}\right.$ médio ), e da energia de corte total, $\mathrm{u}_{\mathrm{c}}(\Sigma)$, com base no desvio padrão combinado de cada média (Figura 4. 30-b).

a)

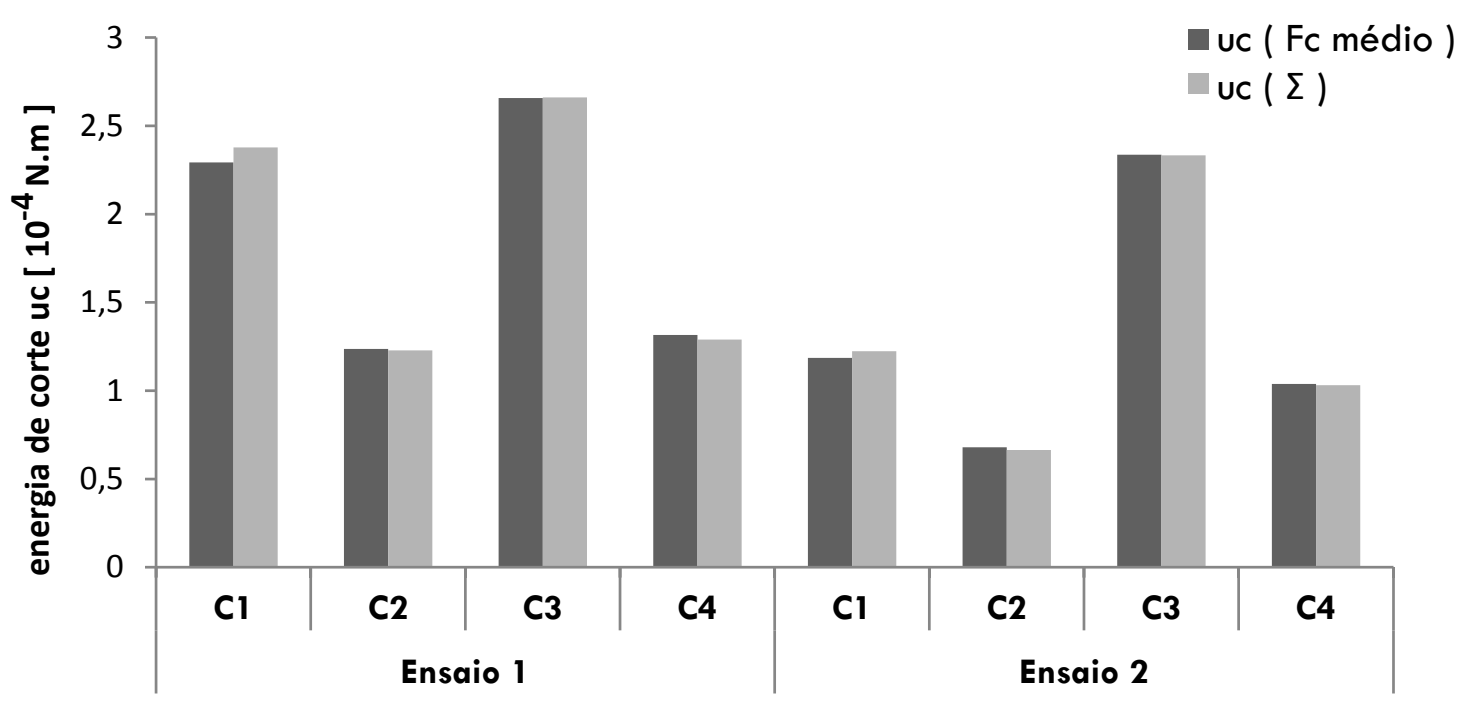

b)

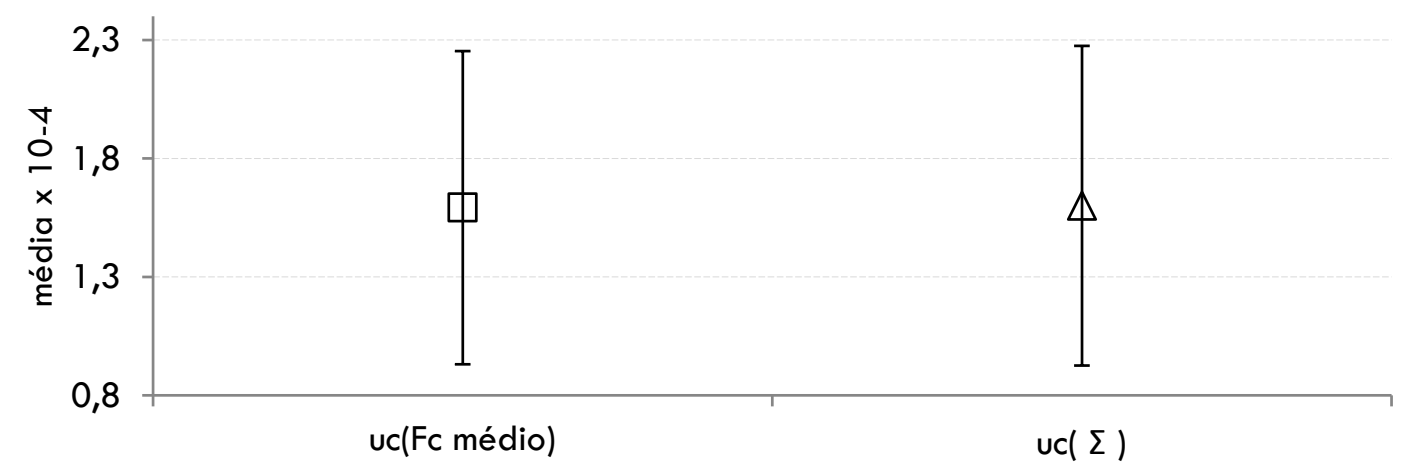

Figura 4. 30 - Energia de corte das condições de microfresamento: a) valores da energia de corte; b) individual intervalo de confiança (99\%) das médias, com base no desvio padrão combinado.

Uma vez que a energia de corte é conhecida, a energia específica de corte pode ser determinada pelo quociente entre a energia de corte e o volume de material removido. No caso do fresamento frontal parcial com tempo de movimento em vazio, tal volume corresponde ao volume do cavaco $\left(f_{z} \cdot a_{e} \cdot a_{p}\right)$. A Tabela 4.8 fornece os valores da energia específica de corte. 
Tabela 4. 8 - Energia específica de corte ( $\left.\mathrm{J} / \mathrm{mm}^{3}\right)$.

\begin{tabular}{cccccc}
\hline & & C1 & C2 & C3 & C4 \\
\hline Ensaio 1 & (re 3,287 $\mu \mathrm{m})$ & 2,15 & 2,34 & 1,47 & 1,22 \\
Ensaio 2 & $($ re 2,368 $\mu \mathrm{m})$ & 1,32 & 1,58 & 1,20 & 1,15 \\
\hline
\end{tabular}

O comportamento da energia específica de corte com o decréscimo da espessura é igual ao da pressão específica de corte, pois uma é equivalente a outra, porém os conceitos de ambas são distintos. Enquanto a pressão específica de corte é expressa pela pressão que a camada de material a ser removida exerce sobre a ferramenta de corte, a energia específica de corte exprime a energia empregada pela ferramenta para remover uma quantidade de volume da peça.

A pressão específica de corte foi determinada por três variáveis $\left(F_{c}, h\right.$ e $\left.a_{p}\right)$, já a energia específica de corte foi determinada por quatro variáveis $\left(u_{c}, f_{z}, a_{e}\right.$ e $\left.a_{p}\right)$. Na prática, o controle de tais variáveis é algo difícil de se alcançar, e pelo fato da energia específica de corte possuir mais variáveis do que a pressão específica de corte, tal grandeza se desviou levemente dos valores da pressão específica de corte como demonstra a Figura 4. 31:

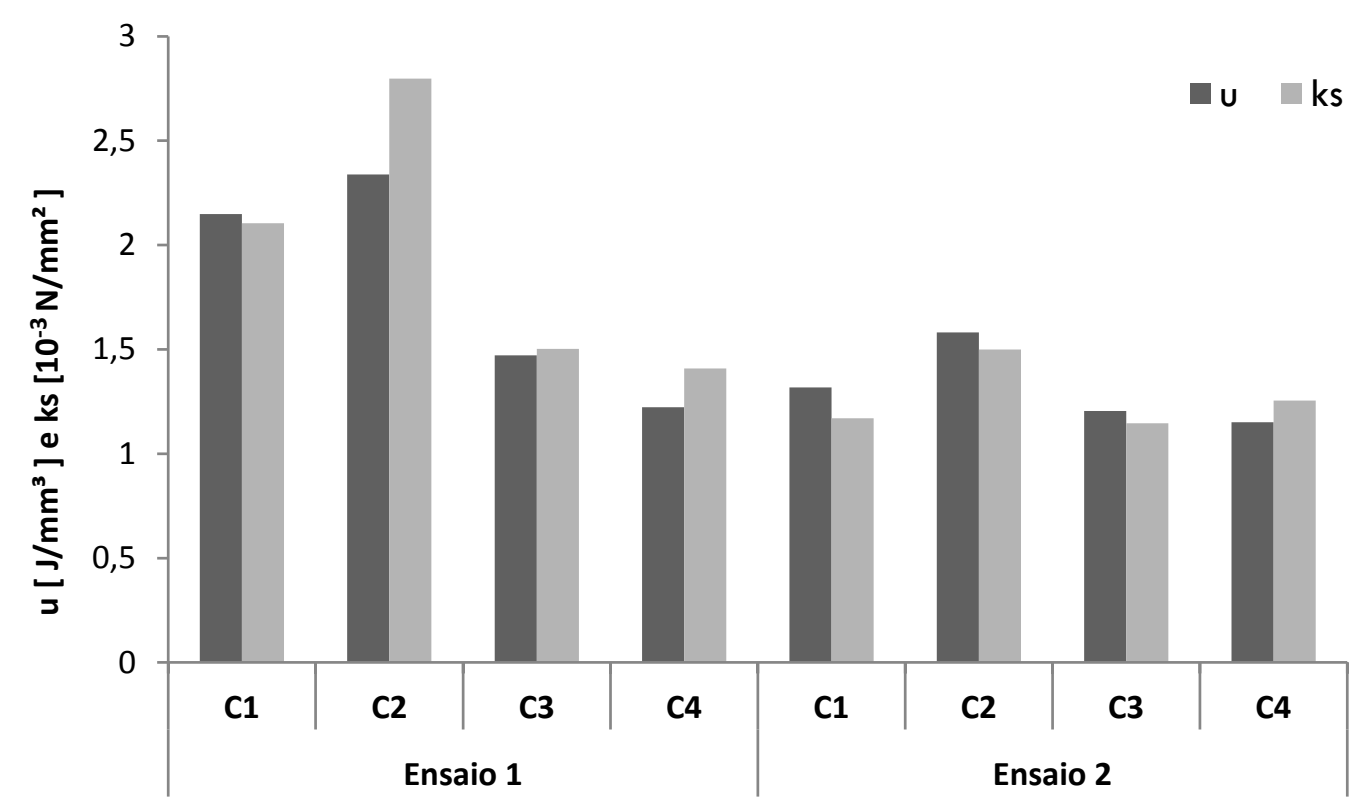

Figura 4. 31 - Energia específica de corte versus Pressão específica de corte.

\subsection{POTÊNCIA DE CORTE}

Como já mencionado, a potência de corte foi analisada de duas maneiras: a primeira foi com base no produto entre a força de corte e a velocidade de corte, Equação (3.12), da página 
72; a segunda foi determinada pelo produto entre a pressão específica de corte e a taxa efetiva de material removido, Equação (3.13), da página 72.

Uma análise das diversas representações da potência de corte é demonstrada pela Figura 4. 32, que retrata a potência de corte sendo consumida na formação de um cavaco ( $\mathrm{P}_{\mathrm{c}_{\text {real }}}$ : linha contínua espessa), a qual aumenta com o acréscimo da espessura de corte, devido ao maior esforço da ferramenta de corte para remover uma maior quantidade de material.

A potência de corte real foi determinda pelo produto da força de corte medida pelo dinamômetro piezoelétrico e a velocidade de corte. O método de cálculo que mais se aproximou da variação desta potência de corte foi o que tomou como base a força de corte média. Por outro lado, calculando a potência pela taxa de material removido, os valores mostraram uma nítida diferença. A potência estimada pela constante $\mathrm{k}_{\mathrm{s} 1}$ e pelo coeficiente angular da reta $\mathrm{m}$, apresentou uma significativa diferença dos valores reais.

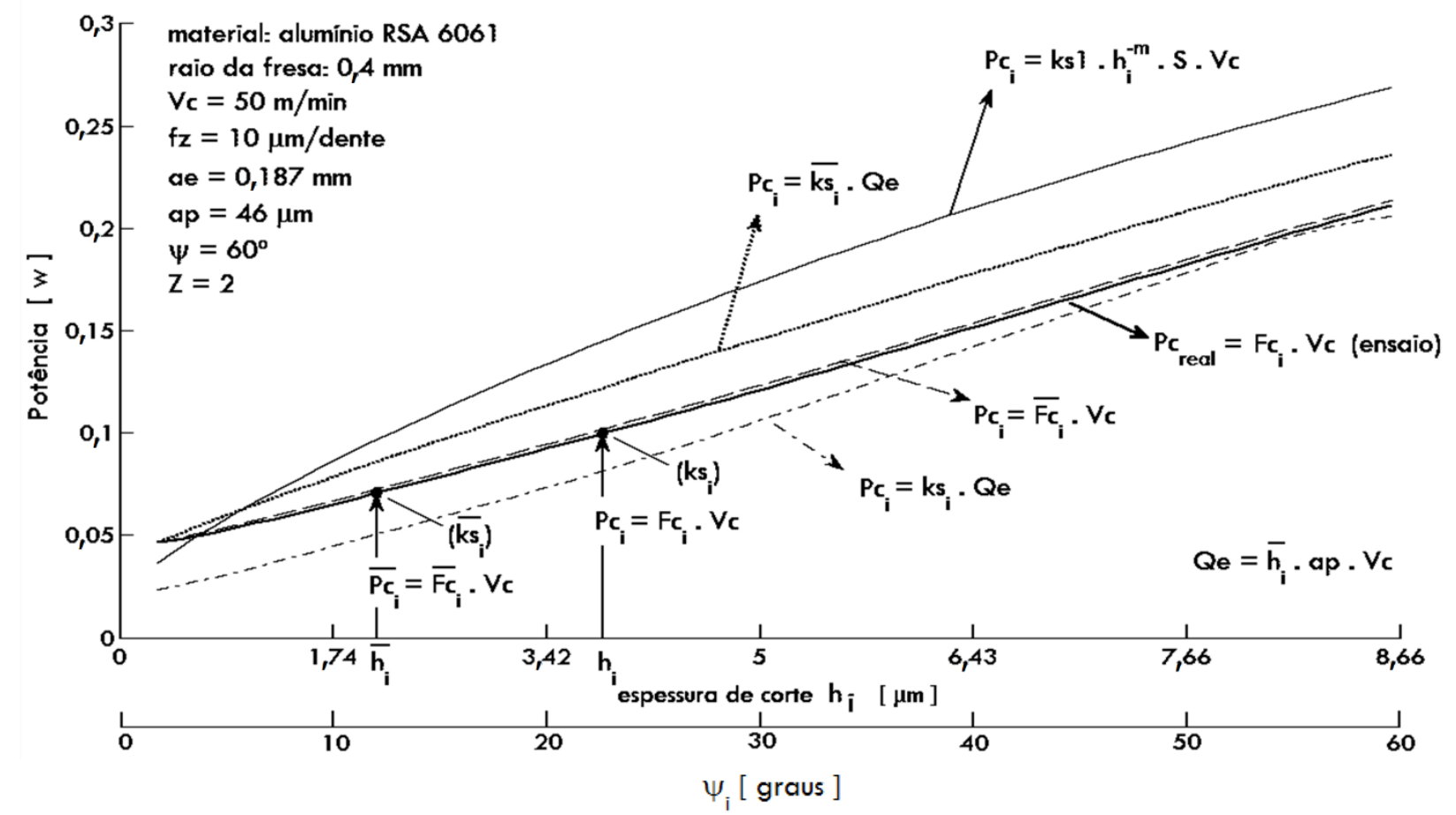

Figura 4. 32 - Potência de corte em microfresamento parcial com tempo de movimento em vazio.

Portanto, sendo o método mais preciso o que toma como base a força de corte média, a potência das condições de fresamento foram calculadas por tal método $\left(\mathrm{P}_{\left.\mathrm{c}_{(} \mathrm{F}_{\mathrm{c}} \text { médio }\right)}\right)$ e comparadas com a integral discreta da energia de corte consumida pelo tempo de contato da ferramenta na zona de usinagem ( potência de corte total, $\mathrm{P}_{\mathrm{c}\left(\mathrm{u}_{\mathrm{c}}(\Sigma)\right)}$ ): 


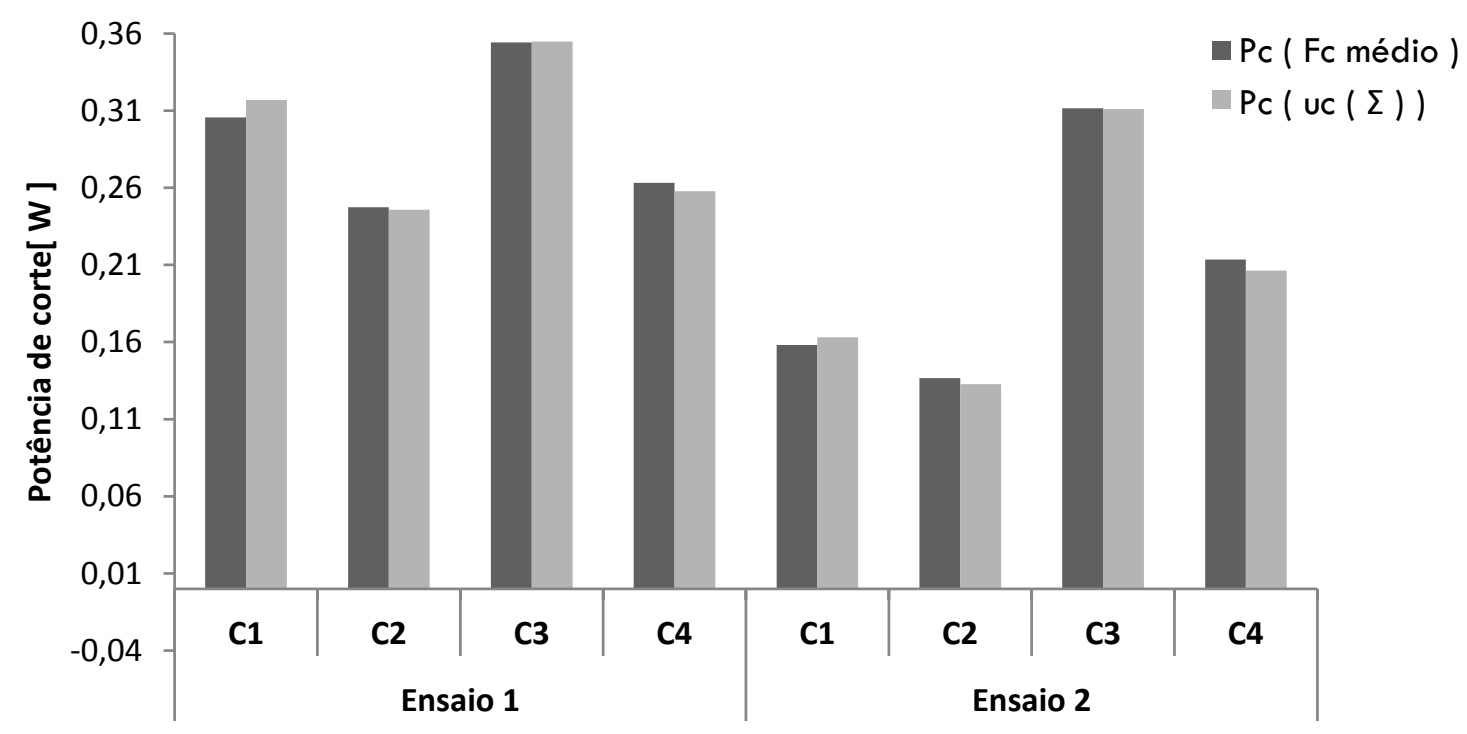

Figura 4. 33 - Potência de corte das condições de microfresamento.

Por fim, a Figura 4. 34 apresenta uma comparação entre a potência calculada tanto em função da taxa de material removido convencional $\left(Q=a_{e} \cdot a_{p} \cdot V_{f}\right)$, como em função da taxa efetiva de material removido $\left(Q_{e}=\bar{h} \cdot a_{p} \cdot V_{c}\right)$. Apresenta ainda a real potência de corte consumida.

Pode-se observar, na Figura 4. 34, que a potência calculada em função da taxa de material removido convencional, $\mathrm{P}_{\mathrm{c}}(\mathrm{Q})$, apresentou valores menores que a potência de corte real $\mathrm{P}_{\mathrm{c}}\left(\mathrm{u}_{\mathrm{c}}(\Sigma)\right)$. Este efeito deve-se ao intervalo de tempo em que não houve usinagem, uma vez que tal tempo é considerado no cálculo da taxa de material removido, os valores da potência de corte tendem a ser menores, pois Q é uma relação entre o volume e o tempo.

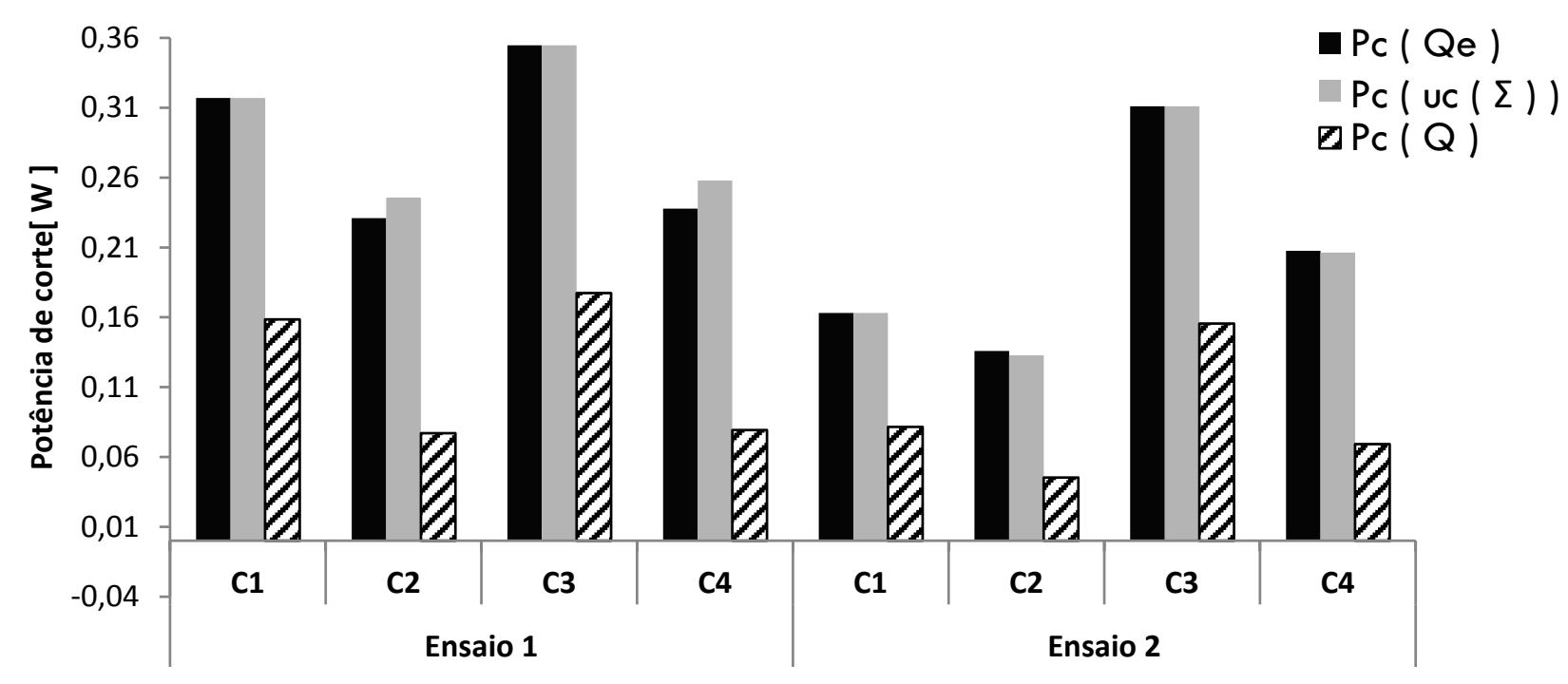

Figura 4. 34 - Comparação entre $\mathrm{P}_{\mathrm{c}}\left(\mathrm{Q}_{\mathrm{e}}\right), \mathrm{P}_{\mathrm{c}}(\mathrm{Q})$ e $\mathrm{P}_{\mathrm{c}}\left(\mathrm{u}_{\mathrm{c}}(\Sigma)\right)$. 


\subsection{CAVACOS}

O Tabela 4. 9 apresenta a imagem dos cavacos, obtidas por microscopia eletrônica de varredura (MEV), das condições de microfresamento. Por meio deste quadro pode-se observar que em todas as condições houve formação do cavaco. Algumas imagens apresentam diferentes aumentos para melhor visualização do mecanismo de formação dos cavacos.

Tabela 4. 9 - Cavacos gerados em microfresamento frontal parcial.

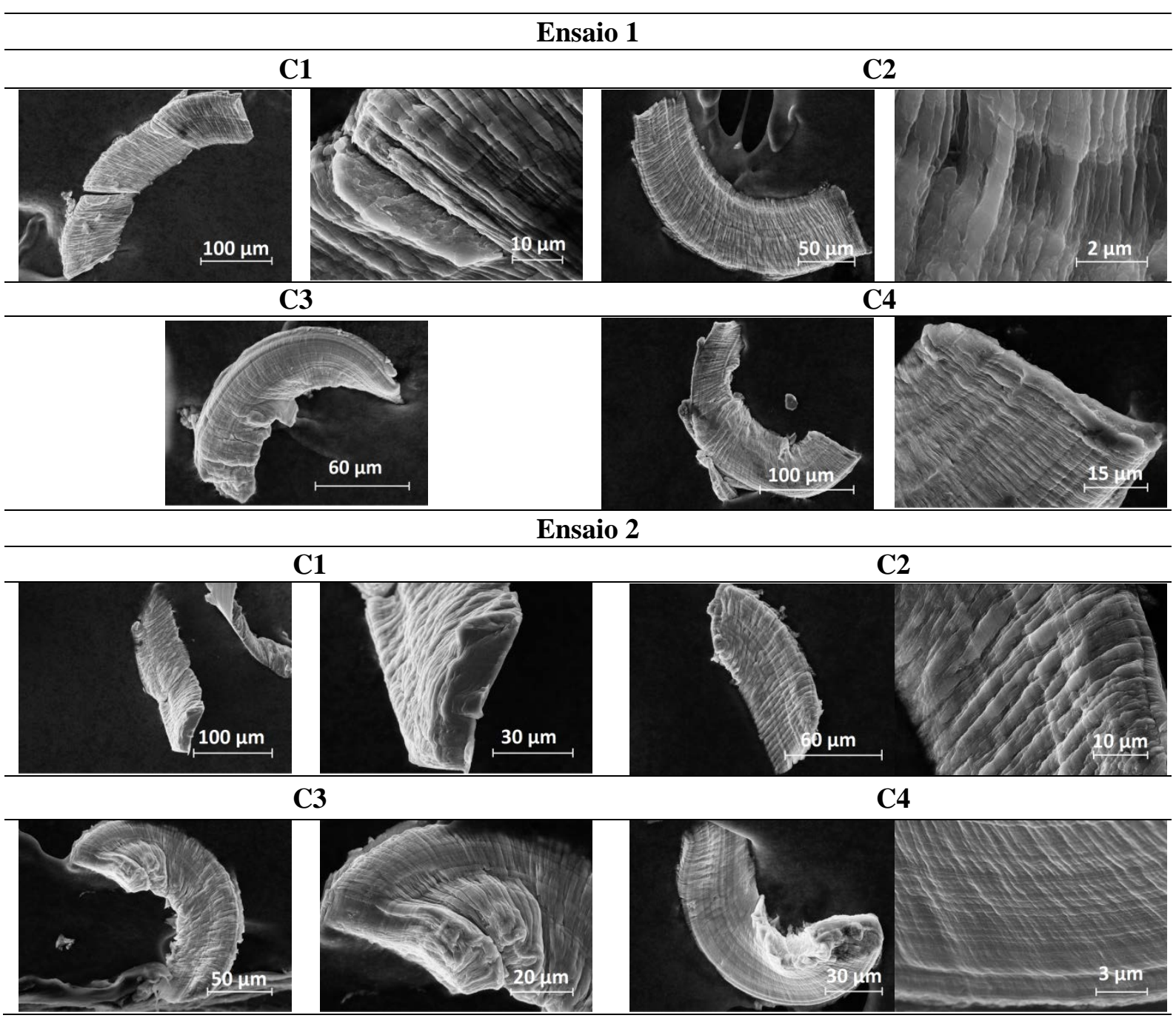

Pode-se, também, observar pela Tabela 4. 9 e pela Figura 4. 35 que os cavacos gerados foram em forma de vírgula, com lamelas justapostas numa disposição contínua e agrupadas em grupos lamelares. Este fato caracteriza o comportamento dúctil do material alumínio de grãos ultrafinos (RSA 6061) durante a microusinagem. 


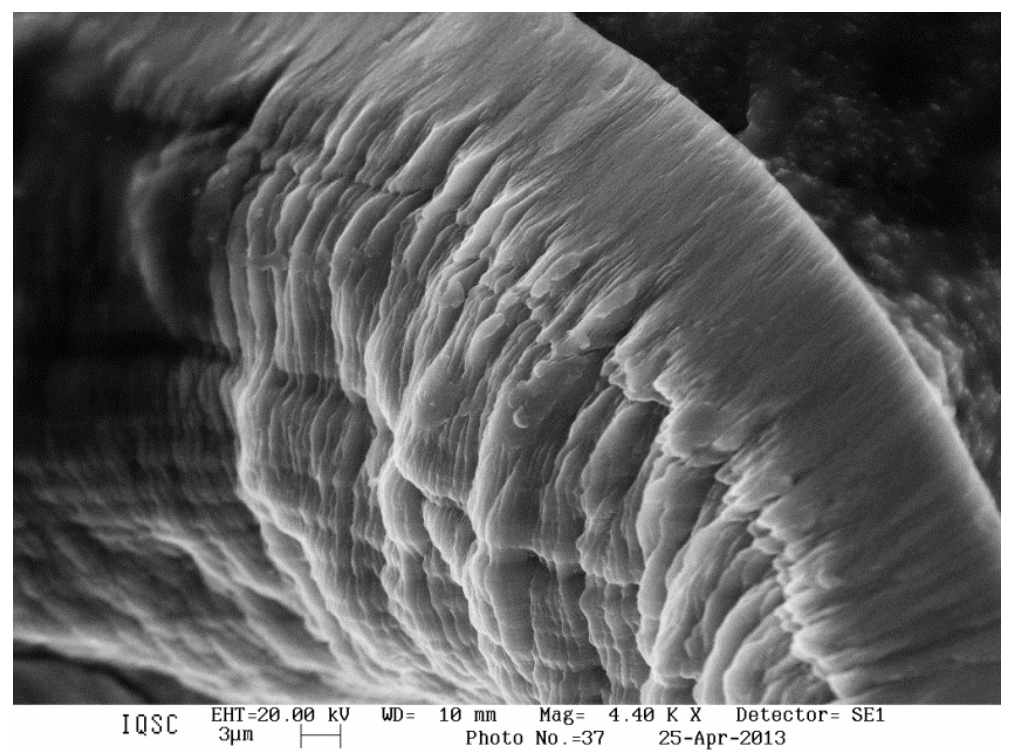

Figura 4. 35 - Cavaco, condição C4 ( $\mathrm{f}_{\mathrm{z}}=10 \mu \mathrm{m} /$ dente), constituído de lamelas justapostas.

O grau de compressão dos cavacos (grau de recalque $R_{c}$ ) foi encontrado de acordo com duas imagens obtidas no MEV. Uma já foi apresentada para determinar o ângulo de cisalhamento (Figura 4.25, da página 97). Esta forneceu a espessura máxima do cavaco (16,8 $\mu \mathrm{m})$ para a referida condição que possibilitou determinar o grau de recalque $(3,36)$. A outra é a Figura 4. 36 que apresenta o valor do comprimento do cavaco $(0,174 \mathrm{~mm})$, em que, para tal condição, o valor do comprimento de corte calculado (Lc) é de 0,617 . Fazendo a relação entre o comprimento de corte e o comprimento do cavaco, também, tem-se o grau de recalque $(3,55)$.

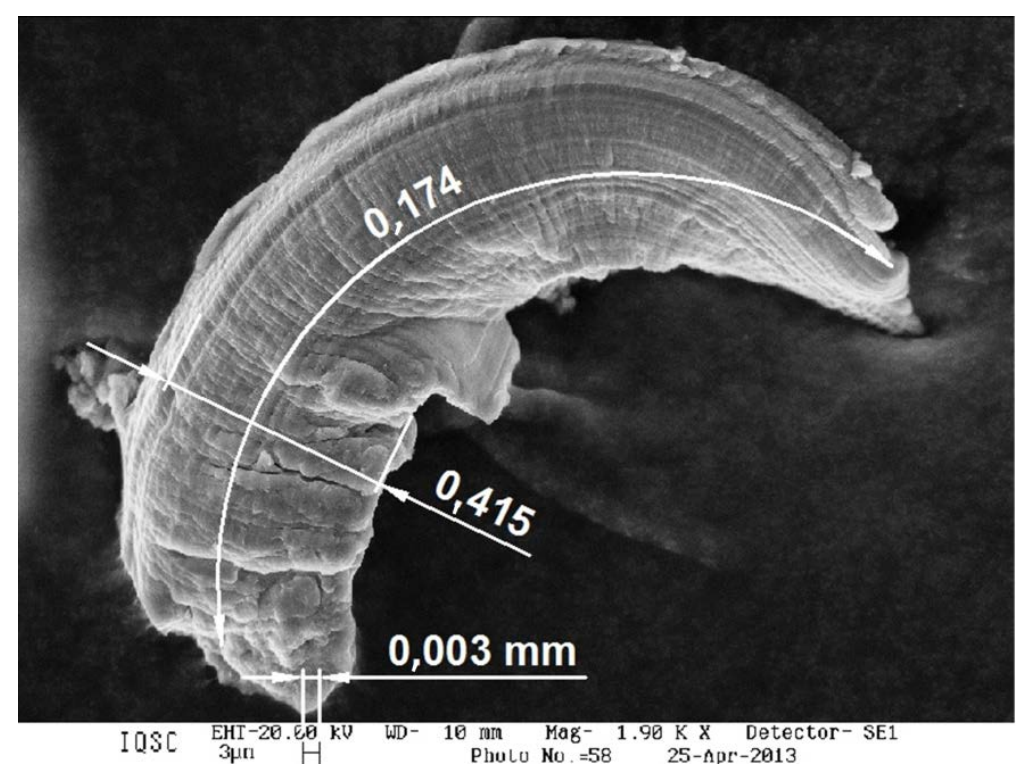

Figura 4. 36 - Cavaco, condição C3: $\mathrm{f}_{\mathrm{z}}=10 \mu \mathrm{m} /$ dente, $\mathrm{a}_{\mathrm{e}}=0,393 \mathrm{~mm}, \mathrm{a}_{\mathrm{p}}=0,446 \mathrm{~mm}$ e $\psi=90^{\circ}$. 
A Figura 4. 37-a, apresenta o início da formação do cavaco da operação de microfresamento em cheio (da abertura do canal) correspondente a condição C3. Constatou-se, conforme a Tabela 4.3, da página 93, que a espessura mínima de corte varia de 1,1 $\mu \mathrm{m}$ a 2,2 $\mu \mathrm{m}$. Considerando o grau de recalque de 3,35, as espessuras dos cavacos correspondentes a esta faixa $(1,1 \mu \mathrm{m}$ a 2,2 $\mu \mathrm{m})$ varia de 3,7 $\mu \mathrm{m}$ a 7,35 $\mu \mathrm{m}$ conforme a Equação (4.1), da página 97. Por meio da Figura 4. 37-a observa-se que a espessura de corte crítica do cavaco se comportou correspondente a esta faixa de medidas.

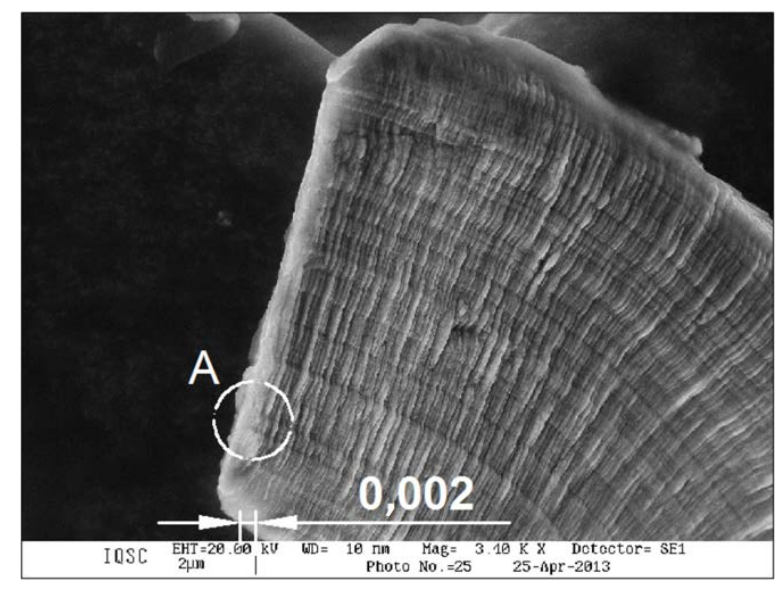

a)

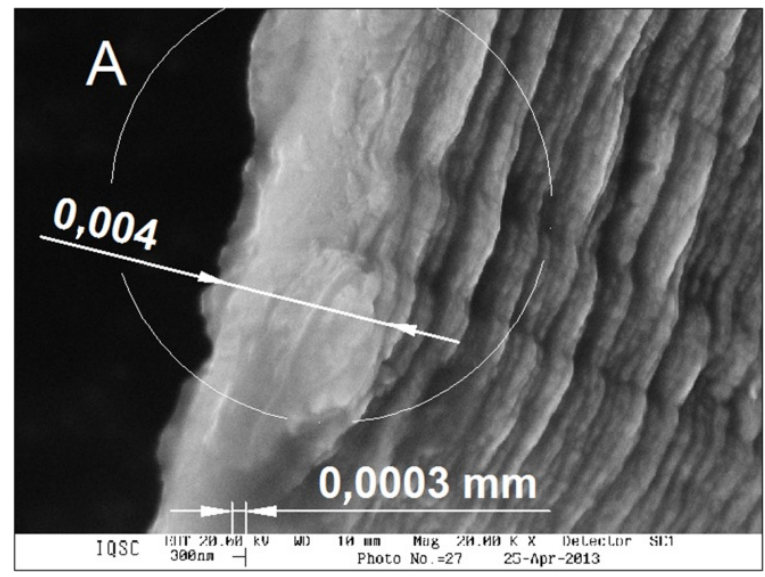

b)

Figura 4. 37 - Investigação da espessura mínima de corte por meio da análise do cavaco no MEV.

Por fim, conforme mostra a Figura 4. 38, foi possível determina a frequência de formação das lamelas $\left(\mathrm{F}_{\mathrm{la}}\right)$ com base em uma parte do comprimento do cavaco $\left(\mathrm{L}_{\mathrm{C}_{\mathrm{i}}}\right)$. Por meio do grau de recalque pode-se estimar a parte correspondente ao comprimento de corte $\left(\mathrm{L}_{\mathrm{c}_{\mathrm{i}}}=\mathrm{L}_{\mathrm{c}_{\mathrm{i}}}^{\prime} \cdot \mathrm{R}_{\mathrm{c}}\right)$ e consequentemente estimar o tempo que a ferramenta levou para passar por tal comprimento e formar as lamelas $\left(\mathrm{t}_{\mathrm{c}}=\mathrm{L}_{\mathrm{c}_{\mathrm{i}}} / \mathrm{V}_{\mathrm{c}}\right)$. Conhecido tal tempo, basta fazer a relação do número de lamelas correspondentes a parte do comprimento do cavaco $\left(\Delta_{\mathrm{L}_{\mathrm{c}}^{\prime}}\right)$ e o tempo que a ferramenta levou para formá-las. Assim sendo, tem-se a seguinte equação para estimar a frequência de formação das lamelas:

$$
\mathrm{F}_{\mathrm{la}}=\frac{\Delta_{\mathrm{L}^{\prime}{ }_{\mathrm{c}}}}{\mathrm{L}_{\mathrm{C}_{\mathrm{i}}}^{\prime} \cdot \mathrm{R}_{\mathrm{c}}} \mathrm{V}_{\mathrm{c}}
$$


Para o caso da Figura 4. 38, um grau de recalque de 3,35 e uma velocidade de corte de $50 \mathrm{~m} / \mathrm{min}$, a frequência de formação das lamelas foi de, aproximadamente, $100 \mathrm{kHz}$.

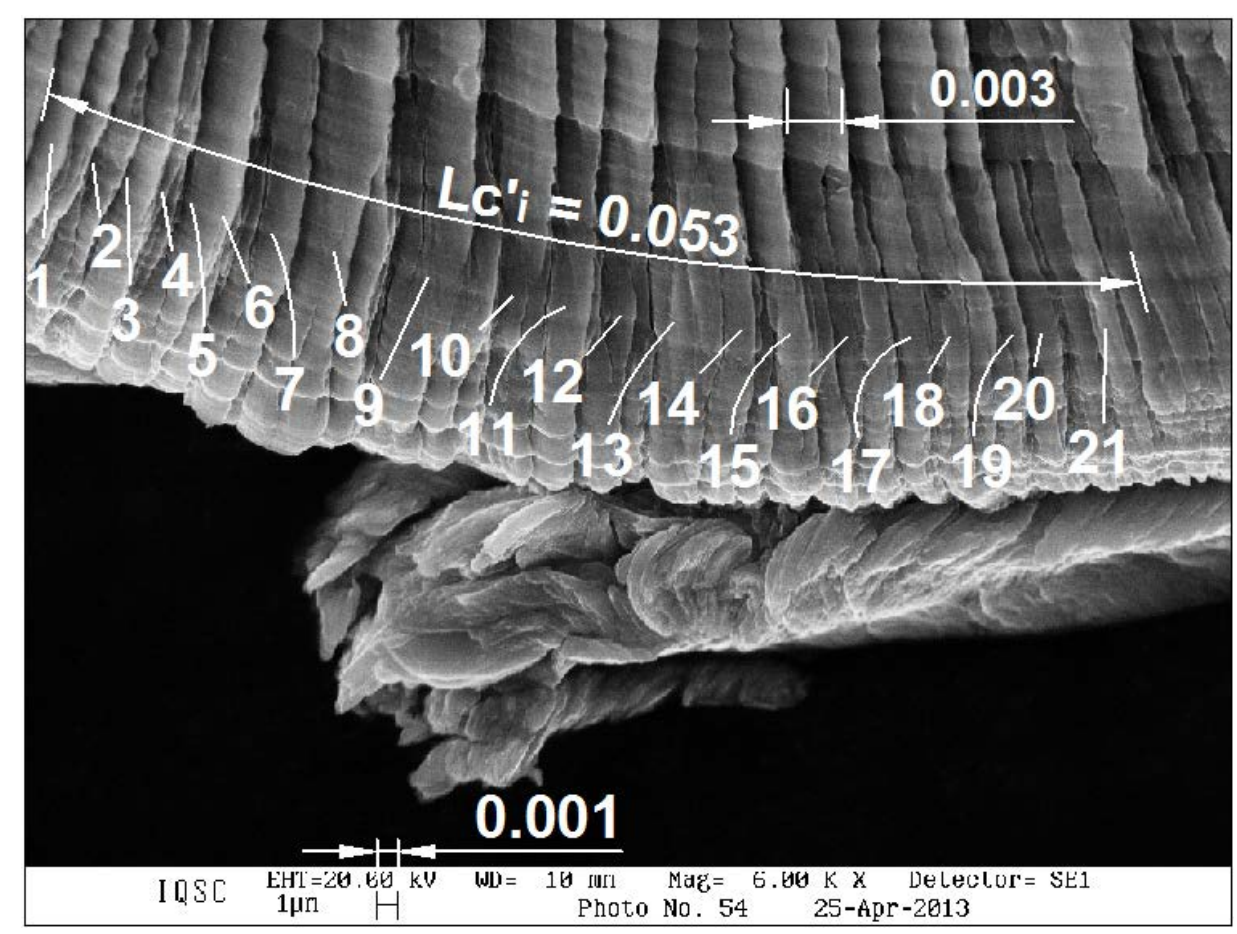

Figura 4. 38 - Frequência de formação das lamelas.

\subsection{RUGOSIDADE}

Neste subitem serão apresentados os resultados superficiais obtidos das condições de fresamento. Inicialmente são apresentados o estado dos canais de abertura (juntamente com os fresamentos parciais), a seguir serão discutidos as rugosidades Ra, Rq e Rt nas direções de avanço e perpendicular ao avanço. Por fim serão analisadas as técnicas de rugosidade Sa, Sq, Sz, Ssk e Sku.

O método de estimativa das rugosidades das condições consiste da seguinte forma: para os parâmetros de medição Ra, Rq e Rt foi tomada uma amostra do meio dos canais e analisado cinco faixas dentro desta amostra, de modo que para determinar Ra, Rq e Rt é feito a média destas faixas; para a análise dos parâmetros de medição Sa, Sq, Sz, Ssk e Sku foi tomada três amostras e calculada a média entre estas, a primeira no começo do canal, a segunda no meio e a terceira no final do canal (de acordo com a Figura 4.1, da página 73, tais regiões são nomeadas como AA', BB' e CC') 


\subsubsection{Apresentação das superfícies}

A Tabela 4. 10 e a Tabela 4. 11 apresentam as imagens do estado das superfícies geradas pelas condições de fresamento do primeiro ensaio e do segundo ensaio (réplica), obtidas por perfilometria óptica. Conforme observa-se na primeira coluna da Tabela 4 . 10 e Tabela 4. 11, os canais são inicialmente abertos em fresamento em cheio e posteriormente são realizados os fresamentos frontais parciais.

Tabela 4. 10 - Apresentação das superfícies geradas no primeiro ensaio (Ensaio 1).

C1
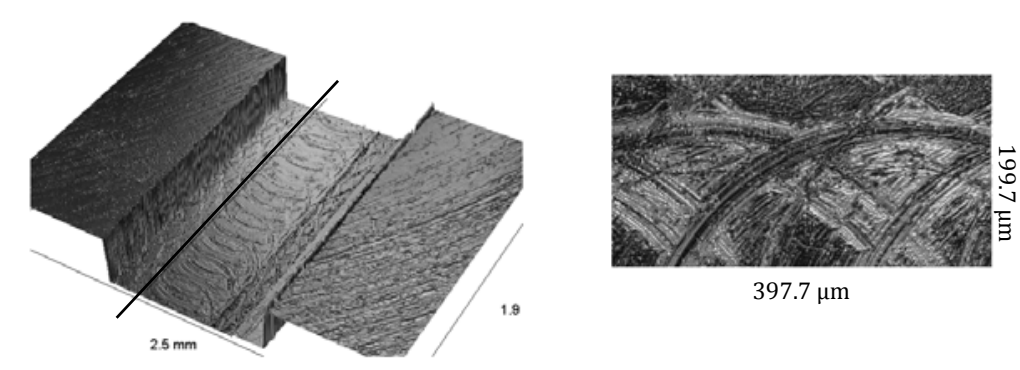

$397.7 \mu \mathrm{m}$
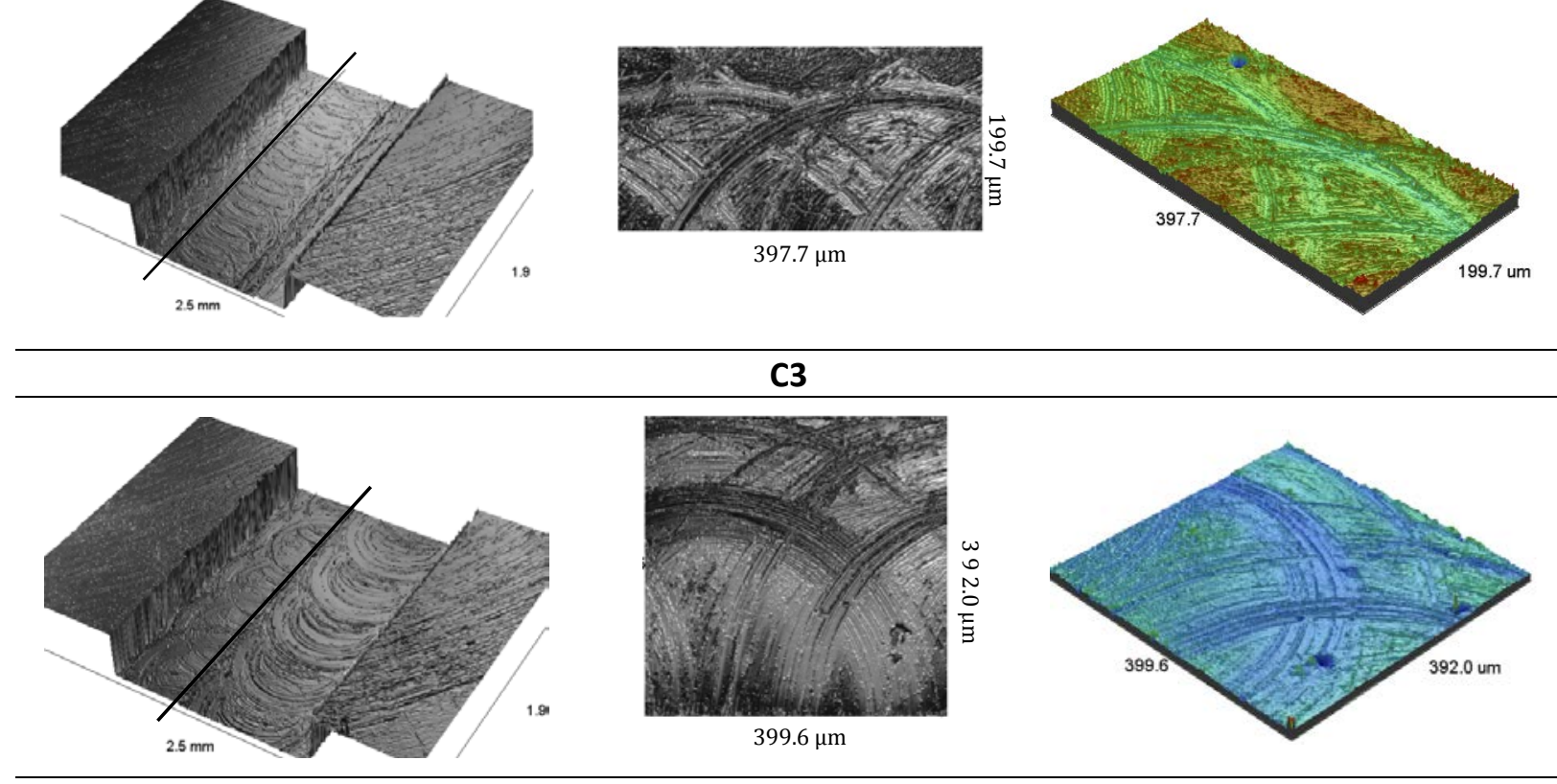

C4
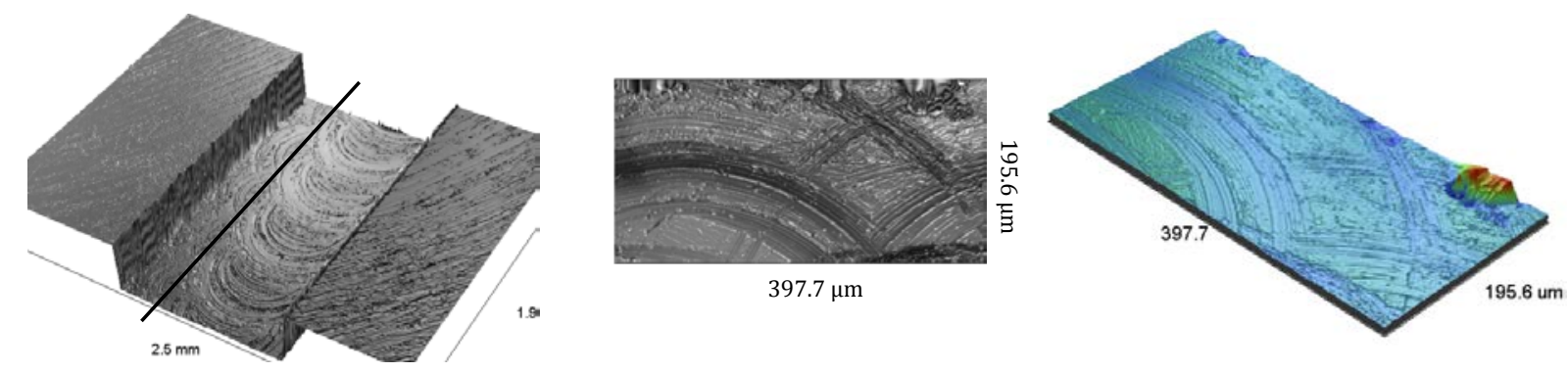
Tabela 4. 11 - Apresentação das superfícies geradas no segundo ensaio (Ensaio 2).

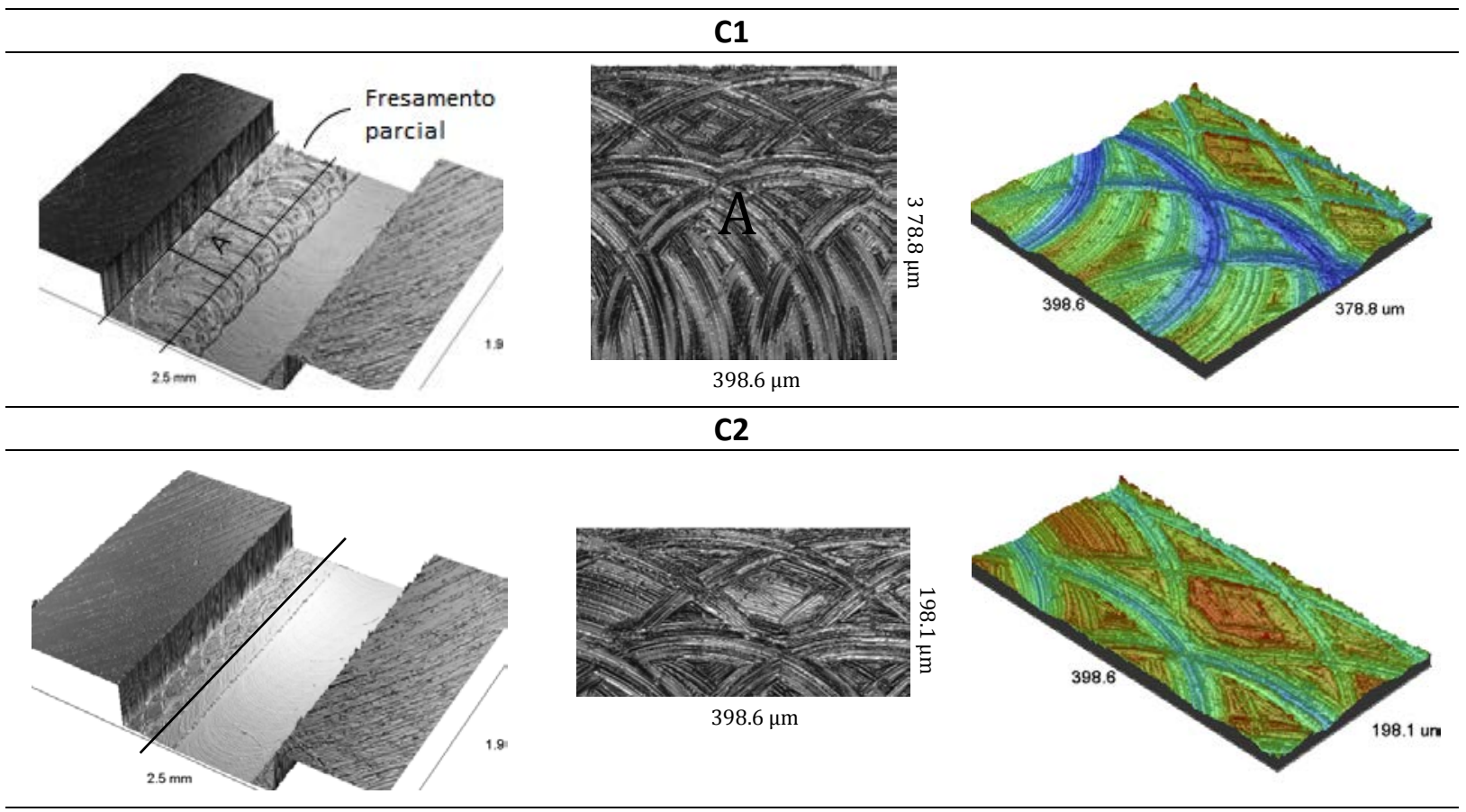

C3
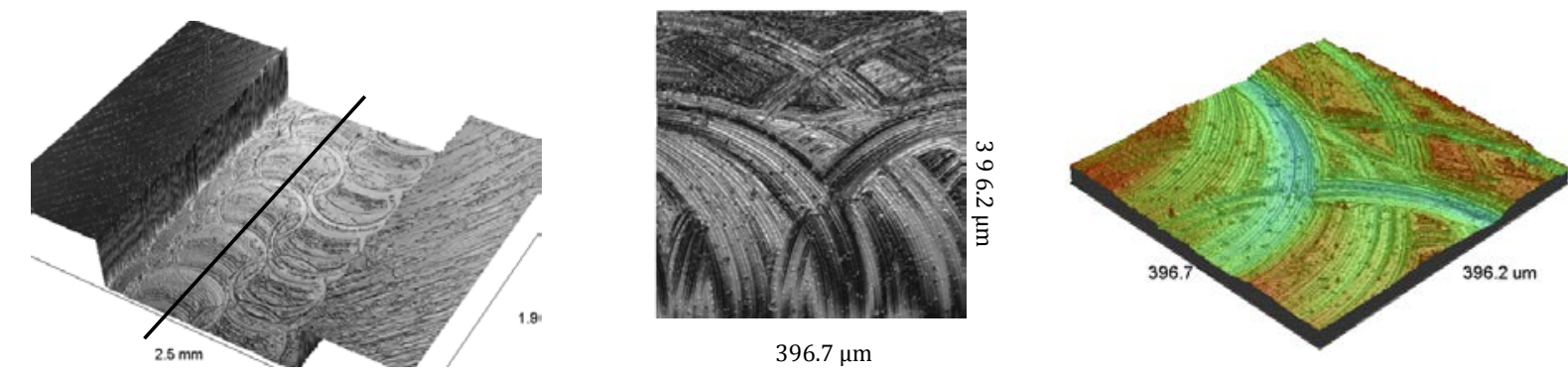

$396.7 \mu \mathrm{m}$

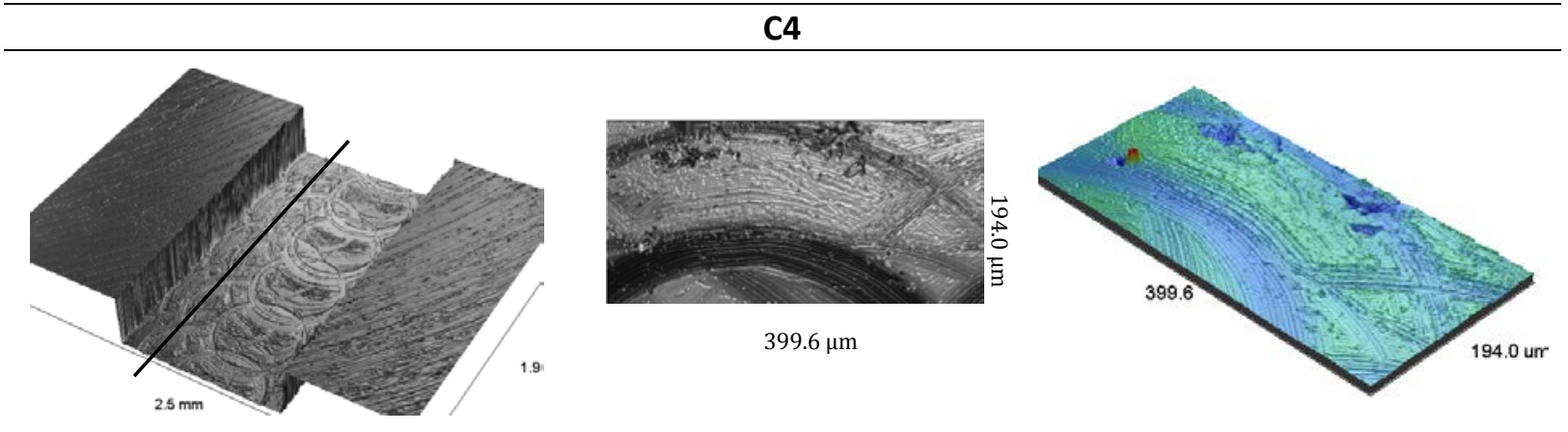

Por meio da primeira coluna do Tabela 4. 10 e da Tabela 4. 11 pode-se observar que na abertura do canal (fresamento em cheio) da condição C1 dos dois ensaios, foi obtido um bom acabamento. Após o deslocamento lateral da fresa e realização do fresamento parcial, nota-se que o acabamento não atingiu o mesmo padrão do fresamento em cheio.

A hipótese assumida para este efeito é o fato de que quando se trabalha com uma fresa de dois dentes em fresamento em cheio, esta fica condicionada a largura do canal e as deflexões 
ocorrem somente no sentido oposto ao avanço, dada pela força de avanço (Figura 4. 39-a). Além disso, neste caso, o corte é engajado e a deflexão aumenta e diminui gradativamente. Tudo isto favorece a vida da fresa e corrobora para um melhor acabamento.

Por outro lado, quando se trabalha com a fresa em fresamento frontal parcial, a força de compressão que se encontra na direção perpendicular à superfície principal de corte sentido ao centro da fresa, tende a empurrar a mesma em sentido oposto a tal superfície, assim como a força de avanço tende a empurrar a ferramenta em sentido contrário ao movimento de avanço. Tais efeitos ocasionam maiores deflexões da ferramenta (Figura 4. 39-b). Além disso, em fresamento parcial com tempo de movimento em vazio (corte não engajado), ora a fresa sofre deflexões com aumento gradativo ora a fresa volta ao seu estado natural em um período rápido de tempo. Isto faz com que a ferramenta sofra solicitações drásticas na área de contato da fresa e a peça e assim, pequenas trincas e lascamentos da ponta da ferramenta (Figura 4. 39-c) podem ocorrer bem mais rápido do que no fresamento em cheio, prejudicando a superfície usinada.

a)

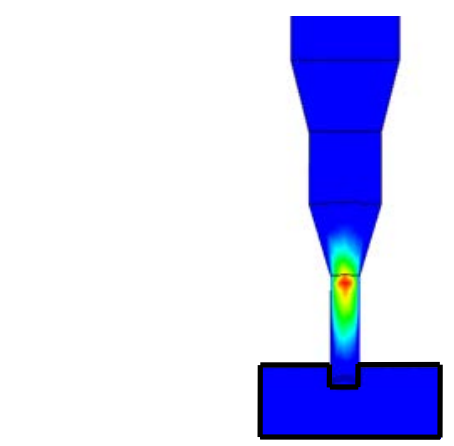

b)

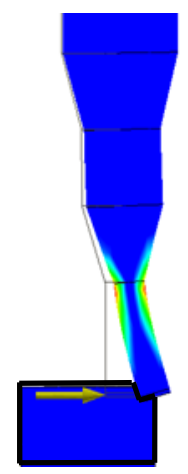

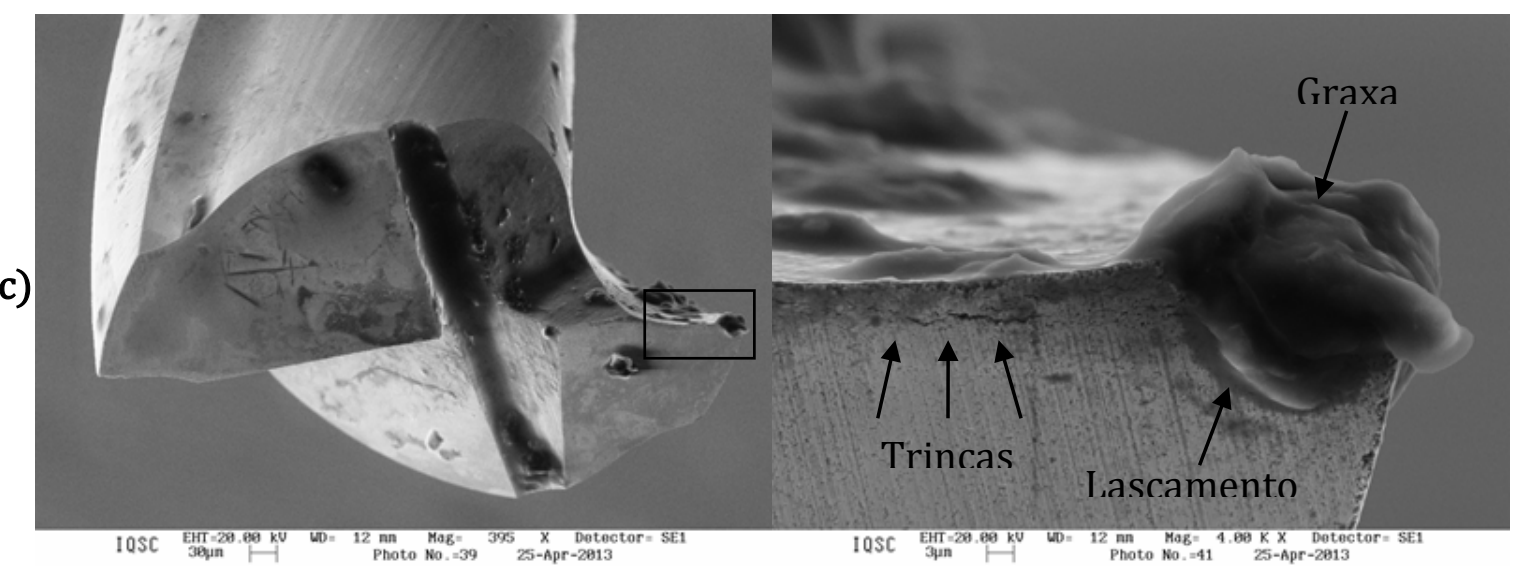

Figura 4. 39 - Processo de microfresamento: a) fresa condicionada ao canal no fresamento em cheio; b) deflexão da ferramenta no fresamento parcial; c) lascamento da ponta da ferramenta. 


\subsubsection{Ra, Rq e Rt na direção de avanço (y)}

A Tabela 4. 12 e a Tabela 4.13 apresentam as imagens das amostras que foram tomadas da região fresada para análise dos parâmetros de medição Ra, Rq e Rt. Também apresentam o perfil da rugosidade de uma das direções medidas e os valores obtidos para cada medida realizada. Para cada amostra foram feito cinco medidas

Tabela 4. $12-\mathrm{Ra}_{\mathrm{y}}, \mathrm{Rq}_{\mathrm{y}}$ e $\mathrm{Rt}_{\mathrm{y}}$ do primeiro ensaio (unidades em $\mu \mathrm{m}$ ).

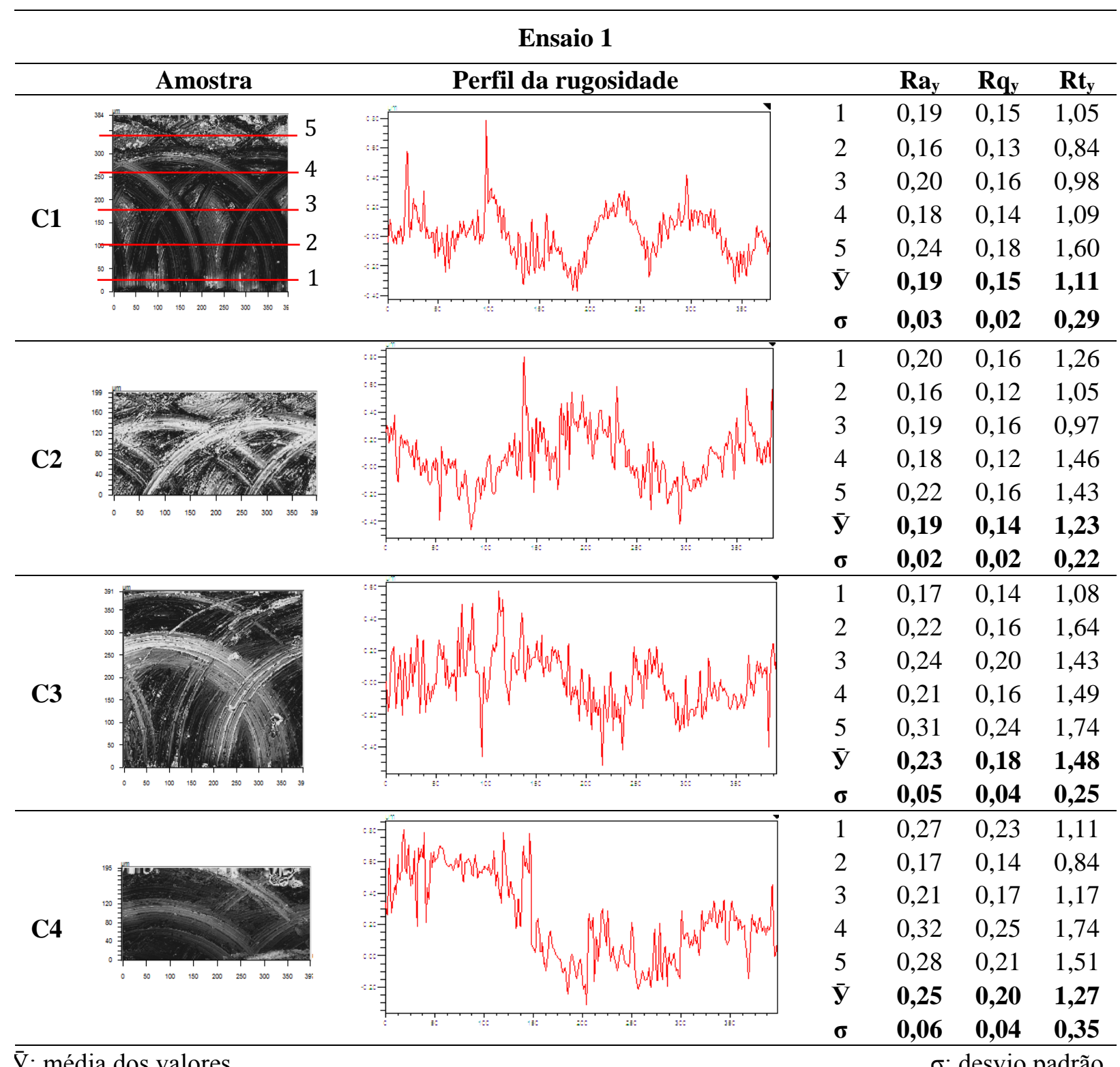


Tabela 4. $13-\mathrm{Ra}_{\mathrm{y}}, \mathrm{Rq}_{\mathrm{y}}$ e $\mathrm{Rt}_{\mathrm{y}}$ do segundo ensaio (unidades em $\mu \mathrm{m}$ ).

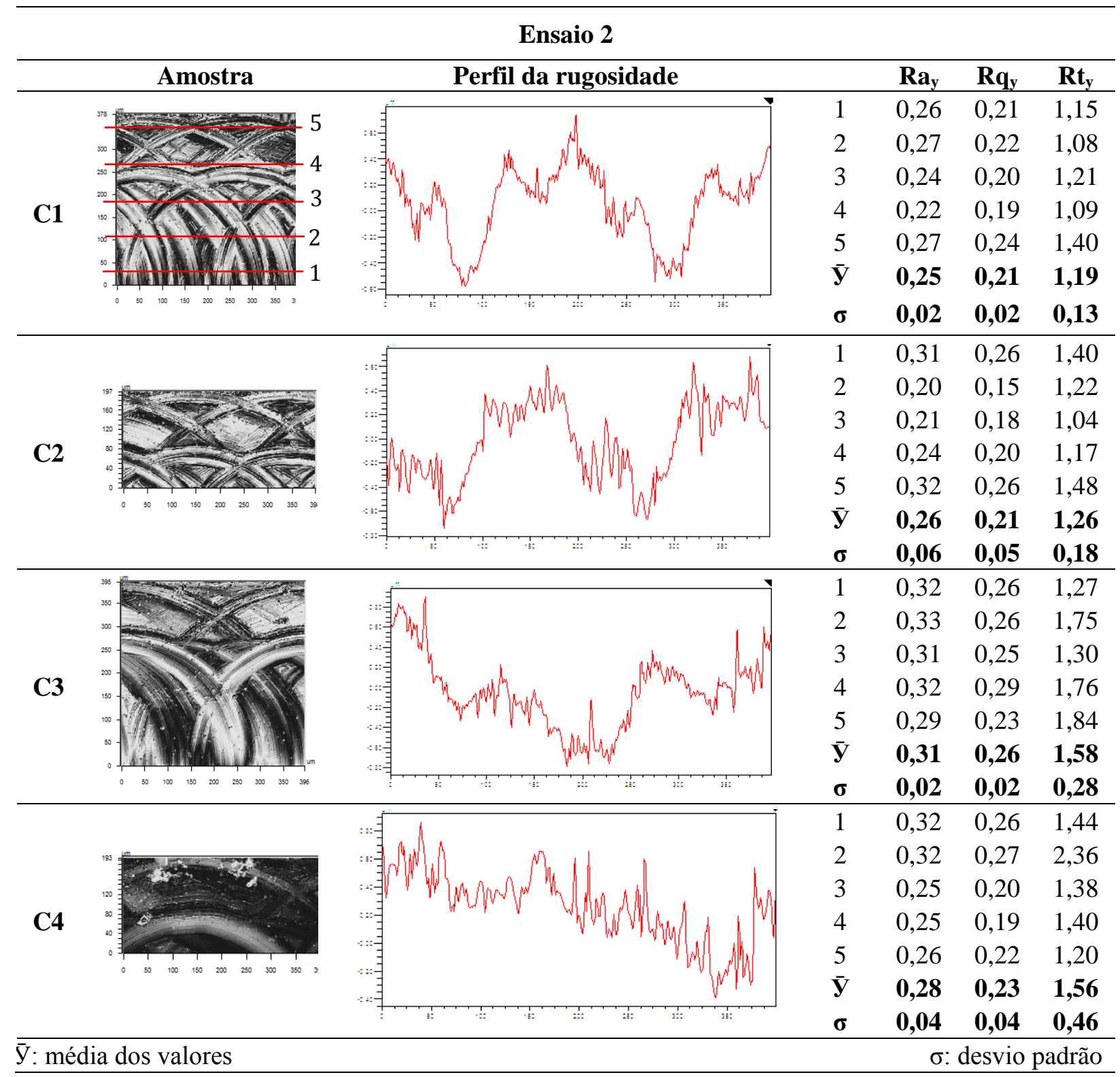

A Figura 4. 40 fornece um gráfico, para melhor visualização, dos valores dos parâmetros de medição na direção de avanço apresentados pela Tabela 4. 12 e Tabela 4. 13. Por meio desta figura pode-se ver que os parâmetros Ra e Rq obtiveram valores com uma diferença baixa, porém a maioria dos intervalos de confiança (99\%) se encontraram. Os valores de Ra, Rq e Rt das condições $\mathrm{C} 1$ e $\mathrm{C} 2\left(\mathrm{f}_{\mathrm{z}}=5 \mu \mathrm{m} /\right.$ dente $)$ são menores do que os valores das condições C3 e $\mathrm{C} 4\left(\mathrm{f}_{\mathrm{z}}=10 \mu \mathrm{m} /\right.$ dente) . 


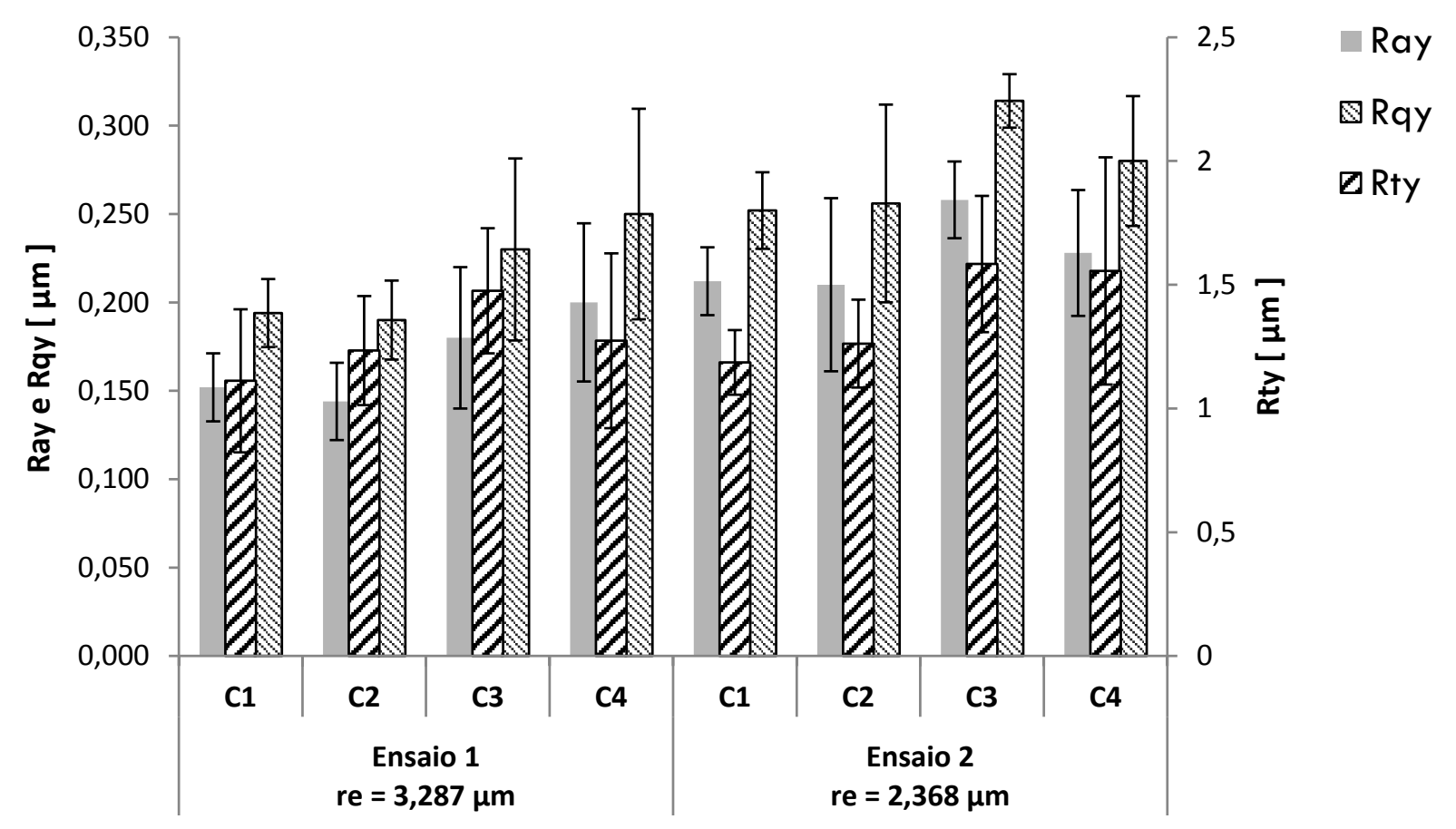

Figura 4. 40 - Valores da rugosidade na direção de avanço.

Com base nos parâmetros de usinagem das condições de fresamento e dos resultados médios da Tabela 4. 12 e a Tabela 4. 13, pode-se montar um gráfico e verificar seus efeitos. Conforme a Figura 4. 41, observa-se que o aumento do avanço por dente $\mathrm{f}_{\mathrm{z}}$, apresentou influência no parâmetro Rt na direção de avanço. A penetração de trabalho $\mathrm{a}_{\mathrm{e}} \mathrm{e}$ o raio de aresta $r_{e}$ não apresentaram influência significativa no parâmetro Rt.

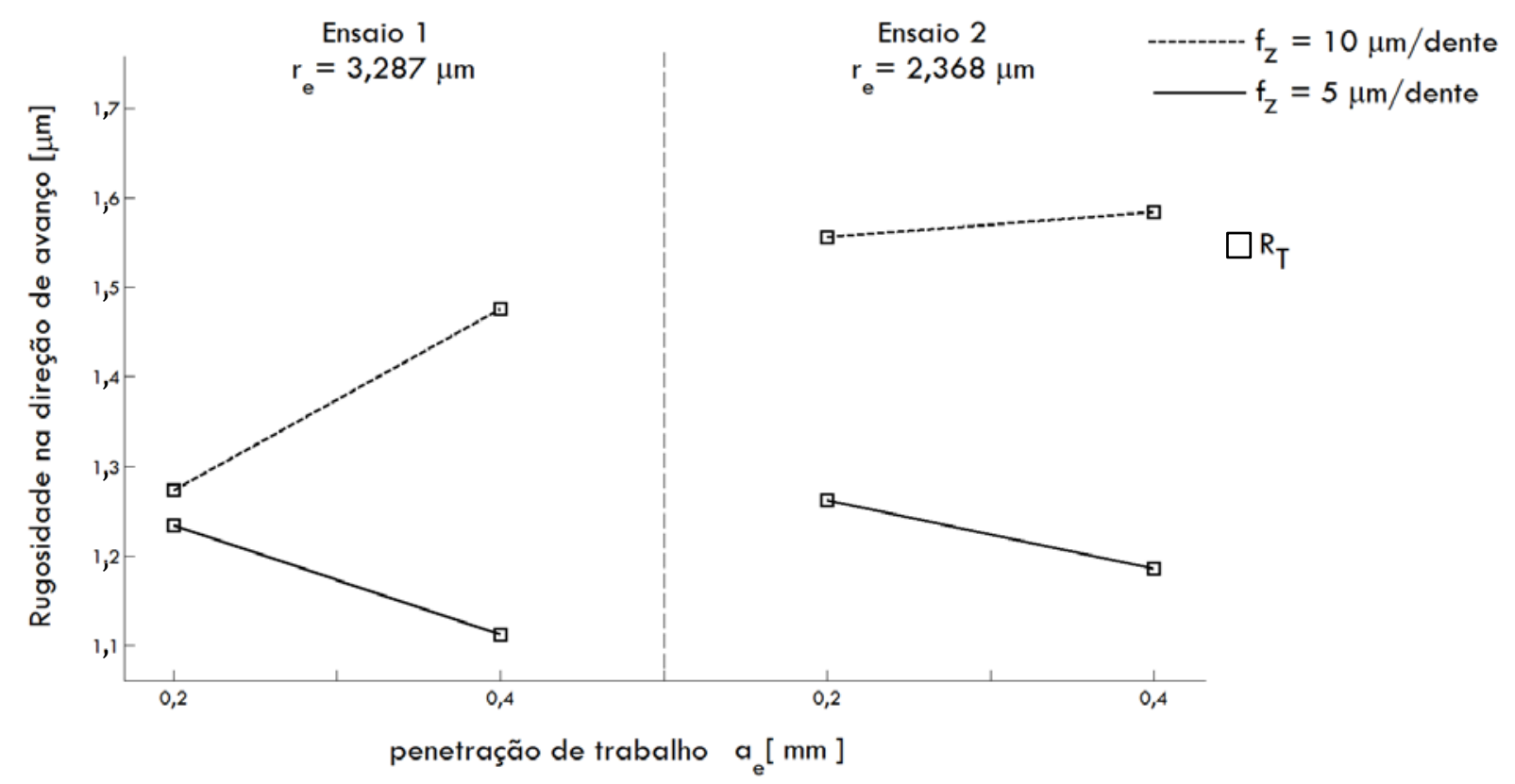

Figura 4. 41 - Rt na direção de avanço, em função do $a_{e}, f_{z}$ e $r_{e}$ 
Conforme a Figura 4. 42, o avanço por dente $f_{z}$ e o raio de aresta $r_{e}$ apresentaram influência nos parâmetros $\mathrm{Ra}$ e $\mathrm{Rq}$ na direção de avanço. A penetração de trabalho $\mathrm{a}_{\mathrm{e}}$ não apresentou influência significativa no parâmetro Ra e Rq.

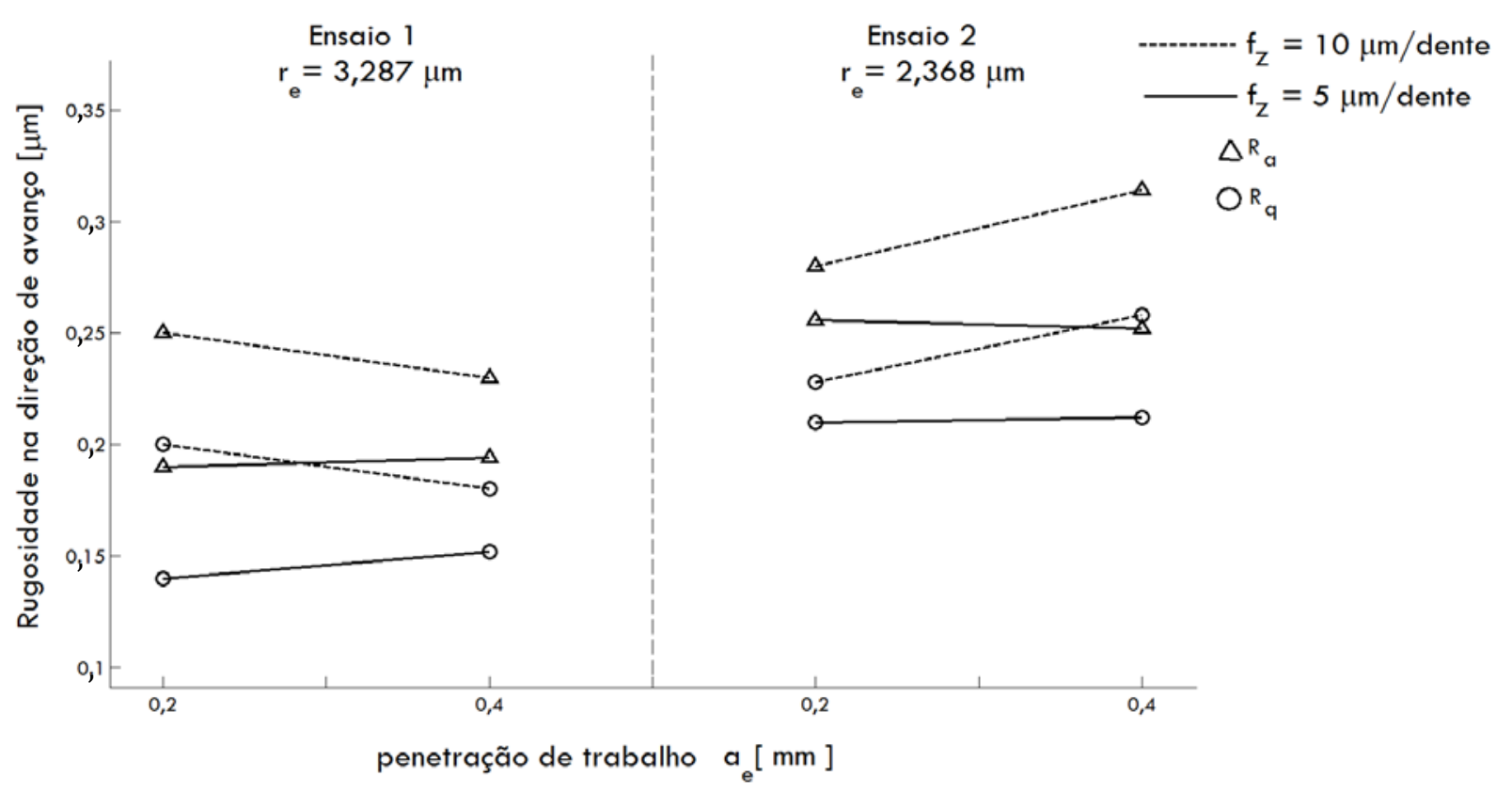

Figura 4. 42 - Ra, Rq na direção de avanço, em função do $a_{e}, f_{z}$ e $r_{e}$

\subsubsection{Ra, Rq e Rt na direção perpendicular ao avanço (x)}

Neste item a apresentação será semelhante ao anterior, a diferença é que ao invés de analisar a rugosidade no sentido horizontal, esta será analisada no sentido vertical. A Tabela 4.14 e Tabela 4.15 apresentam os valores de Ra, Rq e Rt na direção perpendicular ao avanço, o perfil da rugosidade e os valores obtidos para cada medida realizada.

Tabela 4. 14 - $\mathrm{Ra}_{\mathrm{x}}, \mathrm{Rq}_{\mathrm{x}}$ e $\mathrm{Rt}_{\mathrm{x}}$ do primeiro ensaio (unidades em $\mu \mathrm{m}$ ).

\begin{tabular}{|c|c|c|c|c|c|c|}
\hline \multicolumn{7}{|c|}{ Ensaio 1} \\
\hline & Amostra & Perfil da rugosidade & & $\mathbf{R} \mathbf{a}_{\mathrm{x}}$ & $\mathbf{R q}_{\mathbf{x}}$ & $\mathbf{R} \mathbf{t}_{\mathrm{x}}$ \\
\hline \multirow{7}{*}{ C1 } & 1223345 & & 1 & 0,27 & 0,21 & 1,78 \\
\hline & & & 2 & 0,24 & 0,18 & 1,23 \\
\hline & & & 3 & 0,27 & 0,23 & 1,47 \\
\hline & & (1) & 4 & 0,23 & 0,18 & 1,50 \\
\hline & & 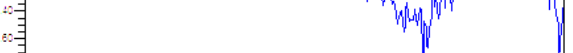 & 5 & 0,21 & 0,15 & 1,36 \\
\hline & & $w=$ & $\overline{\mathbf{y}}$ & 0,24 & 0,19 & 1,47 \\
\hline & 6 & 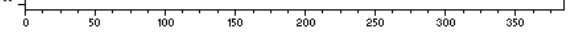 & $\sigma$ & 0,03 & 0,03 & 0,20 \\
\hline
\end{tabular}


Continuação da Tabela 4. 14.

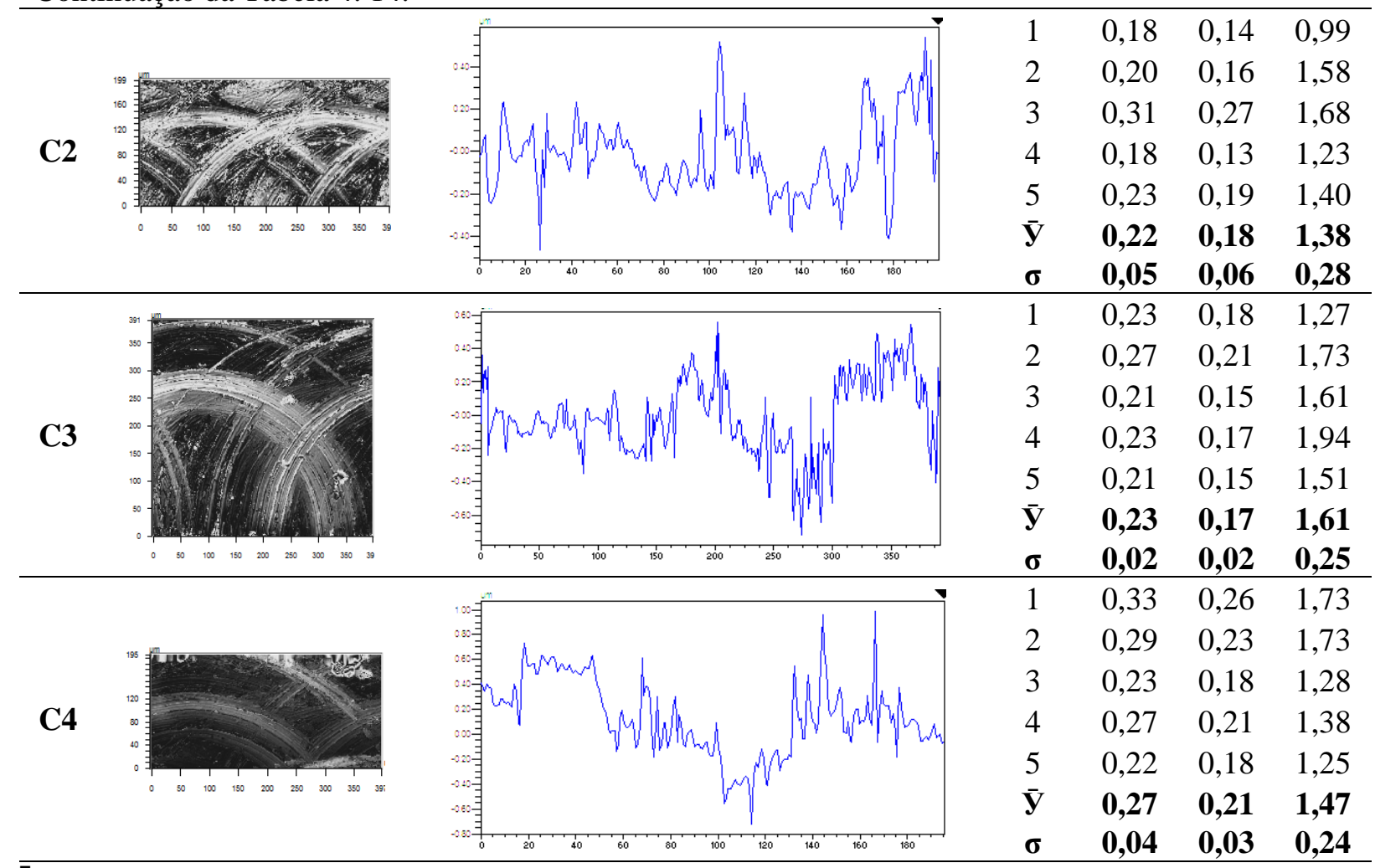

$\overline{\mathrm{y}: \text { média dos valores }}$ $\sigma:$ desvio padrão

Tabela 4. 15 - $\mathrm{Ra}_{\mathrm{x}}, \mathrm{Rq}_{\mathrm{x}}$ e $\mathrm{Rt}_{\mathrm{x}}$ do segundo ensaio (unidades em $\mu \mathrm{m}$ ).

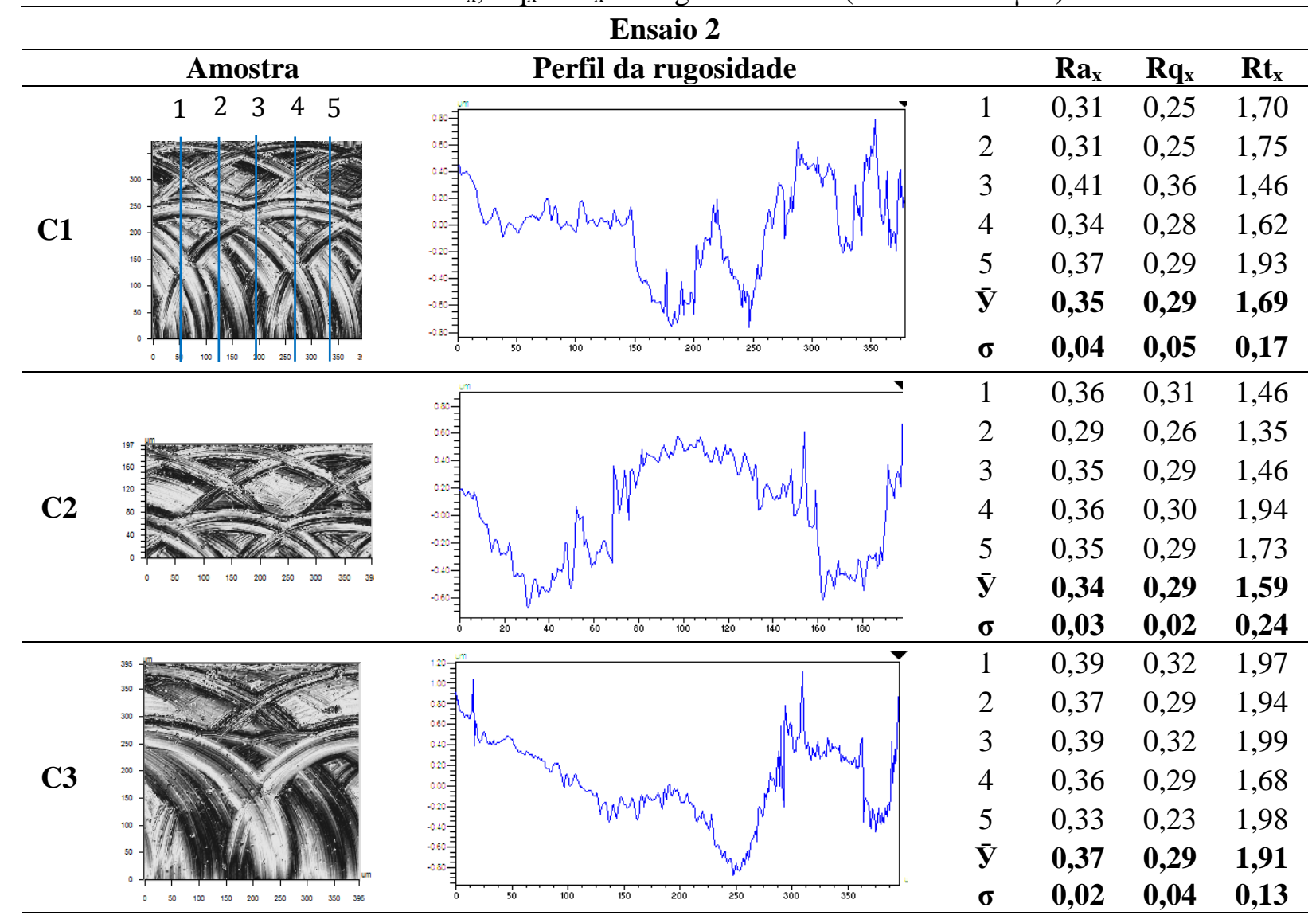




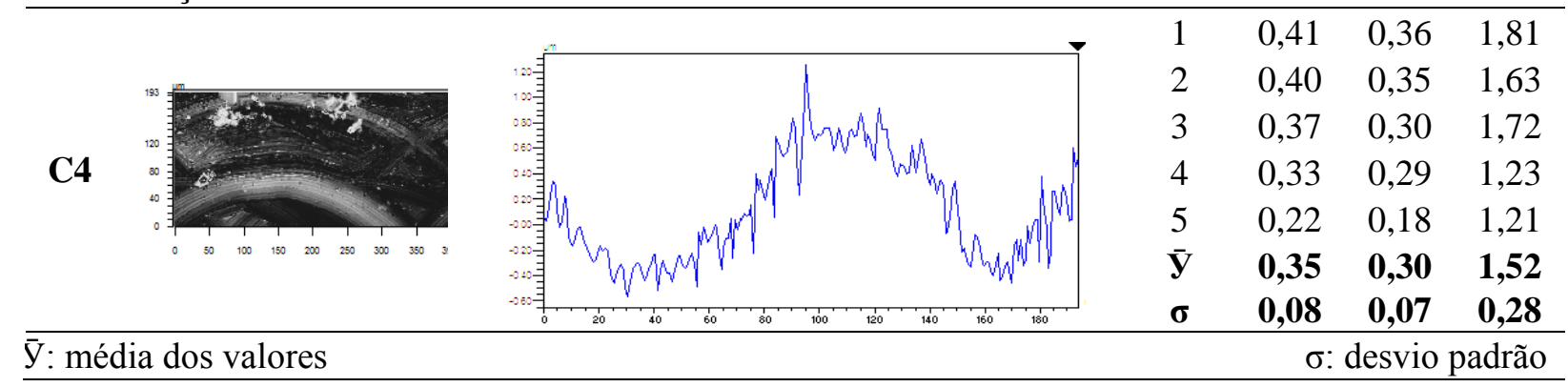

A Figura 4. 40 fornece um gráfico dos valores da rugosidade na direção perpendicular ao avanço conforme a Tabela 4. 14 e a Tabela 4. 15. Por meio desta figura pode-se ver que os parâmetros Ra e Rq, também, obtiveram valores com uma diferença baixa, porém a maioria dos intervalos de confiança (99\%) se encontraram. Os valores de Ra, Rq e Rt das condições C1 e $\mathrm{C} 2\left(\mathrm{f}_{\mathrm{z}}=5 \mu \mathrm{m} /\right.$ dente $)$ não demonstraram uma diferença significativa comparado com os valores das condições C3 e C4 ( $f_{z}=10 \mu \mathrm{m} /$ dente $)$.

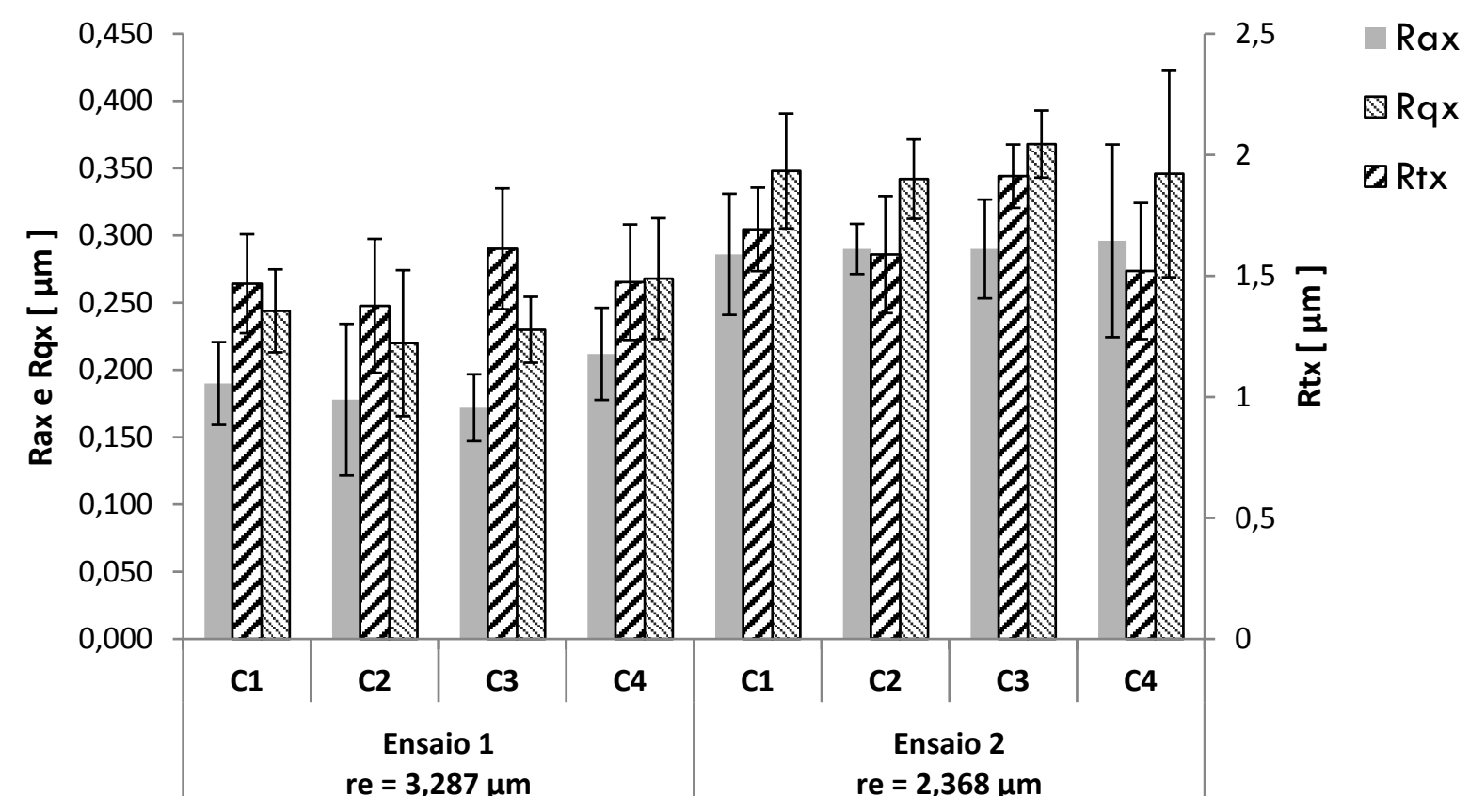

Figura 4. 43 - Valores da rugosidade na direção perpendicular ao avanço.

Com base nos parâmetros de corte das condições de fresamento e dos resultados médios da Tabela 4. 14 e da Tabela 4. 15, pode-se montar um gráfico para investigar a influência das variáveis de entrada. De acordo com a Figura 4. 44, o aumento da penetração de trabalho $\mathrm{a}_{\mathrm{e}} \mathrm{e}$ do avanço por dente $f_{z}$, apresentou influência no parâmetro de medição Rt na direção perpendicular ao avanço. O raio de aresta $r_{e}$ não apresentou influência significativa em Rt. 


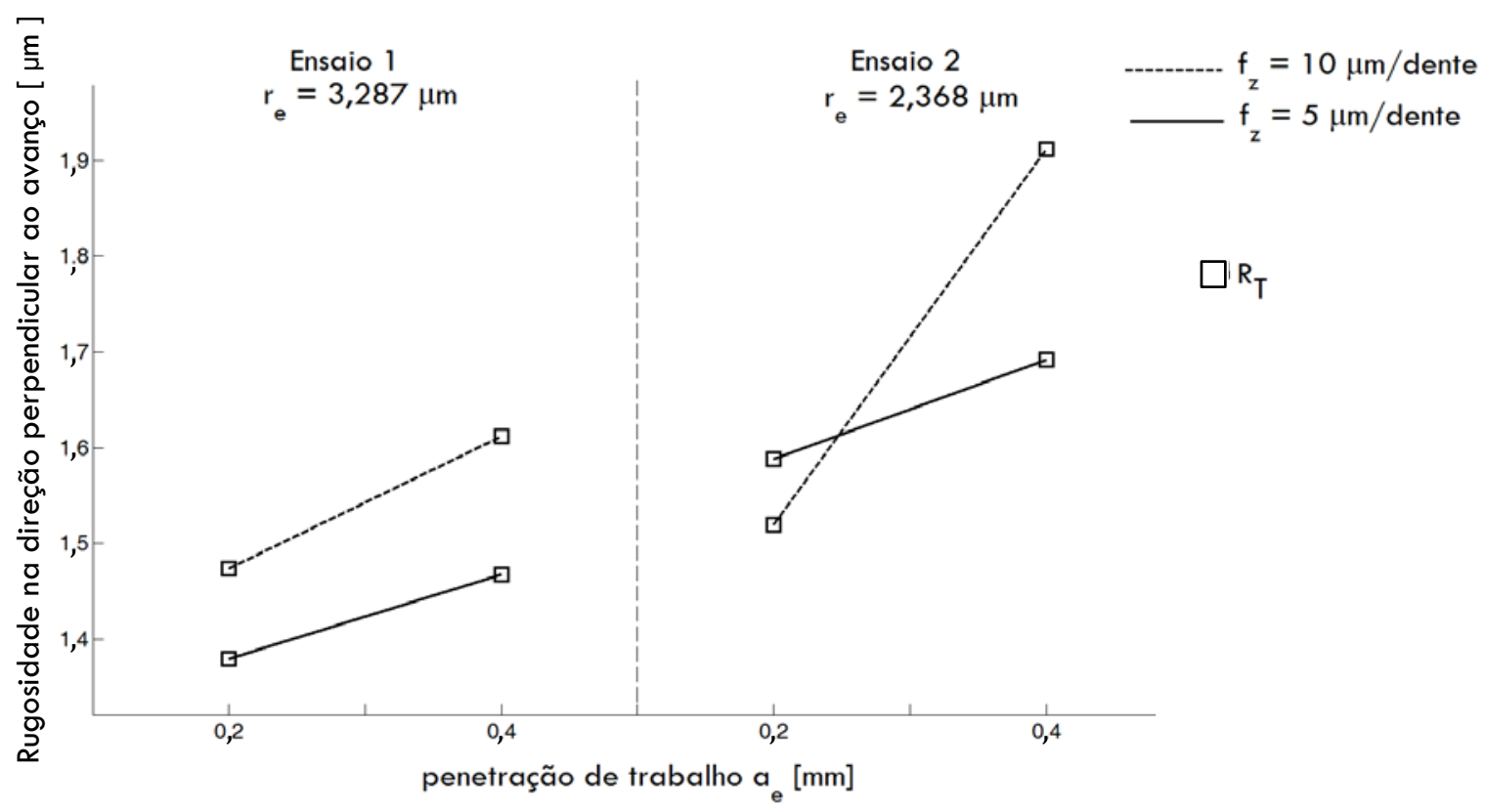

Figura 4. 44 - Rt na direção perpendicular ao avanço, em função do $a_{e}, f_{z}$ e $r_{e}$

Conforme a Figura 4. 45, o avanço por dente $f_{z}$ e o raio de aresta $r_{e}$ apresentaram influência nos parâmetros $\mathrm{Ra}$ e $\mathrm{Rq}$ na direção perpendicular ao avanço. A penetração de trabalho $\mathrm{a}_{\mathrm{e}}$ não apresentou influência significativa no parâmetro Ra e Rq.

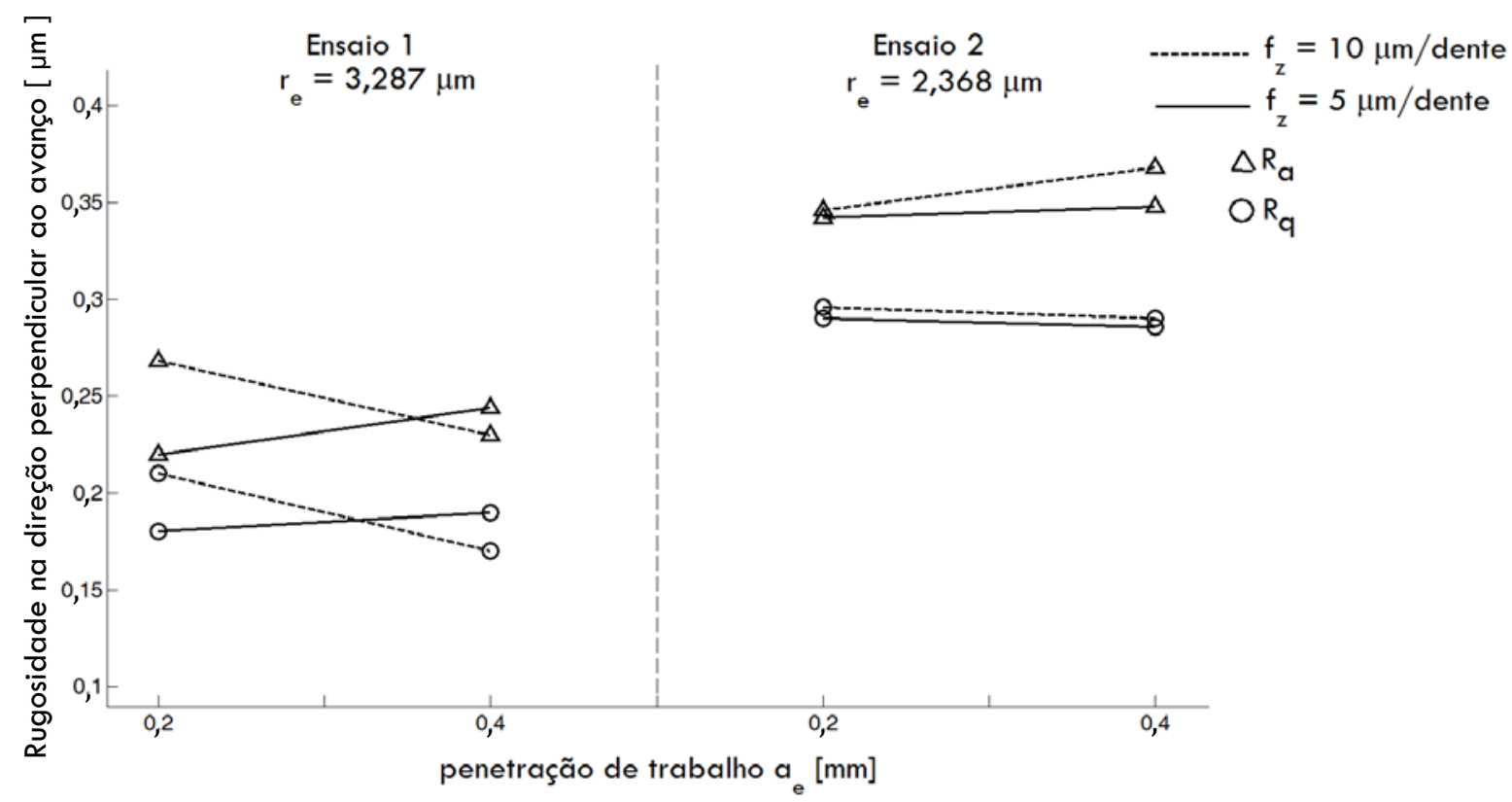

Figura 4. 45 - Ra, Rq na direção perpendicular ao avanço, em função do $a_{e}, f_{z}$ e $r_{e}$ 
Com o intuito de verificar se há uma diferença significativa entre os valores da rugosidade na direção de avanço (direção y) e na direção perpendicular ao avanço (direção x), uma análise estatística do intervalo de confiança (99\%, 95\% e 90\%) das médias obtidas dos parâmetros Ray, Rqy e Rty e dos parâmetros Rax, Rqx e Rtx, com base no desvio padrão combinado de cada média, foram comparados. Para os experimentos realizados por este trabalho, conforme mostra a Figura 4. 46, não existe diferenças significativas, para uma confiabilidade de 99\%, entre as direções para análise de tais parâmetros de medição. Por outro lado, para um intervalo de confiança de 95\% e 90\%, existe uma diferença significativa entre o parâmetro Rt medido na direção de avanço e na direção perpendicular ao avanço.
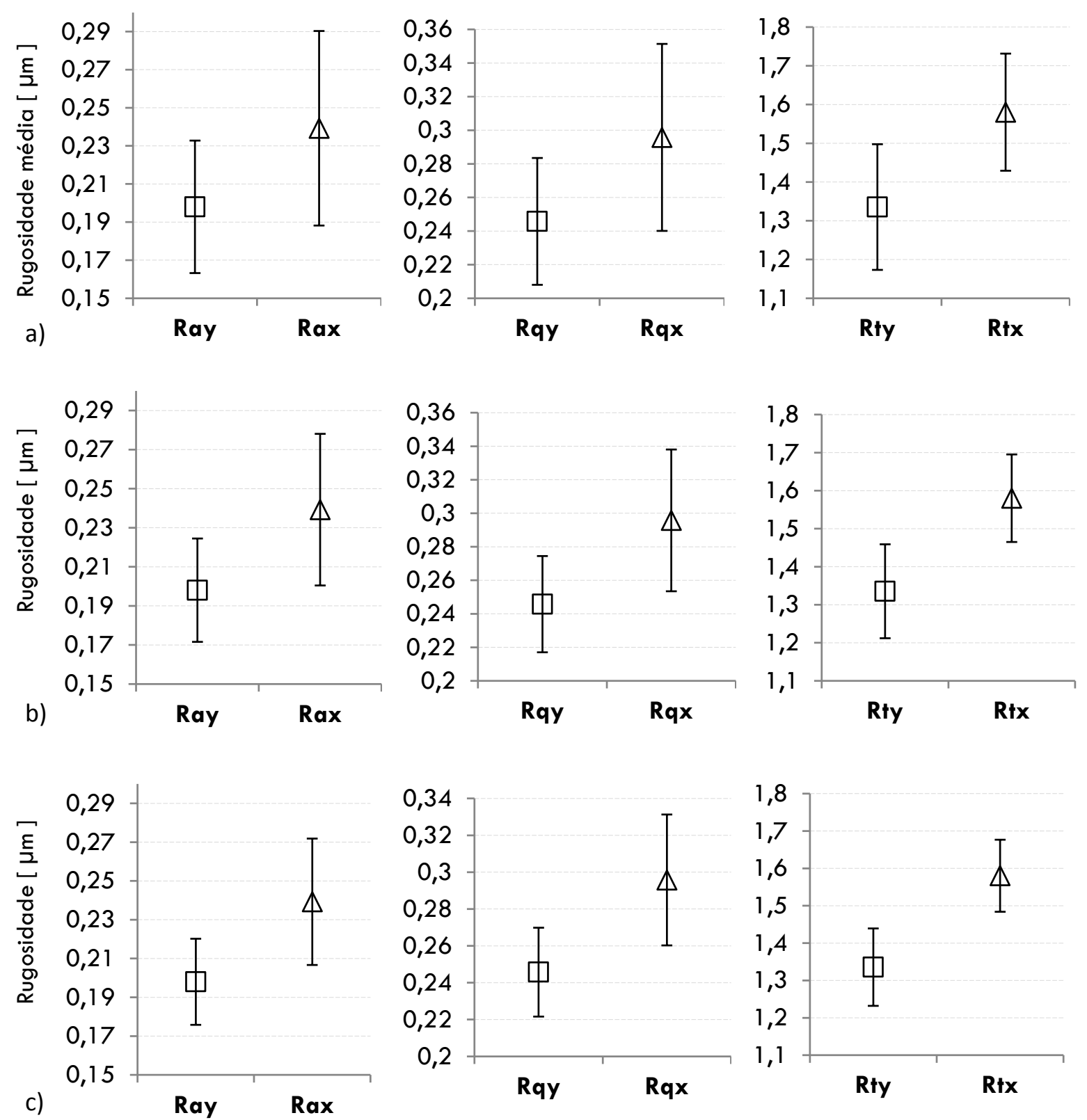

Figura 4. 46 - Intervalo de confiança: a) 99\%; b)95\%; c) 90\% 


\subsubsection{Sa, Sq, Sz, Ssk e Sku da superfície}

Sa e Sq são a média aritmética das alturas da superfície a partir de um plano médio e a rugosidade média quadrática, avaliadas em uma superfície tridimensional. Sa e Sq podem ser utilizados para indicar desvios significativos nas características da superfície. Sq é normalmente usado para especificar superfícies ópticas e Sa é usado para superfícies usinadas. Sz é a altura máxima da superfície, as implicações típicas para este parâmetro pode incluir superfícies de vedação e aplicação de revestimentos. Ssk (Skewness) representa o grau de simetria das alturas da superfície em relação ao plano médio. Ssk indica a predominância de picos na superfície (Ssk $>0$ ) ou vales (Ssk $<0)$. Sku (Kurtosis) indica a existência de picos abruptos na distribuição da superfície $(\mathrm{Sku}>3)$ ou vales $(\mathrm{Sku}<3)$. Ssk $=0$ e Sku $=3$ indica que as alturas da superfície são normalmente distribuídas (MICHIGAN METROLOGY, 2013).

Para verificar os parâmetros mencionados, foram tomadas três amostras de superfície, a primeira do início do canal (AA'), a segunda do meio do canal (BB') e a terceira no final do canal (CC'), conforme apresenta a Tabela 4.16 e Tabela 4.17.

Tabela 4. 16 - Apresentação das superfícies e seus parâmetros de medição (Ensaio 1).

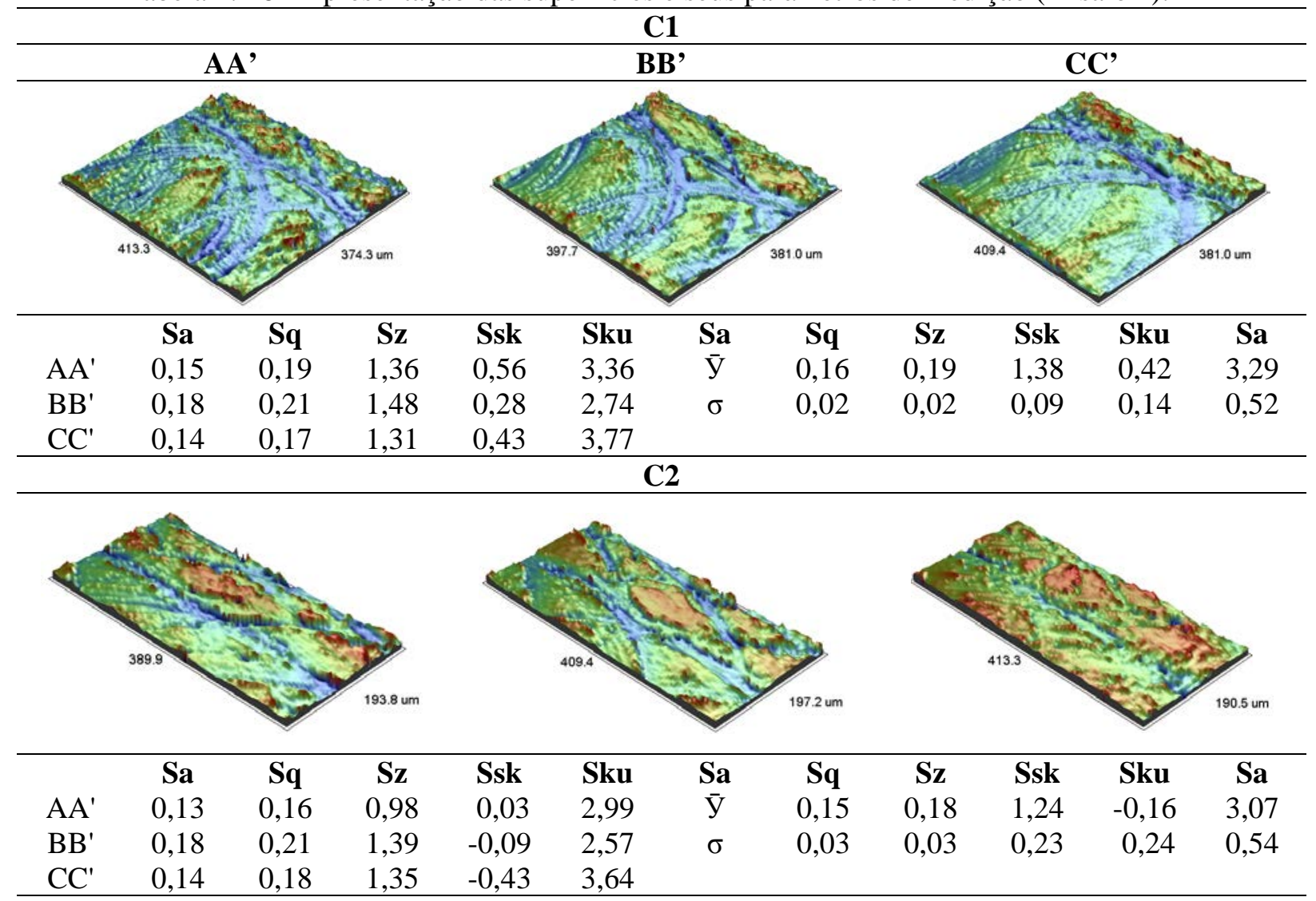


Continuação da Tabela 4. 16.

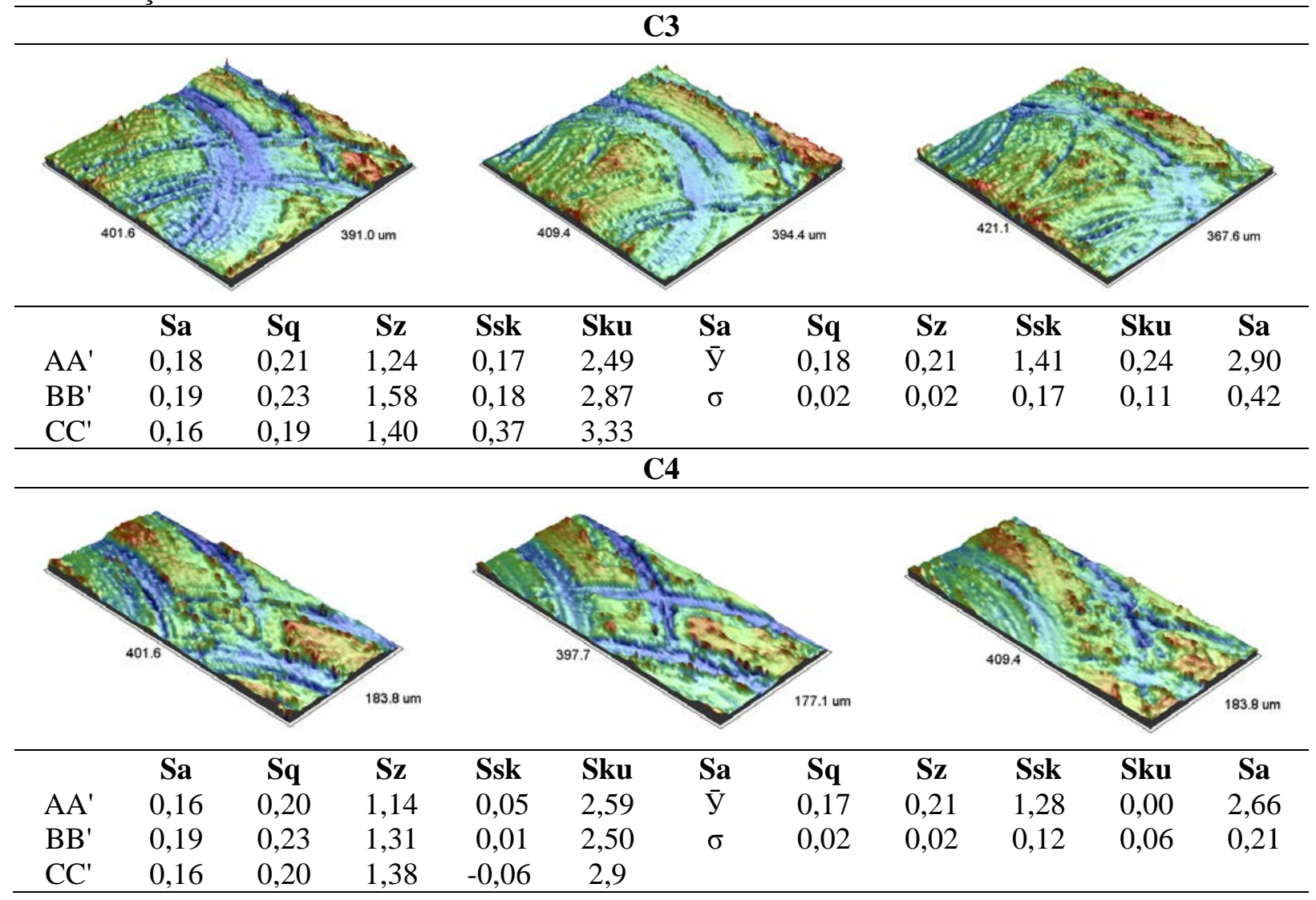

Tabela 4. 17 - Apresentação das superfícies e seus parâmetros de medição (Ensaio 2).

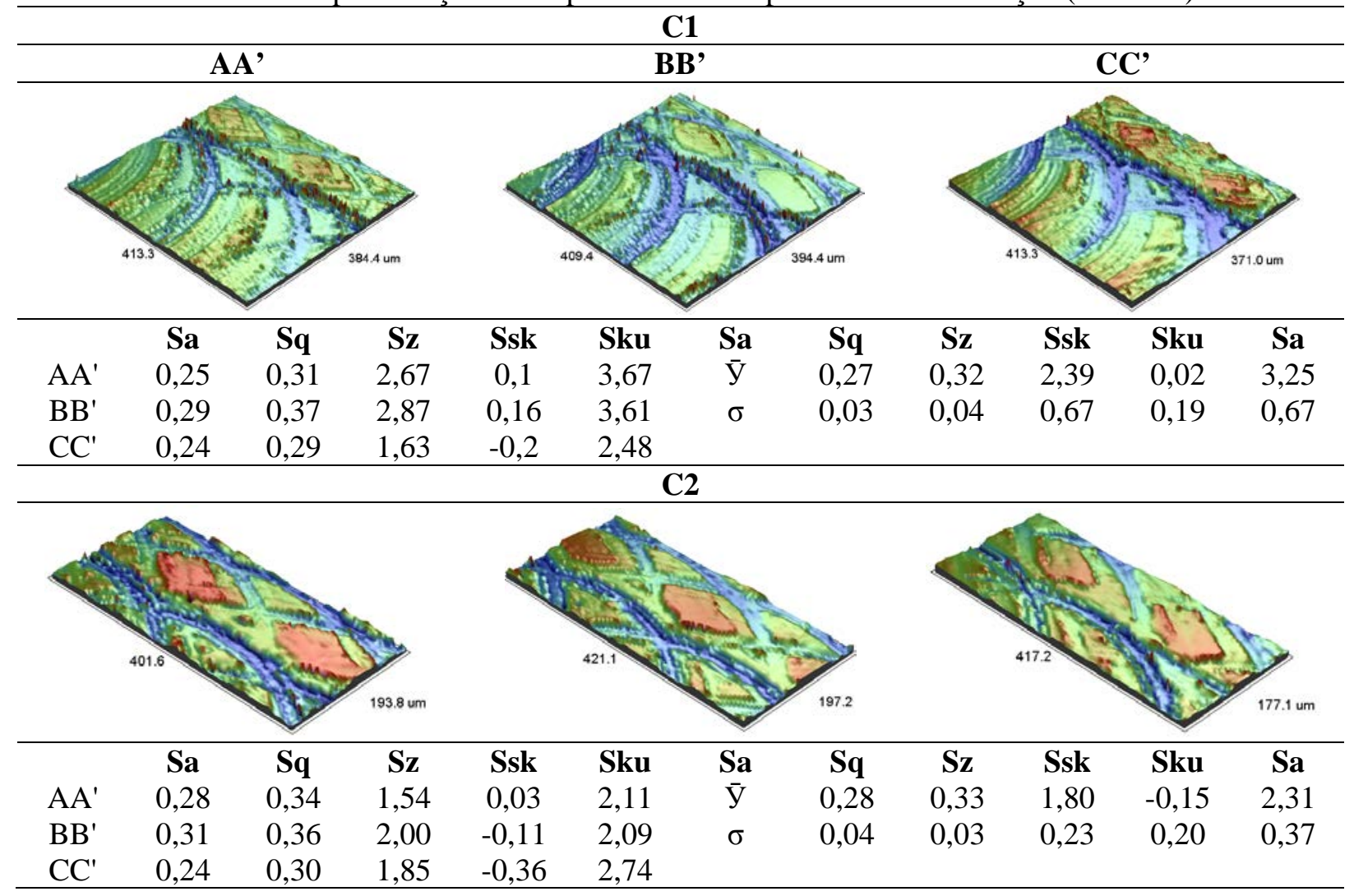




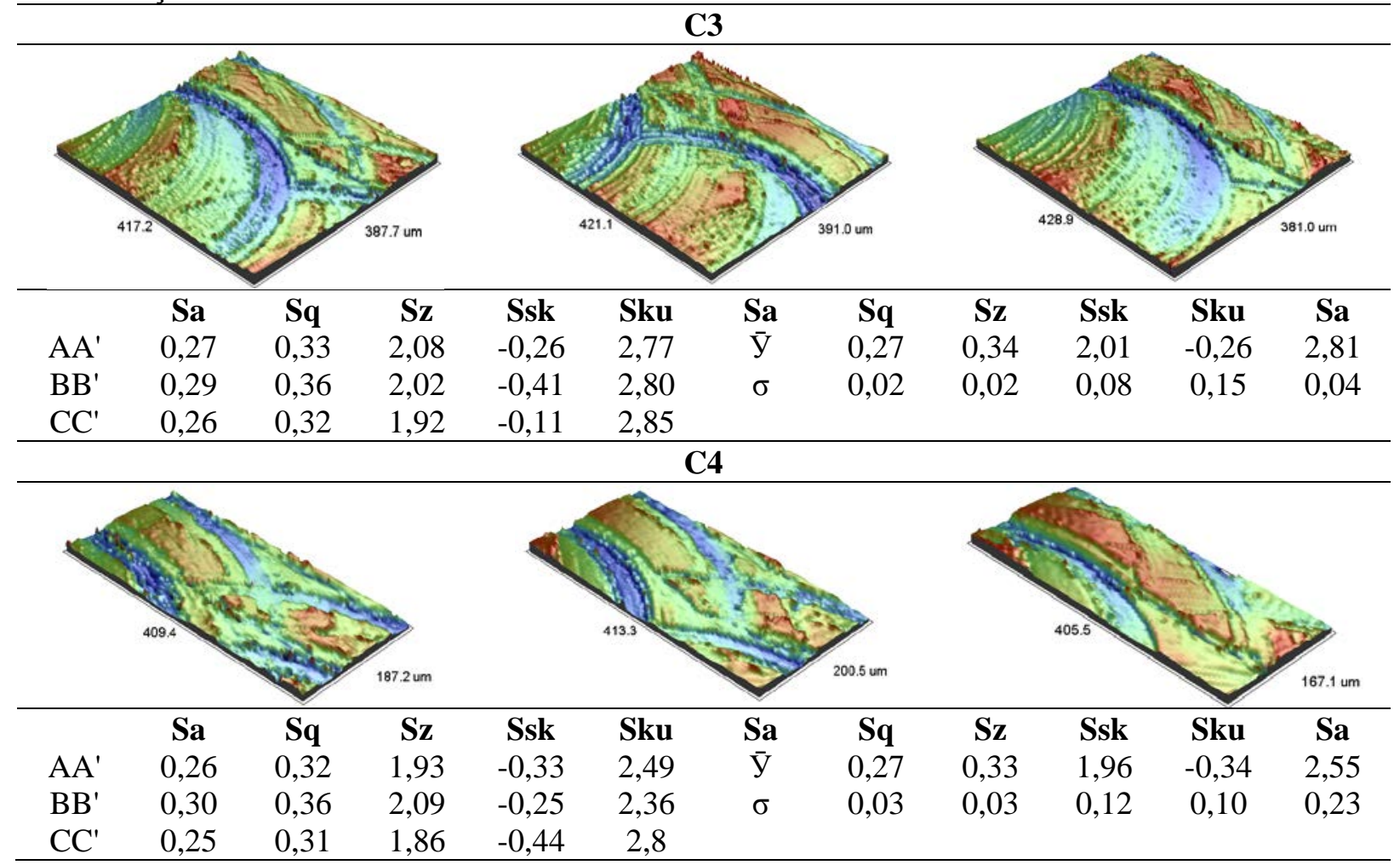

Com base na Tabela 4.16 e Tabela 4.17, monta-se um gráfico dos parâmetros de medição Sa, Sq e Sz (Figura 4. 47). Por meio desta figura pode-se ver que a rugosidade, praticamente, se manteve constante entre as condições do primeiro ensaio e entre as condições do segundo ensaio. Houve uma diferença entre os valores do primeiro ensaio e os valores do segundo ensaio, este fato provavelmente pode estar relacionado ao raio de aresta.

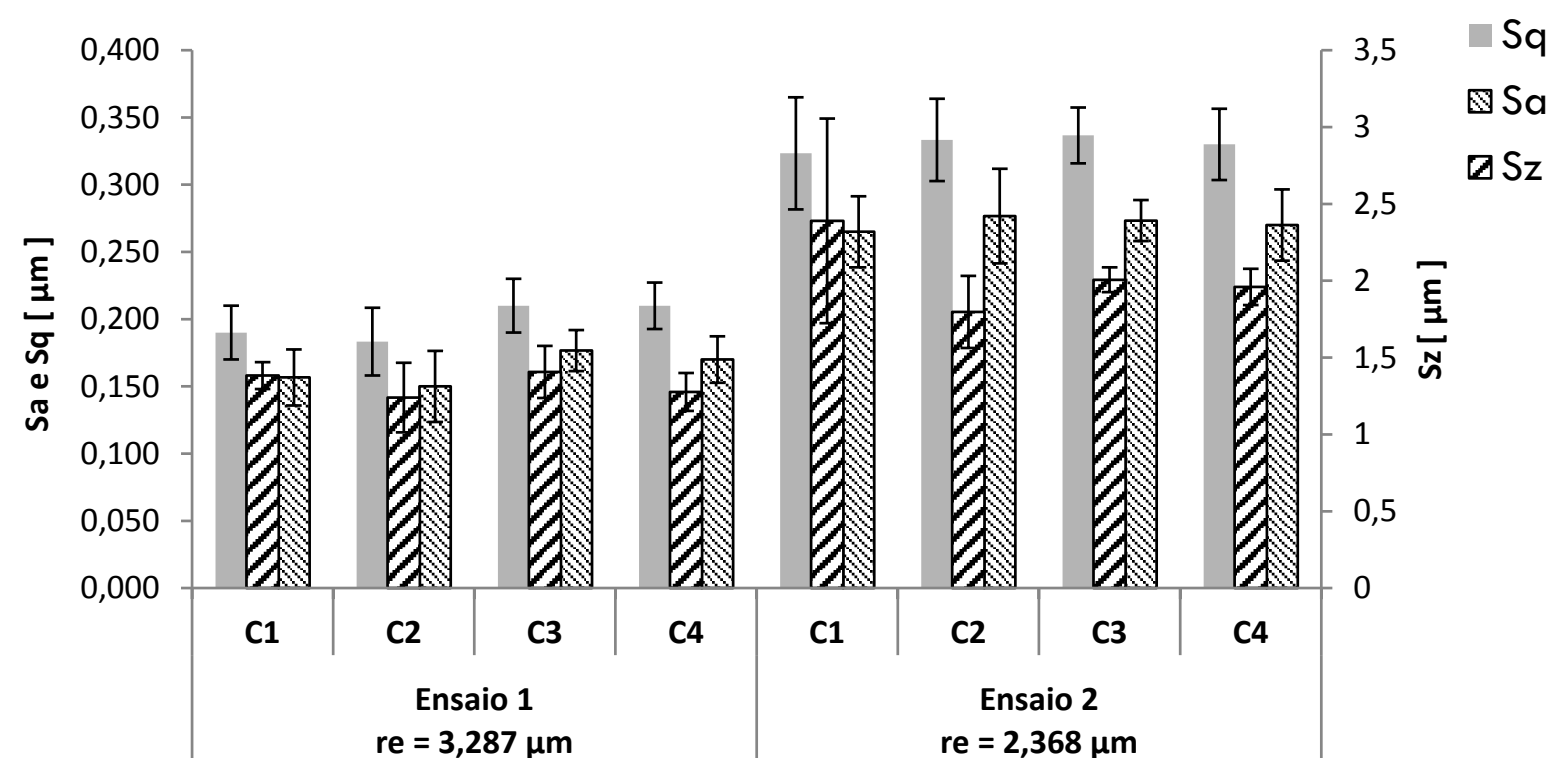

Figura 4. 47 - Valores dos parâmetros de rugosidade Sa, Sq e Sz. 
Uma comparação rápida do intervalo de confiança (99\%) das médias obtidas dos parâmetros Ra, Rq e Rt e dos parâmetros Sa, Sq e Sz, com base no desvio padrão combinado de cada média, mostra que também, para este caso particular, não existe uma diferença significativa entre estes parâmetros como demonstra a Figura 4.48, Ra, Rq e Rt são calculados com base nos valores de Ray, Rqy, Rty, Rax, Rqx e Rtx.
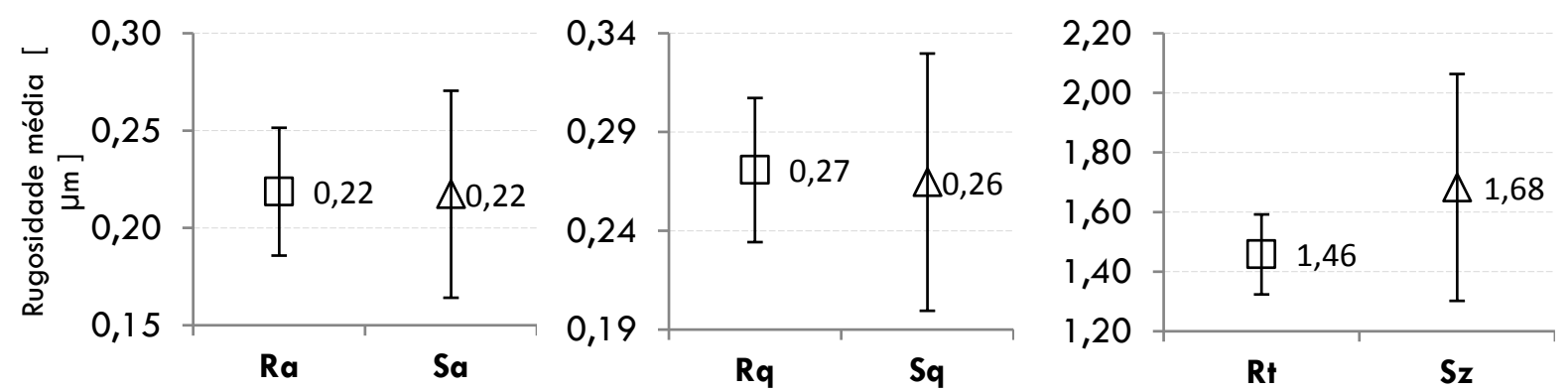

Figura 4. 48 - Individual intervalo de confiança das médias, com base no desvio padrão combinado

Por fim, a Figura 4. 49 apresenta os valos de Ssk e Sku das condições de fresamento. Por meio desta figura pode-se ver que os valores de Sku no primeiro ensaio variaram de Sku $>$ 3 à Sku < 3, e no segundo ensaio predominou Sku $<3$. Isto significa que no primeiro ensaio foi encontrado picos e vales, já no segundo ensaio foi encontrada com mais frequência a presença de vales. Este fato pode ser reforçado pelo parâmetro Ssk. No primeiro ensaio Ssk variou em volta do eixo zero tanto para mais como para menos, indicando uma superfície normalmente distribuída, pois os valores são próximos de zero. No segundo ensaio Ssk se manteve com mais frequência negativo, indicando uma superfície constituída de mais vales do que picos.

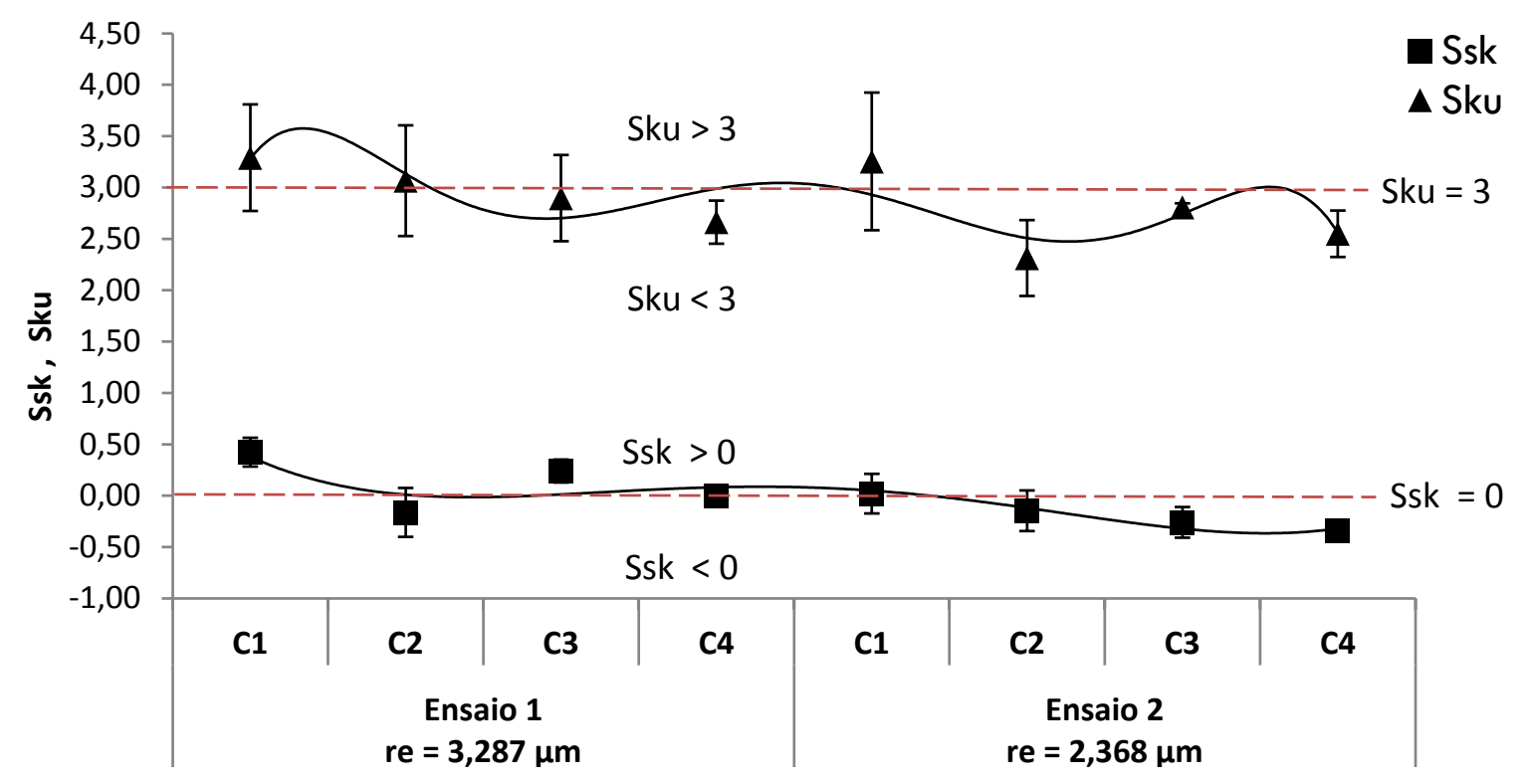

Figura 4. 49 - Parâmetros de rugosidade tridimensional Ssk e Sku. 


\section{CONCLUSÕES}

Apresentou-se neste trabalho um estudo analítico experimental sobre os fundamentos do fresamento aplicados ao microfresamento. Diversos princípios foram estudados, os quais se baseiam na força de corte e pressão específica de corte. Com base nos experimentos apresentados, as conclusões que se pôde chegar foram:

- A força de corte, bem como a pressão específica de corte, correspondentes à espessura de corte média, são equivalentes à média da variação da força de corte e da pressão específica de corte.

- O razão entre as forças no plano de cisalhamento, praticamente, manteve-se constante com as variações dos parâmetros de corte. Entre tais parâmetros estão o avanço por dente, a penetração de trabalho e o raio da aresta principal.

- A pressão específica de corte no microfresamento apresentou o fenômeno - efeito de escala - como encontrado na literatura, a qual aumenta com o decréscimo da espessura de corte. A variação da pressão específica de corte até a espessura mínima de corte, apresenta um alto decaimento assintótico (de $12000 \mathrm{MPa}$ à 3000MPa), tornando-se mais suave à medida que a espessura de corte torna-se maior que o raio de aresta da ferramenta de corte (de 3000Mpa à $2000 \mathrm{MPa}$ ).

- A energia de corte despendida durante a formação do cavaco pode ser representada pela energia de corte média, devido à variação progressiva da espessura de corte instantânea.

- A potência calculada em função da força de corte média e em função da taxa efetiva de material removido, são equivalentes à potência de corte real. Por outro lado, para um fresamento com tempo de movimento em vazio, a potência de corte calculada em função da taxa de material removido convencional, fornece valores menores que os reais.

- No caso da operação de fresamento, para um determinado percurso de avanço da ferramenta em um tempo (por exemplo: $500 \mathrm{~mm} / \mathrm{min}$ ), nem sempre tal tempo é correspondente ao volume de material removido, ou seja, em fresamentos com movimentos em vazios (não engajados) existe uma distinção entre o tempo para remover 
um determinado volume de material e o material removido em um determinado tempo de deslocamento no sentido de avanço da ferramenta.

- Conforme as medições dos parâmetros de rugosidade dos experimentos realizados, o avanço por dente $f_{z}$ e a penetração de trabalho $a_{e}$ influenciam nos valores de $R_{T}$; Os parâmetros $R_{a}$ e $R_{q}$ são sensíveis ao avanço por dente $f_{z}$ e ao raio de aresta $r_{e}$.

- Por fim, com base nas análises do par material alumínio de grãos ultra finos (RSA 6061) e ferramenta de metal duro, espaço amostral $\mathrm{f}_{\mathrm{z}}$ de $5 \mu \mathrm{m}$ e $10 \mu \mathrm{m}, \mathrm{R}$ de $0,4 \mathrm{~mm}, \mathrm{a}_{\mathrm{e}}$ de $0,2 \mathrm{~mm}$ e $0,4 \mathrm{~mm}, \mathrm{a}_{\mathrm{p}}$ de $50 \mu \mathrm{m}$ e $\mathrm{V}_{\mathrm{c}}$ de $50 \mathrm{~m} / \mathrm{min}$, e levando em consideração o raio de aresta e espessura mínima de corte, observou-se que o comportamento da variação das forças de usinagem, decaimento da pressão específica de corte, energia de corte, potência de corte, a representação da energia e potência com base na força de corte média durante a formação do cavaco, são semelhantes ao comportamento do processo convencional. Com base nestes resultados, foi mostrado que os fundamentos do fresamento podem ser aplicados em microfresamento para explicar o comportamento da microusinagem. 


\subsection{RECOMENDAÇÕES PARA TRABALHOS FUTUROS}

- Investigar a espessura mínima de corte na superfície principal de corte da peça.

- Investigar o efeito de fadiga nas ferramentas de corte para fresamentos não engajados (com tempo de movimento em vazio).

- Avaliar a potência consumida diretamente na máquina ferramenta para o fresamento engajado e não engajado.

- Estudar o efeito na força de corte, pressão específica de corte e potência de corte para um fresamento com mais que um dente na zona de usinagem.

- Quantificar a taxa de aquisição mínima para que o sinal das forças de usinagem representem a real variação das componentes.

- Investigar o efeito da frequência de formação das lamelas do cavaco na força de corte. 


\section{REFERÊNCIAS}

AMAREGO, E. J. A.; BROWN, R. H. (1969). The Machining of metals. Englewood Cliffs: Prentice-Hall.

ARAMCHAROEN, A.; MATIVENGA, P.T. (2009). Size effect and tool geometry in micromilling of tool steel. Precision Engineering, v. 33, n. 4, p. 402-407, Oct.

BAO,W. Y.; TANSEL, I. N. (2000). Modeling micro-end-milling operations. Part II: tool runout. Internacional Journal of Machine Tools \& Manufacture, n. 40, p.2175-2192, June.

BÄKER, M.; RÖSLER, J.; SIEMERS, C. (2002). A Finite element model of high speed metal cutting with adiabatic shearing. Computers \& Structures, v. 80, n. 5-6, p. 495-513, Jan.

BASURAY, P. K.; MISRA, B. K.; LAL, G. K. (1977). Transition from ploughing to cutting during machining with blunt tools. Wear, v. 43, p. 341-349. July.

BLACK, P. H. (1961). Theory of metal cutting. New York: McGraw-Hill Book.

BOOTHROYD, G.; KNIGHT, W. (1989). Fundamentals of machining and machine tools. $2^{\text {nd }}$ ed. New York: Marcel Dekker.

CÂMARA, M. A et al. (2012). State of the art on micromilling of materials, a review. ScienceDirect, v. 28, n. 8, p. 673-685, July.

CHAE, J.; PARK, S. S.; FERIHEIT, T. 2006. Investigation of micro-cutting operations. Internacional Journal of Machine Tools \& Manufacture, n. 46, p.313-332, Aug.

COLAFEMINA, J. P. (2005). Estudo da microestrutura do Ti (CP) da liga Ti-6Al-4V no torneamento com ferramenta de diamante. 132p. Dissertação (Mestrado) - Escola de Engenharia de são Carlos, Universidade de São Paulo, São Carlos, 2005.

DHANORKER, A.; LIU, X.; ÖZEL, T. (2007). Micromilling process planning and modeling for micromold manufacturing. In: ASME INTERNATIONAL CONFERENCE ON MANUFACTURING SCIENCE AND ENGINEERING, 2007, Atlanta. Proceedings... [S.l.:s.n.]. p.759-769.

DINIZ, A.E.; MARCONDES, F.C.; COPPINI, N. L. (2009). Tecnologia da usinagem dos materiais. 7. ed. São Paulo: Artliber.

DORMER. (2013). Disponível em:<http://www.dormertools.com/SANDVIK/2531/Internet/P ortugese/S004461.nsf>. Acesso em: 19 July 2013.

DUCOBU, F.; LORPHÈVRE, E. R.; FILIPPI, E. (2012). Dynamic simulation of the micromilling process including minimum chip thickness and size effect. Key Engineering Materials, v. 504-506, p. 1269-1274, Feb. 
FERRARESI, D. (1977). Fundamentos da usinagem dos metais. São Paulo: Edgard Blücher.

FERRARESI, D.; RUFFINO, R. T; PALLEROSI, C. A.(1974). Usinagem dos metais: processo de fresamento. 3 ed. São Paulo: ABM.

FILIZ, S. et al. (2007). An experimental investigation of micro-machinability of copper 101 using tungsten carbide micro-endmills. International Journal of Machine Tools and Manufacture, v. 47, n. 7-8, p. 1088-1100.

FISCHER, U. et al. (2008). Manual de tecnologia metal mecânica. São Paulo: Edgard Blucher.

GAHR, Z.; HEINZ, K. (1943). Microstructure and wear of materials. New York: Elsevier. (Tribology Series, 10).

GIECK, K. (2001). Manual de fórmulas técnicas. Tadução de C.A.LAUAND. São Paulo: Hemus.

HALLIDAY, D.; RESNICK, R.; WALKER, J. (1996). Fundamentos de física. Tradução de Ronaldo Sérgio de Biasi. Rio de Janeiro: LTC.

HEWITT, P. G. (2001). Conceptual physics. $9^{\text {th }}$ ed. San Francisco: Addison Wesley.

HINES, W. W.; MONTGOMERY, D. C. (1990). Probability and statistics in engineering and management science. $3^{\text {th }}$ ed. Singapore: John Wiley.

HONG, Y.-C.; HA, S.- J.; CHO, M.-W. (2012). Predicting of cutting forces in a micromilling process based on frequency analysis of sensor signals and modified polynomial neural network algorithm. International Journal of Precision Engineering and Manufacturing, v. 13, n. 1, p. 17-23.

ISCAR. (2012). Disponível em:<http://www.iscar.com/>. Acesso em: 28 May 2012.

JASINEVICIUS, R. G. et al. (2004). Ferramentas monocortantes de diamante monocristalino. In: PORTO, A. J. V.et al. Usinagem de ultraprecisão. São Carlos: RiMA; FAPESP. Cap. 3, p. 25-43.

KALPAKJIAN, S.; SCHMID, S. R. (2007). Manufacturing processes for engineering materials. $5^{\text {th }}$ ed. New Jersey: Pearson Education.

KENNAMETAL. (2012). Disponível em:<http://www.kennametal.com/en-US/home.jhtml?_ requestid=234698 >. Acesso em: 28 May 2012.

KRONEMBERG, M. (1966). Machining science and application: theory and practice for operation and development of machining processes. London: Pergamon Press.

MACHADO, A. R. et al. (2009). Teoria da usinagem dos materiais. São Paulo: Blucher.

MALKIN, S.; GUO, C. (2008). Grinding technology: theory and applications of machining with abrasives. $2^{\text {nd }}$ ed. New York: Industrial Press. 
MICHIDAN METROLOGY. (2012). Disponível em:<http://www.michmet.com/3d_s_heigh t_parameters_sasq.htm>. Acesso em: 17 July 2012.

MORIWAKI, T.; OKUDA, K. (1989). Machinability of copper in ultra-precision micro diamond cutting. Annals of the CIRP, v.38, n.1, p.115-118.

OERLIKON BALZERS. (2012). Disponível em:<http://www.oerlikon.com/balzers>. Acesso em: 25 May 2012.

ÖZEL, T.; LIU, X. (2009). Investigations on Mechanics-Based Process Planning of Micro-End Milling in Machining Mold Cavities. Materials and Manufacturing Processes. v. 24, n. 12, p. 1274-1281, Dec.

PORTO, A. J. V. et al. (2004). Usinagem de ultraprecisão. São Carlos: RiMa.

RODRIGUES, A. R. (2005). Estudo da geometria de arestas de corte aplicadas em usinagem com altas velocidades de corte. 174f. Tese (Doutorado) - Escola de Engenharia de São Carlos, Universidade de São Paulo, São Carlos, 2005.

RODRIGUES, A. R.; COELHO, R. T. (2007). Influence of the tool edge geometry on specific cutting energy at high-speed cutting. Journal of the Brazilian Society of Mechanical Science and Engineering, v. 29, n. 3, p. 279-283, Sept.

RUFFINO, R.T. (1971). Algumas considerações sobre as forças de usinagem no torneamento de aço-carbono. 159p. Tese (Doutorado) - Escola de Engenharia de São Carlos, Universidade de São Paulo, São Carlos, 1971.

SANDVIK (2006). Metalworking products. CoroPak 2006.1. [S.l.:s.n.].

SANDVIK COROMANT. (2005). Cemented carbide, sandvik new developments and applications. Sandvik Hard Materials. [S.l.:s.n.].

SANDVIK COROMANT. (2012). Disponível em:<http://www.sandvik.coromant.com/ptpt/knowledge/milling/getting_started/general_guidelines/entering_angle/Pages/default.aspx $>$. Acesso em: 20 Aug. 2012.

SANDVIK COROMANT. (2012). Disponível em:<http://www.sandvik.coromant.com/ptpt/knowledge/milling/application_overview/face_milling/high_feed_milling/Pages/default.as px>. Acesso em: 20 Aug. 2012.

SANDVIK COROMANT. (2013). Disponível em:<http://www.sandvik.coromant.com/ptpt/knowledge/milling/getting_started/general_guidelines/cutter_position/pages/default.aspx $>$. Acesso em: 22 Jan. 2013.

SEDRIKS, A. J.; MULHEARN, T. O. (1964). The effect of work-hardening on the mechanics of cutting in simulated abrasive processes. Wear, v. 7, n. 5, p. 451-459.

SHAW, M. C. (2005). Metal cutting principles. $2^{\text {nd }}$ ed. New York: Oxford University Press. 
SO , S.M.; LIM, H.S.; AHN, J.H. (2005). Effects of the friction coefficient on the minimum cutting thickness in micro cutting. International Journal of Machine Tools and Manufacture, n. 45, p. 529-535, Nov.

STEMMMER, C. E. (2007). Ferramentas de corte I. $7^{\text {th }}$ ed. Florianópolis: Ed.UFSC.

TANIGUCHI, N. (1983) Current status in, and future trends of, ultraprecision machining and ultrafine materials processing. CIRP Annals - Manufacturing Technology, v. 32, p. 573-582.

WEULE, H.; HÜNTRUP, V.; TRITSCHLER, H. (2001). Micro-cutting of steel to meet new requirements in miniaturization. CIRP Annals - Manufacturing Technology, v. 50, p. 61-64.

WU, J. H.; LIU, Z. Q. (2009). Modeling the minimum chip thickness in orthogonal microcutting based on plastic strain gradient. Advanced Materials Research, v. 69-70, p. 203-208, May.

YUAN, Z. J.; ZHOU, M.; DONG, S. (1996). Effect of diamond tool sharpness on minimum cutting thickness and cutting surface integrity in ultraprecision machining. Journal of Materials Processing Technology, n. 62, p. 327-330. 
Apêndice A

\section{APÊNDICE A - RESOLUÇÃO DA TABELA 2.1 E EQUAÇÕES, (2.20) e (2.21).}

Para que ocorra o engajamento no fresamento, o ângulo de contato $\psi$ deve ser no mínimo igual ao ângulo formado entre os dentes da fresa $\psi_{\mathrm{z}}$. Assim, basta calcular o mínimo $\mathrm{a}_{\mathrm{e}}$ conforme o ângulo $\psi_{\mathrm{z}}$ para que o corte seja engajado. $\mathrm{O}$ desenho abaixo fornece a estrutura do desenvolvimento dos cálculos.

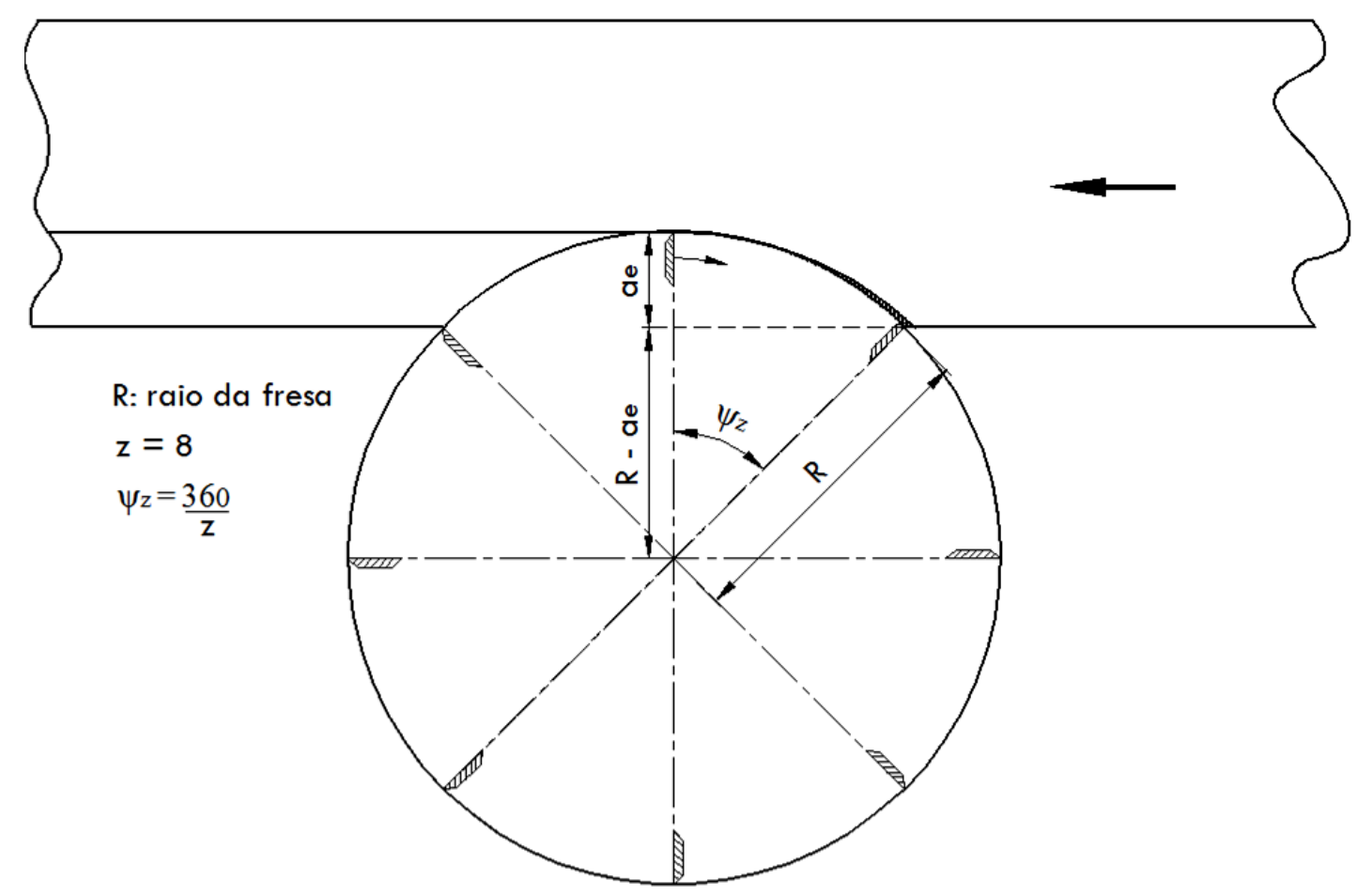

Figura A. 1- Mínimo $\mathbf{a}_{\mathbf{e}}$ para o corte engajado com uma fresa de 8 dentes em fresamento frontal parcial.

$$
\cos \psi_{\mathrm{z}}=\frac{\mathrm{R}-\mathrm{a}_{\mathrm{e}}}{\mathrm{R}}=1-\frac{\mathrm{a}_{\mathrm{e}}}{\mathrm{R}}
$$

Isolando o $\mathrm{a}_{\mathrm{e}}$, tem-se: 
Apêndice A - Resolução da Tabela 2.1 e as Equações (2.20) e (2.21).

$$
\mathrm{a}_{\mathrm{e}}=\left(1-\cos \psi_{\mathrm{z}}\right) \mathrm{R}=\left(1-\cos \frac{360^{\circ}}{\mathrm{z}}\right) \mathrm{R}
$$

\section{Equação (2.20)}

$$
A_{s}=\frac{f}{4}\left[\sqrt{4 R^{2}-f^{2}}-4\left(R-a_{e}\right)\right]+R^{2} \operatorname{arcsen}\left(\frac{f}{2 R}\right)
$$

No fresamento frontal parcial, a área superficial do cavaco indeformado assume um perfil de uma vírgula, caracterizado pela intersecção de dois semicírculos, alinhados num eixo horizontal, intercalados a uma distância correspondente ao avanço f. O cálculo desta área será baseado conforme o desenho abaixo:

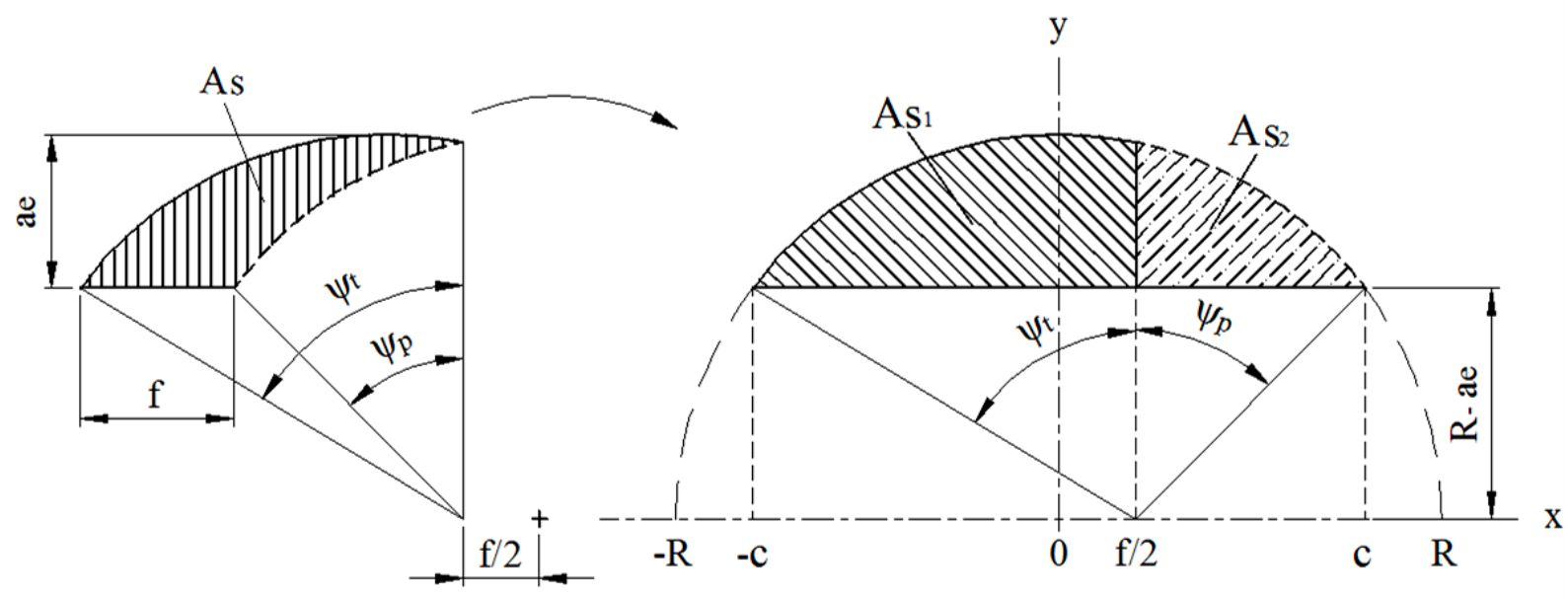

Figura A. 2 - Área superficial do cavaco indeformado.

Conforme a Figura A. 2, a área superficial As pode ser expressa por:

$$
A_{s}=A_{s_{1}}-A_{s_{2}}
$$

O primeiro termo pode ser calculado da seguinte forma:

$$
A_{s_{1}}=\int_{-c}^{\frac{f}{2}} \sqrt{R^{2}-x^{2}} d x-(c+f / 2)\left(R-a_{e}\right)
$$

Onde, 


$$
\int_{-c}^{\frac{f}{2}} \sqrt{R^{2}-x^{2}} d x=\frac{1}{2}\left[\frac{f}{2} \sqrt{R^{2}-\frac{f^{2}}{4}}+R^{2} \operatorname{arcsen}\left(\frac{f}{2 R}\right)+c \sqrt{R^{2}-c^{2}}+R^{2} \operatorname{arcsen}\left(\frac{c}{R}\right)\right]
$$

O segundo termo pode ser calculado da seguinte forma:

$$
A_{s_{2}}=\int_{\frac{f}{2}}^{c} \sqrt{R^{2}-x^{2}} d x-(c-f / 2)\left(R-a_{e}\right)
$$

Onde,

$$
\int_{\frac{f}{2}}^{c} \sqrt{R^{2}-x^{2}} d x=\frac{1}{2}\left[c \sqrt{R^{2}-c^{2}}+R^{2} \operatorname{arcsen}\left(\frac{c}{R}\right)-\frac{f}{2} \sqrt{R^{2}-\frac{f^{2}}{4}}-R^{2} \operatorname{arcsen}\left(\frac{f}{2 R}\right)\right]
$$

Substituindo as equações (A. 5) em (A. 4), (A. 7) em (A. 6), (A. 4) e (A. 6) em (A. 3) e rearranjando tem-se:

$$
A_{s}=\frac{f}{4}\left[\sqrt{4 R^{2}-f^{2}}-4\left(R-a_{e}\right)\right]+R^{2} \operatorname{arcsen}\left(\frac{f}{2 R} \operatorname{rad}\right)
$$

\section{Equação (2.21)}

$$
A_{s}=f_{z} \cdot a_{e}
$$

A aproximação assumida para simplificar a Equação (2.20) e chegar à Equação (2.21) foi a seguinte: traçou-se uma linha circular, com raio correspondente ao da fresa, que aproximadamente se comporta como uma linha de simetria dentro do perfil da área superficial do cavaco indeformado (Figura A. 3). Um ângulo de contato $\left(\psi^{\prime}\right)$ foi traçado até esta linha de simetria circular ao final do perfil do cavaco indeformado. A área "Ai” da Figura A. 3-a foi desconsiderada, e para compensar tal desconsideração, o arco interno (arco tracejado) foi prolongado até a reta do ângulo de contato $\Psi^{\prime}$ (Figura A. 3-b). 


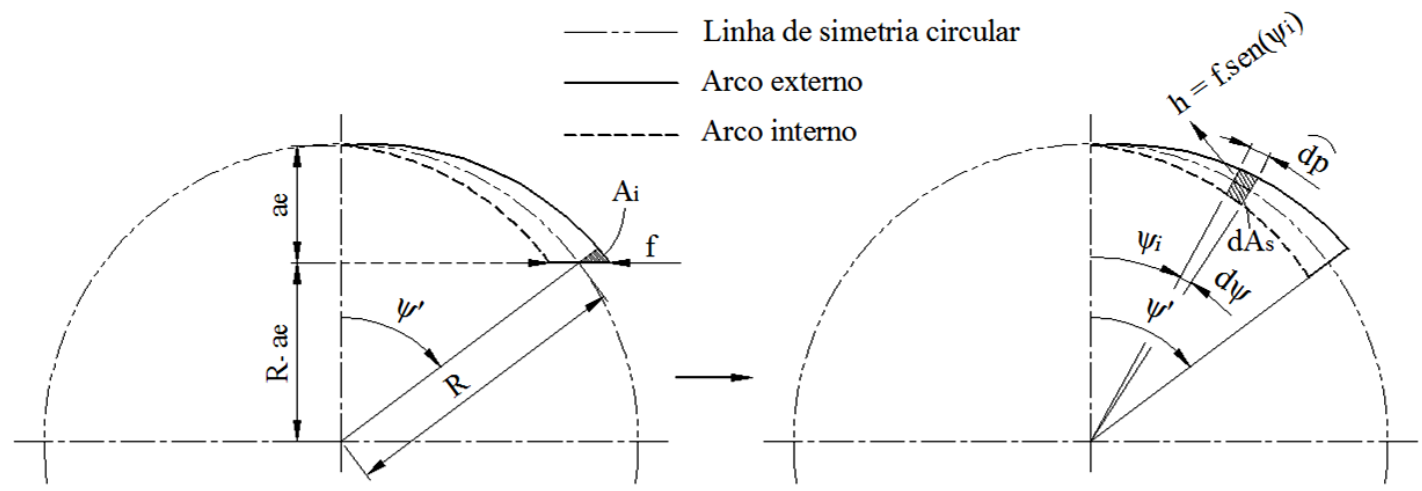

a)

b)

Figura A. 3 - Método para aproximação da área superficial As

Da Figura A. 3-b, pode-se representar a equação diferencial da área superficial do cavaco indeformado conforme a equação abaixo:

$$
d A_{s}=f \cdot \operatorname{sen}\left(\Psi_{i}\right) \cdot d p
$$

A base $d p$ pode ser representada por $d \psi$ pela seguinte relação:

$$
\mathrm{dp}=\mathrm{R} \cdot \mathrm{d} \psi
$$

Assim, a Equação (A. 9) se transforma em:

$$
\mathrm{dA}_{\mathrm{s}}=\text { R.f. } \operatorname{sen}\left(\psi_{\mathrm{i}}\right) \cdot \mathrm{d} \psi
$$

Integrando a Equação (A. 9) no intervalo de 0 a $\psi^{\prime}$, tem-se:

$$
A_{s}=\int_{0}^{\psi^{\prime}} \text { R.f. } \operatorname{sen}(x) \cdot d x=\text { R.f. }\left(1-\cos \psi^{\prime}\right)
$$

Conforme a Figura A. 3-a:

$$
\cos \psi^{\prime}=\frac{\mathrm{R}-\mathrm{a}_{\mathrm{e}}}{\mathrm{R}}=1-\frac{\mathrm{a}_{\mathrm{e}}}{\mathrm{R}}
$$

Substituindo a Equação (A. 13) em (A. 12), tem-se: 
Apêndice A - Resolução da Tabela 2.1 e as Equações (2.20) e

(2.21).

$$
A_{s}=f_{z} \cdot a_{e}
$$




\section{APÊNDICE B - EXEMPLO NUMÉRICO: DETERMINANDO $\mathbf{k}_{\mathrm{s} 1}$ e z}

Tabela B.1 - Material da peça (RUFFINO, 1977)

\begin{tabular}{ccccc}
\hline \multicolumn{5}{c}{ Material SAE 1045 (St 52) } \\
\hline $\mathrm{C} \%$ & $\mathrm{Si} \%$ & $\mathrm{Mn} \%$ & $\mathrm{P} \%$ & $\mathrm{~S} \%$ \\
0,46 & 0,22 & 0,84 & 0,021 & 0,032 \\
\hline
\end{tabular}

DurezaBrinel Limite de Resistência limite de escoamento alongamento Estricção

$\left[\begin{array}{llll}\left.\mathrm{kgf} / \mathrm{mm}^{2}\right] & {\left[\mathrm{kgf} / \mathrm{mm}^{2}\right]} & {\left[\mathrm{kgf} / \mathrm{mm}^{2}\right]} & {\left[\mathrm{kgf} / \mathrm{mm}^{2}\right]}\end{array}\right]\left[\mathrm{kgf} / \mathrm{mm}^{2}\right]$

$\begin{array}{lllll}207 & 58,7 & - & 22,1 & 40,7\end{array}$

Tabela B.2 - Ferramenta de corte: pastilha de metal duro 7,5x11x17 mm (RUFFINO, 1977).

\begin{tabular}{|c|c|c|c|c|c|}
\hline \multicolumn{6}{|c|}{ pastilha de metal duro } \\
\hline DurezaBrinel & $\begin{array}{l}\text { Massa } \\
\text { específica }\end{array}$ & $\begin{array}{l}\text { tensão de } \\
\text { ruptura a } \\
\text { flexão }\end{array}$ & $\begin{array}{l}\text { coeficiente } \\
\text { de dilatção } \\
\text { térmica }\end{array}$ & $\begin{array}{l}\text { módulo de } \\
\text { elasticidade na } \\
\text { compressão }\end{array}$ & $\begin{array}{l}\text { coeficiente } \\
\text { de poisson }\end{array}$ \\
\hline 90,3 RA & $13,35 \mathrm{~g} / \mathrm{cm}^{3}$ & $193 \mathrm{Kgf} / \mathrm{mm}^{3}$ & $3,3 \times 10^{-6}$ & $5500 \mathrm{Kgf} / \mathrm{mm}^{2}$ & 0,214 \\
\hline$\alpha$ & $\gamma$ & $\lambda$ & $\chi$ & $\varepsilon$ & $\mathrm{r}_{\varepsilon}$ \\
\hline $8^{\circ}$ & $6^{\circ}$ & $5^{\circ}$ & $60^{\circ}$ & $90^{\circ}$ & $1 \mathrm{~mm}$ \\
\hline
\end{tabular}

Tabela B.3 - Dados de Ruffino (1971)

\begin{tabular}{crrrrrrrrrrr}
\hline Observações & $\mathrm{f}$ & $\mathrm{ap}$ & $\mathrm{h}$ & $\mathrm{b}$ & $\mathrm{S}$ & $\mathrm{Ks}$ & $\mathrm{x}=\ln (\mathrm{h})$ & $\mathrm{y}=\ln (\mathrm{ks})$ & \multicolumn{1}{c}{$\mathrm{x}^{*} \mathrm{y}$} & $\mathrm{x}^{2}$ & $\mathrm{Vc}$ \\
\hline 1 & 0,16 & 1 & 0,139 & 1,155 & 0,16 & 2555,8 & $-1,976$ & 7,846 & $-15,507$ & 3,906 & \\
2 & 0,29 & 1 & 0,251 & 1,155 & 0,29 & 2319,8 & $-1,382$ & 7,749 & $-10,707$ & 1,909 & \\
3 & 0,5 & 1 & 0,433 & 1,155 & 0,5 & 2292,8 & $-0,837$ & 7,738 & $-6,476$ & 0,701 & 46 \\
4 & 0,6 & 1 & 0,520 & 1,155 & 0,6 & 2304,6 & $-0,655$ & 7,743 & $-5,069$ & 0,429 & \\
5 & 0,68 & 1 & 0,589 & 1,155 & 0,68 & 2150,2 & $-0,530$ & 7,673 & $-4,063$ & 0,280 & \\
\hline 6 & 0,16 & 1 & 0,139 & 1,155 & 0,16 & 2721,3 & $-1,976$ & 7,909 & $-15,631$ & 3,906 & \\
7 & 0,29 & 1 & 0,251 & 1,155 & 0,29 & 2407,7 & $-1,382$ & 7,786 & $-10,759$ & 1,909 & \\
8 & 0,5 & 1 & 0,433 & 1,155 & 0,5 & 2345,7 & $-0,837$ & 7,760 & $-6,495$ & 0,701 & 47 \\
9 & 0,6 & 1 & 0,520 & 1,155 & 0,6 & 2262,1 & $-0,655$ & 7,724 & $-5,057$ & 0,429 & \\
10 & 0,68 & 1 & 0,589 & 1,155 & 0,68 & 2189,2 & $-0,530$ & 7,691 & $-4,073$ & 0,280 & \\
\hline 11 & 0,16 & 1 & 0,139 & 1,155 & 0,16 & 3052,3 & $-1,976$ & 8,024 & $-15,858$ & 3,906 & \\
12 & 0,29 & 1 & 0,251 & 1,155 & 0,29 & 2772,9 & $-1,382$ & 7,928 & $-10,954$ & 1,909 & \\
13 & 0,5 & 1 & 0,433 & 1,155 & 0,5 & 2502,6 & $-0,837$ & 7,825 & $-6,550$ & 0,701 & \\
14 & 0,6 & 1 & 0,520 & 1,155 & 0,6 & 2392,8 & $-0,655$ & 7,780 & $-5,093$ & 0,429 & \\
\hline
\end{tabular}




\begin{tabular}{|c|c|c|c|c|c|c|c|c|c|c|c|}
\hline 15 & 0,68 & 1 & 0,589 & 1,155 & 0,68 & 2267,1 & $-0,530$ & 7,726 & $-4,091$ & 0,280 & \\
\hline 16 & 0,16 & 1 & 0,139 & 1,155 & 0,16 & 3052,3 & $-1,976$ & 8,024 & $-15,858$ & 3,906 & \\
\hline 17 & 0,29 & 1 & 0,251 & 1,155 & 0,29 & 2772,9 & $-1,382$ & 7,928 & $-10,954$ & 1,909 & \\
\hline 18 & 0,5 & 1 & 0,433 & 1,155 & 0,5 & 2449,7 & $-0,837$ & 7,804 & $-6,532$ & 0,701 & 60 \\
\hline 19 & 0,6 & 1 & 0,520 & 1,155 & 0,6 & 2304,6 & $-0,655$ & 7,743 & $-5,069$ & 0,429 & \\
\hline 20 & 0,68 & 1 & 0,589 & 1,155 & 0,68 & 2228,1 & $-0,530$ & 7,709 & $-4,082$ & 0,280 & \\
\hline 21 & 0,16 & 1 & 0,139 & 1,155 & 0,16 & 3377,1 & $-1,976$ & 8,125 & $-16,058$ & 3,906 & \\
\hline 22 & 0,29 & 1 & 0,251 & 1,155 & 0,29 & 3043,4 & $-1,382$ & 8,021 & $-11,082$ & 1,909 & \\
\hline 23 & 0,5 & 1 & 0,433 & 1,155 & 0,5 & 2555,6 & $-0,837$ & 7,846 & $-6,567$ & 0,701 & 63 \\
\hline 24 & 0,6 & 1 & 0,520 & 1,155 & 0,6 & 2481,1 & $-0,655$ & 7,816 & $-5,117$ & 0,429 & \\
\hline 25 & 0,68 & 1 & 0,589 & 1,155 & 0,68 & 2304,6 & $-0,530$ & 7,743 & $-4,100$ & 0,280 & \\
\hline 26 & 0,16 & 1 & 0,139 & 1,155 & 0,16 & 2390,4 & $-1,976$ & 7,779 & -15 & 3,906 & \\
\hline 27 & 0,29 & 1 & 0,251 & 1,155 & 0,29 & 2137,2 & $-1,382$ & 7,667 & $-10,594$ & 1,909 & \\
\hline 28 & 0,5 & 1 & 0,433 & 1,155 & 0,5 & 1977,0 & $-0,837$ & 7,589 & $-6,352$ & 0,701 & 35 \\
\hline 29 & 0,6 & 1 & 0,520 & 1,155 & 0,6 & 2085,5 & $-0,655$ & 7,643 & & 0,429 & \\
\hline 30 & 0,68 & 1 & 0,589 & 1,155 & 0,68 & 2033,4 & $-0,530$ & 7,617 & $-4,033$ & 0,280 & \\
\hline 31 & 0,16 & 1 & 0,139 & 1,155 & 0,16 & 3052,3 & $-1,976$ & 8,024 & $-15,858$ & 3,906 & \\
\hline 32 & 0,29 & 1 & 0,251 & 1,155 & 0,29 & 2772,9 & $-1,382$ & 7,928 & $-10,954$ & 1,909 & \\
\hline 33 & 0,5 & 1 & 0,433 & 1,155 & 0,5 & 2396,7 & $-0,837$ & 7,782 & & 0,701 & 68 \\
\hline 34 & 0,6 & 1 & 0,520 & 1,155 & 0,6 & 2392,8 & $-0,655$ & 7,780 & $-5,093$ & 0,429 & \\
\hline 35 & 0,68 & 1 & 0,589 & 1,155 & 0,68 & 2267,1 & $-0,530$ & 7,726 & $-4,091$ & 0,280 & \\
\hline 36 & 0,16 & 1 & 0,139 & 55 & 0,16 & & & 8,024 & & 3,906 & \\
\hline 37 & 0,29 & 1 & 0,251 & 1,155 & 0,29 & 3043,4 & $-1,382$ & 8,021 & $-11,082$ & 1,909 & \\
\hline 38 & 0,5 & 1 & 0,433 & 1,155 & 0,5 & 2502,6 & $-0,837$ & 7,825 & $-6,550$ & 0,701 & 74 \\
\hline 39 & 0,6 & 1 & 0,520 & 1,155 & 0,6 & 2392,8 & $-0,655$ & 7,780 & $-5,093$ & 0,429 & \\
\hline 40 & 0,68 & 1 & 0,589 & 1,155 & 0,68 & 2228,1 & $-0,530$ & 7,709 & $-4,082$ & 0,280 & \\
\hline 41 & 0,16 & 1 & 0,139 & 1,155 & 0,16 & 3211,7 & $-1,976$ & 8,075 & $-15,959$ & 3,906 & \\
\hline 42 & 0,29 & 1 & 0,251 & 1,155 & 0,29 & 2772,9 & $-1,382$ & 7,928 & $-10,954$ & 1,909 & \\
\hline 43 & 0,5 & 1 & 0,433 & 1,155 & 0,5 & 2396,7 & $-0,837$ & 7,782 & $-6,513$ & 0,701 & 85 \\
\hline 44 & 0,6 & 1 & 0,520 & 1,155 & 0,6 & 2217,9 & $-0,655$ & 7,704 & $-5,044$ & 0,429 & \\
\hline 45 & 0,68 & 1 & 0,589 & 1,155 & 0,68 & 2267,1 & $-0,530$ & 7,726 & $-4,091$ & 0,280 & \\
\hline 46 & 0,16 & 1 & 0,139 & 1,155 & 0,16 & 2721,3 & $-1,976$ & 7,909 & $-15,631$ & 3,906 & \\
\hline 47 & 0,29 & 1 & 0,251 & 1,155 & 0,29 & 2499,0 & $-1,382$ & 7,824 & $-10,810$ & 1,909 & \\
\hline 48 & 0,5 & 1 & 0,433 & 1,155 & 0,5 & 2239,8 & $-0,837$ & 7,714 & $-6,457$ & 0,701 & 113 \\
\hline 49 & 0,6 & 1 & 0,520 & 1,155 & 0,6 & 2217,9 & $-0,655$ & 7,704 & $-5,044$ & 0,429 & \\
\hline 50 & 0,68 & 1 & 0,589 & 1,155 & 0,68 & 2072,4 & $-0,530$ & 7,636 & $-4,044$ & 0,280 & \\
\hline soma & & & & & & & $-53,793$ & 390,556 & $-422,881$ & 72,249 & \\
\hline & & & & & & & $-1,076$ & 7,811 & & & \\
\hline
\end{tabular}




$$
\begin{gathered}
\bar{y}=\frac{1}{n} \sum_{j=1}^{n} y_{j}=7,811 \\
\bar{x}=\frac{1}{n} \sum_{j=1}^{n} x_{j}=-1,076 \\
S_{x y}=\sum_{j=1}^{n} x_{j} y_{j}-\left(\sum_{j=1}^{n} x_{j}\right)\left(\sum_{j=1}^{n} y_{j}\right) \\
n
\end{gathered}
$$

$$
\begin{gathered}
S_{x x}=\sum_{j=1}^{n} x_{j}^{2}-\frac{\left(\sum_{j=1}^{n} x_{j}\right)^{2}}{n}=72,249-\frac{(53,793)^{2}}{50}=14,375 \\
\beta_{1}=\frac{S_{x y}}{S_{x x}}=\frac{-2,6974}{14,375}=-0,1876 \\
\beta_{0}=\bar{y}-\beta_{1} \bar{x}=7,811-(-0,1876) .-1,076=7,609 \\
k_{s 1}=e^{\beta_{0}}=e^{7,609} \cong 2016 \\
-z=\beta_{1} \cong-0,19
\end{gathered}
$$

Portanto,

$$
\mathrm{k}_{\mathrm{s}}=\mathrm{e}^{\beta_{0}} \cdot \mathrm{h}^{\beta_{1}}=\mathrm{k}_{\mathrm{s} 1} \cdot \mathrm{h}^{-\mathrm{z}}=2016 \cdot \mathrm{h}^{-0,19}
$$

